UNIVERSIDADE DE SÃO PAULO

PROGRAMA INTERUNIDADES DE PÓS-GRADUAÇÃO EM ENERGIA

TATIANA MAGALHÃES GEROSA

O ESTUDO DA UTILIZAÇÃO DO GÁS NATURAL COMO INSUMO PARA A INDÚSTRIA QUÍMICA E PETROQUÍMICA: MODELAGEM DE UMA PLANTA

GÁS-QUÍMICA

São Paulo 


\section{O ESTUDO DA UTILIZAÇÃO DO GÁS NATURAL COMO INSUMO PARA A INDÚSTRIA QUÍMICA E PETROQUÍMICA: MODELAGEM DE UMA PLANTA GÁS-QUÍMICA}

Dissertação apresentada ao Programa Interunidades de Pós-graduação em Energia da Universidade de São Paulo ( Instituto de Eletrotécnica e Energia / Escola Politécnica / Instituto de Física / Faculdade de Economia e Administração ) para obtenção do título de Mestre em Energia.

Orientadora: Prof ${ }^{a}$. Dra. Patrícia Helena Lara dos Santos

Matai 


\section{AUTORIZO A REPRODUÇÃO E DIVULGAÇÃO TOTAL OU PARCIAL DESTE TRABALHO, POR QUALQUER MEIO CONVENCIONAL OU ELETRÔNICO, PARA FINS DE ESTUDO E PESQUISA, DESDE QUE CITADA A FONTE.}

\section{FICHA CATALOGRÁFICA}

Gerosa, Tatiana Magalhães.

O estudo da utilização do gás natural como insumo para a indústria química e petroquímica: modelagem de uma planta gás-química / Tatiana Magalhães Gerosa; orientadora Patrícia Helena Lara dos Santos Matai. São Paulo, 2006.

155 p. : il.; $30 \mathrm{~cm}$.

Dissertação (Mestrado - Programa Interunidades de Pós-Graduação em Energia) - EP / FEA / IEE / IF da Universidade de São Paulo.

1. Gás Natural 2. Petroquímica

3. Insumo químico e petroquímico

4. Gás de Síntese I. Título. 


\section{UNIVERSIDADE DE SÃO PAULO \\ PROGRAMA INTERUNIDADES DE PÓS-GRADUAÇ̃̃O EM ENERGIA \\ EP - FEA - IEE - IF}

\section{TATIANA MAGALHÃES GEROSA}

"O estudo da utilização do gás natural como insumo para a indústria quimica e petroquimica: Modelagem de uma planta gás-quimica".

Dissertação de Mestrado defendida e aprovada em 26/02/2007 pela Comissão Julgadora:

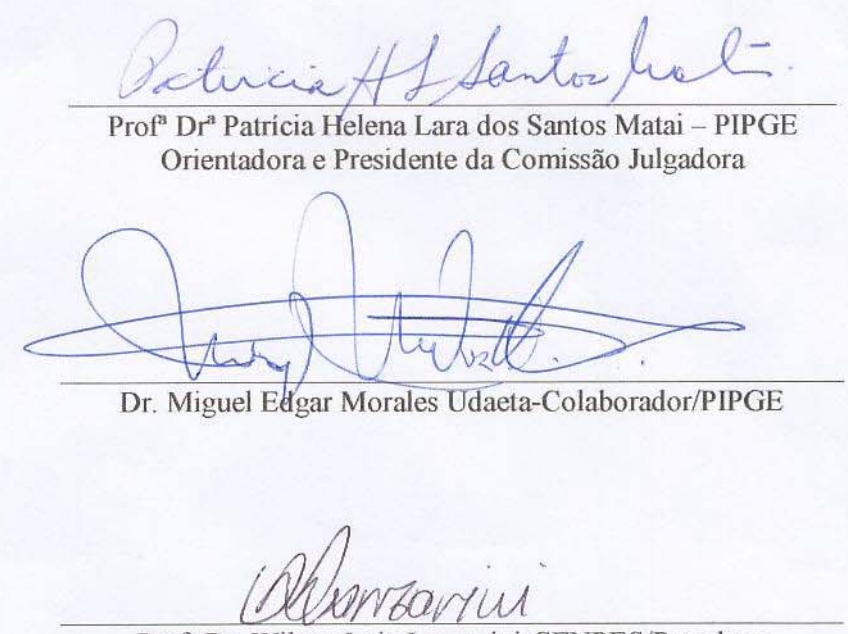

Prof. Dr. Wilson Luiz Lanzarini-CENPES/Petrobras 


\section{AGRADECIMENTOS}

Agradeço, primeiramente, a Deus, a toda a minha família, em especial aos meus pais, Paulo Gerosa e Cecília Gerosa, aos meus avós e tios, por todo apoio e incentivo prestado durante a realização da pesquisa.

Igualmente, a minha orientadora, Patrícia Helena Lara dos Santos Matai, pela confiança em mim depositada, por toda a orientação prestada no desenvolvimento do presente trabalho e a sua grande amizade. Aos professores do PIPGE, que através de suas disciplinas e trabalhos contribuíram de forma significativa para o aprimoramento dos meus conhecimentos, especialmente aos professores: Edmilson Moutinho dos Santos e Miguel Udaeta, que muito me incentivaram e ensinaram ao longo destes dois anos. Agradeço, aos amigos, Victório Oxilia, Sidney Rosin, Marilin Mariano, Julieta Puerto Rico, Fábio Romero, Daniele Cristina, Jonathas Bernal, Jurandir Ferreira e Alexandre Jeronymo, com os quais tive o prazer e a oportunidade de conviver durante estes anos. Aos grandes amigos, Pascoal Rigolin, Henrique Tavares e Roberto Callari, por todos os momentos que passamos ao longo destes dois anos, aos trabalhos realizados conjuntamente, bem como aos momentos vividos fora do IEE, onde realmente solidificamos a nossa amizade. Agradeço, ao meu grande professor da graduação, Alcindo Ludovice, por toda ajuda, leitura e correção do texto, além de todo o incentivo durante estes anos.

Ademais, à Agência Nacional do Petróleo, pela bolsa concedida e pelos recursos que viabilizaram a realização e conclusão do presente trabalho. Ao Coordenador do PRH 04, Professor Murilo Fagá, pela compreensão e amizade. Aos funcionários do IEE, em especial as amigas Rosa e Adriana, da Secretaria de Pós-Graduação.

Agradeço aos membros da banca de qualificação: Miguel Udaeta e Edmilson Moutinho dos Santos por orientar e auxiliar no desenvolvimento do texto final, com suas sugestões. Aos membros da Banca de Defesa, Wilson Lanzarini e Miguel Udaeta, pela contribuição técnico-científica transmitida no dia da argüição do presente trabalho.

Finalizando, um agradecimento especial à Cecília Gerosa, pela leitura, revisão e correção gramatical do texto final, e, também, por ser uma excelente amiga, mãe e professora. 


\section{RESUMO}

\section{GEROSA. T. M. O estudo da utilização do gás natural como insumo para a indústria química e petroquímica: modelagem de uma planta gás-química. 2007. 155 p. Tese}

de Mestrado - Programa Interunidades de Pós-Graduação em Energia. Universidade de São Paulo.

Este trabalho tem como objetivo apresentar, através da modelagem de uma planta gásquímica e da identificação das tecnologias disponíveis, a versatilidade do uso do gás natural como insumo para a indústria química, visando à produção de metanol, amônia e hidrogênio, a partir da fração metano, bem como na indústria petroquímica a obtenção do eteno através da fração etano. Baseado nas pesquisas de mercado, determinou-se que dentre os produtos a serem obtidos a partir do metano, o metanol é o que apresenta o cenário interno mais crítico. Esta situação é refletida através do contínuo aumento da importação, sem que haja nenhuma sinalização deste déficit ser sanado, através da construção de novas unidades industriais. Por outro lado, o cenário da amônia se mostra estável e, ainda que haja um déficit na produção nacional, a situação atual não se mostra tão crítica, mesmo quando realizada a projeção da demanda até 2030. Analisando-se o cenário petroquímico, em poucos anos a produção de eteno atingirá o seu gargalo, e o maior entrave diagnosticado, para a expansão das centrais produtoras, está relacionado à disponibilidade do insumo. Dentro da abordagem técnica proposta, a modelagem da planta gás-química aponta ser viável concentrar a produção de amônia, metanol e hidrogênio no mesmo pólo e que, para estes produtos, a tecnologia atual encontra-se madura e em estágio avançado. Já a produção de eteno, a partir do etano, não deve estar diretamente vinculada, a princípio, à obtenção dos demais produtos, pelo alto volume de gás natural necessário para liberar a fração de etano ideal para a sustentabilidade do projeto.

Palavras-chave: gás natural, insumo químico e petroquímico, petroquímica e gás de síntese. 


\begin{abstract}
GEROSA, T.M. The study of the use of natural gas as a feedstock for the chemical and petrochemical industry: the modeling of a gas-chemical plant. 2007. 155 f. Work. Program os Post-Graduation in Energy, Universidade de São Paulo, São Paulo, 2007.
\end{abstract}

This work has as objective to present, through the modeling of a gas-chemical plant and also, through the identification of the current available technologies, the versatility of the use of natural gas as a raw material for the chemical industry, aiming the production of methanol, ammonia and hydrogen, from the fraction methane, as well as in the petrochemical industry, the attainment of ethene from the ethane fraction. Based in a market research, it was determined that amongst the products to be obtained from methane, methanol is the product that presents the most critical internal scenario. This situation is reflected through the continuous increase of the importation; without it there is no signaling that this deficit can be overcome, unless new industrials units are constructed. On the other hand, the ammonia scenario is steady and, despite presenting a deficit in the national production, the current situation does not reveal to very so critical, carried through the projection of the demand up to 2030. Analyzing the petrochemical scene, in a few years the ethene production will reach its pass and the biggest diagnosed impediment is related to the availability of the feedstock. Considering the technique proposal, the modeling of the gas-chemical plant shows the viability of concentrating the production of ammonia, methanol and hydrogen in the same site and that, for these products, the current technologies are mature and very well developed. Already the ethene production, from ethane, does not have to be directly entailed, in principle, to the attainment of the other products, considering the high volume of natural gas necessary to liberate the necessary amount of ethane for the sustainable of the project.

Key-words: natural gas, gas-chemical plant, plant modeling, ethane, ethene, ammonia, hydrogen 


\section{SUMÁRIO}

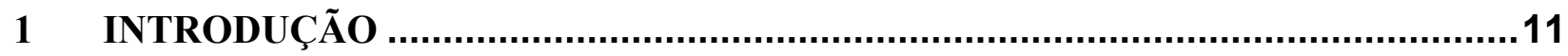

1.1 Panorama dos Derivados do Metano ................................................................... 12

1.1.1 Panorama Mundial do Metanol ............................................................................... 12

1.1.2 Cenário Brasileiro do Metanol ............................................................................. 15

1.1.3 Panorama Mundial da Produção de Amônia .............................................................. 17

1.1.4 Cenário Nacional da Produção de Amônia................................................................. 19

1.2 O Setor Petroquímico ............................................................................................... 21

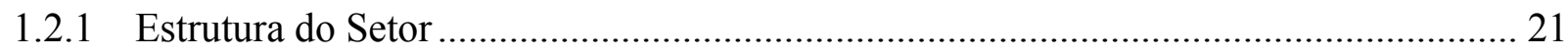

1.2.2 Panorama Mundial da Produção de Eteno................................................................ 25

1.2.3 Setor Petroquímico Brasileiro ....................................................................... 27

1.2.4 A Questão do Insumo .................................................................................... 31

2 MODELAGEM DA PLANTA GÁS QUÍMICA ............................................... 38

2.1 O Conceito Petroquímico ..................................................................................................... 38

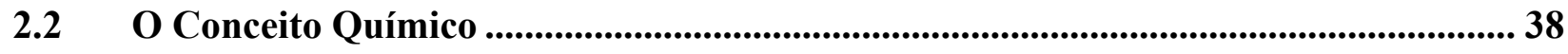

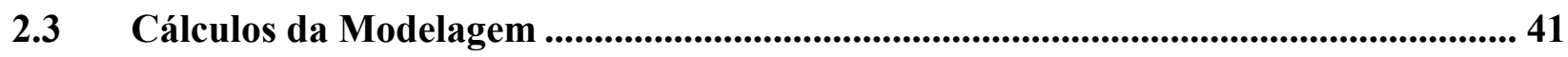

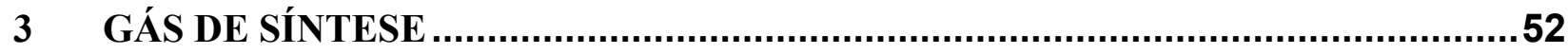

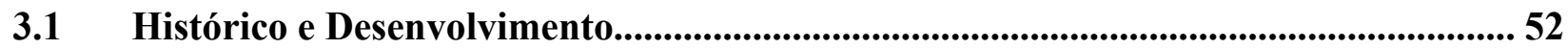

3.2 Reforma a Vapor do Metano - SMR ................................................................................ 54

3.2.1 Histórico e Evolução do Processo ......................................................................... 54

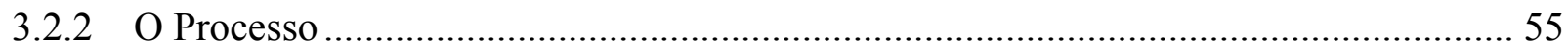


3.2.3 Razão Molar Água:Carbono 57

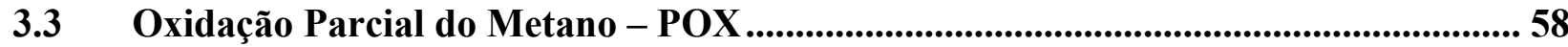

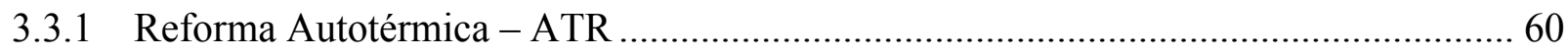

3.4 Estado da Arte da Tecnologia de Produção do Gás de Síntese ................................. 61

3.4.1 Processo CRG - Pré-reforma, empobrecimento e metanação - Licenciado pela Davy Process Technology e catalisador licenciado pela Synetix .............................................. 61

3.4.2 Tecnologia Syngas ATR - Licenciado pela Haldor Topsoe .................................... 63

3.4.3 Processo Syngas Autothermal - Licenciado pela Hower-Baker Engineers, Ltd ......... 64

3.4.4 Processo SMR avançado - Licenciado pela Haldor Topsoe ...................................... 65

3.4.5 Processo de Reforma a Vapor do Metano - Licenciado pela Uhde GTmbH.............. 66

3.4.6 Processo Gas-To-Liquids - Davy Process Technology ......................................... 66

3.4.7 Processo Gas-To-Liquids - Licenciado pela Synytroleum Corporation ...................... 68

3.4.8 Panorama Atual da Produção de Gás de Síntese ................................................... 69

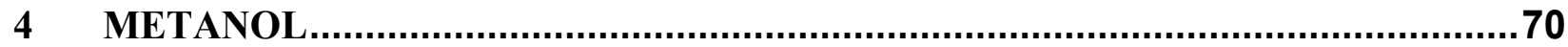

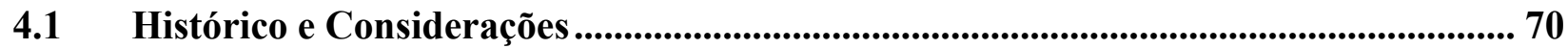

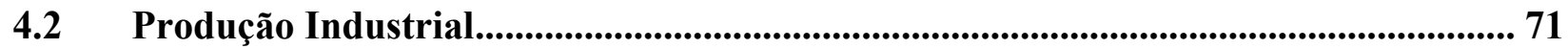

Evolução dos Processos de Produção do Metanol ..................................................... 72

4.4 A evolução dos Processos: da síntese em alta pressão à baixa pressão...................... 73

4.5 Obtenção do Metanol .......................................................................................................... 74

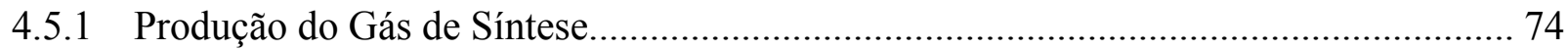

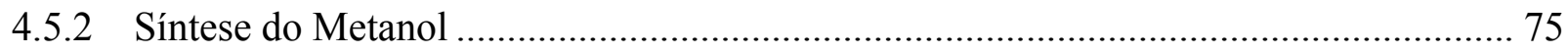

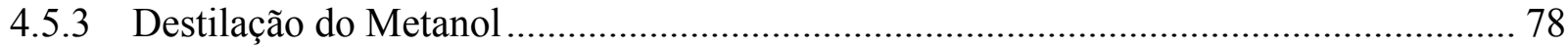

4.6 Exemplo de uma planta industrial de produção de metanol ..................................... 80

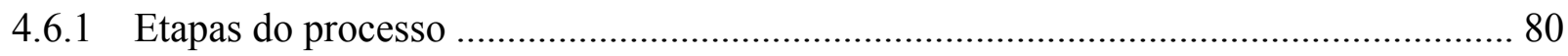

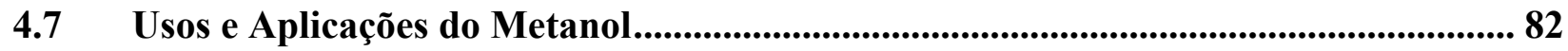




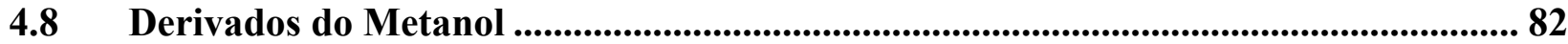

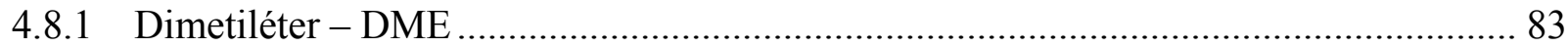

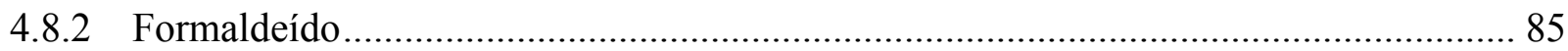

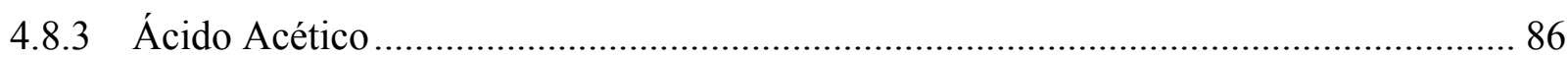

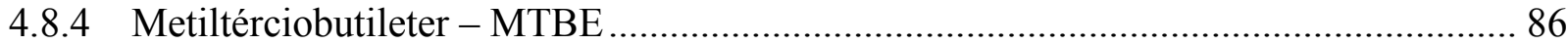

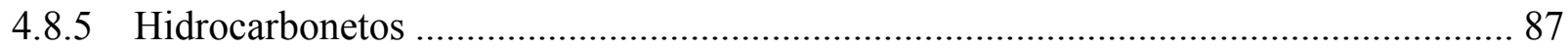

4.9 Estado da Arte da Tecnologia de Produção de Metanol................................................... 90

4.9.1 Tecnologia Haldor Topsoe (Haldor Topsoe, 2006)..................................................... 90

4.9.2 Tecnologia Haldor Topsoe - Plantas de larga escala ................................................... 92

5 AMÔNIA

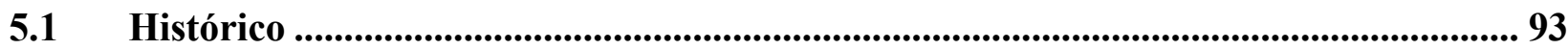

5.2 Processos de Produção de Amônia........................................................................................ 93

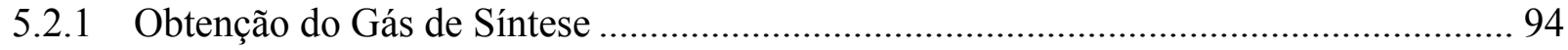

5.2.2 Remoção do CO Através da Shift Conversion ………………………………............ 94

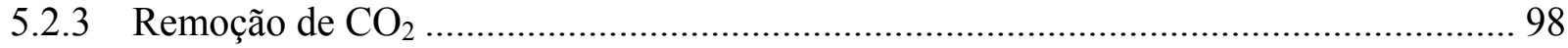

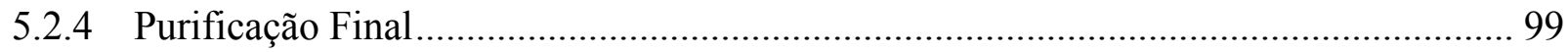

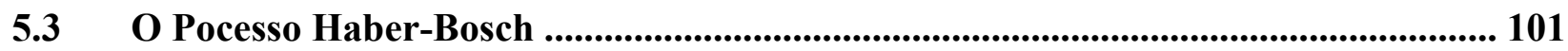

5.3.1 Detalhes do Processo Haber-Bosch......................................................................... 102

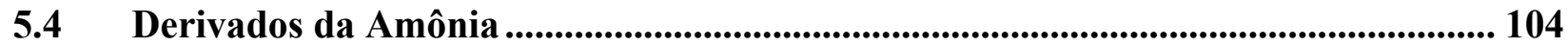

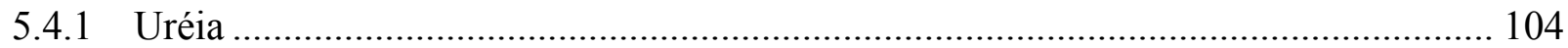

5.4.2 Nitrato de Amônio .................................................................................................. 106

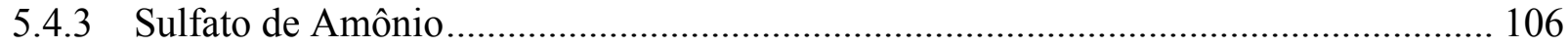

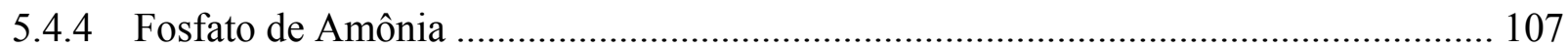

5.5 Estado da Arte da Tecnologia de Produção de Amônia .................................................. 107

5.5.1 Lurgi A.G. MegaAmmonia .................................................................................. 107

5.5.2 KAAP plus process - Kellogg Brown \& Root (KBR) ………………………......... 109 
6.1 Produção de Hidrogênio ............................................................................................................. 113

6.2 Purificação do $\mathrm{H}_{2}$ Através da Rota Pressure Swing Adsorption (PSA) ....................... 116

6.2.1 Etapas do Processo PSA ……………………......................................................... 117

6.3 Estado da Arte da Tecnologia de Produção do Hidrogênio ......................................... 118

6.3.1 Produção de Hidrogênio - Processo Licenciado pela Foster Wheeler.......................... 118

6.3.2 Produção de Hidrogênio a partir da Reforma a Vapor do Metano - Licenciado pela

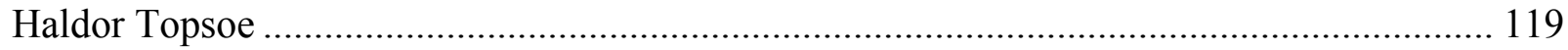

6.3.3 Produção de Hidrogênio a partir da reforma a vapor. Licenciado pela Lurgi Oel-Gas-

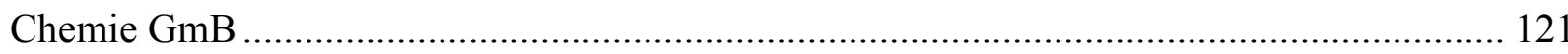

6.3.4 Produção de Hidrogênio. Licenciado pela UhdE GmbH …………………................ 122

$7 \quad$ ETENO

7.1 Matéria-Prima …............................................................................................................ 123

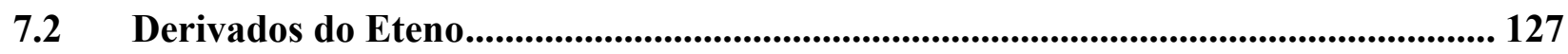

7.2.1 Polietileno de Alta Densidade ............................................................................... 127

7.2.2 Polietileno de Baixa Densidade - PEBD .................................................................. 127

7.2.3 Polietileno de Baixa Densidade Linear - PEBDL ...................................................... 128

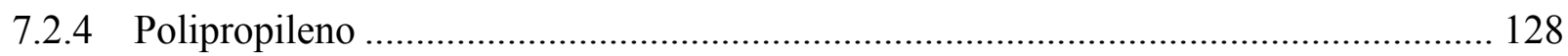

7.2.5 Polietileno Tereftalato - PET ………………………........................................... 129

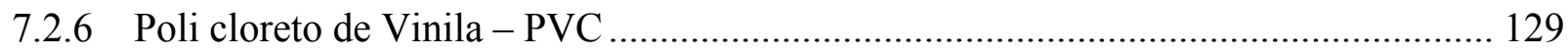

7.3 Estado da Arte da Tecnologia de Produção do Etileno................................................... 130

7.3.1 Tecnologia de produção de etileno - Licenciada pela Lurgi AG - (Petrochemical

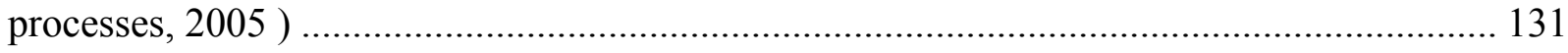

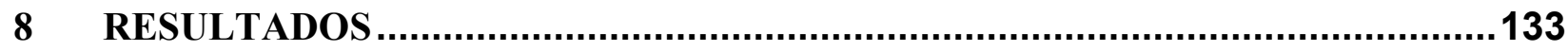

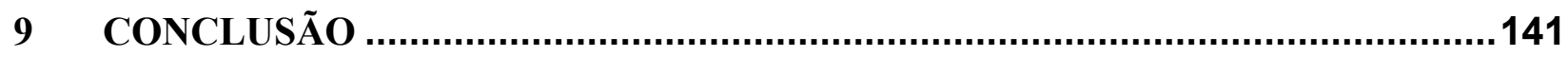




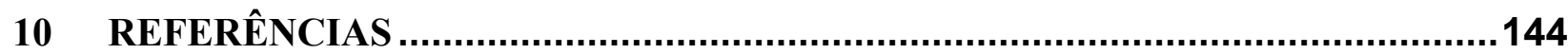
APÊNDICE A - SIMULAÇÃO DA PRODUÇÃO DE BIODIESEL PELA ROTA

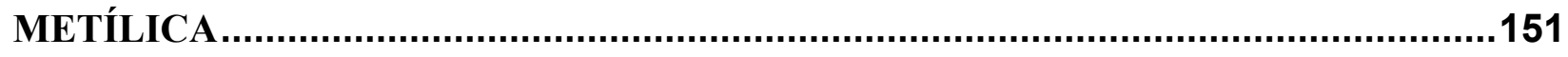




\section{INTRODUÇ̃̃̃O}

O presente trabalho tem como objetivo a realização da modelagem de uma planta gás química, onde os produtos finais a serem obtidos são: o eteno, a partir da fração etano, o metanol, a amônia e o hidrogênio, sendo estes três últimos, produzidos através da fração metano.

Dentre as motivações que levaram a realização deste trabalho, a principal delas consiste no uso do gás natural $(\mathrm{GN})$ como matéria-prima para as indústrias dos segmentos químico e petroquímico.

No Brasil, o uso do GN para esta finalidade é pouco difundido e, conseqüentemente, pouco conhecido. Países como os Estados Unidos, Canadá, Austrália, Nova Zelândia, Kuwait e Qatar utilizam o GN como insumo e os principais produtos obtidos são: amônia, metanol e eteno. $\mathrm{Na}$ Austrália, por exemplo, cerca de $90 \%$ do metanol consumido é proveniente do GN (COOGEE, 2005). Em Trinidad e Tobago, 100\% da produção de metanol e amônia é também oriunda do GN.

No Brasil, a utilização do GN como fonte industrial de matéria-prima, teve início em 1971, com a partida da Fábrica de Fertilizantes Nitrogenados (FAFEN-BA), localizada em Camaçari e pertencente ao grupo Petrobras. O GN utilizado provinha dos campos de Sergipe e da Bahia. Em 1982, teve início a operação da unidade de Laranjeiras, em Sergipe. Atualmente, estas unidades produzem um total de 900.000 t/ano de amônia, 1 milhão t/ano de uréia, 36.000 t/ano de ácido nítrico e 150.000 t/ano de gás carbônico. (PETROBRAS, 2006).

O dado mais atual sobre a utilização do GN como matéria-prima, advém da inauguração da planta da Rio Polímeros (RioPol), localizada em Duque de Caxias - Rio de Janeiro, a qual utiliza as frações de etano e propano, para produzir etileno e propeno. Esta planta terá capacidade produtiva nominal igual a $520.000 \mathrm{t} /$ ano de eteno e 75.000 t/ano de propeno (RIOPOL, 2006).

A figura 1.1 aponta as rotas química e petroquímica, que o GN pode percorrer como insumo industrial. 


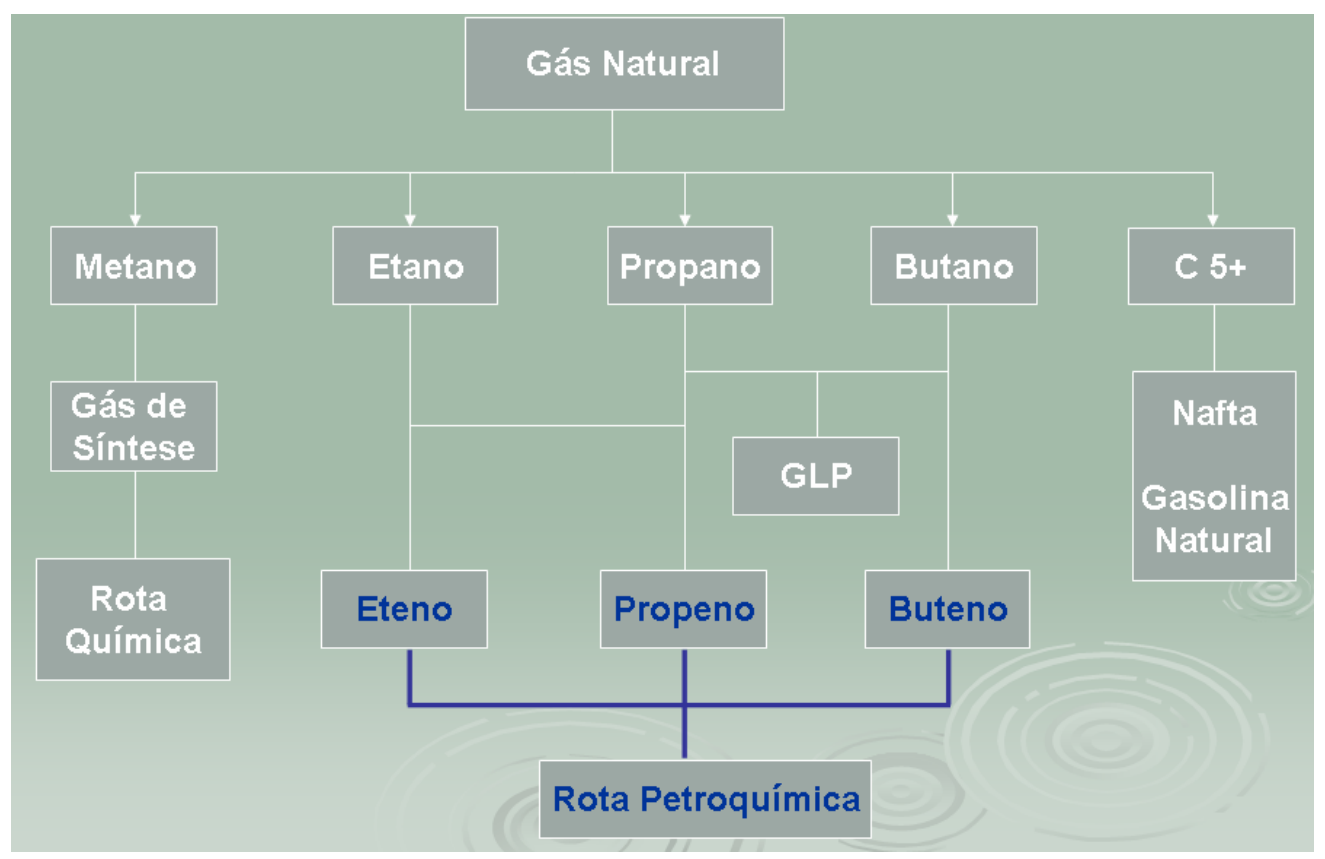

Figura 1.1 Rotas de aplicação do GN como insumo industrial

Fonte: (GEROSA, T., 2006)

\subsection{Panorama dos Derivados do Metano}

\subsubsection{Panorama Mundial do Metanol}

A utilização da fração metano do GN, como insumo na indústria química, é a base para a obtenção de metanol, amônia e hidrogênio em diversos países. Estudos da Lurgi AG (2003) apontam que cerca de 5\% do GN consumido no mundo, seja aplicado em processos conhecidos como química do $\mathrm{C}_{1}{ }^{1}$. Os derivados do metano, estudados neste trabalho, apresentam grande importância tanto no mercado nacional quanto no internacional.

Quanto ao uso do GN como insumo para a obtenção de metanol, estudos da British Petroleum (2003) indicam que um grande salto de produção será alcançado até 2010. Os dados

\footnotetext{
${ }^{1}$ Entende-se por química do $\mathrm{C} 1$ a cadeia produtiva desenvolvida a partir da transformação química do metano em derivados diretos e indiretos.
} 
apontam que, para o ano de 2003, a produção das plantas espalhadas ao redor do mundo, somava cerca de 2.500 t/dia. Em 2004, houve um aumento para 5.000 t/dia, e, para o ano de 2007, projeta-se 10.000 t/dia. Como complemento, o estudo aponta que os mercados emergentes com alto potencial para a absorção de todo o metanol produzido são: produção de olefinas (MTO Methanol to Olefins, MTP - Methanol to Propylene), gasolina (MTG - Methanol to Gasoline), dimetiléter (DME), célula combustível e energia.

As plantas consideradas no estudo apontado estão ilustradas na figura 1.2.

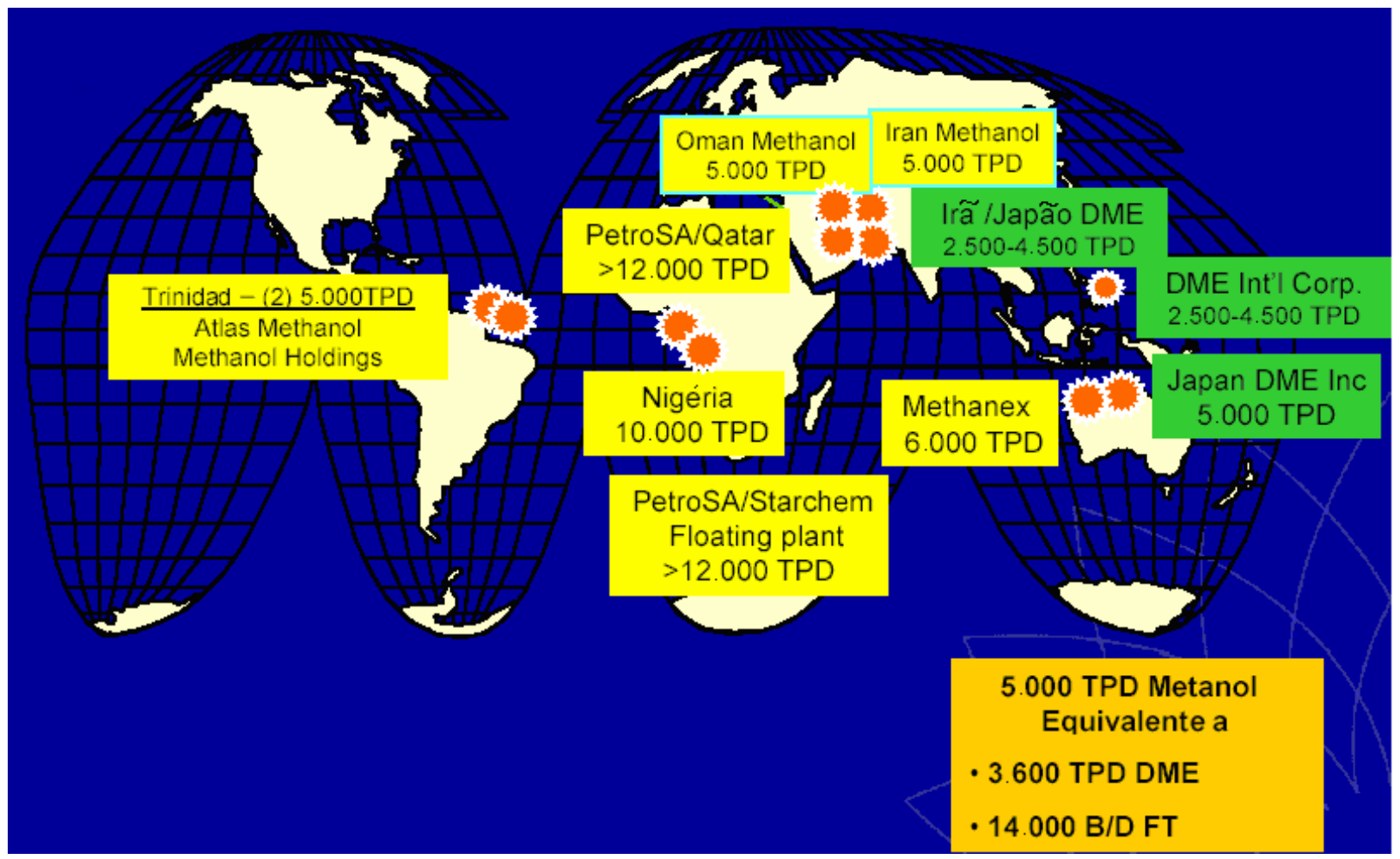

Figura 1.2 Plantas de produção de metanol a partir do GN

Fonte: (FLEISH, T., 2003; adaptação própria).

Conforme dados de Fleisch e Sills (2005), cerca de 85 milhões de $\mathrm{m}^{3}$ de GN foram consumidos para a produção de metanol, no ano de 2005.

Dados da Sociedade Francesa de Química (2006) apontam que a capacidade instalada de produção de metanol, em 2006, foi estimada em 42 milhões de toneladas e, o consumo previsto, estimado em 33 milhões de toneladas. A maior produtora é a Methanex, cuja produção esperada para 2006 foi de 6,3 milhões de toneladas. 
A tabela 1.1 mostra o perfil dos países produtores de metanol, com valores referentes ao ano de 2003.

Tabela 1.1 - Produção mundial de metanol por país no ano de 2003

\begin{tabular}{lr}
\hline \multicolumn{1}{c}{ País } & M t/ano \\
\hline Arábia Saudita & 4,93 \\
Trinidad e Tobago & 4,78 \\
China & 4,04 \\
Estados Unidos & 3,70 \\
Chile & 3,00 \\
Rússia & 2,93 \\
Alemanha & 1,95 \\
Irã & 1,44 \\
Venezuela & 1,40 \\
Canadá & 1,30 \\
Indonésia & 0,99 \\
Malásia & 0,66 \\
Índia & 0,41 \\
\hline
\end{tabular}

Fonte: (SOCIEDADE FRANCESA DE QUÍMICA, 2006).

As principais aplicações do metanol no cenário mundial estão apresentadas na figura 1.3.

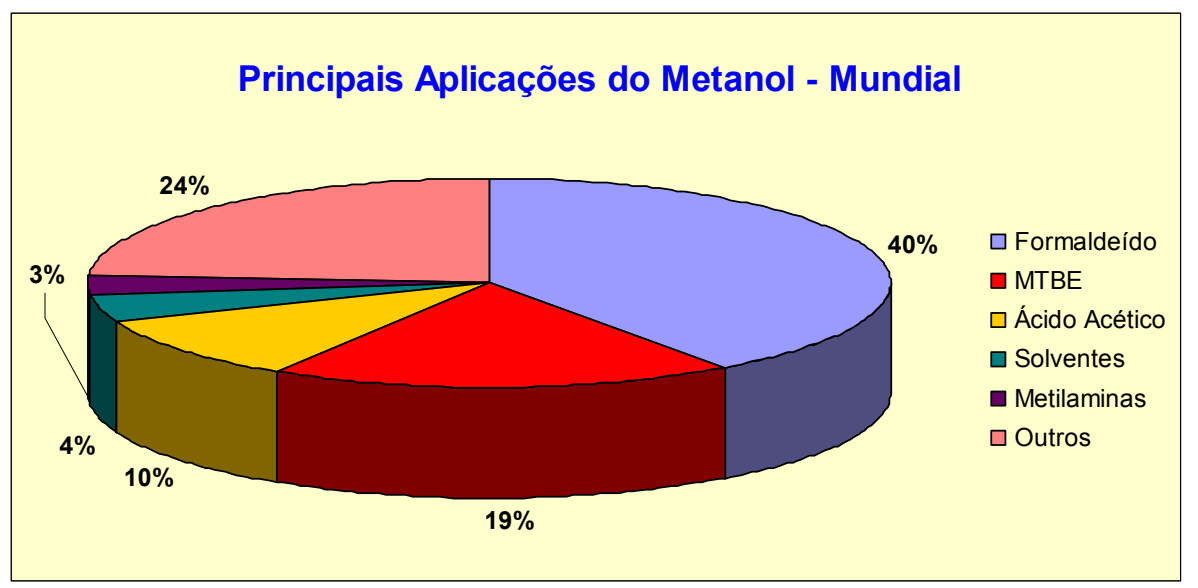

Figura 1.3 Principais aplicações do metanol no cenário mundial

Fonte: (SOCIEDADE FRANCESA DE QUÍMICA, 2006, LURGI AG, 2005; adaptação própria ). 


\subsubsection{Cenário Brasileiro do Metanol}

O cenário brasileiro do metanol é preocupante, pois seu consumo aumenta a cada ano e a capacidade produtiva nacional não é suficiente para atender à demanda, restando como opção a importação do referido produto. Esta importação acaba por aumentar o déficit da balança comercial do setor químico. No ano de 2004, por exemplo, foram gastos US\$ 62.100.800,00 com a importação de 272.302 toneladas. Para o mesmo ano, foi registrada uma produção nacional de 273.595,9 toneladas, ou seja, o consumo interno é quase o dobro do que se produz, sendo o restante importado (ABIQUIM, 2005).

A figura 1.4 mostra a produção, a importação e a demanda de metanol, no Brasil, para o intervalo de anos compreendido entre 2001 e 2004.

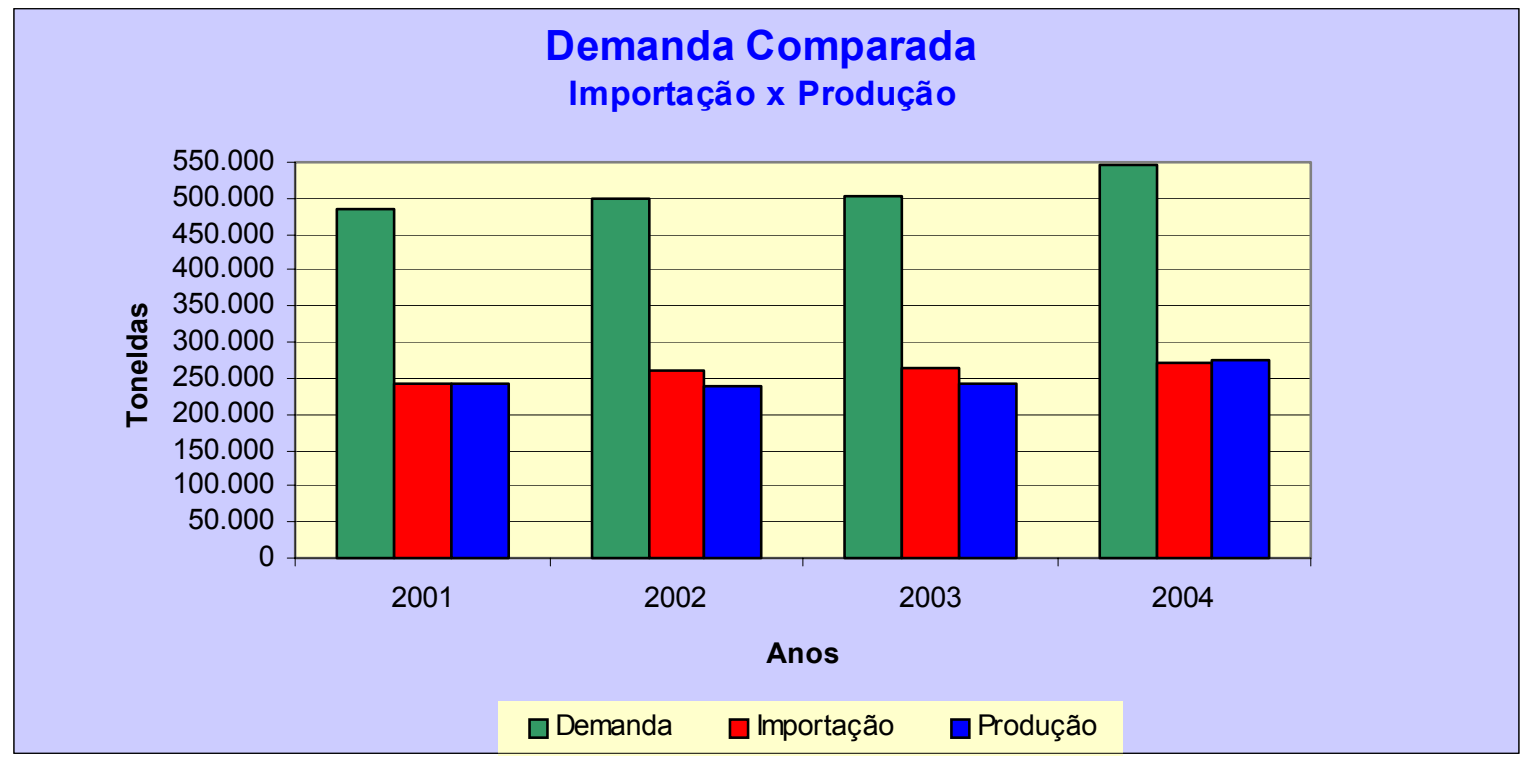

Figura 1.4 Demanda de metanol comparada à importação e produção

Fonte: (ABIQUIM, 2005; adaptação própria).

A maior produtora de metanol, no Brasil, é a empresa Prosint, localizada no Estado do Rio de Janeiro, com capacidade produtiva de 180.000 t/ano. Está previsto entrar em operação, no 
ano de 2007, a expansão desta planta, onde haverá um incremento de 80.000 t/ano na capacidade produtiva. O investimento a ser realizado está em torno de US\$ 12,5 milhões (ABIQUIM, 2005).

A segunda maior produtora é a Metanor S.A. (Metanol do Nordeste), localizada no pólo petroquímico de Camaçari - BA, cuja capacidade produtiva é de 82.500 t/ano e sua produção em 2004, foi de 89.247 t/ano, apresentando queda de 16,2\% em 2005, com volume de produção de 74.792 t/ano, devido à parada técnica realizada por um fornecedor de matéria-prima.

As demais produtoras são Ultrafértil, no Paraná e Vicunha Têxtil, na Bahia, com capacidade produtiva de 7.000 e 7.680 t/ano, respectivamente.

Ao aplicar-se uma análise de tendência para a importação do metanol, tem-se como resultado uma reta ascendente com coeficiente de correlação de 0,90 , conforme mostrado na figura 1.5 .

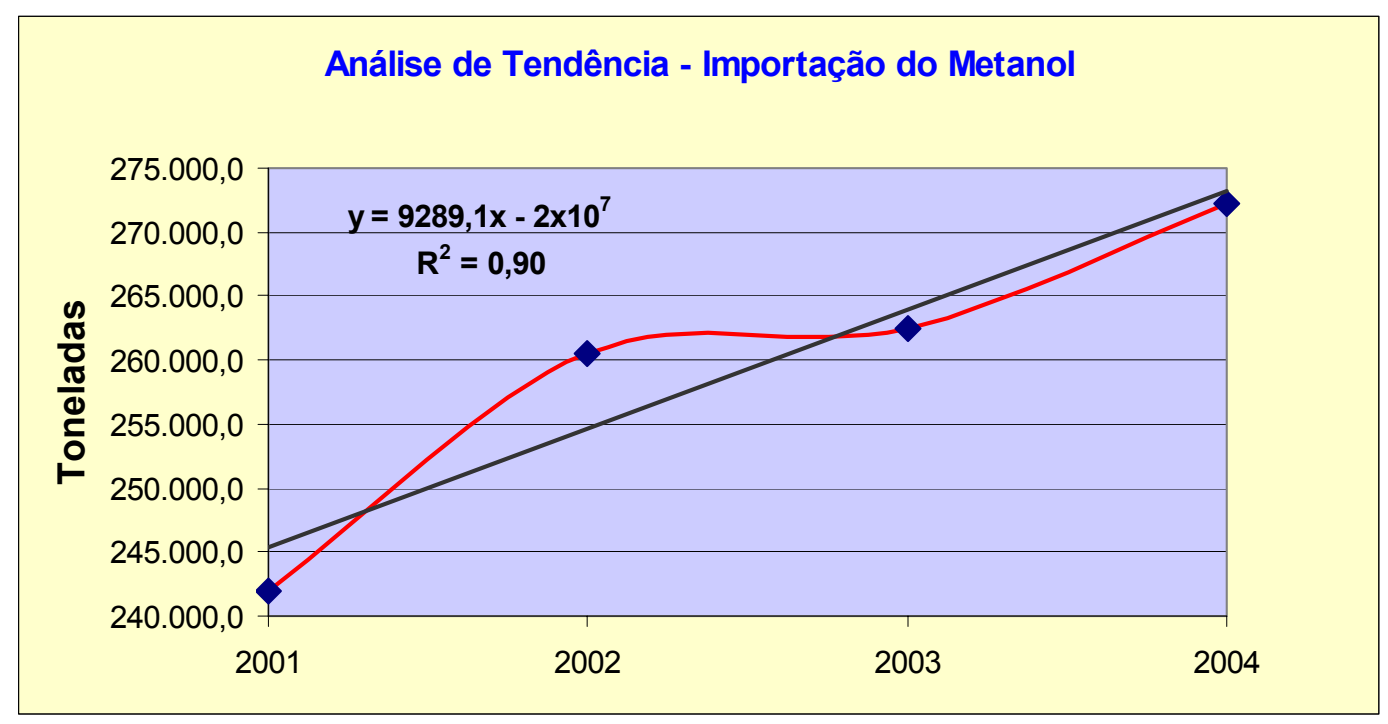

Figura 1.5 Análise de tendência da importação do metanol

Fonte: (ABIQUIM, 2005; Elaboração própria)

Ao somar-se a tendência apontada com a falta de expectativa de outras ampliações da capacidade produtiva nacional de metanol e, com o fato de, na atual demanda, não ser computado seu uso na produção do biodiesel, forma-se um cenário mais crítico e com maior tendência de aumento da importação. Uma simulação da produção de biodiesel, no Brasil, através da rota metílica, encontra-se no apêndice A, do presente trabalho. 
Assim como no restante do mundo, o Brasil aplica grande parte da sua produção de metanol na fabricação de formaldeído. A figura 1.6 mostra os principais destinos das vendas internas de metanol registradas no ano de 2004.

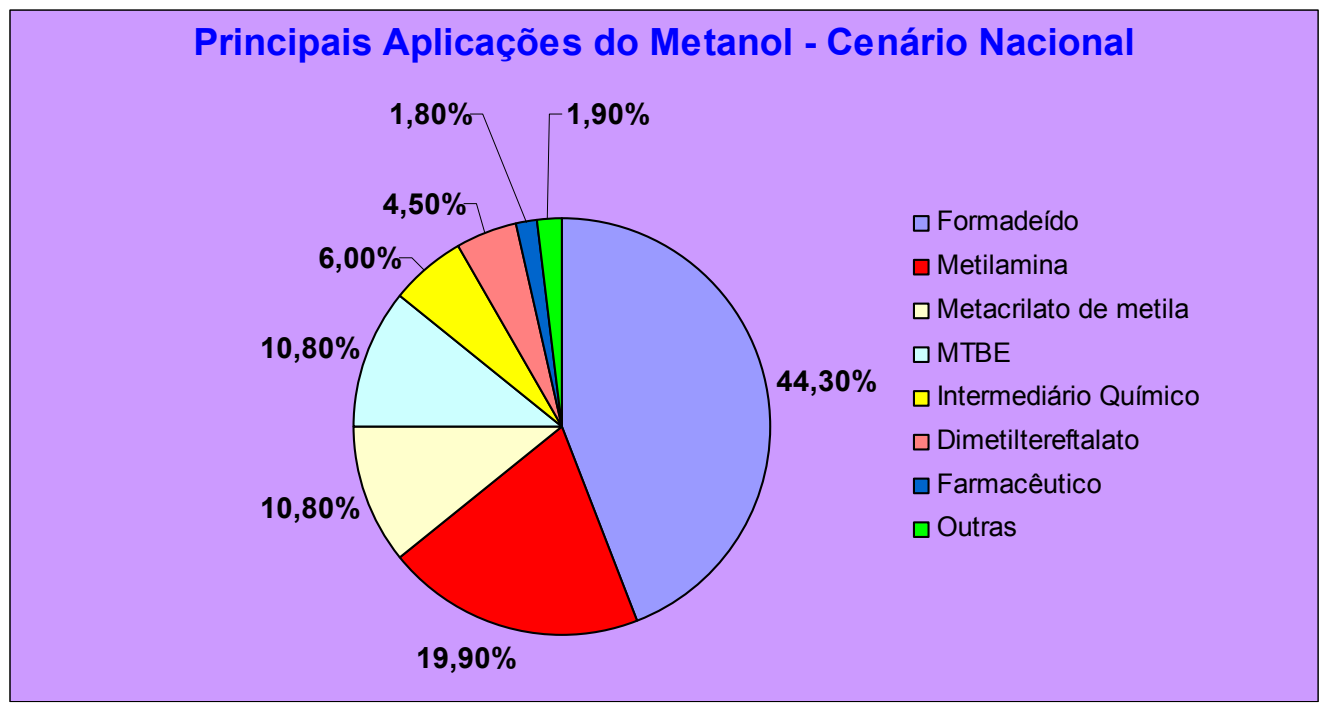

Figura 1.6 Principais aplicações do metanol no Brasil

Fonte: (ABIQUIM, 2005; elaboração própria)

\subsubsection{Panorama Mundial da Produção de Amônia}

Fleisch e Sills (2005) apontam que, no ano de 2005, cerca de 340 milhões de $\mathrm{m}^{3}$ de GN foram consumidos para a produção de amônia. O maior uso desta é para a fabricação de fertilizantes. Conforme Kramer (2004), cerca de 85\% da produção norte-americana recebe este destino.

Abram e Forsters (2005) indicam que a produção anual de amônia no ano de 2003, foi de aproximadamente 146 milhões de toneladas. São os seguintes países com maior capacidade de produção: China, Índia, Rússia e Estados Unidos. A tabela 1.2 apresenta a capacidade de produção destes países e as suas respectivas taxas de utilização. 
Tabela 1.2 - Maiores países produtores de amônia e suas respectivas taxas de utilização

\begin{tabular}{lcc}
\hline \multicolumn{1}{c}{ País } & Mt/ano & $\begin{array}{c}\text { Taxa de } \\
\text { Utilização }\end{array}$ \\
\hline China & 36,721 & $100 \%$ \\
Índia & 11,804 & $85 \%$ \\
Rússia & 11,065 & $79 \%$ \\
USA & 10,664 & $74 \%$ \\
\hline
\end{tabular}

Fonte: (ABRAM E FORSTERS, 2005; adaptação própria)

A figura 1.7 apresenta a evolução da produção mundial de amônia.

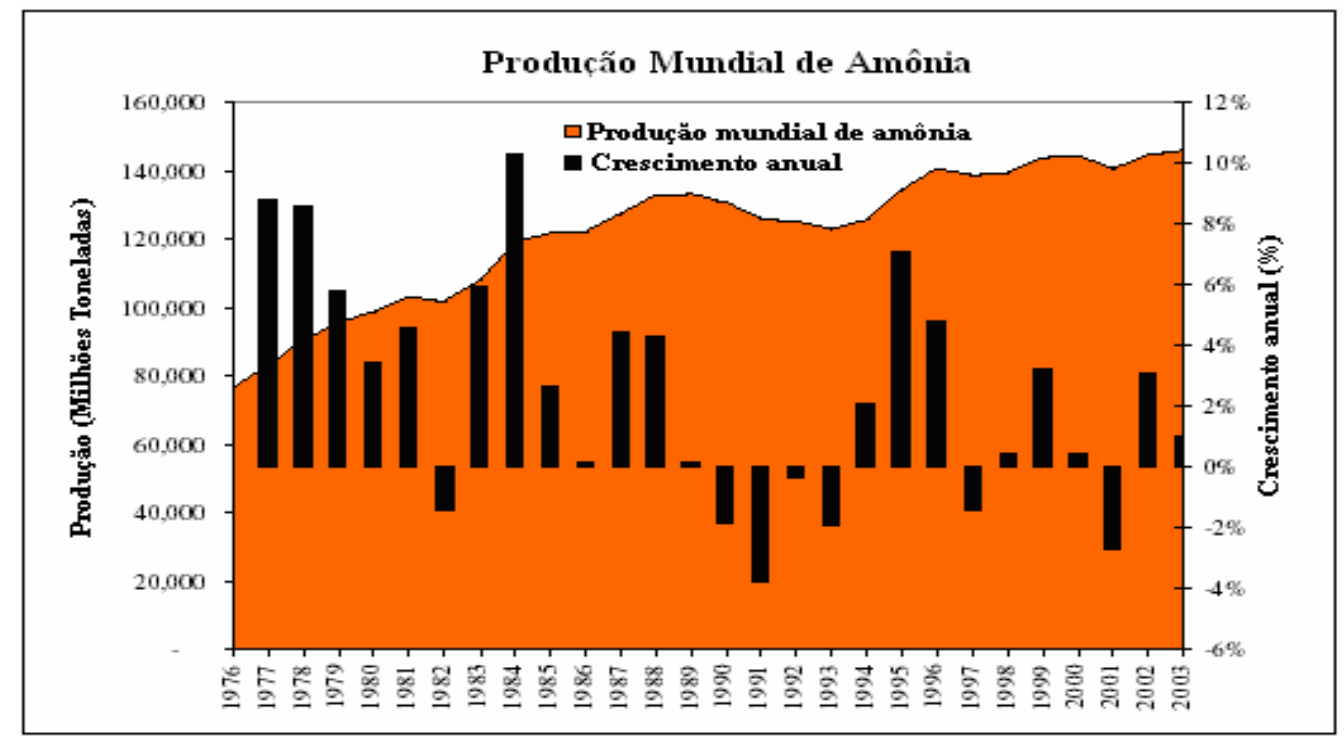

Figura 1.7 Produção mundial de amônia e taxa anual de crescimento

Fonte: (ABRAM E FORSTERS, 2005)

Segundo dados da KBR (2005), a amônia está entre os produtos químicos básicos que apresentam maior demanda. Esta, em 2004, foi de 142 milhões de toneladas e $82 \%$ do total foi utilizado para a produção de fertilizantes.

O mesmo estudo aponta que, em 2010, a capacidade produtiva mundial estará em torno de 190 milhões de toneladas ano, o que representa, a partir de 2005, um crescimento médio de 2,2\% ao ano da capacidade nominal instalada. Para que este volume seja atingido, será necessário a partida de 5 a 6 novas plantas por ano, representando um incremento médio de 2.000 t/dia na 
produção de amônia. Para o ano de 2010, a demanda projetada está em torno de 155 milhões de toneladas. Como última informação, o estudo indica que $75 \%$ desta nova produção será destinada ao mercado exportador.

Conforme Krammer (2004), o mercado de amônia encontra-se altamente atrelado ao preço do gás natural, sua principal matéria-prima, ou seja, é um mercado que apresenta alta volatilidade e faz com que países que apresentem o menor preço de insumo, sejam grandes produtores.

\subsubsection{Cenário Nacional da Produção de Amônia}

A figura 1.8 mostra paridade no aumento entre a demanda e a produção nacional de amônia, no período compreendido entre 2001 e 2004, através da observação dos coeficientes de correlação entre estas retas, que são fruto da regressão linear. A diferença entre a demanda e a produção é suprida através da importação, a qual se apresenta constante ao longo do mesmo período, sendo suficiente apenas para complementar a produção até que se atinja a demanda necessária.

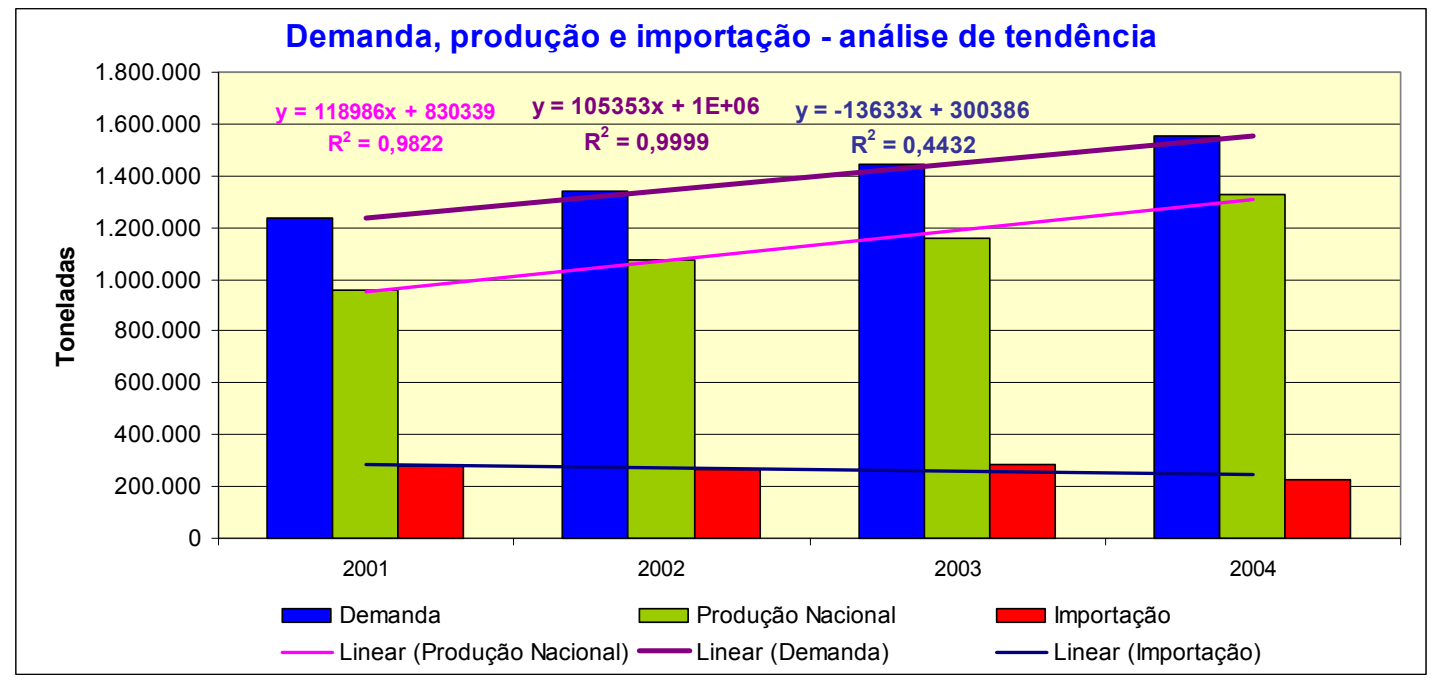

Figura 1.8 Análise de tendência da demanda, produção e importação de amônia no mercado brasileiro

Fonte: (ABIQUIM, 2005; elaboração própria) 
Uma análise preliminar mostra que, caso os custos da produção nacional da amônia fiquem abaixo de US\$207/ton, (valor médio ponderado por volume importado, calculado para o período de 2001 até 2004), poderia ocorrer a viabilidade de projetos internos para a produção de volumes compatíveis com as quantidades importadas, na faixa de 266 mil t/ano. Considerando-se o incremento médio da demanda em $8 \%$ ao ano e, o incremento médio da produção de $10 \%$ ao ano, a capacidade instalada de produção de amônia, que tem $15 \%$ de ociosidade em relação ao consumo de 2004, atingiria o seu pico em 2006. Conforme informações da ABIQUIM (2005), não há previsão da ampliação do parque nacional para os próximos anos. Por outro lado, a Petrobras, em seu plano estratégico, compreendido entre 2007-2011, pretende investir no setor petroquímico US\$ 3,3 bilhões e, parte deste montante será destinada à unidade da FAFEN-BA e também, na produção de fertilizantes nitrogenados.

Torna-se, então, parte do objeto de estudo, a produção de amônia a partir do GN na planta gás-química, a ser modelada como forma de não somente complementar a lacuna de fornecimento interno existente, como também o aumento da capacidade produtiva nominal.

Assim como no restante do mundo, o Brasil também aplica grande parte da sua produção de amônia na fabricação de fertilizantes nitrogenados, sendo a uréia o mais importante. A figura 1.9 mostra os principais destinos das vendas internas de amônia registradas no ano de 2004 .

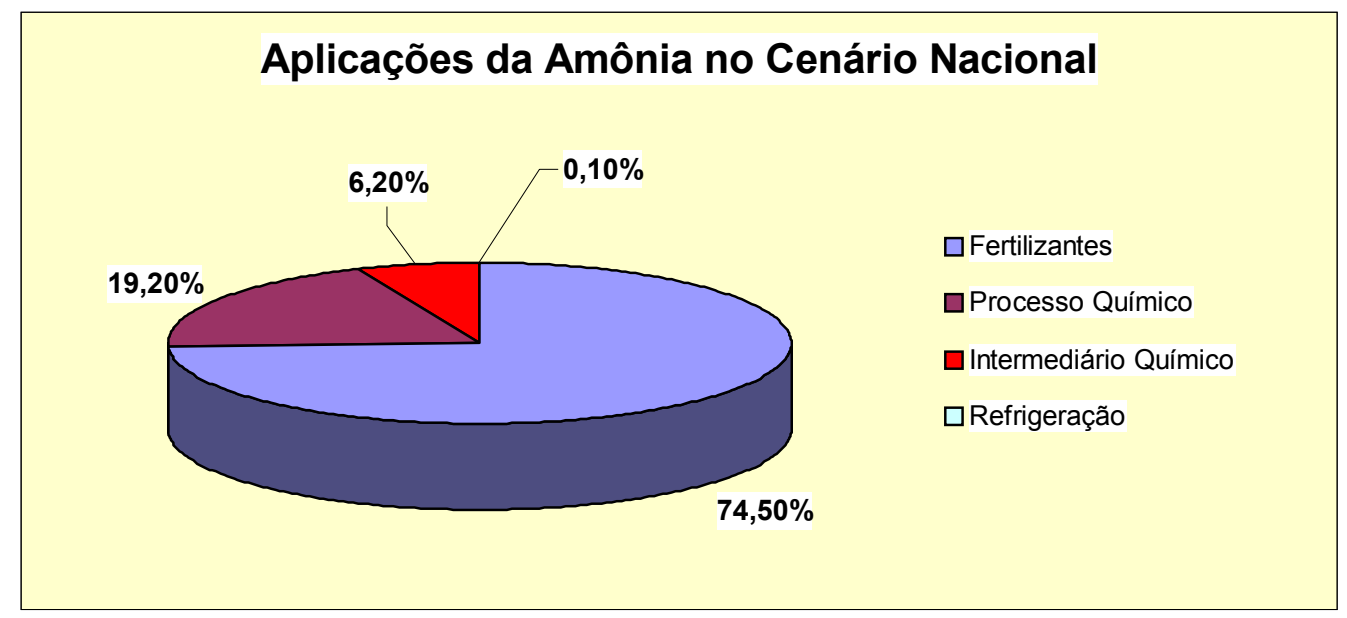

Figura 1.9 Aplicação da amônia no cenário nacional

Fonte: (ABIQUIM, 2005; elaboração própria) 


\subsection{O Setor Petroquímico}

Podemos considerar a indústria petroquímica como a maior responsável pela grande disponibilidade de produtos existentes no mundo moderno atual, sendo os plásticos, produtos petroquímicos. Por outro lado, tecidos e fibras sintéticas, tais como a microfibra, também são oriundos do setor petroquímico. Um outro ramo da indústria, conhecido como química fina, responsável por produtos desde medicamentos até fertilizantes, tem suas matérias-primas originadas na indústria petroquímica.

Quando analisada sob o contexto histórico dentro de seu ramo setorial (como um braço da química), é considerada como sendo a mais recente e a que mais apresentou evolução desde seu surgimento, tanto em termos de tecnologia quanto de ocupação de mercado. Seu nascimento data do final do século XIX, com o desenvolvimento de uma resina chamada baquelite, cujo intuito era a substituição do marfim, utilizado na produção das bolas de bilhar. Em 1930, a tecnologia que possibilitava a produção de polietileno foi desenvolvida. Uma outra parcela de seu

desenvolvimento está relacionada a II Guerra Mundial, onde os cientistas procuravam um substituto para a borracha natural (MANO, 1990).

Sendo derivada dos hidrocarbonetos (petróleo, gás natural, gásoleo, entre outros), a petroquímica foi importante na substituição de matérias-primas, tais como madeira, algodão, celulose, entre outras, há muito tempo utilizadas pelo homem. Tornou-se, também, uma das propulsoras do crescimento industrial, pois sua influência está presente desde a área de eletroeletrônicos até a área médica, na fabricação de bolsas de sangue, próteses e demais produtos.

\subsubsection{Estrutura do Setor}

O setor petroquímico é o responsável por realizar a transformação de correntes obtidas do refino do petróleo, como por exemplo, a nafta. E, também, por processar as frações de etano e propano contidas no gás natural.

De uma forma geral, podemos dividir o setor petroquímico em três distintas categorias, onde cada uma delas é responsável por uma determinada fase de transformação: 


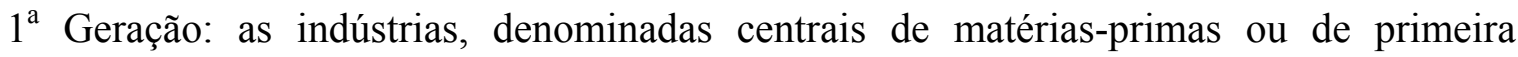
geração, são as responsáveis por realizar a operação denominada craqueamento, através da qual são obtidas olefinas (eteno, propeno e butadieno), os aromáticos (benzeno, tolueno e xileno) e, secundariamente, combustíveis como a gasolina de pirólise. Os insumos utilizados são os hidrocarbonetos leves, como a nafta, gás natural (frações etano e propano), entre outros. Dentre os processos mais utilizados por estas centrais estão o craqueamento, pirólise e reforma catalítica.

$2^{a}$ Geração: as indústrias, denominadas petroquímicas de segunda geração, são aquelas responsáveis pelo processamento dos insumos petroquímicos adquiridos juntamente aos produtores de primeira geração (eteno, propeno, butadieno, entre outros). A partir destes, obtém-se produtos petroquímicos intermediários, ou, até mesmo finais. Dentre os intermediários destacamos o estireno e o monômero do cloreto de vinila. Nos produtos finais têm-se o polietileno, o polipropileno, os elastômeros, entre outros, que serão fornecidos diretamente às empresas de terceira geração. Atualmente, o Brasil conta com cerca de 50 empresas deste setor (SUZANO PETROQUÍMICA, 2005).

$3^{\mathrm{a}}$ Geração: são as indústrias responsáveis pelas transformações finais dos produtos petroquímicos, transformando as matérias-primas em produtos finais para o consumidor, tais como: embalagens plásticas (sacos, sacolas, frascos), utilidades domésticas, brinquedos, calçados, solados, sandálias, pneus e autopeças.

A competitividade, envolvida na indústria petroquímica, focando, principalmente nas empresas de primeira geração, está diretamente relacionada à disponibilidade de matéria-prima. Segundo o BNDES (2005), outros pontos que influenciam a competitividade do setor são: escala de produção, integração, tecnologia, acesso ao mercado consumidor (escoamento da produção) e custo de capital.

Neste contexto, os grandes investimentos, não somente em projetos novos, mas também em ampliações, são realizados nas regiões do Oriente Médio, onde há versatilidade de insumos com os preços mais baixos do mercado.

A tabela 1.3 apresenta os principais projetos de aumento da capacidade produtiva de eteno entre os anos de 2005-2009. Até o presente momento, não é possível saber com exatidão, quais são os projetos em fase de operação, nem quanto estão produzindo. 
Tabela 1.3 - Relação dos projetos de expansão da capacidade nominal de produção de eteno por país em t/ano

\begin{tabular}{|c|c|c|c|c|c|c|}
\hline País & 2005 & 2006 & 2007 & 2008 & 2009 & Total País \\
\hline Áustria & & 150.000 & & & & 150.000 \\
\hline Brasil & 500.000 & 200.000 & & & & 700.000 \\
\hline China & 1.400 .000 & 680.000 & & 800.000 & & 2.880 .000 \\
\hline República Checa & 25.000 & 50.000 & & & & 75.000 \\
\hline Hungria & & & 85.000 & & & 85.000 \\
\hline Índia & 300.000 & & & & & 300.000 \\
\hline Irã & 3.420 .000 & 100.000 & & 1.318 .000 & 500.000 & 5.338 .000 \\
\hline Israel & & 40.000 & & & & 40.000 \\
\hline Kwait & & & 850.000 & & & 850.000 \\
\hline Polônia & 320.000 & & & & & 320.000 \\
\hline Qatar & & 195.000 & 1.300 .000 & & & 1.495 .000 \\
\hline Arábia Saudita & 202.000 & & 1.300 .000 & 3.500 .000 & & 5.002 .000 \\
\hline Coréia do Sul & & 100.000 & & & & 100.000 \\
\hline Turquia & & 120.000 & & & & 120.000 \\
\hline Estado Unidos & 295.000 & & & & & 295.000 \\
\hline Venezuela & & & & & 900.000 & 900.000 \\
\hline Romênia & 100.000 & & & 1.050 .000 & & 1.150 .000 \\
\hline Total & 6.562 .000 & 1.635 .000 & 3.535 .000 & 6.668 .000 & 1.400 .000 & 19.800 .000 \\
\hline
\end{tabular}

Fonte: (OIL AND GAS JOURNAL, 2005; adaptação própria)

Outra característica deste setor é a forma cíclica com que ele se manifesta, não somente no cenário mundial, pois, quando se encontra na fase de alta, normalmente associada a grandes crescimentos das economias de mercado, ocorrem muitos investimentos na ampliação da capacidade produtora do setor; conseqüentemente, isto leva a um excesso de oferta, fazendo com que os preços dos produtos diminuam.

Estudos apontavam que o ciclo de alta $(f l y$-up) da indústria petroquímica, iniciado em 2005, atingiria seu pico de rentabilidade em meados de 2006, com taxas de ocupação previstas acima de 92\%, valor médio do ano de 2005 (BNDES, 2005 e OIL AND GAS JOURNAL, 2005). 
O cenário, para 2007, ainda é positivo, embora esteja previsto o início da queda da taxa de ocupação do parque petroquímico mundial, voltando, possivelmente, a casa dos 90\%, valor médio do ano de 2004. Especialistas apontam que o ciclo de baixa seja iniciado entre os anos de 2008-2009, quando as novas capacidades adicionais estiverem em operação (BNDES, 2005 e Oil and Gas Journal, 2005).

A figura 1.10 mostra a evolução do fator de utilização do parque petroquímico mundial e, também, uma comparação entre demanda e capacidade de produção. Todas as análises são relativas ao período de 2000-2010.

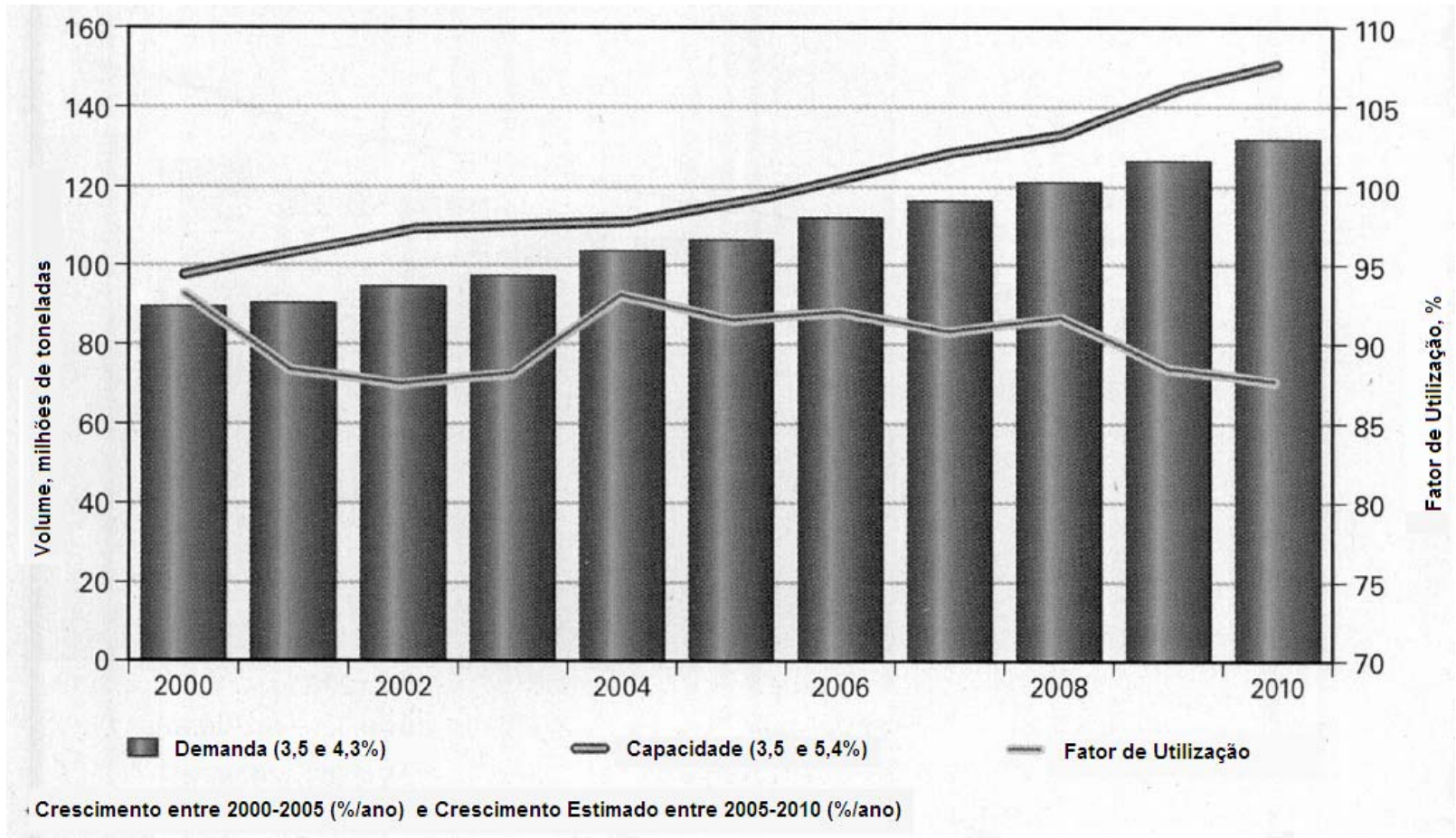

Figura 1.11 Utilização do parque petroquímico mundial, comparação entre demanda e capacidade

Fonte: (OIL AND GAS JOURNAL, 2005, adaptação própria) 


\subsubsection{Panorama Mundial da Produção de Eteno}

O aumento de 3,1\% da demanda global de etileno, registrada no ano de 2005, é considerada baixa, quando comparada com a taxa média de crescimento anual, na faixa de 4-5\%. As projeções, para o período compreendido entre 2005-2010, apontam que esta será em torno de $4,3 \%$ ao ano. Para atender a demanda, a capacidade produtiva mundial deve crescer cerca de 5,3\% no mesmo período, sendo que, entre 2000-2005, a capacidade cresceu apenas 3,5\%. (OIL AND GAS JOURNAL, 2005).

A capacidade produtiva, em 2004, era de 110,8 milhões de toneladas e a de 2005, de 112,9 milhões de toneladas. O fator de carga global, para o ano de 2004 , foi de $90 \%$, elevando-se para $92 \%$, no ano de 2005 .

A maior parte da produção mundial de eteno é originada da nafta, devido a sua flexibilidade de transporte para os grandes centros consumidores de olefinas. Europa e Ásia apresentam estruturas petroquímicas baseadas neste insumo.

A utilização do etano, como matéria-prima, é mais comum em regiões onde há produção de gás natural associado, como América do Norte e Oriente Médio. Neste último, a utilização do etano baseia-se no preço fixo regional do gás US\$ 0,75-1,50/MBtu e acaba por produzir o etileno de menor custo mundial. Para o período compreendido entre 2005-2010, prevê-se um aumento de 7,1\% da utilização do etano como insumo (OIL AND GAS JOURNAL, 2005).

Recentemente, a alta de preço do gás natural na América do Norte, atingindo valores de até US\$10,0/MBtu, tornou o etileno, produzido nesta região, muito menos competitivo.

Para 2010, a capacidade de abastecimento global de etileno está prevista em 133 milhões

de toneladas e a maior parte da mesma estará localizada no Oriente Médio, com 51\%, e na Ásia, com 36\%. A figura 1.11 mostra o crescimento da participação dos insumos. 


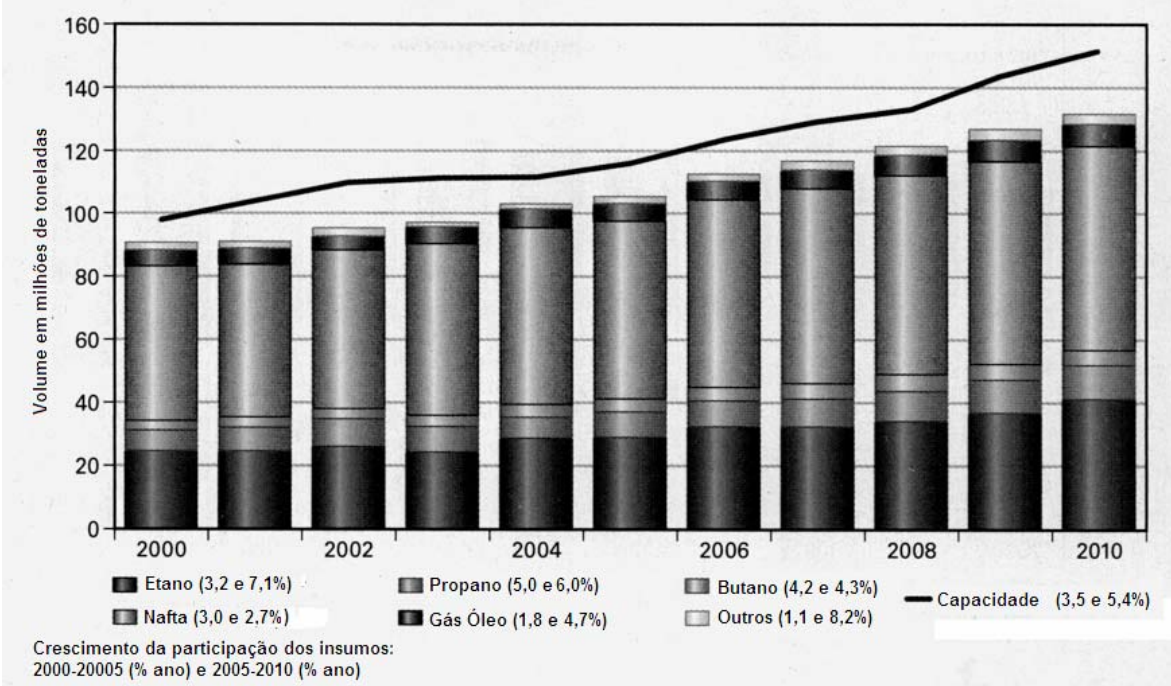

Figura 1.11 Crescimento da matéria-prima para os períodos de 2000-2005, 2005-2010 e capacidade produtiva

Fonte: (OIL AND GAS JOURNAL, 2005)

A tabela 1.4 mostra a capacidade produtiva nominal em t/ano, separada por região demográfica, abrangendo o período de 2003 a 2005. A tabela, também, apresenta a variação em t/ano e porcentual, em cada uma das regiões citadas.

Tabela 1.4 - Capacidade produtiva nominal e variação da produção de eteno, por região demográfica, no período entre 2003-2005

\begin{tabular}{lrrrrrrr}
\hline & \multicolumn{2}{c}{ Capacidade Produtiva (toneladas) } & \multicolumn{2}{c}{ Variação 2003-2004 } & \multicolumn{2}{c}{ Variação 2004-2005 } \\
& \multicolumn{1}{c}{ 1/jan/03 } & \multicolumn{1}{c}{ 1/jan/04 } & \multicolumn{1}{c}{ 1/jan/05 } & \multicolumn{1}{c}{ t/ano } & \multicolumn{1}{c}{$\%$} & \multicolumn{1}{c}{ t/ano } & \% \\
\hline Ásia-Pacífico & 28.326 .000 & 29.346 .000 & 30.095 .000 & 1.020 .000 & $3,60 \%$ & 749.000 & $2,55 \%$ \\
Leste Europeu & 7.417 .000 & 7.582 .000 & 8.137 .000 & 165.000 & $2,22 \%$ & 555.000 & $7,32 \%$ \\
Oriente Médio e África & 9.982 .000 & 11.012 .000 & 11.217 .000 & 1.030 .000 & $10,32 \%$ & 205.000 & $1,86 \%$ \\
América do Norte & 35.830 .000 & 34.412 .000 & 35.114 .000 & -1.418 .000 & $-3,96 \%$ & 702.000 & $2,04 \%$ \\
América do Sul & 4.338 .000 & 4.363 .000 & 4.385 .500 & 25.000 & $0,58 \%$ & 22.500 & $0,52 \%$ \\
Oeste Europeu & 23.541 .000 & 24.063 .000 & 23.957 .000 & 522.000 & $2,22 \%$ & -106.000 & $-0,44 \%$ \\
Total & 109.434 .000 & 110.778 .000 & 112.905 .500 & 1.344 .000 & $1,23 \%$ & 2.127 .500 & $1,92 \%$ \\
\hline
\end{tabular}

Fonte: (OIL AND GAS JOURNAL, 2005; adaptação própria) 
Nota-se que houve uma variação negativa entre os anos de 2003-2004, na América do Norte, que foi motivada pela parada de duas plantas localizadas nos Estados Unidos. Já no intervalo de 2004-2005, a variação negativa ficou a cargo do Oeste Europeu, mais precisamente Turquia e França, devido à perda na capacidade nominal.

\subsubsection{Setor Petroquímico Brasileiro}

A história da indústria petroquímica no Brasil pode ser dividida em cinco distintas fases de desenvolvimento:

$1^{\text {a }}$ Fase: iniciou-se quase no final da década de 40 e durou até 1964 , sendo marcada pelas instalações de pequenas fábricas privadas no Brasil, normalmente subsidiárias das empresas multinacionais. O país começou a dar seus primeiros passos no setor, através de investimento em estatais. Em 1955, é implantada no Estado de São Paulo, a Refinaria de Cubatão, proporcionando o surgimento de novas unidades produtoras de eteno, propeno, negro de fumo, entre outros;

$2^{\mathrm{a}}$ Fase: iniciada em 1965 e perdurando até meados da década de 70, ocorrendo após definiçõos políticas de cunho federal tomadas entre os anos de 1965 a 1967. No ano de 1967, há a criação da Petroquisa, realizada pela Petrobras, com o objetivo de desenvolver e consolidar a indústria petroquímica no Brasil. Esta fase teve como marco a inauguração, em 1972, do pólo petroquímico em Mauá, o primeiro do Brasil.

$3^{\mathrm{a}}$ Fase: iniciada em meados da década de 70, finalizando no início do ano de 1990, teve como marco principal um grande crescimento do setor petroquímico e a sua descentralização. Nesta fase foram construídos os pólos de Camaçari e de Triunfo, 1978 e 1982, respectivamente, os quais passaram por ampliações no fim da década de 80, início da de 90.

$4^{\mathrm{a}}$ Fase: iniciada em 1990, sendo marcada por fusões, novos investimentos e expansões.

$5^{\mathrm{a}}$ Fase: iniciada em meados de 2000, com o início da implantação do pólo gás químico da Rio Polímeros, como característica geral temos a diversificação de matériaprima, no setor petroquímico, em produção de larga escala. 


\subsubsection{Centrais Petroquímicas Brasileiras}

Até o ano de 2005, as centrais petroquímicas eram basicamente processadoras de nafta, porém, no respectivo ano, ocorreu a entrada da empresa Rio Polímeros, a qual utiliza como matéria-prima para a produção de eteno e propeno, as correntes do gás natural, etano e propano.

A figura 1.12 mostra a distribuição das centrais petroquímicas brasileiras.

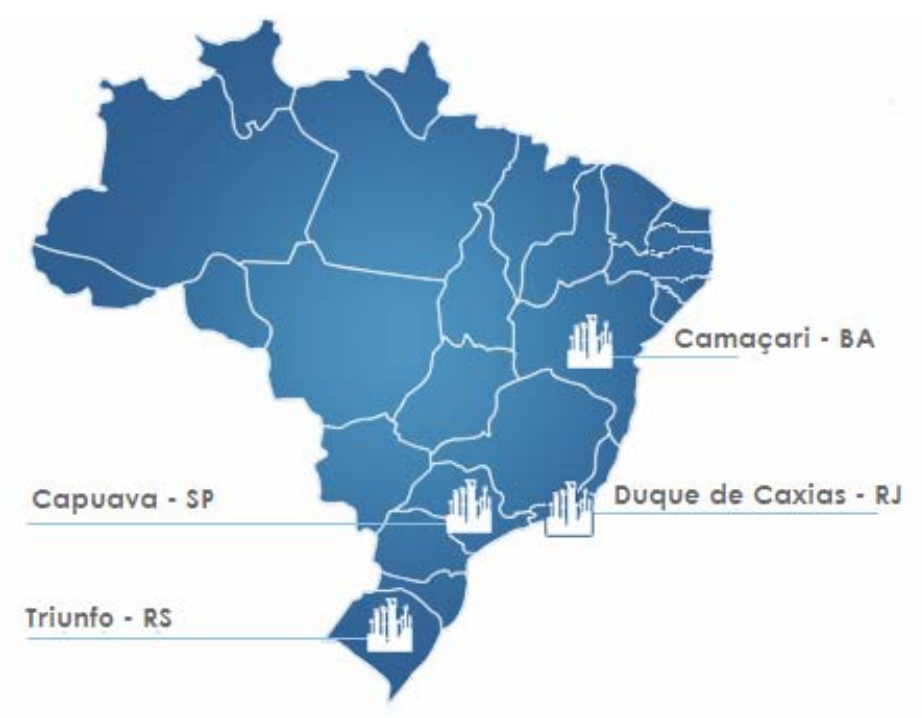

Figura 1.12 Localização geográfica das centrais petroquímicas brasileiras

Fonte: (SUZANO PETROQUÍMICA, 2006, adaptação própria)

\subsection{Central Petroquímica de Capuava, Santo André - São Paulo}

A Petroquímica União (PQU) é a primeira central localizada na região sudeste, o que a coloca bem próxima aos principais mercados consumidores. A sua produção, de eteno e outros petroquímicos, é fornecida às empresas de segunda geração, localizadas no pólo, por intermédio de dutos.

Seu principal problema é relacionado a sua baixa escala produtiva, com capacidade nominal de 500.000 t/ano e com expansão de 200.000 toneladas, prevista para entrar em operação no final de 2007. Mesmo com o novo volume de 700.000 t/ano, ainda não poderá ser classificada como de escala mundial, que são plantas com capacidade igual ou maior que 1 milhão de t/ano. 
Devido a sua localização, recebe a totalidade de sua matéria-prima, a nafta, enviada pelas refinarias da Petrobras, através de dutos. Porém, dados do BNDES (2005) apontam que a nafta recebida pela PQU não apresenta boas condições de processamento, em virtude da baixa qualidade do petróleo brasileiro.

A PQU não dispõe de terminal próprio, o que impossibilita a importação de nafta. A indisponibilidade de insumo é o principal entrave para a expansão desta central, que acaba perdendo em competitividade, quando comparada as demais centrais brasileiras.

O fato de ser uma central independente, ou seja, com pequena integração empresarial com as indústrias de segunda geração, localizada no pólo petroquímico, para as quais fornece matériaprima, é o segundo fator a afetar a competitividade desta central (BNDES, 2005)

\subsection{Central Petroquímica de Triunfo - Rio Grande do Sul}

A Companhia Petroquímica do Sul (Copesul) é a única central localizada na região sul do Brasil. Com capacidade produtiva de 1.135.000 t/ano de eteno, é considerada uma planta de escala mundial. Um outro fator, a aumentar a competitividade desta central, é a versatilidade de matéria-prima, pois é capaz de processar, além da nafta, o GLP e condensado, sendo este último disponível no mercado internacional e com baixo custo de importação.

Por estar geograficamente próxima a Argentina, apresenta como vantagem a facilidade de escoamento de sua produção para o Mercosul e facilita a importação de matéria-prima. Cerca de $80 \%$ de sua produção, não somente de eteno, como também dos demais petroquímicos produzidos, é comercializada no próprio pólo de Triunfo (BNDES, 2005). Os 20\% restantes são vendidos no mercado interno, principalmente São Paulo, ou exportados para o Mercosul.

A central tem seu controle realizado pelos grupos Braskem e Ipiranga.

\subsection{Central Petroquímica de Camaçari - Bahia}

A central, de primeira geração do pólo petroquímico de Camaçari, pertence a Braskem (grupo Odebrecht), que é responsável por quase $50 \%$ da produção nacional de petroquímicos 
básicos, olefinas e aromáticos e também, resinas termoplásticas. Esta unidade da Braskem, atualmente, desenvolve as atividades realizadas anteriormente pela Copene (Companhia Petroquímica do Nordeste).

Sua capacidade produtiva nominal, no ano de 2004, foi de 1.280.000 t/ano de eteno, 530.000 t/ano de propeno, 170.000 t/ano de butadieno e 1.022.000 t/ano de aromáticos (ABIQUIM, 2005).

As duas principais plantas de polietileno da Braskem não estão localizadas no pólo de Camaçari. Uma, localiza-se no pólo de Triunfo, e a outra, no estado de Maceió.

A principal matéria-prima utilizada por esta empresa é a nafta, sendo $70 \%$ fornecido pela Petrobras e os outros 30\%, importados de países da África e da América do Sul. Como forma de diversificar os insumos, a Braskem tem investido no processamento de condensado, sendo a maior parte importada de países da África e do Oriente Médio (BNDES, 2005).

Como vantagem competitiva está a sua participação tanto na primeira, quanto na segunda gerações. Nesta última, como principal produto tem-se as resinas PE, PP, PVC. Outra vantagem é a sua localização; afinal, quando o pólo de Camaçari foi idealizado, considerou-se a futura instalação das empresas de segunda geração.

\subsection{Central Gás-Química de Duque de Caxias - Rio de Janeiro}

Inaugurada em meados de 2005, a RioPolímeros (RioPol) é a primeira central petroquímica a utilizar o gás natural como insumo para a produção de olefinas leves (eteno e

propeno). É, também, a única empresa de primeira geração a agregar no mesmo espaço físico os processos pertencentes à segunda geração da cadeia petroquímica: a produção de polietileno. $\mathrm{O}$ empreendimento da RioPol é o maior complexo gás-químico da América Latina.

Conforme dados da própria empresa, (RioPol, 2006), a etapa de pré-operação teve início em agosto de 2005, através da partida da unidade de eteno. Em setembro do mesmo ano, iniciouse a venda de hidrogênio, propeno e gasolina, que são os denominados subprodutos de pirólise.

A sua capacidade produtiva nominal é de 520.000 t/ano de eteno, 75.000 t/ano de propeno e 540.000 t/ano de polietileno. A empresa apresenta parte de sua produção comprometida, devido a um contrato de longo prazo (10 anos), para exportação de 150.000 toneladas de polietileno, nos 
quatro primeiros anos e, de 100.000 toneladas de polietileno, nos seis anos seguintes (RioPol, 2006).

A RioPol pode ser classificada como uma empresa monoprodutora, pois toda a sua produção de eteno será consumida internamente na obtenção de polietileno (BNDES, 2005).

Analisada sob o ponto de vista de competitividade, a RioPol apresenta como vantagens a sua grande integração, a localização próxima a grandes centros consumidores e, com facilidade de escoamento da produção, também por via marítima. A desvantagem consiste na utilização somente do etano e propano como matérias-primas, cujos preços estão altamente interligados com o do gás natural. Durante o ano de 2006, grandes produtoras americanas de etileno foram prejudicadas, quando o preço do gás atingiu cerca de US\$10,00/MBtu. A nafta, também apresenta uma forte tendência de aumento de preço.

\subsubsection{A Questão do Insumo}

Através da correlação de preços entre o gás natural e o etano, realizadas para valores canadenses e, considerando que os mercados do Brasil e do Canadá podem ser comparados, em termos de dimensões e disponibilidades, inferindo-se que o preço do gás natural e do etano nacionais, caminharam paralelamente, nos últimos três anos.

Cabe observar que as anomalias de alta dos preços, no terceiro quadrimestre de 2005, referem-se aos efeitos causados pela passagem dos furacões Katrina e Rita, pela Costa Sul dos Estados Unidos. Estes fenômenos naturais ocasionaram danos e perdas nas instalações de transporte e produção de gás daquele país. Como os mercados canadense e norte-americano são integrados, onde o Canadá é responsável por $85 \%$ da importação de gás natural dos Estados Unidos, aqueles fatos levaram a forte alta no preço do produto, durante o período pós- furacões.

Soma-se a este fato, o forte rigor do inverno em todo hemisfério norte naquela época, incrementando ainda mais o aumento do preço do gás natural.

A figura 1.13 apresenta as curvas para os preços do gás natural e do etano, no período compreendido entre o segundo quadrimestre de 2004 até o terceiro quadrimestre de 2006, para o mercado canadense. $\mathrm{O}$ gás etano é o insumo mais importante para a sustentabilidade da indústria petroquímica, sendo a nafta o segundo insumo. 


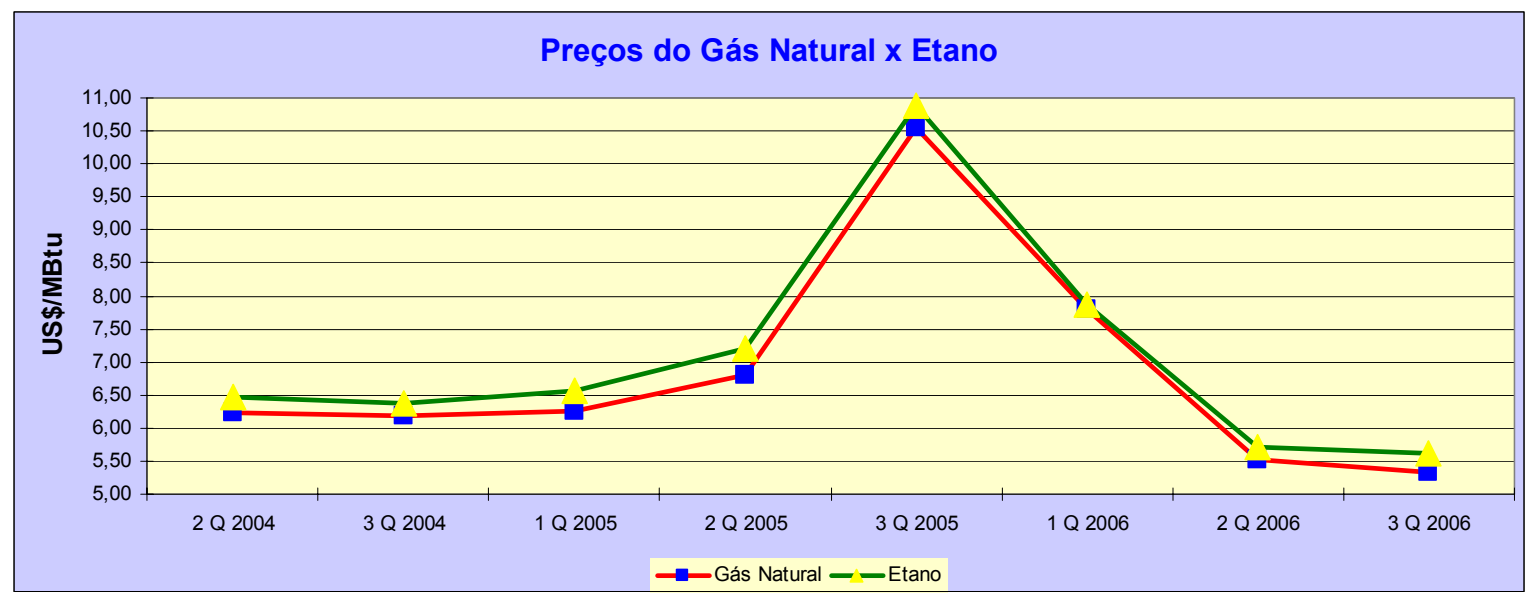

Figura 1.13 Preços do gás natural e do etano

Fonte: (ENERGY PRICE INFORMATION, 2006, elaboração própria)

Quando se analisa a evolução dos preços apresentados na figura 1.14, é ideal não considerar o período de pico, já que este influencia em um aumento de $8,5 \%$, tanto para o preço do GN quanto do etano.

Conforme informação obtida através de entrevistas com os profisssionais da área, o preço da fração etano é vinculado ao preço do gás natural, existindo um fator que relaciona a razão entre estes $(r=\mathrm{U}=\mathrm{Etano} / \mathrm{U} \$ \mathrm{GN})$.

A importância deste fator está na possibilidade de previsão dos preços futuros do etano, visando à avaliação de projetos, seja para ampliação de uma capacidade já existente, como para implantação de novas unidades produtoras. Extinguindo-se o período de pico, tem-se que a evolução deste fator, também apresenta estabilidade.

Fazendo-se a mesma análise para o preço da nafta, tem-se o comportamento deste, apresentado na figura 1.14. Os preços referem-se ao mercado internacional, mas é importante ressaltar que a política de preços, adotada pela Petrobras, para o mercado nacional deste insumo, segue os preços internacionais; logo, a análise feita apresenta-se coerente à realidade brasileira. 


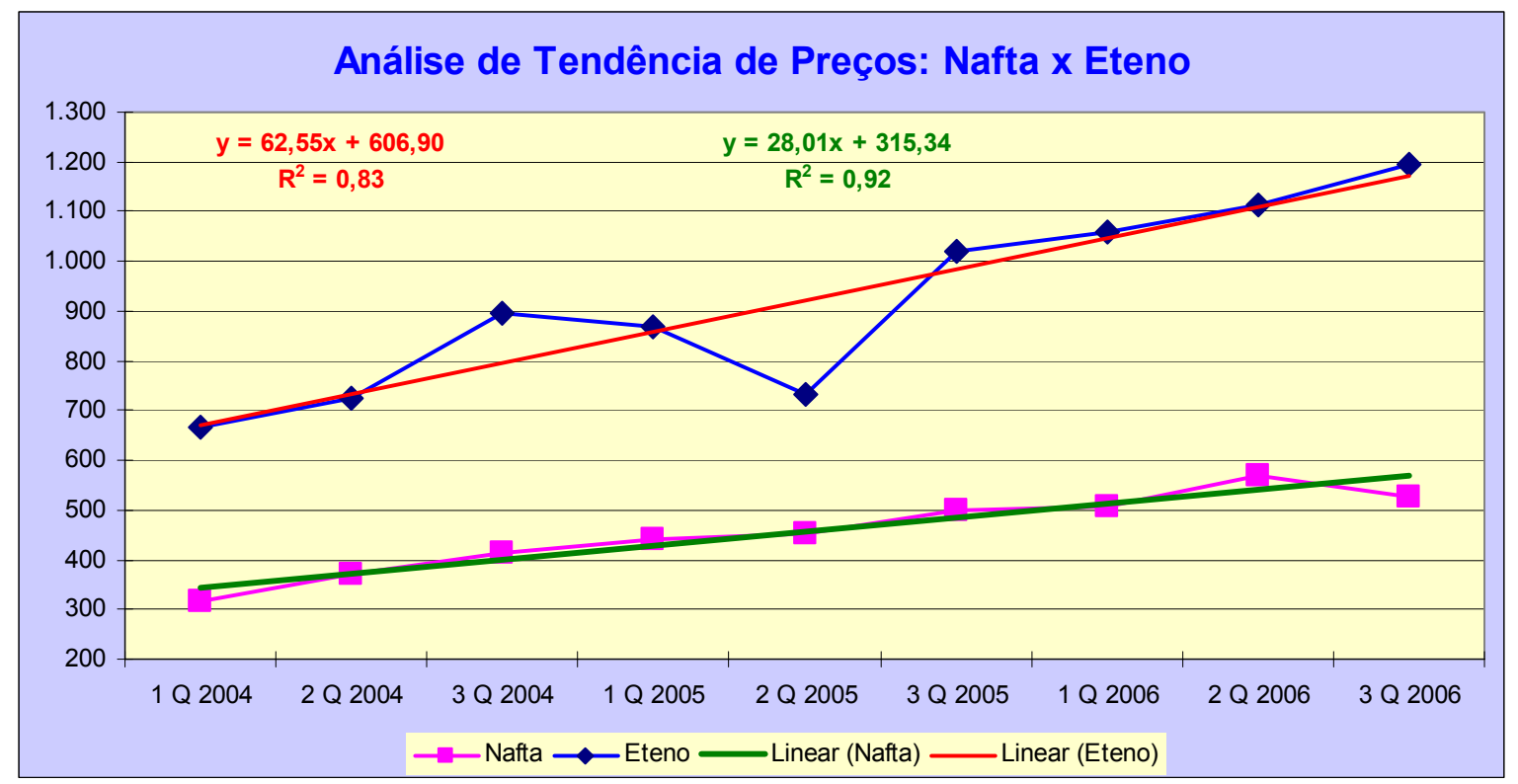

Figura 1.14 Análise de tendência de preços da nafta e do eteno

Fonte: (ABIPLAST, 2006)

Realizando-se a análise de tendência para o preço da nafta, obtém-se um fator de correlação de 0,92 , dando a entender que a propensão do aumento contínuo de preço deste insumo, continuará a acontecer para os próximos períodos.

A análise de tendência do preço do eteno confirma o comportamento, já explicado anteriormente, deste mercado, onde os períodos de baixa (como o segundo quadrimestre de 2005), ocorrem quando as ampliações da capacidade produtiva mundial entram em operação. O próximo período de baixa está previsto para sobrevir entre 2008-09 (OIL AND GAS JOURNAL, 2005).

As figuras 1.15 e 1.16 apresentam a produção e a importação de nafta, no mercado brasileiro, respectivamente. 


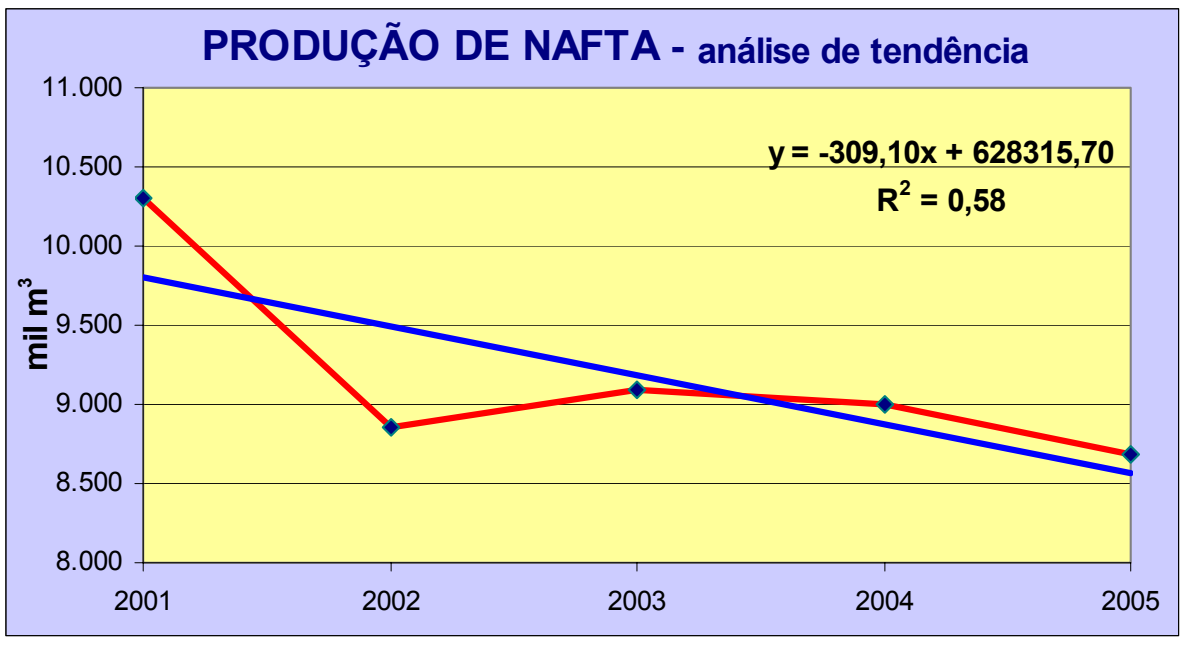

Figura 1.15 Análise de tendência da produção nacional de nafta Fonte (BEN, 2006; elaboração própria)

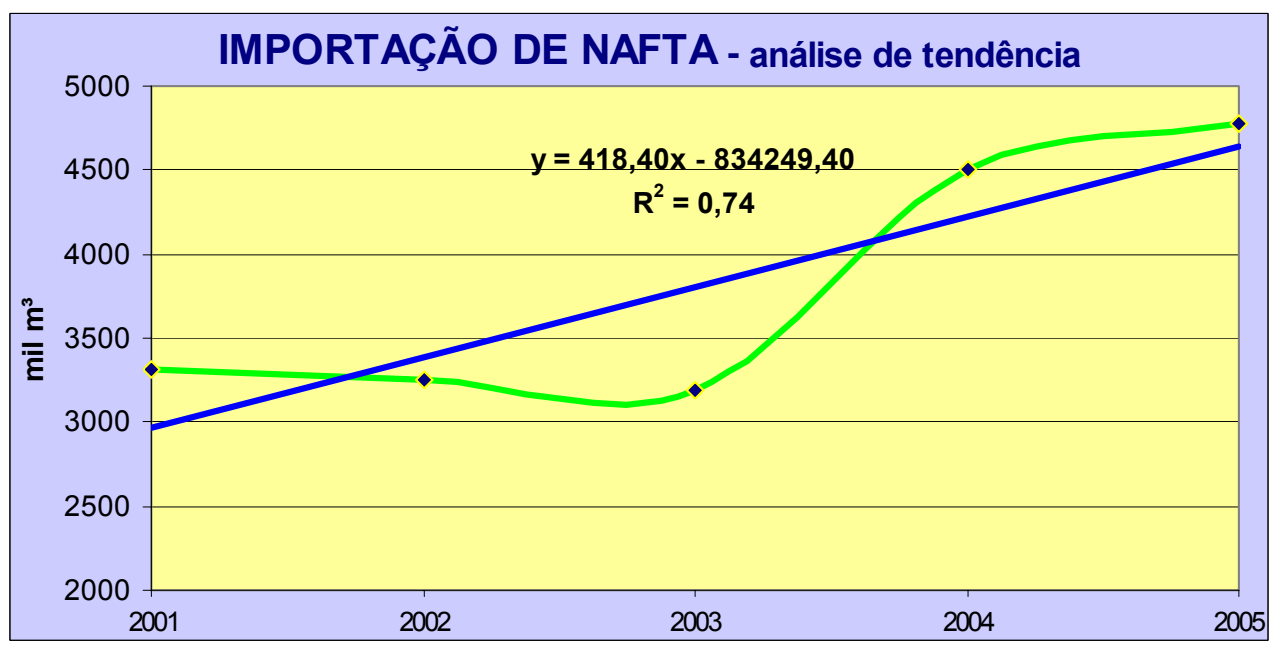

Figura 1.16 Análise de tendência da importação brasileira de nafta

Fonte (BEN 2006, elaboração própria)

Através da análise conjunta dos dados fornecidos pelas figuras $1.14,1.15$ e 1.16 , é possível construir o atual cenário, vivenciado por $75 \%$ das centrais petroquímicas brasileiras, que operam em base nafta. A análise, de tendência do preço deste insumo, aponta para a manutenção do aumento do mesmo com o passar do tempo. Já a produção nacional de nafta, não apresenta boas perspectivas de crescimento para os próximos anos; ao contrário, desde o ano de 2003, vem 
apresentando queda. Previsões do BNDES apontam que o mercado nacional de resina crescerá nos próximos anos, conforme pode ser visto na tabela 1.4.

\section{Tabela 1.4 - Demanda e projeção de demanda para os derivados de eteno no mercado brasileiro}

\begin{tabular}{lrlrll}
\hline Ano & \multicolumn{1}{l}{ PEAD } & \multicolumn{1}{l}{ PEBD } & PEBDL & \multicolumn{1}{l}{ PET } & \multicolumn{1}{l}{ PVC } \\
\hline $\mathbf{2 0 0 6}$ & 847.007 & 645.100 & 465.585 & 581.625 & 776.261 \\
$\mathbf{2 0 0 7}$ & 959.114 & 698.571 & 543.973 & 676.592 & 866.895 \\
$\mathbf{2 0 0 8}$ & 1.086 .059 & 756.473 & 635.560 & 787.066 & 968.111 \\
$\mathbf{2 0 0 9}$ & 1.229 .806 & 819.175 & 742.566 & 915.577 & 1.081 .145 \\
$\mathbf{2 0 1 0}$ & 1.392 .579 & 887.074 & 867.589 & 1.065 .072 & 1.207 .376 \\
$\mathbf{2 0 1 1}$ & 1.576 .896 & 960.602 & 1.013 .661 & 1.238 .976 & 1.348 .346 \\
$\mathbf{2 0 1 2}$ & 1.785 .609 & 1.040 .223 & 1.184 .327 & 1.441 .275 & 1.505 .775 \\
$\mathbf{2 0 1 3}$ & 2.021 .946 & 1.126 .445 & 1.383 .727 & 1.676 .605 & 1.681 .585 \\
\hline
\end{tabular}

Fonte: (BNDES, 2005; adaptação própria)

Para que a demanda de nafta seja atendida, faz-se necessária a sua importação, que apresenta um contínuo crescimento e, através de sua análise de tendência, é possível observar que esta continuará a crescer, com o passar dos anos. Atualmente, cerca de $30 \%$ da nafta consumida é importada. Com o aumento deste porcentual, o déficit da balança comercial do setor químico, que inclui o petroquímico, aumentará.

O maior receio reside na hipótese de que a demanda nacional de eteno, seja maior que a capacidade nacional de produção, o que culminará num cenário que combinará o aumento da importação da matéria-prima (nafta) com a importação de produtos, com maior valor agregado, como o próprio eteno e as resinas termoplásticas, também.

Nota-se que a ampliação da primeira geração brasileira pode ser feita através da utilização do etano, como matéria-prima, trazendo maior versatilidade ao setor. A figura 1.17 apresenta o crescimento da produção de gás natural e, com base nestes dados, calculou-se a produção anual de etano, sendo que este apresenta porcentual médio em volume de $6,0 \%$. 


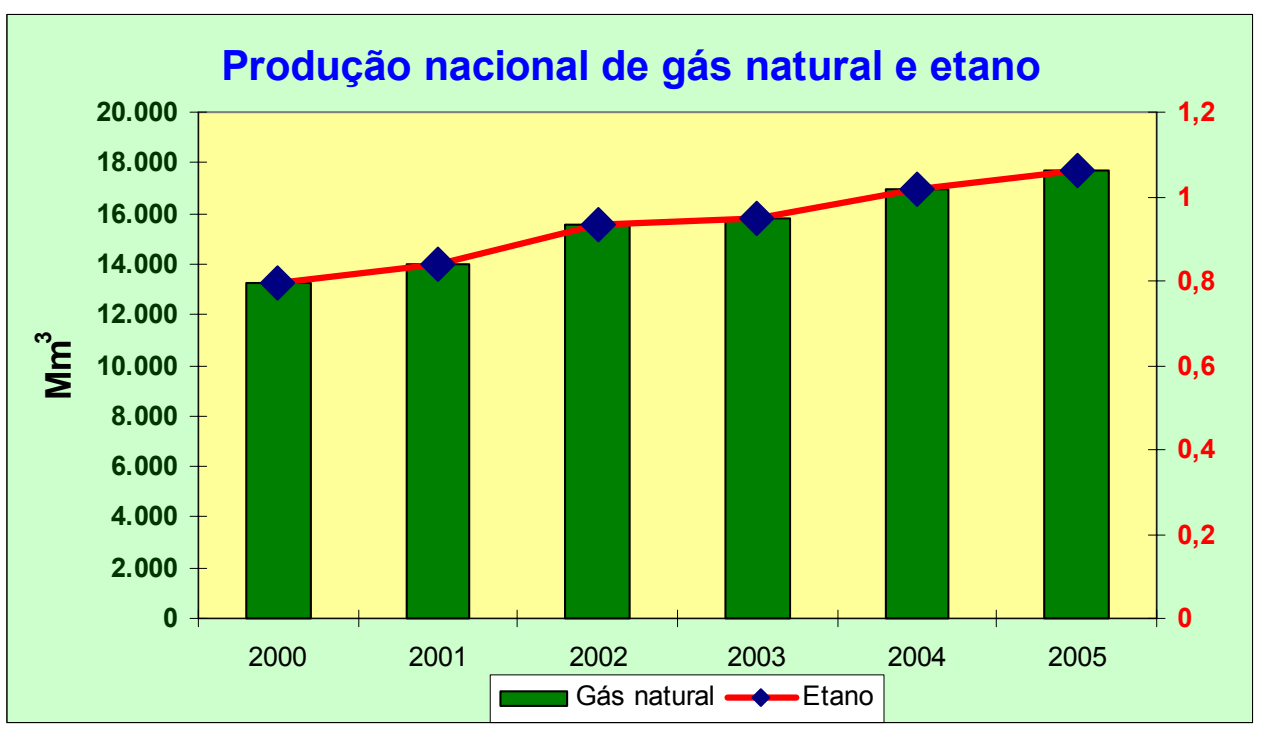

Figura 1.18 Produção nacional de gás natural e etano

Fonte: (BEN, 2006; elaboração própria)

Sabe-se que esta produção de etano não é centralizada, ou seja, não se pode fazer nenhuma avaliação de novos projetos, utilizando o volume total produzido.

$\mathrm{Na}$ análise de viabilidade de uma planta que utilizará o etano como insumo, devem constar parâmetros como: local de produção e processamento do GN, sistema de transporte do etano, escoamento da produção de eteno, volume de GN produzido diariamente, tamanho da(s) reserva(s) e, também, o impacto ambiental.

Estes fatores não devem ser analisados separadamente, pois será através da soma dos mesmos que o estudo apontará ou não a viabilidade do projeto. Informações como o volume de gás natural a ser extraído e processado diariamente, bem como o teor de etano presente neste gás, tornarão possível o dimensionamento da quantidade máxima de eteno que poderá ser produzida. O conhecimento do volume da(s) reserva(s) permite prever a vida útil do empreendimento, pois plantas de grande porte são projetadas a longo prazo, normalmente maior do que 15 anos, a fim de ter seus custos amortizados.

Sendo suficiente o volume da(s) reserva(s) e do etano a ser produzido, o estudo da localização da unidade de processamento de gás natural (UPGN), onde é separada a fração etano, é fundamental para que se determine os custos da infra-estrutura de transporte do etano, até a 
unidade produtora de eteno. O resultado deste estudo será combinado com a análise do escoamento da produção do eteno, ou seja, a sua proximidade com o mercado consumidor ou até, eventualmente, a implantação de uma unidade de segunda geração para se obter as resinas termoplásticas, as quais apresentam maior facilidade de transporte e armazenamento. Correndo em paralelo, tem-se a análise ambiental.

Como se pode observar, é através da combinação dos resultados obtidos durante a avaliação destes parâmetros, que torna possível definir se o projeto é viável ou não. 


\section{MODELAGEM DA PLANTA GÁS QUÍMICA}

\subsection{O Conceito Petroquímico}

A modelagem da planta gás química teve como ponto de partida a definição da quantidade mínima ideal de eteno ao ano, a ser produzida a partir da fração etano. Para tal determinação foram realizadas pesquisas em literatura especializada e entrevistas com especialistas do setor.

No quesito insumo, considerou-se a questão da disponibilidade do gás natural e sua fração etano, a qual se sugere aqui neste trabalho, seja totalmente separada das demais frações do gás natural, a fim de que esta possa ser utilizada como insumo industrial.

A soma destes fatores proporcionou a obtenção de três valores chave para a capacidade nominal de produção anual de eteno, em toneladas, sendo o mínimo de 300 mil, o valor médio de 400 mil e o máximo de 500 mil, mesmo sabendo que estas não seriam plantas de grande porte, mas pela atual situação da matéria-prima, a instalação de plantas de escala mundial, dedicadas a um só tipo de insumo, poderia ser uma decisão comprometedora. A expansão desta planta estaria condicionada a sua flexibilidade de processamento da carga. Como será visto no sétimo capítulo, é possível um processo que produza eteno a partir de dois ou mais tipos de carga, sendo apenas necessário o ajuste de parâmetros.

Para demonstração dos cálculos da produção nominal de eteno, escolheu-se o valor médio de 400 mil toneladas ano.

\subsection{O Conceito Químico}

Na etapa de modelagem da produção de metanol, amônia e hidrogênio foram adotadas várias premissas referentes às etapas do processo como um todo. $\mathrm{O}$ primeiro passo foi a definição da rota a ser utilizada para a obtenção do gás de síntese. Esta é composta por uma unidade de 
separação e tratamento de ar (oxigênio), uma unidade de reforma a vapor (SMR), com tubos de 10,5 metros de comprimento, 94,5 milímetros de diâmetro. Após esta unidade, o gás de síntese produzido, segue para a unidade de oxidação parcial não catalítica, a fim de eliminar o metano residual do SMR.

É importante salientar que o dimensionamento da unidade de SMR é o fator limitante da produção da planta gás-química, pois, será a partir desta etapa, que os dados de consumo de vapor e metano, necessários para a produção do gás de síntese, serão obtidos.

Para a cálculo do volume de mistura gasosa, vapor e metano, cuja relação estequiométrica é de $3 \mathrm{H}_{2} \mathrm{O}: 1 \mathrm{CH}_{4}$, determinou-se que o volume a ser ocupado pelo catalisador de níquel (esférico) corresponde a $52 \%$ do volume interno total do tubo, restando, portanto, para a mistura gasosa o equivalente a $48 \%$ deste volume. A figura 2.1 ilustra um tubo da unidade de SMR.

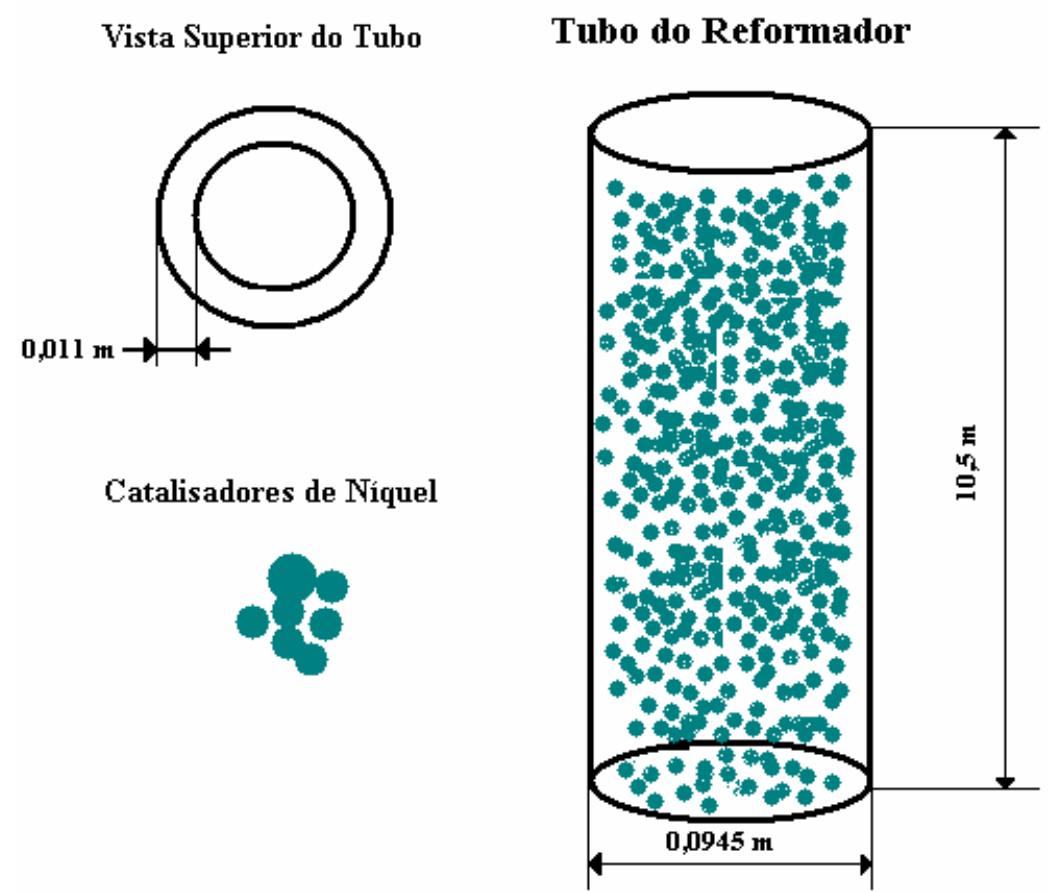

Figura 2.1 Tubo reformador da unidade de SMR

Fonte: (elaboração própria) 
O tempo de residência desta mistura em cada tubo reformador foi estipulado em 2 segundos, conforme informações obtidas em várias referências bibliográficas.

O gás de síntese, obtido na unidade de SMR, apresenta teor de metano não reagido de 3,8\%. Para que se reduza este porcentual, o syngas é enviado a uma unidade de oxidação parcial catalítica (POX), onde através da injeção de oxigênio e vapor, ocorrerá a redução deste valor para 0,04\%. $\mathrm{O} \mathrm{O}_{2}$ utilizado no POX é proveniente do ar, o qual é separado numa unidade denominada Air Separation Unit (ASU).

Para a produção de metanol, será destinado $75 \%$ do volume total de syngas produzido. A decisão de direcionar toda esta quantidade de gás de síntese, baseia-se no fato de que a atual necessidade deste produto, no mercado interno, é muito alta. Conforme já mencionado na introdução, nos últimos 4 anos, a importação de metanol foi equivalente a metade da demanda, no período analisado. Já os $25 \%$ restante, do volume de syngas, será utilizado para a produção de amônia.

O gás de síntese destinado à produção de metanol será enviado a uma unidade denominada Pressure Swing Adosorption (PSA), utilizado para separar correntes de um determinado gás a partir de uma mistura gasosa. No caso, o gás a ser retirado é o $\mathrm{O}_{2}$, herdado do POX.

Na seqüência, a mistura gasosa resultante, será enviada ao reformador responsável pela síntese de metanol, a qual ocorre a temperatura de $220^{\circ} \mathrm{C}$ e pressão de $56,25 \mathrm{~atm}$. Nesta etapa ocorre a adição do $\mathrm{CO}_{2}$, produzido na etapa de shift conversion, visando um aumento do metanol a ser produzida.O metanol produzido é destilado e depois resfriado.

Quanto ao gás de síntese, destinado à produção de amônia, é enviado a uma unidade de Shift Conversion Higth Temperature (SCHT), onde ocorrerá a conversão do $\mathrm{CO}$ em $\mathrm{CO}_{2}$ e $\mathrm{H}_{2} \cdot \mathrm{Na}$ seqüência, a mistura gasosa obtida é enviada a uma unidade de PSA. Neste caso, o $\mathrm{H}_{2}$ é a corrente de gás desejada. $\mathrm{O} \mathrm{N}_{2}$, utilizado na síntese da amônia, é obtido a partir do ar atmosférico. $\mathrm{O}$ processo Haber-Bosch ocorre a uma temperatura de $500^{\circ} \mathrm{C}$ e $198 \mathrm{~atm}$. 


\subsection{Cálculos da Modelagem}

A composição do gás natural (gás não-associado) escolhido para a realização dos cálculos da modelagem é a do gás produzido na Bacia de Santos, no Campo de Merluza, cuja composição é apresentada na Tabela 2.2 .

Tabela 2.1 Composição do gás natural (não-associado) Bacia de Santos - Campo de Merluza

\begin{tabular}{llr}
\hline Elemento & Sigla & Quantidade \\
\hline Metano & $\mathrm{CH} 4$ & $87,12 \%$ \\
Etano & $\mathrm{C} 2 \mathrm{H} 6$ & $6,35 \%$ \\
Propano & $\mathrm{C} 3 \mathrm{H} 8$ & $2,91 \%$ \\
I Butano & & $0,52 \%$ \\
N Butano & $\mathrm{C} 4 \mathrm{H} 10$ & $0,87 \%$ \\
I Pentano & $\mathrm{C} 5 \mathrm{H} 12$ & $0,25 \%$ \\
N Pentano & & $0,23 \%$ \\
Hexano & $\mathrm{C} 6 \mathrm{H} 14$ & $0,18 \%$ \\
Heptano e Sup & & $0,20 \%$ \\
Nitrogênio & $\mathrm{N} 2$ & $1,13 \%$ \\
Dióxido Carbono & $\mathrm{CO} 2$ & $0,24 \%$ \\
Total & & $100,00 \%$ \\
Propriedades & $\mathrm{Unidades}$ & Valores \\
Poder Calorífico Sup & $\mathrm{Kcal} / \mathrm{m} 3$ & $10.223,00$ \\
Poder Calorífico Inf & $\mathrm{Kcal} / \mathrm{m} 3$ & $9.249,00$ \\
Densidade Relativa & $\mathrm{kg} / \mathrm{m} 3$ & 0,66 \\
\hline
\end{tabular}

Fonte: (Conpet, 2005)

A primeira etapa da modelagem consiste em determinar a quantidade de etano necessária para que se produza 400 mil t/ano de eteno e, para tal, foi calculada a produção diária desta olefina. Na seqüência, através da sua densidade, determina-se o volume, $\mathrm{em} \mathrm{m}^{3}$, produzido por dia. Através dos rendimentos de conversão (etano em eteno com $\eta=0,80$ ) e com o rendimento da Unidade de Processamento de Gás Natural (UPGN), obtém-se o volume total necessário de etano. 
$1^{\mathrm{a}}$ Etapa - Cálculo da Produção Diária de Eteno $\left(\mathrm{m}^{3}\right)$

$$
\begin{aligned}
& 400.000 \frac{\text { ton }}{\text { ano }} \times \frac{1.000 \mathrm{~kg}}{\text { ton }}=400.000 .000 \frac{\mathrm{kg}}{\text { ano }} \\
& 400.000 .000 \frac{\mathrm{kg}}{\text { ano }} \times \frac{1 \text { ano }}{365 \text { dias }}=1.095 .890 \frac{\mathrm{kg}}{\text { dia }}(\text { eteno }) \\
& \rho_{\text {eteno }}=1,178 \mathrm{~kg} / \mathrm{m}^{3}
\end{aligned}
$$

Produção Diária de Eteno $\left(\mathrm{P}_{\mathrm{de}}\right)$

$$
\begin{aligned}
& P_{d e}=\frac{1.095 .890 \frac{\mathrm{kg}}{\mathrm{dia}}}{1,178 \frac{\mathrm{kg}}{\mathrm{m}^{3}}}=930.297 \frac{\mathrm{m}^{3}}{\mathrm{dia}}(\text { eteno }) \\
& \therefore P d e=930.297 \mathrm{~m}^{3}
\end{aligned}
$$

$2^{\text {a }}$ Etapa - Cálculo dos Volumes Diários de Etano

$$
\eta_{\text {conv }}=0,80 \quad \eta_{U P G N}=0,94
$$

Volume de Etano (Insumo) para Conversão $\left(\mathrm{V}_{\mathrm{ec}}\right)$

$$
\frac{930.278 \frac{\mathrm{m}^{3}}{\mathrm{dia}}}{0,80}=1.162 .871 \mathrm{~m}^{3} / \mathrm{dia}
$$

Volume Necessário de Etano $\left(\mathrm{V}_{\text {et }}\right)$

$$
\frac{1.162 .871 \frac{\mathrm{m}^{3}}{d i a}}{0,94}=1.237 .097 \mathrm{~m}^{3} / \mathrm{dia}
$$

Através do porcentual de etano contido no GN, 6,35\%, calcula-se o volume total de gás natural produzido. Utilizando o mesmo raciocínio, determina-se o volume total da fração metano produzida diariamente. 
$3^{\mathrm{a}}$ Etapa -Cálculo do Volume Diário de Gás Natural $\left(\mathrm{V}_{\mathrm{dGN}}\right)$

$\%$ Etano no $\mathrm{GN}=6,35$

$$
\begin{aligned}
& V_{d G N}=\frac{V e t}{6,35 \%}=\frac{1.237 .097 \frac{\mathrm{m}^{3}}{d i a}}{0,0635}=19,482 \text { milhões } \mathrm{m}^{3} / \text { dia } \\
& V_{d G N}=19,482 \mathrm{M} \mathrm{m}^{3} / \text { dia } \\
& 4^{\mathrm{a}} \text { Etapa - Cálculo do Volume Diário de Metano (Processado) } \\
& \% \text { Metano no GN }=87,12 \% \\
& \mathrm{~V}_{\mathrm{dCH}_{4}}=V_{d G N} \times 0,8712=16,972 \mathrm{Mm}^{3} / \mathrm{dia}
\end{aligned}
$$

A quinta etapa dos cálculos diz respeito aos tubos do reformador SMR, onde ocorrerá a reforma a vapor do metano. Os dados técnicos utilizados, como diâmetro interno e externo, espessura e comprimento foram obtidos em literaturas especializadas. Para o volume ocupado pelo catalisador de níquel, foi admitido que este ocupa cerca de 52\% do volume, restando os outros $48 \%$, para serem preenchidos pela mistura gasosa de metano e vapor.

$5^{\circ}$ Etapa - Cálculos do Reformador SMR (Tubos)

a) Volume do tubo $\left(\mathrm{V}_{\mathrm{t}}\right)$

$$
\begin{aligned}
& V_{t}=\pi \times r^{2} \times h \\
& V_{t}=\pi \times(0,04725)^{2} \times 10,5 \\
& V_{t}=0,074 \mathrm{~m}^{3}
\end{aligned}
$$

b) Volume Catalisador $\left(\mathrm{V}_{\text {cat }}\right)$

$$
\begin{aligned}
& V_{\text {cat }}=V t \times 52 \% \\
& V_{\text {cat }}=0,074 \times 0,52 \\
& \mathrm{~V}_{\text {cat }}=0,038 \mathrm{~m}^{3}
\end{aligned}
$$

c) Volume da Mistura Gasosa $\left(\mathrm{V}_{\mathrm{mg}}\right)$

$$
\begin{aligned}
& V_{m g}=V_{t}-V_{c a t} \\
& V_{m g}=0,074-0,038 \\
& V_{m g}=0,036 \mathrm{~m}^{3}
\end{aligned}
$$


$\mathrm{Na}$ sexta etapa da modelagem será calculado o valor da densidade do metano nas condições de $300^{\circ} \mathrm{C}$ e $30 \mathrm{~atm}$. Condições estas, adquiridas após passagem pelo sistema de préaquecimento, onde entra a $25^{\circ} \mathrm{C}$ e a $1 \mathrm{~atm}$, que são as condições de recebimento do gás metano, advindo da UPGN. Este mesmo gás é recebido isento de compostos sulfurosos e umidade.

A densidade deste gás será calculada pela equação de Clapeyron (Equações de estado dos gases). Como o metano encontra-se pressurizado, através de sua condição crítica, pressão e temperatura, a sua fração molar (100\%) calculou-se através de fórmulas e ábacos, o seu fator de compressibilidade, o qual resultou em $\mathrm{z}=1,03$.

Para o cálculo da densidade da água, foi realizada consulta ao manual de termodinâmica, utilizando as condições de operação da saída da caldeira, de $30 \mathrm{~atm}$ e $300^{\circ} \mathrm{C}$. Determinou-se o volume específico e a sua densidade (inverso do volume específico).

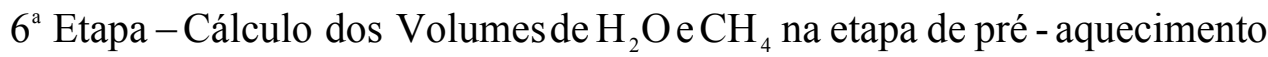

a) Metano

Massa Molar $-M_{\mathrm{CH}_{4}}=0,016 \mathrm{~kg}$

$\rho_{\mathrm{CH}_{4}}=? \quad P=30 \mathrm{~atm} \quad T=300^{\circ} \mathrm{C} \quad z=1,03$

$P \times V=n \times R \times T \times z$

$30 \times 101.325 \times V=1 \times 8,3144 \times 573,15 \times 1,03$

$V=1,61 \times 10^{-3} \mathrm{~m}^{3}$

$\rho_{C_{4}}=\frac{0,016}{1,61 \times 10^{-3}}=9,909 \mathrm{~kg} / \mathrm{m}^{3}$

b) Vapor

$\rho_{\mathrm{H}_{2} \mathrm{O}}=12,47 \mathrm{~kg} / \mathrm{m}^{3} \quad$ Massa Molar $-M_{\mathrm{H}_{2} \mathrm{O}}=0,018 \mathrm{~kg} \quad P=30,0 \mathrm{~atm}$

$\rho_{\mathrm{H}_{2} \mathrm{O}}=\frac{M_{\mathrm{H}_{2} \mathrm{O}}}{V_{\mathrm{H}_{2} \mathrm{O}}} \therefore V_{\mathrm{H}_{2} \mathrm{O}}=0,00157 \mathrm{~m}^{3}$

$\mathrm{Na}$ sétima etapa foram encontrados os volumes estequiométricos do vapor e do gás metano e calculada a razão volumétrica (r), através da qual se determina o volume que cada gás ocupará em um tubo do reformador. Com estes dados, passa-se para a oitava etapa, onde foi admitido um tempo de residência da mistura no SMR de um segundo, a fím de calcular os volumes de operação da unidade, considerando os valores de tempo de um segundo, uma hora e 
um dia e um reformador de 200 tubos. Com estes cálculos, determina-se a quantidade de vapor e de gás metano a ser consumida por um trem de SMR em um dia.

$7^{\text {a }}$ Etapa - Cálculos dos Volumes Estequiométricos

$1 \mathrm{~mol} \mathrm{CH}_{4}=0,00161 \mathrm{~m}^{3}$

3 mols $\mathrm{H}_{2} \mathrm{O}=0,00470 \mathrm{~m}^{3}$

soma $=0,00632 \mathrm{~m}^{3}$

Razão Volumétrica $(r)$

$r=\frac{V m g}{\text { soma }}=\frac{0,0353}{0,00632} r=5,95$

Atualizando os Volumes

$V_{\mathrm{CH}_{4}}=5,95 \times 0,00161$

$V_{\mathrm{CH}_{4}}=0,00903 \mathrm{~m}^{3}$

$V_{\mathrm{H}_{2} \mathrm{O}}=5,95 \times 0,00470$

$V_{\mathrm{H}_{2} \mathrm{O}}=0,0263 \mathrm{~m}^{3}$

$V_{t}=0,0353 m^{3}$

$8^{\text {a }}$ Etapa-Cálculo dos Volumes de Gás no SMR

tempo de residência $=2,0$ segundos $(\mathrm{Tr})$

1hora $(\mathrm{t}=3600$ segundos $)$

$V^{\prime} m g=\left[3600 \times\left(V_{\mathrm{CH}_{4}}+V_{\mathrm{H}_{2} \mathrm{O}}\right)\right] \div T r$

$V m g^{\prime}=[3600 \times(0,00903+0,0263)] \div 2$

$V m g^{\prime}=63,63 m^{3} \therefore V_{C_{4}}=16,26 m^{3}$ e $V_{H_{2} \mathrm{O}}=47,37 m^{3}$ 
Tabela 2.2 - Cálculo dos volumes de metano e vapor consumidos na unidade de SMR

Cálculo dos volumes $\left(\mathrm{m}^{3}\right)$ oepracionais de $\mathrm{CH} 4$ e $\mathrm{H} 2 \mathrm{O}$ pré-aquecidos e passarão pela unidade de SMR

\begin{tabular}{lcrrr}
\hline & \multicolumn{2}{c}{ Valores para 1 tubo } & \multicolumn{2}{c}{ 200 tubos } \\
& 2 segundos & $\mathbf{1}$ hora & $\mathbf{1 ~ d i a}$ & $\mathbf{1}$ dia \\
VCH4 & 0,00903 & 16,263 & 390,30 & $78.060,3$ \\
VH2O & 0,02631 & 47,367 & $1.136,80$ & $227.360,0$ \\
Vmg & 0,03535 & 63,629 & $1.527,10$ & $305.420,21$ \\
\hline
\end{tabular}

Fonte: (elaboração própria)

Tabela 2.3 - Cálculo dos números de mols de metano e vapor consumidos na unidade de SMR

Cálculo do número de mols de vapor e metano que serão adicionados a unidade de SMR

\begin{tabular}{lrrrr}
\hline & \multicolumn{2}{c}{ Valores para 1 tubo } & \multicolumn{2}{c}{200 tubos } \\
& 2 segundos & 1 hora & 1 dia & 1 dia \\
nCH4 & 5,6 & $10.071,4$ & $241.713,8$ & $48.342 .753,9$ \\
nH2O & 16,8 & $30.214,2$ & $725.141,3$ & $145.028 .261,8$ \\
ntotal & 22,4 & $40.285,6$ & $966.855,1$ & $193.371 .015,8$ \\
\hline
\end{tabular}

Fonte: (elaboração própria)

Como etapa seguinte, tem-se a determinação da composição de saída do SMR, conforme mostrado da tabela 2.4, sabendo-se que as condições de operação do gás de saída eram de $850^{\circ} \mathrm{C}$ e $30 \mathrm{~atm}$. 
Tabela 2.4 - Composição de saída do SMR a $850^{\circ} \mathrm{C}$ e $30 \mathrm{~atm}$

\begin{tabular}{lrr}
\hline & M.Molar(kg) & \multicolumn{2}{c}{$\%$ Vol } \\
\hline H2 & 0,002 & $69,50 \%$ \\
CO & 0,028 & $15,20 \%$ \\
CO2 & 0,044 & $6,50 \%$ \\
CH4 & 0,016 & $3,80 \%$ \\
H2O & 0,018 & $5,00 \%$ \\
total & & $100,0 \%$ \\
\hline
\end{tabular}

Fonte: (elaboração própria)

A corrente gasosa, que deixa o SMR, flui para a unidade de oxidação parcial não catalítica, onde será adicionado o volume de $15.444,1 \mathrm{~m}^{3}$ de vapor e $7.837,9 \mathrm{~m}^{3}$ de oxigênio, ambos a $300^{\circ} \mathrm{C}$ e $30 \mathrm{~atm}$. É importante ressaltar que o $\mathrm{O}_{2}$ foi inserido contendo $45 \%$ de excesso, a fim de deslocar o equilíbrio químico da reação para a direita. Este porcentual de excesso foi adotado com base na literatura, a qual indicava que este excesso varia de 40 a 50\% (SONG E GUO; 2006).

Como vapor de água também é adicionado no reator e, este também reagirá com o metano, presente na mistura gasosa, ocorrerá uma "competição" entre os dois reagentes, $\mathrm{O}_{2}$ e vapor de água. Em virtude desta "competição" e, também do fato de uma parcela de $\mathrm{O}_{2}$, ao reagir com o metano, gerar combustão completa, a quantidade de $\mathrm{O}_{2}$, presente na mistura gasosa de saída, será diferente da quantidade de excesso.

Tabela 2.4 - Composição de saída do POX a $1100^{\circ} \mathrm{C}$ e $30 \mathrm{~atm}$

\begin{tabular}{lrr}
\hline & M.Molar(kg) & \multicolumn{2}{c}{$\%$ Vol } \\
\hline H2 & 0,002 & $65,59 \%$ \\
CO & 0,028 & $18,26 \%$ \\
CO2 & 0,044 & $9,20 \%$ \\
CH4 & 0,016 & $0,04 \%$ \\
H2O & 0,018 & $6,95 \%$ \\
O2 & 0,032 & $2,04 \%$ \\
total & & $102,1 \%$ \\
\hline
\end{tabular}

Fonte: (elaboração própria) 
A tabela 2.5 concentra as informações técnicas referentes ao volume de $25 \%$ do gás de síntese destinado à produção de amônia, enviado à unidade de Shift Conversion. A tabela 2.6 apresenta os valores de saída do processo.

Tabela 2.5 - Informações técnicas referentes ao volume de gás de síntese na entrada do processo de Shift Conversion

\begin{tabular}{|c|c|c|c|c|}
\hline \multirow[b]{3}{*}{ H2 } & \multicolumn{4}{|c|}{ Entrada Shift Conversion } \\
\hline & M.Molar (kg) & $\%$ Vol & N.Mols & Volume $\left(\mathrm{m}^{3}\right)$ \\
\hline & 0,002 & $64,28 \%$ & $1,64 \mathrm{E}+07$ & $65.841,08$ \\
\hline $\mathrm{CO}$ & 0,028 & $17,89 \%$ & $4,24 \mathrm{E}+06$ & $18.326,22$ \\
\hline $\mathrm{CO} 2$ & 0,044 & $9,01 \%$ & $2,19 \mathrm{E}+06$ & $9.233,43$ \\
\hline CH4 & 0,016 & $0,00 \%$ & $3,29 \mathrm{E}+02$ & 1,42 \\
\hline H2O & 0,018 & $6,81 \%$ & $1,86 \mathrm{E}+06$ & $6.980,09$ \\
\hline $\mathbf{O 2}$ & 0,032 & $2,00 \%$ & $5,36 \mathrm{E}+05$ & $2.052,16$ \\
\hline total & & $100,0 \%$ & $2,52 \mathrm{E}+07$ & $102.434,4$ \\
\hline
\end{tabular}

Fonte: (elaboração própria)

Tabela 2.6 - Informações técnicas referentes ao volume de gás de síntese na entrada do processo de Shift Conversion

\begin{tabular}{|c|c|c|c|c|}
\hline & \multicolumn{4}{|c|}{ Saída Shif Conversion HT @ $T=400 C$ e $P=15$ atm } \\
\hline & M.Molar (kg) & $\%$ Vol & N.Mols & Volume $\left(\mathbf{m}^{3}\right)$ \\
\hline H2 & 0,002 & $63,02 \%$ & $1,67 \mathrm{E}+07$ & $62.184,5$ \\
\hline CO & 0,028 & $2,50 \%$ & $1,23 \mathrm{E}+05$ & 458,2 \\
\hline $\mathrm{CO} 2$ & 0,044 & $35,80 \%$ & $9,59 \mathrm{E}+06$ & $35.325,8$ \\
\hline $\mathrm{CH} 4$ & 0,016 & $0,00 \%$ & $3,29 \mathrm{E}+02$ & 1,1 \\
\hline $\mathrm{H} 2 \mathrm{O}$ & 0,018 & $0,65 \%$ & $1,75 \mathrm{E}+05$ & 645,2 \\
\hline O2 & 0,032 & $0,06 \%$ & $1,71 \mathrm{E}+04$ & 61,2 \\
\hline total & & $102,04 \%$ & $2,66 \mathrm{E}+07$ & $98.676,0$ \\
\hline
\end{tabular}

Fonte: (elaboração própria) 
Conforme já explicado anteriormente, a mistura gasosa que deixa o reator do shift conversion, é encaminhada as unidades de PSA a fim de realizar a separação da corrente de $\mathrm{H}_{2}$, utilizado na síntese de amônia, e a corrente de $\mathrm{CO}_{2}$ a ser aproveitada na síntese do metanol.

A tabela 2.7 apresenta as características técnicas da entrada do processo HaberBosch, enquanto que a tabela 2.8 concentra as informações de saída do referido processo.

Tabela 2.7 - Dados de entrada do processo Haber-Bosch

\begin{tabular}{lccrr}
\hline \multicolumn{5}{c}{ Entrada Processo Haber-Bosch } \\
\hline & M.Molar & N.Mols & Massa & Volume (m $\left.\mathbf{3}^{\mathbf{3}}\right)$ \\
H2 & 0,02 & $3,86 \mathrm{E}+06$ & $77.267,63$ & $17.980,88$ \\
N2 & 0,028 & $1,80 \mathrm{E}+07$ & $504.815,16$ & $29.112,06$ \\
\hline
\end{tabular}

Fonte: (elaboração própria)

Tabela 2.8 - Dados de saída do processo Haber-Bosch

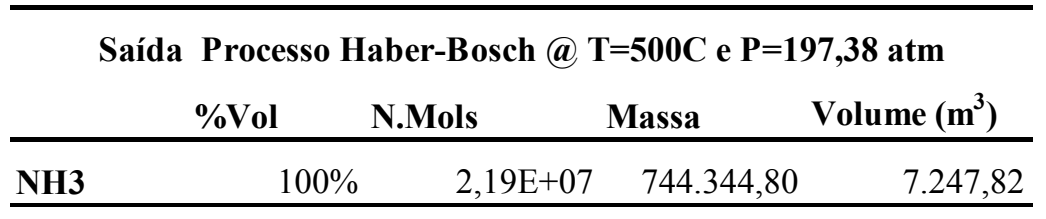

Fonte: (elaboração própria)

Os dados da modelagem apontam que para a produção de $1 \mathrm{~m}^{3}$ de amônia é necessário $0,71 \mathrm{~m}^{3}$ de gás natural. O rendimento global do processo é de $90 \%$, incluindo o loop de síntese. Para as perdas e o uso do GN como combustível, foi considerado o valor de $14 \%$.A tabela 2.9 concentra os dados de produção da amônia. 
Tabela 2.9 - Dados finais da produção de amônia

\begin{tabular}{lrrrr}
\hline & \multicolumn{2}{c}{ Amônia @ 25C e 1 atm } & & GN Consumido \\
\hline & Volume $\left(\mathbf{m}^{\mathbf{3}}\right)$ & Massa $(\mathbf{k g})$ & Massa (t) & Volume $\left.\mathbf{( M m}^{\mathbf{3}}\right)$ \\
\hline $\mathbf{1}$ dia & $426.994,8$ & $307.436,23$ & 307,44 & 0,3045 \\
$\mathbf{1}$ mês & $12.809 .842,7$ & $9.223 .086,8$ & $9.223,09$ & 9,136 \\
$\mathbf{1}$ ano & $153.718 .112,9$ & $110.677 .041,3$ & $110.677,0$ & 109,64 \\
\hline
\end{tabular}

Fonte: (elaboração própria)

Para a síntese do metanol, é necessário submeter o volume de gás de síntese, destinado a este processo, a uma unidade de PSA a fim de retirar o $\mathrm{O}_{2}$ presente. $\mathrm{Na}$ seqüência adiciona-se o $\mathrm{CO}_{2}$ proveniente do Shift Conversion a esta mistura, isenta de $\mathrm{O}_{2}$, e a envia ao reator onde ocorrerá a síntese do metanol. A tabela 2.10 concentra as informações da entrada deste processo, enquanto que a tabela 2.11 apresenta os dados relacionados à saída.

Tabela 2.10 - Entrada do processo de síntese de metanol

\begin{tabular}{|c|c|c|c|c|c|}
\hline & \multicolumn{5}{|c|}{ Entrada da Síntese de Metanol (adicionado CO2) } \\
\hline & M.Molar (kg) & $\%$ Vol & N.Mols & Massa (kg) & Volume $\left(\mathrm{m}^{3}\right)$ \\
\hline H2 & 0,002 & $58,92 \%$ & $4,91 \mathrm{E}+07$ & $98.300,0$ & $228.753,0$ \\
\hline $\mathbf{C O}$ & 0,028 & $15,26 \%$ & $1,27 \mathrm{E}+07$ & $356.404,5$ & $59.241,9$ \\
\hline $\mathrm{CO} 2$ & 0,044 & $19,20 \%$ & $1,62 \mathrm{E}+07$ & $711.829,6$ & $74.549,6$ \\
\hline CH4 & 0,016 & $0,00 \%$ & $9,86 \mathrm{E}+02$ & 15,8 & 4,3 \\
\hline $\mathrm{H} 2 \mathrm{O}$ & 0,018 & $6,62 \%$ & $5,58 \mathrm{E}+06$ & $100.356,1$ & $25.691,7$ \\
\hline total & & $100,00 \%$ & $8,36 \mathrm{E}+07$ & $1.266 .906,0$ & $388.240,5$ \\
\hline
\end{tabular}

Fonte: (elaboração própria) 
Tabela 2.10 - Saída do processo de síntese de metanol

\begin{tabular}{|c|c|c|c|c|}
\hline \multicolumn{5}{|c|}{ Saída da Síntese de Metanol (adicionado CO2) @ T=220C P=56,25atm } \\
\hline & M.Molar (kg) & N.Mols & Massa (kg) & Volume $\left(\mathrm{m}^{3}\right)$ \\
\hline $\mathbf{H 2}$ & 0,002 & $4,51 \mathrm{E}+07$ & $90.251,0$ & $181.639,6$ \\
\hline CO & 0,028 & $0,00 \mathrm{E}+00$ & 0,0 & \\
\hline $\mathrm{CO2}$ & 0,044 & $0,00 \mathrm{E}+00$ & 0,0 & \\
\hline CH4 & 0,016 & $9,86 \mathrm{E}+02$ & 15,8 & 0,0 \\
\hline total & & $4,51 \mathrm{E}+07$ & $90.266,8$ & $181.639,6$ \\
\hline H2O & 0,018 & $1,22 \mathrm{E}+07$ & $219.484,6$ & 331,5 \\
\hline СН3ОН & 0,032 & $2,63 \mathrm{E}+07$ & $842.012,88$ & 998,8290378 \\
\hline
\end{tabular}

Fonte: (elaboração própria)

Os dados da modelagem apontam que para a produção de $1 \mathrm{~m}^{3}$ de metanol são necessários $949,90 \mathrm{~m}^{3}$ de gás natural. O rendimento global do processo é de $98 \%$, incluindo o loop de síntese. Para as perdas de processo e o uso do GN como combustível, foi considerado o valor de $10 \%$. A tabela 2.11 concentra os dados de produção metanol. A tabela 2.12 concentra as informações referentes à produção de metanol.

Tabela 2.12 - Dados finais da produção de amônia

\begin{tabular}{lrrrr}
\hline & \multicolumn{2}{c}{ Metanol $@$ a $25 C$ e 1 atm } & GN Consumido \\
\hline & Volume $\left(\mathbf{m}^{\mathbf{3}}\right)$ & Massa $(\mathbf{k g})$ & Massa $(\mathbf{t})$ & Volume $\left.\mathbf{( M m}^{\mathbf{3}}\right)$ \\
\hline $\mathbf{1}$ dia & 961,84 & $750.233,48$ & 750,23 & $913.648,17$ \\
$\mathbf{1}$ mês & $28.855,1$ & $22.507 .004,3$ & $22.507,0$ & $27.409 .445,2$ \\
$\mathbf{1}$ ano & $346.261,6$ & $270.084 .051,0$ & $270.084,1$ & $328.913 .342,9$ \\
\hline
\end{tabular}

Fonte: (elaboração própria) 


\section{GÁS DE SÍNTESE}

\subsection{Histórico e Desenvolvimento}

A síntese de hidrocarbonetos, a partir da hidrogenação do monóxido de carbono (CO), foi descoberta em 1902 por Sabatier e Sanderens, que obtiveram metano $\left(\mathrm{CH}_{4}\right)$ através da passagem de hidrogênio $\left(\mathrm{H}_{2}\right)$ e monóxido de carbono $(\mathrm{CO})$, por catalisadores a base de níquel, ferro e cobalto. A reação mostrou ser do tipo reversível. Através da passagem do metano por leito catalítico de níquel, uma mistura gasosa de hidrogênio e monóxido de carbono era obtida.

No mesmo período, foi realizada a primeira produção comercial de hidrogênio a partir do gás de síntese (syngas), sendo este obtido através da reforma a vapor do metano. No ano de 1910, Fritz Habber e Carl Bosch desenvolveram a síntese da amônia a partir do hidrogênio e nitrogênio, sendo, o primeiro, obtido a partir do gás de síntese. De acordo com Spath (2003), a primeira planta comercial de produção de amônia entrou em operação em 1913.

Durante a década de 20, os cientistas Franz Fischer e Hans Tropsch iniciaram a produção de hidrocarbonetos líqüidos a partir da conversão do gás de síntese, utilizando catalisador a base de ferro.

Muitos processos de obtenção de gás de síntese foram desenvolvidos na Alemanha, durante a I e a II Guerras Mundiais, quando os recursos naturais começaram a apresentar uma certa escassez, forçando a descoberta de novas rotas para a produção de amônia (destinada à fabricação de explosivos) e combustíveis em geral. Na ocasião, o gás de síntese era obtido através da gaseificação do carvão.

A partir de 1940, a indústria do petróleo passou a se desenvolver rapidamente, quando várias reservas foram descobertas. A produção de combustíveis, derivados de petróleo, tornou inviável a continuidade da fabricação de combustíveis sintéticos a partir do syngas. Metanol, amônia e hidrogênio continuaram a ser produzidos a partir do gás de síntese, o que fez com que os estudos para o aprimoramento destas tecnologias não parassem. Conforme a indústria de gás natural foi se desenvolvendo na Europa, a matéria prima destes processos passou a ser o metano. Desde a década de 1980, a maior parte do gás de síntese é produzida a partir do metano contido no gás natural (MARSCHNER; RENNER, 1994). 
$\mathrm{O}$ gás de síntese é uma mistura composta por $\mathrm{H}_{2}$ e $\mathrm{CO}$, cuja razão estequiométrica varia de acordo com o processo utilizado e com a matéria da qual se origina o metano. Neste trabalho será considerado apenas o metano proveniente do GN. Em nenhum processo de obtenção do gás de síntese, o rendimento é de 100\%, podendo-se, então, encontrar metano não reagido, vapor de água e dióxido de carbono $\left(\mathrm{CO}_{2}\right)$ (HALDOR TOPSOE, 2003).

Atualmente, o uso principal do gás de síntese é na manufatura de amônia e metanol, na síntese de hidrocarbonetos via processos de Fischer-Tropsch, e na obtenção de hidrogênio que, dependendo do seu grau de pureza, pode ser utilizado em diversos setores industriais. Dentro do conceito de gás-química, um grau de pureza na ordem de $99 \%$, permite o seu uso em processos internos desta planta, tais como: metanação e hidrogenação. A figura 3.1 mostra as principais aplicações do syngas. Não há informações disponíveis que quantifiquem o porcentual de gás de síntese utilizado no processo GTL, portanto se torna plausível interpretar que o mesmo esteja incluso na classificação outros usos, que representa $6 \%$ do volume total.

\section{Usos e Aplicações do Syngas}
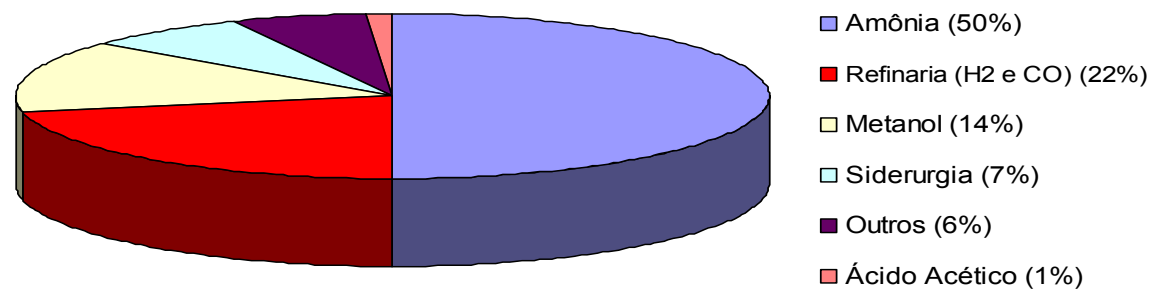

\section{Figura 3.1 - Principais usos e aplicações do syngas}

Fonte: (GEROSA E MATAI, 2006).

Atualmente, a tecnologia industrial mais antiga e mais utilizada para a produção de gás de síntese, é a reforma catalítica do metano com vapor de água (LURGI AG, 2005). É um processo de alto custo industrial por ser endotérmico e por trabalhar com altas temperaturas $\left(500 \mathrm{a} 800^{\circ} \mathrm{C}\right)$. Essas condições reacionais levam à desativação do catalisador por deposição de carbono na sua superfície (formação de coque), (MARSCHNER; RENNER, 2002).

Há, também, outros processos para a obtenção do gás de síntese. Na oxidação parcial do metano (Partial Oxidation - POX), o catalisador de níquel (leito fixo) não é utilizado e o gás de 
entrada não necessita estar tão limpo quanto para o SMR. O POX catalítico requer uma matériaprima com o mesmo grau de pureza quanto àquela requerida para o SMR. Estes dois últimos processos utilizam oxigênio $\left(\mathrm{O}_{2}\right)$ ou ar como reagente e, ambos podem constituir uma etapa seqüencial do SMR, visando garantir uma menor quantidade de metano residual.

Ambos os processos, POX catalítico e POX não catalítico utilizam o $\mathrm{O}_{2}$ ou ar enriquecido como reagente, ocorrendo a combustão espontânea do metano, tornando o processo exotérmico.

Normalmente, para a produção de amônia a partir do syngas, utiliza-se o ar como reagente. O nitrogênio presente no ar atmosférico é um dos componentes da molécula da amônia. Neste caso, o ar atmosférico é passado por uma unidade de tratamento, a fim de que ocorra a separação do $\mathrm{O}_{2}, \mathrm{~N}_{2}$ e de gases inertes.

\subsection{Reforma a Vapor do Metano - SMR}

\subsubsection{Histórico e Evolução do Processo}

A BASF Group desenvolveu em 1920, um processo catalítico para a conversão endotérmica de hidrocarbonetos gasosos na presença de vapor de água e catalisador de níquel. Entre os anos de 1926-1928, esta lançou o processo de reforma a vapor através da catálise em

fornalhas, utilizando reformadores tubulares (Basf Group, 2006). No início da década de 30, o processo foi aplicado, comercialmente, em duas plantas nos Estados Unidos. A primeira delas visava obter hidrogênio a partir do gás natural; a segunda planta era voltada para a síntese da amônia a partir do gás natural. Na ocasião, o SMR era realizado a baixa pressão (entre 0,4-1,0 $\mathrm{MPa}$ ) e temperatura de aproximadamente $800^{\circ} \mathrm{C}$. Desde o início da década de 50, até os dias atuais, o SMR tem operado com pressões acima de $4 \mathrm{MPa}$ e temperaturas em torno de $900^{\circ} \mathrm{C}$. (Marschner; Renner, 1994).

No início, as plantas, que utilizavam a SMR para a obtenção de syngas e $\mathrm{H}_{2}$, eram instaladas próximas às necessidades de consumo destes produtos. A partir de 1970, passaram a ser implantadas onde havia abundância da matéria-prima, o GN. Este é o caso de Trinidad \& Tobago. 


\subsubsection{O Processo}

A SMR consiste na conversão do gás natural por reação com vapor de água em altas temperaturas em um processo catalítico. Tanto a alta temperatura quanto a grande quantidade de calor requeridas neste processo, são fornecidas através dos queimadores localizados no interior dos fornos, onde se encontram reatores tubulares, nos quais ocorre o processo de conversão. De acordo com dados da Haldor Topsoe (2004), a SMR é a tecnologia mais utilizada para a conversão do GN em hidrogênio e para a obtenção do gás de síntese, para a fabricação de amônia, metanol e outros insumos petroquímicos. Por este motivo, o SMR é o processo que mais recebe atenção dos setores de desenvolvimento, visando à melhoria da sua eficiência.

Através do processo SMR, os hidrocarbonetos gasosos podem ser convertidos cataliticamente em $\mathrm{H}_{2}$ e $\mathrm{CO}$, ou seja, no gás de síntese, de acordo com a reação 3.1:

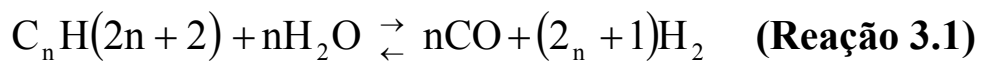

Aplicando esta reação para o metano tem-se:

$$
\mathrm{CH}_{4}+\mathrm{H}_{2} \mathrm{O} \underset{\leftarrow}{\rightarrow} \mathrm{CO}+3 \mathrm{H}_{2} \quad \Delta \mathrm{H}=206 \mathrm{~kJ} / \mathrm{mol}(\text { Reação 3.2) }
$$

A reação é endotérmica e na maioria dos casos, ocorre à alta temperatura, baixa pressão e necessita de uma alta razão molar vapor: carbono, isto é, trabalha-se com excesso de um dos reagentes. Quando acontece o resfriamento da mistura gasosa, uma reação conhecida como water shift gas ou shift gas conversion ocorre. Esta reação acontece em reformadores específicos e o processo e suas variações serão detalhados no capítulo sobre a produção de amônia.

$$
\mathrm{CO}+\mathrm{H}_{2} \mathrm{O} \underset{\leftarrow}{\stackrel{C}{C} \mathrm{O}_{2}}+\mathrm{H}_{2} \quad \Delta \mathrm{H}=-41 \mathrm{~kJ} / \mathrm{mol} \text { (Reação 3.3) }
$$

Na saída do processo de produção do syngas, sempre estará presente uma mistura de $\mathrm{H}_{2}$, $\mathrm{CO}, \mathrm{CO}_{2}$ e $\mathrm{CH}_{4}$, não reagido. A composição média do syngas, obtido através do processo SMR com reformadores tubulares, está apresentada na Tabela 3.1. 


\section{Tabela 3.1 - Composição média do gás de síntese}

\begin{tabular}{lcccc}
\hline Composto & $\mathrm{H}_{2}$ & $\mathrm{CO}$ & $\mathrm{CO}_{2}$ & $\mathrm{CH}_{4}$ \\
\% Volume & 73 & 16 & 7 & 4 \\
\hline
\end{tabular}

Fonte: (MARSCHNER; RENNER, 2002)

O calor, requerido pelo processo, é obtido através do aquecimento indireto do reator tubular, onde está o catalisador de leito fixo de níquel, através do qual há a passagem do gás. Conforme Marschner (1994), a alta sensibilidade do catalisador requer concentrações de compostos sulfurosos menores que $0,5 \mathrm{ppm}$. Porém, esta quantidade pode variar de acordo com o processo escolhido.

O metano, que entra no processo, é misturado com vapor de água na razão vapor-carbono de 2,5-4,5 mol (MATAR, 2000). Uma etapa opcional de pré-aquecimento pode ser realizada e a mistura é enviada ao primeiro reformador. Normalmente, considerando-se uma configuração padrão, o primeiro reformador contém cerca de 400 tubos, cujo comprimento varia de 10 e 12 metros, com 75 a $140 \mathrm{~cm}$ de diâmetro interno e 11 a $18 \mathrm{~mm}$ de espessura, arranjados verticalmente dentro de um forno, que possui vários queimadores responsáveis pelo aquecimento e manutenção da temperatura de processo (BAKEMEIER, 1994). De acordo com as empresas Lurgi AG (2003) e Haldor Topsoe (2003), estas configurações podem sofrer variações.

Conforme apresentado na tabela 1, existe neste processo uma porcentagem de 4 a $10 \%$ em volume de metano. Pressão, temperatura e razão molar vapor-carbono são as variáveis que influenciam estes valores. De acordo com (MARSCHNER; RENNER, 1994), em alguns casos, o valor do metano residual pode chegar até 30\% do volume. Entretanto, os autores não especificam em quais casos, nem em que condições isto ocorre.

Nas condições usuais, com o volume de metano residual na faixa de 4-10\%, é necessário que o gás de síntese seja submetido a um outro processo para reduzir esta taxa. Normalmente, o que se faz é utilizar a oxidação parcial do metano no segundo reformador. O produto final, a ser obtido, é que determinará o reagente a ser usado: ar ou $\mathrm{O}_{2}$, e, a necessidade da presença ou não de catalisador. Neste trabalho serão utilizados um processo endotérmico (SMR) e um exotérmico (POX); pode-se considerar esta seqüência como autotérmica, embora existam reformadores específicos para este processo, onde o SMR e o POX acontecem simultaneamente. 
O gás de síntese, dentro do primeiro reformador, atinge uma temperatura em torno de $600^{\circ} \mathrm{C}$ (temperatura média da reação) (MARSCHNER; RENNER, 2002), sendo que, na saída deste, o gás de síntese atinge uma temperatura média de $830^{\circ} \mathrm{C}$. O produto obtido é combinado com $\mathrm{O}_{2}$ ou ar e pré-aquecido. Uma parcela da mistura gasosa é queimada através de combustão espontânea e a temperatura média da mesma na saída do segundo reator, eleva-se em torno de $1200^{\circ} \mathrm{C}$. A partir deste momento, a conversão do metano ocorre, adiabaticamente, no leito catalítico de níquel. Na saída do processo, a temperatura do gás de síntese está por volta de $1200^{\circ} \mathrm{C}$, contendo de 0,2 a $0,3 \%$ de metano residual, faixa de valor aceitável para vários processos subseqüentes.

O catalisador do reformador secundário e o revestimento do refratário devem ser praticamente isentos de sílica, cuja presença pode gerar compostos, que se depositarão ao longo do reator, gerando perdas de calor durante o processo.

\subsubsection{Razão Molar Água:Carbono}

No processo SMR é necessário que se trabalhe com o excesso de um dos reagentes, no caso, o vapor, para deslocar o equilíbrio químico no sentido direto, ou seja, seguindo o princípio de Le Chatellier. De acordo com Marschner e Renner (1994) e Hydrocarbon Processing - Gas Processes (2002), o excesso não deve alterar ou prejudicar o resultado do processo. Para efeito de desenvolvimento metodológico e demonstração de cálculos, o valor utilizado será 3,0. A análise da reação 3.4 mostra que se têm 2,0 mols de excesso de vapor de água. A razão estequiométrica de entrada varia de acordo com o que se deseja obter na saída do processo.

$$
\mathrm{CH}_{4}+3 \mathrm{H}_{2} \mathrm{O} \underset{\leftarrow}{\rightarrow} \mathrm{CO}+3 \mathrm{H}_{2}+" 2 \mathrm{H}_{2} \mathrm{O} " \Delta \mathrm{H}=\text { não calculado (Reação 3.4) }
$$

Outra razão, pela qual se deve utilizar um excesso de vapor, é a de prevenir a deposição de carbono na superfície do catalisador presente nos tubos do primeiro reformador; esta deposição poderia causar um fenômeno conhecido como hot-spot, o que reduziria a vida útil deste. 


\subsection{Oxidação Parcial do Metano - POX}

O processo de oxidação parcial é uma reação de hidrocarbonetos com uma certa quantidade de oxigênio, insuficiente para que aconteça a combustão completa, que ocorre na faixa de temperatura $1100-1600^{\circ} \mathrm{C}$ e com pressões de até $15 \mathrm{MPa}$ (150 atm). Esta operação é classificada como um processo contínuo e é descrito por três reações básicas $(3.5,3.6,3.7)$ :

$$
\begin{gathered}
\mathrm{C}_{\mathrm{n}} \mathrm{H}_{\mathrm{m}}+\frac{\mathrm{n}}{2} \mathrm{O}_{2} \underset{\rightarrow}{\leftarrow} \mathrm{nCO}+\frac{\mathrm{m}}{2} \mathrm{H}_{2} \text { (Reação 3.5) } \\
\mathrm{C}_{\mathrm{n}} \mathrm{H}_{\mathrm{m}}+\mathrm{nH}_{2} \mathrm{O}_{\rightarrow}^{\leftarrow} \mathrm{nCO}+\left(\frac{\mathrm{m}}{2}+\mathrm{n}\right) \mathrm{H}_{2} \text { (Reação 3.6) } \\
\mathrm{C}_{\mathrm{n}} \mathrm{H}_{\mathrm{m}}+\mathrm{nO}_{2} \underset{\rightarrow}{\leftarrow} \mathrm{nCO}_{2}+\frac{\mathrm{m}}{2} \mathrm{H}_{2} \text { (Reação 3.7) }
\end{gathered}
$$

Aplicando estas reações para o metano têm-se:

$$
\begin{aligned}
& \mathrm{CH}_{4}+\frac{1}{2} \mathrm{O}_{2} \underset{\leftarrow}{\leftarrow} \mathrm{CO}+2 \mathrm{H}_{2} \quad \Delta \mathrm{H}=-36 \mathrm{~kJ} / \mathrm{mol} \text { (Reação 3.8) } \\
& \mathrm{CH}_{4}+\mathrm{H}_{2} \mathrm{O} \underset{\leftarrow}{\rightarrow} \mathrm{CO}+3 \mathrm{H}_{2} \quad \Delta \mathrm{H}=206 \mathrm{~kJ} / \mathrm{mol} \text { (Reação 3.9) } \\
& \mathrm{CH}_{4}+\mathrm{O}_{2} \underset{\leftarrow}{\rightarrow} \mathrm{CO}_{2}+2 \mathrm{H}_{2} \quad \Delta \mathrm{H}=\text { não calculado } \quad \text { (Reação 3.10) }
\end{aligned}
$$

A quantidade mínima requerida de $\mathrm{O}_{2}$, para que ocorra a conversão completa do hidrocarboneto está indicada na reação 3.8 .

Para evitar uma temperatura excessiva no processo, adiciona-se vapor, que reage com os hidrocarbonetos de acordo com a reação 3.9 (endotérmica). Este procedimento, porém, resulta numa maior formação de hidrogênio quando comparado ao processo ocorrido, de acordo com a reação 3.8 .

Independentemente da natureza da matéria-prima, os compostos de entrada (contendo carbono, hidrogênio, oxigênio e compostos sulfurosos), depois de atingir o equilíbrio químico e termodinâmico, serão totalmente convertidos em monóxido de carbono, dióxido de carbono, hidrogênio, água, metano, ácido sulfídrico e COS. 
O deslocamento (reação 3.11), equilíbrio do metano (reação 3.12), equilíbrio do ácido sulfídrico (reação 3.13), produção e equilíbrio de $\mathrm{CO}_{2}$ (reações 3.14 e 3.15) são as variáveis capazes de alterar o tempo padrão, a fim de que o equilíbrio do processo seja atingido, bem como influenciar na estequiometria de saída.

$$
\begin{aligned}
& \mathrm{CO}+\mathrm{H}_{2} \mathrm{O} \underset{\leftarrow}{\stackrel{C^{2}}{\longrightarrow}}+\mathrm{H}_{2} \quad \text { (Reação 3.11) }
\end{aligned}
$$

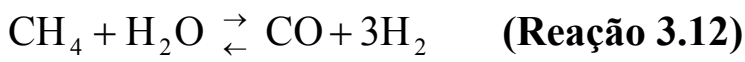

$$
\begin{aligned}
& \mathrm{H}_{2} \mathrm{~S}+\mathrm{CO}_{2} \underset{\leftarrow}{\leftarrow} \mathrm{H}_{2} \mathrm{O}+\mathrm{COS} \text { (Reação 3.13) } \\
& \mathrm{CO}+\frac{1}{2} \mathrm{O}_{2} \underset{\leftarrow}{\leftarrow} \mathrm{CO}_{2} \quad \text { (Reação 3.14) } \\
& \mathrm{CH}_{4}+\mathrm{CO}_{2} \underset{\leftarrow}{\leftarrow} \mathrm{CO}+2 \mathrm{H}_{2} \text { (Reação 3.15) }
\end{aligned}
$$

Todas estas reações ocorrem, compulsoriamente, no interior do reator. A ocorrência e o que diferencia os dois tipos de oxidação parcial, é a presença ou não de catalisador a base de níquel.

Para unidades não catalíticas, as reações de 11 até 15 ocorrem e a temperatura de saída da mistura gasosa tende a ser mais alta. Neste tipo de processo, é necessária a instalação de unidades de remoção de $\mathrm{CO}_{2}$ e compostos sulfurosos antes do envio do syngas para as unidades de produção de amônia e metanol.

Nas unidades de POX catalítico, a matéria-prima de entrada deve estar isenta de compostos sulfurosos, já que estes danificam o catalisador. A presença do catalisador faz com que a temperatura do processo seja um pouco mais baixa. Desta forma, a temperatura de saída da mistura gasosa é de aproximadamente $1000^{\circ} \mathrm{C}$.

No caso do modelo proposto neste trabalho, a primeira unidade de transformação do metano é o SMR; a matéria-prima de entrada será considerada isenta de compostos sulfurosos, portanto a reação 3.13 não ocorrerá. 


\subsubsection{Reforma Autotérmica - ATR}

No processo ATR, o gás natural é queimado e reagido de forma simultânea com oxigênio e vapor de água. Esta mistura gasosa é enviada a um leito catalítico de níquel. O agente oxidante utilizado, pode ser ar atmosférico ou oxigênio puro.

Analisando-se o ATR sob os aspectos relacionados às condições de processo tais como, temperatura e pressão, nota-se seu posicionamento entre o SMR e o POX. Seus valores típicos para temperatura e pressão estão na faixa de 2 a $4 \mathrm{MPa}$ e $800-1000^{\circ} \mathrm{C}$, respectivamente (MARSCHNER, 2002). Outras fontes de pesquisa consultadas, tal como Chen (2005), apontam temperaturas de até $1200^{\circ} \mathrm{C}$.

A reação de combustão ocorre rapidamente e gera elevada temperatura no interior do reator. Este processo tem como vantagem, a produção de um syngas ideal para vários processos posteriores de conversão. Como o processo exige a injeção de oxigênio, é recomendável que exista uma planta de separação e limpeza do ar atmosférico, o que encarecerá o projeto. A necessidade está relacionada ao uso final do syngas produzido.

Visto que o processo ATR consiste na combinação do POX catalítico com o SMR, o calor liberado em cada reação atribui uma característica muito peculiar à operação como um todo, tornado-a energeticamente mais eficiente.

O calor requerido no processo, conforme NAE (2004), é obtido através da combustão parcial do metano. O reformador consiste em um reator cerâmico alinhado a uma zona de combustão combinada com uma zona catalítica, na qual se encontram os leitos catalíticos de níquel. O calor gerado na zona de combustão é transferido para a zona catalítica através da própria corrente gasosa interna do reator, fornecendo dessa forma, o calor necessário para que ocorra a reação de reforma a vapor (NAE, 2004).

O POX catalítico é uma reação exotérmica, com $\Delta \mathrm{H}=-36 \mathrm{~kJ} / \mathrm{mol}$ na condição padrão, cujo calor liberado pode ser transferido e utilizado pelo SMR, uma vez que os dois processos, POX e SMR, ocorrem no mesmo reator.

De acordo com Chen (2005), quando o processo ATR é realizado nas condições ideais de operação, com uma quantidade precisa e correta de ar, combustível e vapor, a eficiência teórica pode ser maior que a do processo SMR convencional (93,9\% contra 91,7\%). Porém, de acordo 
com Marschner (2002), a eficiência térmica ${ }^{2}$ está em torno de 88,5\%. Esta mesma comparação, quando feita para o processo SMR, mostra um valor em torno de 81\%, incluindo o hidrocarboneto utilizado como combustível nos queimadores, e em torno de 83,5\% para o POX.

Uma vantagem do processo ATR é a sua flexibilidade para as matérias primas de entrada, pois é possível trabalhar tanto com hidrocarbonetos gasosos, os denominados leves, quanto os mais pesados, tais como a nafta petroquímica, gasolina e óleo diesel.

Entre os processos SMR, POX (catalítico e não catalítico) e o ATR, este último é o mais recente; o que mais precisa ser aperfeiçoado. De acordo com Chen (2005), grandes evoluções poderão surgir com respeito à redução da relação oxigênio: carbono. Isto deverá significar uma redução na temperatura do processo (atualmente é em torno de $1200^{\circ} \mathrm{C}$ ). O ideal seria ter-se 650 $900^{\circ} \mathrm{C}$. O autor, também aponta que avanços nas pesquisas dos catalisadores deverão reduzir o tempo de residência nos reatores.

Ainda conforme Chen (2005), existem algumas patentes para processos ATR em reatores do tipo air-blown que utilizam o ar em vez de oxigênio, dispensando as unidades de tratamento de ar. Entretanto, o syngas produzido, apresenta um elevado porcentual de nitrogênio, exigindo um processo de purificação.

\subsection{Estado da Arte da Tecnologia de Produção do Gás de Síntese}

Neste item, são apresentados alguns dos processos atualmente mais utilizados para a produção do gás de síntese, suas descrições e versatilidades quanto às matérias-primas, os detentores das patentes, bem como as melhores rotas de aplicação do syngas obtido.

\subsubsection{Processo CRG - Pré-reforma, empobrecimento e metanação - Licenciado pela Davy Process Technology e catalisador licenciado pela Synetix}

Aplicação: reforma adiabática a vapor de hidrocarbonetos. Pode ser utilizado no empobrecimento do GN (nas plantas de gás natural liquefeito) como um pré-reformador

\footnotetext{
${ }^{2}$ Razão do teor de carbono da reforma do gás para que o hidrocarboneto utilizado na alimentação seja consumido, ambos a temperatura de $0^{\circ} \mathrm{C}$
} 
adiabático ou na metanação de correntes ricas em hidrogênio e monóxido de carbono na manufatura de gás de síntese.

Matéria prima: GN e hidrocarbonetos mais pesados, variando desde o gás liquefeito de petróleo (GLP) até a nafta.

Processo: utiliza-se leito catalítico fixo com catalisador de níquel, onde ocorre, na presença de vapor, a conversão das correntes de hidrocarbonetos em uma corrente resultante de produtos que contém somente metano junto com hidrogênio, gás carbônico, monóxido de carbono e vapor. A corrente resultante pode ser exportada como produto ou utilizada como carga para processamento em fornos aquecidos de reforma convencional ou, ainda, como carga para reprocessamento pelo próprio processo $\mathrm{CRG}$, quando se deseja enriquecer a corrente de metano. $\mathrm{O}$ processo permite uma economia na unidade primária de reforma, resultante da redução de energia no forno de reforma. A possibilidade de se aumentar, as temperaturas no pré-aquecimento e a transferência de energia radiante para a seção de convecção da unidade primária de reforma, pode minimizar a produção involuntária de vapor.

Condições de operação: A temperatura varia numa faixa entre $250-650^{\circ} \mathrm{C}$ e a pressão acima de 75bar. A figura 3.2 apresenta o diagrama do processo CRG licenciado pela Davy Process.

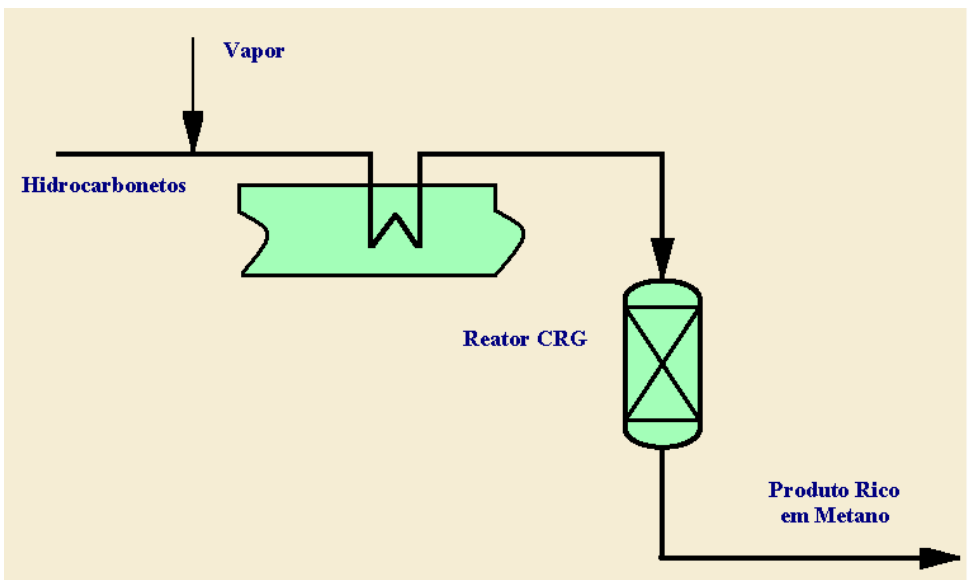

Figura 3.2: Diagrama do processo CRG - Davy Process

Fonte: (GAS PROCESSES, 2004; adaptação própria) 


\subsubsection{Tecnologia Syngas ATR - Licenciado pela Haldor Topsoe}

O processo é utilizado na produção de gás de síntese rico em monóxido de carbono. Os produtos obtidos são: $\mathrm{CO}$ e $\mathrm{H}_{2}$ puros ou gás de síntese para a produção de metanol, de combustíveis sintéticos e na síntese de oxo-compostos ou amônia. Também pode ser aplicado na produção em larga escala de gás de síntese, visando obter combustíveis líqüidos (Gas-to-Liquid).

Matérias-primas: GN, GLP ou nafta petroquímica.

Dos reagentes, além dos hidrocarbonetos, têm-se o $\mathrm{O}_{2}$, que pode ser puro, ar ou ar enriquecido com $\mathrm{O}_{2}$. $\mathrm{O} \mathrm{CO}_{2}$ pode ser proveniente de outras unidades ou do próprio gás de reciclo e tem como finalidade, ajustar a composição do gás de síntese.

O processo consiste na combinação de oxidação parcial com a reforma a vapor adiabática, utilizando um leito catalítico fixo de níquel. A unidade consiste em um pré-aquecedor da carga, dessulfurização, unidade opcional de pré-reforma, um reator de reforma dotado de queimador, câmara de combustão e leito catalítico, seção de recuperação de calor e, quando necessário, uma seção de purificação de gás (para, por exemplo, a remoção de $\mathrm{CO}_{2}$ ).

Condições de operação: temperatura de saída do reator, variando numa faixa de 950 e $1050^{\circ} \mathrm{C}$, e a pressão no reator, variando entre 20 e $70 \mathrm{bar}$.

Relações estequiométricas: razões de entrada $\mathrm{H}_{2} \mathrm{O} / \mathrm{CH}_{4}$ de $0,2-1,5$ e $\mathrm{CO}_{2} / \mathrm{CH}_{4}$ de $0,0-2,0$ são utilizadas para se obter gás de síntese com razão de $\mathrm{H}_{2} / \mathrm{CO}$ de 0,8-2,5.

A figura 3.3 apresenta o diagrama do processo syngas ATR da Haldor Topsoe.

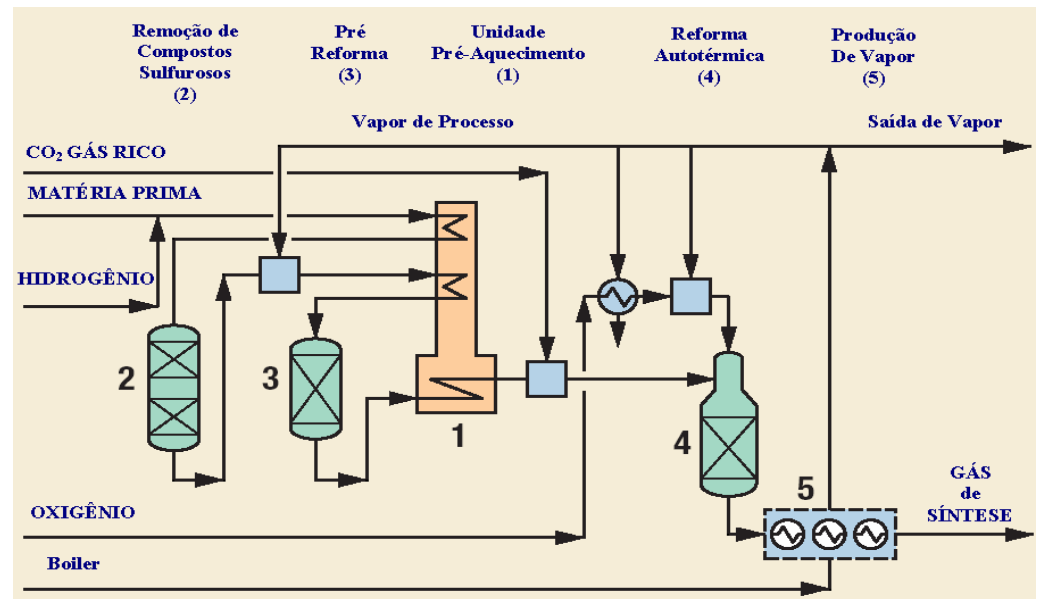

Figura 3.3: Diagrama do processo syngas ATR da Haldor Topsoe

Fonte: (GAS PROCESSES, 2004; adaptação própria) 


\subsubsection{Processo Syngas Autothermal - Licenciado pela Hower-Baker Engineers, Ltd}

O processo é aplicado na produção de monóxido de carbono e hidrogênio para uso na indústria petroquímica. É ideal para a síntese de oxo-álcoois e de metanol.

Os produtos obtidos são gás de síntese contendo monóxido de carbono e hidrogênio. O syngas pode ser utilizado diretamente na obtenção de produtos químicos, ou pode ser processado, fornecendo monóxido de carbono e hidrogênio, com altos teores de pureza.

Descrição do processo: a carga de gás natural é pré-aquecida e, então, dessulfurizada em um sistema convencional de hidrotratamento, na presença de óxido de zinco. Adiciona-se vapor à corrente dessulfurizada. Nesta etapa, pode-se utilizar (opcional) o reciclo de dióxido de carbono. A mistura é enviada a uma unidade de reforma autotérmica (vaso com revestimento refratário) que contem catalisador e é dotada de queimador localizado nas proximidades do topo do vaso. A mistura é, então, queimada na presença de oxigênio e passa através de um leito catalítico, onde ocorrem as reações de reforma. $\mathrm{O}$ gás sai de $926^{\circ} \mathrm{C}$ a $1037^{\circ} \mathrm{C}$, dependendo das especificações finais desejadas, para a corrente gasosa. Esta é resfriada e passada através de uma unidade de remoção de $\mathrm{CO}_{2}$. A corrente resfriada resultante é composta de $\mathrm{CO}$ e $\mathrm{H}_{2}$, pequenas quantidades de $\mathrm{CO}_{2}$ e pode ter uso como gás de síntese ou, então, através de reforma criogênica, obter-se $\mathrm{CO}$ e $\mathrm{H}_{2}$ com alto grau de pureza. $\mathrm{O} \mathrm{CO}_{2}$ pode ser reciclado para que se faça um ajuste na relação monóxido de $\mathrm{CO}_{2} / \mathrm{H}_{2}$. A relação estequiométrica, ótima para a carga de gás natural, é a razão de $\mathrm{CO}_{2} / \mathrm{H}_{2}$ entre 1,6 e 2,7 .

A figura 3.4 apresenta o diagrama do processo syngas autothermal, Hower Baker.

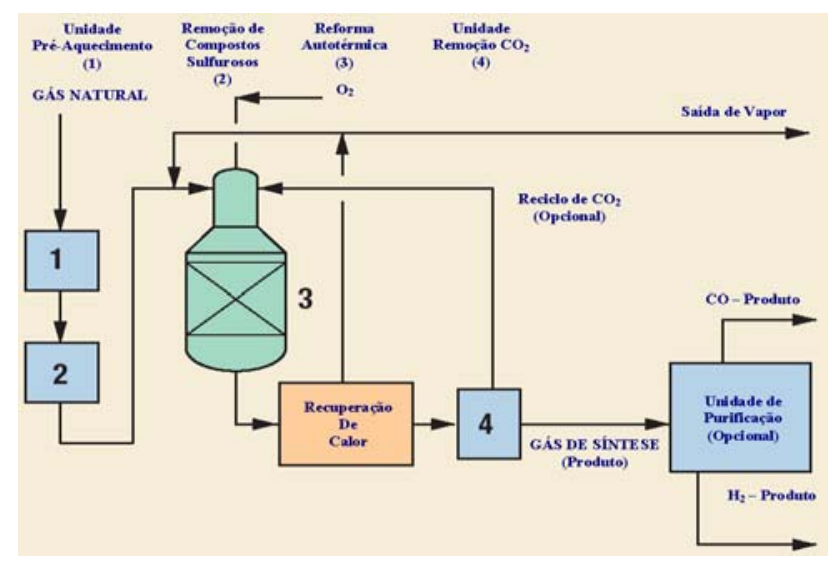

Figura 3.4: Diagrama do processo syngas autothermal, Hower Baker

Fonte: (GAS PROCESSES, 2004; adaptação própria) 


\subsubsection{Processo SMR avançado - Licenciado pela Haldor Topsoe}

O processo é aplicado na produção de gás de síntese, rico em monóxido de carbono.

Os produtos obtidos são monóxido de carbono e hidrogênio puros ou misturas de monóxido de carbono e hidrogênio (gás de síntese), que são utilizados para a produção de ácido acético, oxo-álcoois, isocianatos e outros insumos petroquímicos.

Matérias-primas: GN, GLP ou nafta petroquímica.

O processo possibilita a operação em baixas relações de vapor e carbono, saídas do reformador com altas temperaturas e elevado fluxo de calor. Quando se utilizam hidrocarbonetos mais pesados do que o GN, torna-se necessária a utilização de uma unidade de pré-reforma conectada ao reator tubular. Gás carbônico importado de outras unidades e/ou gás carbônico de reciclo são utilizados na produção de gás de síntese, rico em monóxido de carbono.

As condições de operação e relação estequiométrica são: o gás de síntese, rico em $\mathrm{CO}_{2}$, é obtido através de cargas de $\mathrm{H}_{2} \mathrm{O} / \mathrm{CH}_{4}$, na razão de 1,5 a 2,0 com $\mathrm{CO}_{2}$ de reciclo e/ou $\mathrm{CO}_{2}$ de outras unidades. Isto resulta na razão $\mathrm{H}_{2} / \mathrm{CO}$, abaixo de 1,8 nas condições de saída do reformador a uma temperatura próxima de $950^{\circ} \mathrm{C}$. A unidade consiste de dessulfurização da carga, préreforma e reforma em reator tubular, recuperação e reciclo de gás carbônico e purificação final. A purificação de gás de síntese em membranas ou cold box depende das especificações finais requeridas para o syngas produzido. A figura 3.5 apresenta o diagrama do processo Advanced SMR Haldor Topsoe.

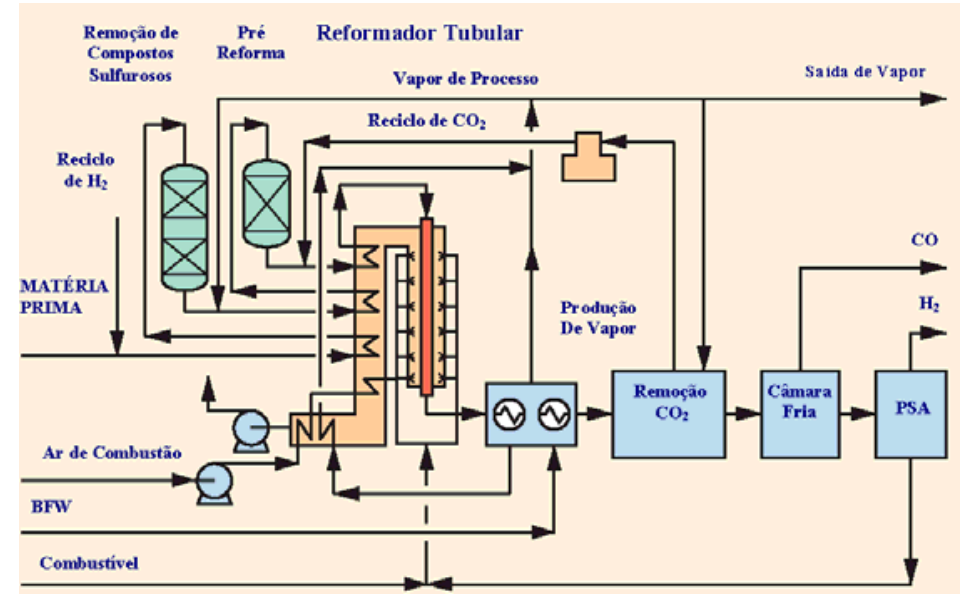

Figura 3.5. Diagrama do processo Advanced SMR Haldor Topsoe

Fonte: (GAS PROCESSES, 2004; adaptação própria) 


\subsubsection{Processo de Reforma a Vapor do Metano - Licenciado pela Uhde GTmbH}

O processo é aplicado para a produção de hidrogênio e/ou gás de síntese, rico em hidrogênio e monóxido de carbono.

Os produtos resultantes são: gás de síntese para a produção de $\mathrm{H}_{2}$, de amônia, de combustíveis sintéticos obtidos pelo processo Fischer-Tropsch (FT), oxo-compostos e metanol.

Matérias-primas: GN, gás de refinaria, nafta leve e GLP

Através da alta temperatura de reação do metano ou dos hidrocarbonetos leves sobre o catalisador de níquel, produz-se hidrogênio e monóxido de carbono. A reforma ocorre em tubos empacotados com o catalisador, colocados verticalmente em uma unidade de reforma a vapor.

Condições de operação: temperaturas de descarga da ordem de 740 a $959^{\circ} \mathrm{C}$ e pressões de até 50bar. A larga faixa de temperaturas dá versatilidade ao reformador.

A figura 3.6 apresenta o diagrama do processo da reforma a vapor do metano, licenciado pela Uhde GmbH.

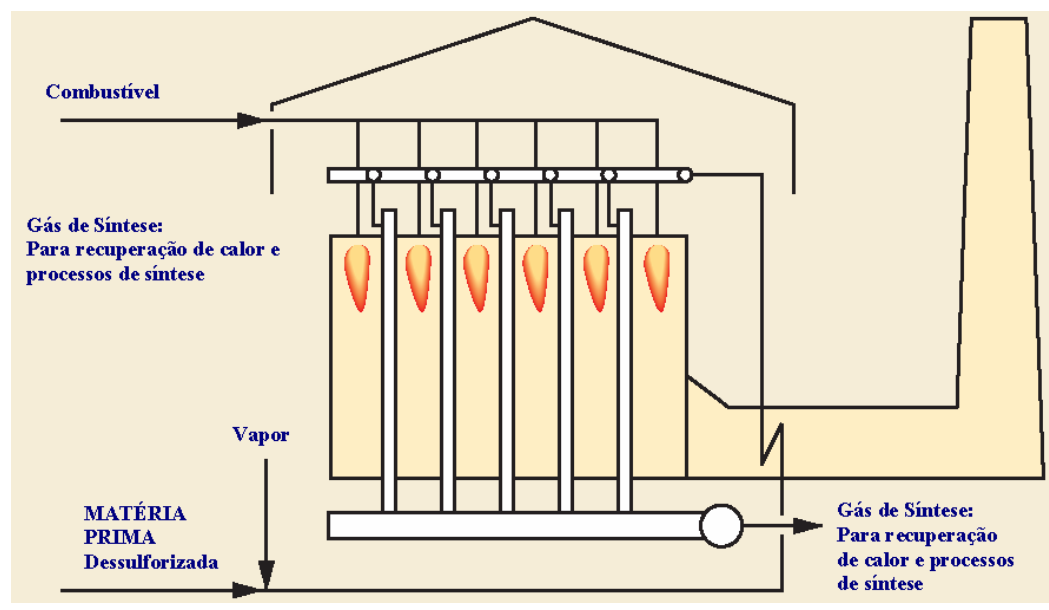

Figura 3.6. Diagrama de processo da reforma a vapor do metano, Uhde GmbH Fonte: (GAS PROCESSES, 2004; adaptação própria)

\subsubsection{Processo Gas-To-Liquids - Davy Process Technology}

O processo é aplicado na produção de um produto cru, bombeável e isento de enxofre.

Os produtos obtidos são: compostos parafínicos e hidrocarbonetos líqüidos, isentos de enxofre. 
Matéria-prima: GN (inclusive com altos teores de $\mathrm{CO}_{2}$ ).

O GN é pré-aquecido com o objetivo de se remover o enxofre (através de tecnologia convencional de dessulfurização). Adiciona-se vapor e gases de reciclo a carga aquecida. Esta mistura gasosa é enviada a unidade de pré-reforma (CRG). A adição de vapor seguida por aquecimento é completada antes que a mistura de gases passe para a unidade compacta de reforma. Esta unidade compacta é um reator multi-tubular, operando em contracorrente, que, na presença de catalisador de níquel, produz uma mistura de óxidos de carbono e hidrogênio. $\mathrm{O}$ aquecimento para esta reação endotérmica é fornecido por uma queima externa do excesso de hidrogênio produzido no processo. O gás, que deixa a unidade de reforma, é resfriado, gerando vapor suficiente para satisfazer às necessidades de aquecimento. O excesso de condensado é, então, removido. O gás de síntese seco obtido é comprimido e passa por separação em membranas, nas quais o excedente de hidrogênio é recuperado e reutilizado como combustível. O produto não separado em membranas é enviado à seção de conversão, na qual o gás de síntese é convertido em produtos parafínicos, utilizando-se catalisador de cobalto. $\mathrm{O}$ gás de síntese não convertido é reciclado e enviado como carga para a unidade compacta de reforma. Os produtos parafínicos, oriundos da seção de conversão, podem passar por hidrocraqueamento, de modo a gerar uma corrente bombeável. Por ser uma unidade compacta é ideal para instalações offshore, onde há restrições de peso e de espaço. A figura 3.7 apresenta o diagrama do processo Gas-ToLiquids, licenciado pela Davy Process Technology

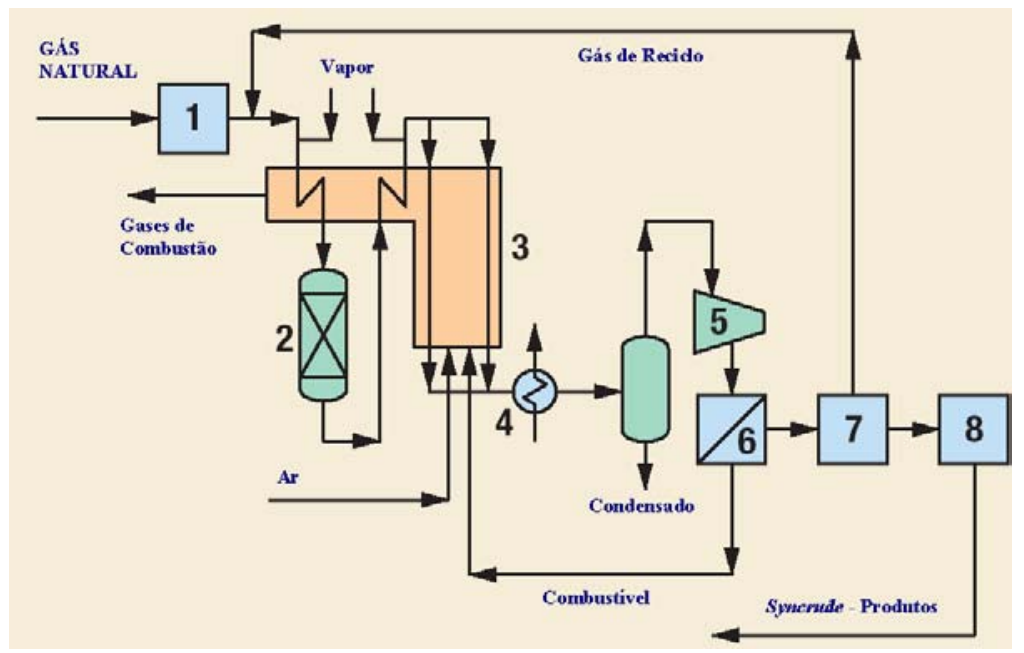

Figura 3.7. Diagrama do processo Gas-To-Liquids, licenciado pela Davy Process Technology

Fonte: (GAS PROCESSES, 2004; adaptação própria) 


\subsubsection{Processo Gas-To-Liquids - Licenciado pela Synytroleum Corporation}

O processo é aplicado na produção de combustíveis sintéticos ultralimpos.

Os produtos obtidos são: GLP, querosene e nafta, isentos de enxofre, aromáticos e/ou metais pesados.

\section{Matéria-prima: GN.}

O processo utiliza ar na produção do gás de síntese. Ar, vapor e gás natural são misturados e reagem em uma unidade de reforma autotérmica. O gás de síntese produzido tem uma relação $\mathrm{H}_{2}: \mathrm{CO}$ de 2:1. O catalisador utilizado é de cobalto. $\mathrm{O} \mathrm{CO}$ obtido é hidrogenado a hidrocarbonetos sintéticos. O gás de síntese não reagido é utilizado como combustível para turbinas, aquecedores e outros equipamentos. As correntes dos crus gerados são refinadas de modo a se obter os combustíveis ultra-limpos. Comparando-se o processo com os processos convencionais de refino de petróleo, este é menos severo, consome menos hidrogênio, as temperaturas e pressões são menores e o catalisador tem a sua vida útil aumentada, devido à ausência de enxofre, metais pesados e de hidrocarbonetos aromáticos. O processo é adequado para instalações onshore e offshore.

A figura 3.8 apresenta o diagrama do Processo Gas-To-Liquids (GTL), licenciado pela Syntroleum Corporation.

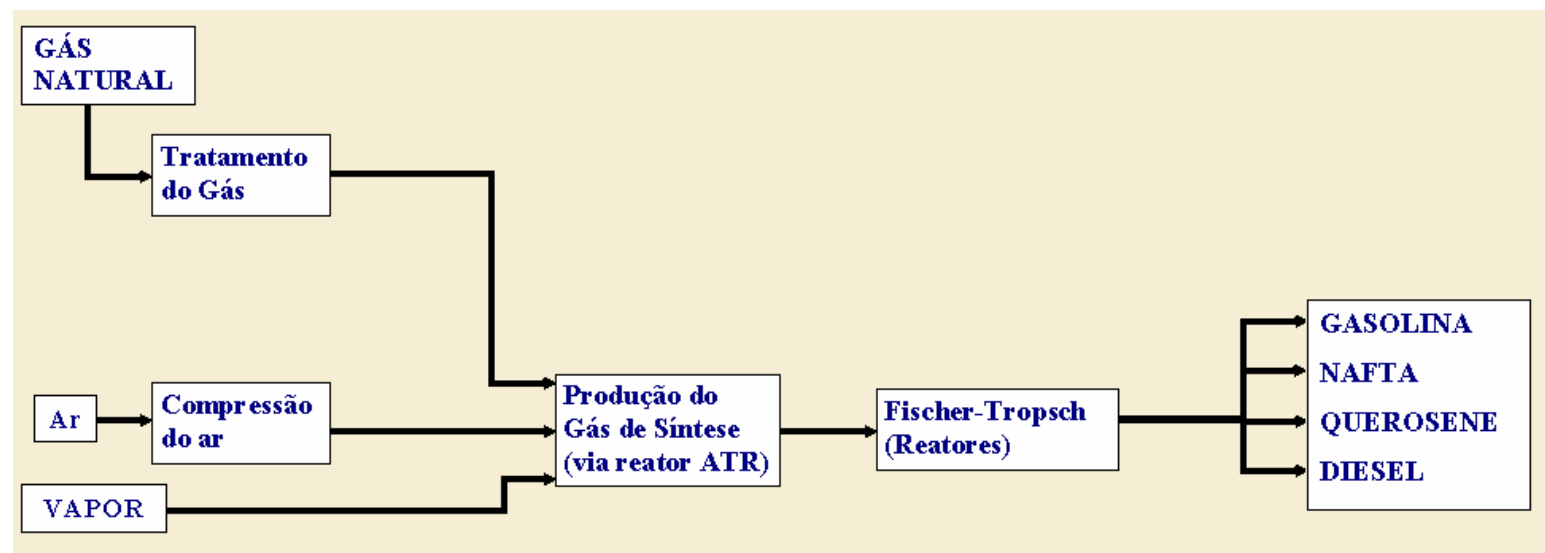

Figura 3.8. Diagrama de processo Gas-To-Liquids, Syntroleum

Fonte: (GAS PROCESSES, 2004; adaptação própria) 


\subsubsection{Panorama Atual da Produção de Gás de Síntese}

A vasta experiência comercial baseada na manufatura do syngas a partir do SMR conduziu a muitas melhorias na tecnologia. De acordo com o NAE (2004), melhorias foram atingidas em termos de redução de custos e aumento na eficiência de conversão. O maior progresso se deu no que diz respeito ao reformador tubular, ao se tornar capaz de trabalhar em temperaturas mais elevadas, devido a maior resistência mecânica das suas paredes; permitiu também, um avanço no controle da deposição do carbono formado durante a reação.

Os processos de purificação do hidrogênio representaram uma importante evolução na utilização do syngas como matéria prima.

O desenvolvimento do processo Pressure Swing Adsorption (PSA), que é capaz de filtrar compostos, tais como metano não reagido e óxidos de carbono, além de outras impurezas em uma única etapa de processamento, permitiu o maior uso do syngas para a produção de $\mathrm{H}_{2}$.

As tecnologias de captação, tratamento e recirculação de $\mathrm{CO}_{2}$ estão disponíveis. $\mathrm{O}$ processo de absorção é o mais utilizado.

Atualmente, o POX, que utiliza como alimentação o gás natural, é uma tecnologia madura e muito aplicada comercialmente. Embora muitas plantas de POX ainda utilizem matérias-primas não nobres como carvão e resíduo de petróleo, o gás natural ainda é a carga preferida.

O processo ATR, a base de oxigênio, é muito utilizado, principalmente, quando a finalidade do syngas obtido é a produção de metanol e síntese de Fischer-Tropsch, já que sua composição é rica em CO. 


\section{METANOL}

\subsection{Histórico e Considerações}

O metanol é um líqüido aqüoso, incolor, volátil, inflamável e com um odor característico de álcool. É tóxico quando respirado ou entra em contato direto com a pele. Por ser miscível em água, álcool e éter é utilizado como solvente e também como matéria prima na indústria da química orgânica. A razão molar de hidrogênio e monóxido de carbono ideal para a fabricação de metanol é de 2:1, mas também é possível realizá-la na razão de 3:1; obtem-se água como subproduto. Atualmente, o metanol é tratado como uma commodity (METHANEX, 2006).

Não é possível precisar as origens e o aparecimento do metanol. Os egípcios o obtinham através da pirólise da madeira, para uso no embalsamamento de corpos. (FIEDLER at al, 1994)

Em 1661, Robert Boyle isolou, pela primeira vez, o metanol composto ao qual denominou álcool de madeira. Em 1834, Jean-Baptiste Dumas e Justus von Liebig determinaram a estrutura molecular do metanol (fórmula química $\mathrm{CH}_{3} \mathrm{OH}$ ), cuja molécula está apresentada na figura 4.1 .

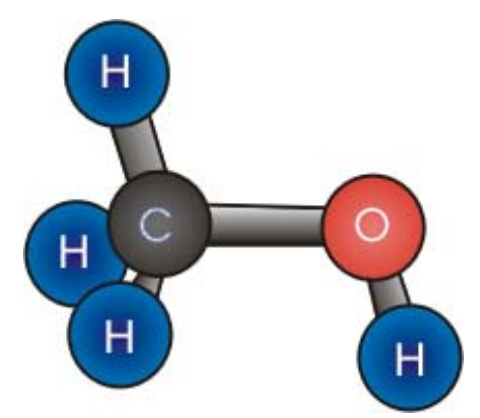

Figura 4.1. Estrutura molecular do metanol

Fonte: (WIKIPEDIA, 2006) 


\subsection{Produção Industrial}

No período compreendido entre os anos 1830-1923, obtinha-se o metanol, exclusivamente, a partir da madeira. Dados da J.E. Consultants (2003) indicam que no ano de 1924, cerca de 3 milhões de toneladas de madeira foram empregadas no mundo, na fabricação do equivalente a 30.000 toneladas de metanol.

A história do desenvolvimento e da evolução do processo de síntese de metanol misturase, com o desenvolvimento do processo de obtenção da amônia e com a história da Basf, na qual os dois produtos foram desenvolvidos, aprimorados e consolidados.

Os trabalhos de pesquisa realizados por Fritz Haber e Carl Bosch permitiram toda a base para a implantação do processo de obtenção da amônia, conhecido como processo Haber-Bosch, apresentado no item 5.4. Baseando-se nos resultados encontrados por Haber e Bosch, Alwin Mittasch obteve, em 1913, uma mistura de compostos, entre eles o metanol, ao passar uma mistura gasosa de hidrogênio e monóxido de carbono por um catalisador de óxido de ferro (FIEDLER at al, 2002).

Na década de 1920, Mathias Pier com sua equipe de pesquisadores da Basf, desenvolveram um catalisador a base de óxido de zinco-óxido de cromo, que se mostrou resistente aos compostos sulfurosos presentes no gás de síntese. A partir deste momento a produção em larga escala do metanol, dito sintético, foi possível. Conforme o site da Basf "Yet another of nature's raw material monopolies is broken: wood alcohol is dethroned by synthetic methanol” (BASF CHEMICAL GROUP, 1923)

Dados da J.E. Sinor Consultants (1999) apontam que com a implantação da rota química, a obtenção de metanol, a partir da madeira, reduziu-se: em 1930, cerca de 50\% do produto obtido, provinha desta fonte e em 1935, somente $20 \%$.

A tecnologia, bem desenvolvida de produção do gás de síntese, é apontada como uma das razões para o rápido desenvolvimento tecnológico da produção de metanol, já que havia sido muito bem estruturada para a obtenção da amônia. Com uma simples adaptação na estequiometria de saída do syngas era possível se produzir metanol. Havia, portanto, uma flexibilidade quanto aos produtos finais obtidos a partir do syngas. 
Conforme dados da DuPont, em 1925, foi inaugurada em Belle, Virgínia (EUA) uma planta para produção de amônia, em larga escala e de metanol, em pequena escala. A empresa obtinha o gás de síntese a partir da gaseificação do carvão. No ano de 1926, após se associar a Imperial Chemical Industries ${ }^{3}$ (ICI), houve a ampliação da planta de metanol cuja produção era de um milhão de galões por ano $\left(3.785,4 \mathrm{~m}^{3} / \mathrm{ano}\right)$.

Os processos desenvolvidos pelas empresas Basf, DuPont e ICI, os quais foram utilizados durante 40 anos, eram baseados na tecnologia desenvolvida entre os anos de 1913-23, operavam sob alta pressão (25-35 MPa) e temperaturas na faixa de $320-450^{\circ} \mathrm{C}$ (Fiedler at al, 1994).

Em 1960, a ICI desenvolveu uma rota para a síntese do metanol a partir de um syngas isento de compostos sulfurosos, que continha uma grande quantidade de dióxido de carbono, passado através de um catalisador de óxido de cobre, altamente seletivo. Essas modificações proporcionaram reduções na pressão e na temperatura de operação: 5-10 $\mathrm{MPa}$ e 200-300 ${ }^{\circ} \mathrm{C}$, respectivamente Esta tecnologia, mundialmente utilizada nos dias atuais, é conhecida como LowPressure (ECKHARD, 1994).

\subsection{Evolução dos Processos de Produção do Metanol}

A utilização de hidrocarbonetos como matéria prima para os processos de gaseificação representaram um grande salto, em termos de desenvolvimento, para toda a indústria química baseada no gás de síntese.

O processo de reforma a vapor foi desenvolvido pela BASF entre os anos de 1926-1928. Em 1930, duas plantas comercias foram instaladas nos Estados Unidos. Entre o final da década de 30 e início da década de 40, a empresa ICI aprimorou a catálise deste processo, o que permitiu a inclusão da nafta petroquímica como matéria prima. As empresas, Shell e Texaco, desenvolveram o processo de oxidação parcial de óleos pesados.

\footnotetext{
${ }^{3}$ a ICI hoje é uma das empresas do grupo One-sinergy, que engloba as empresas Johnson Mathey Catalysts, Davy Process Technology e Aker Kvaerner)
} 


\subsection{A evolução dos Processos: da síntese em alta pressão à baixa pressão}

De acordo com Eckhard (1994), uma nova geração de catalisadores, contendo cobre, foi desenvolvida, proporcionando um aumento na eficiência do processo e uma melhoria das condições de operação. Segundo o autor, a última planta industrial que utilizava o processo de síntese do metanol à alta pressão foi desativada em 1980.

Dados da J.E. Consultants (1999) indicam que na década de 1940, o consumo médio de energia para uma planta de metanol à alta pressão era de $70 \mathrm{GJ} /$ ton.

Muito antes de a ICI implementar o seu processo a baixa pressão, com catalisadores a base de cobre, a Basf Chemical Group já vinha estudando e utilizando em suas próprias plantas desde a década de 1920, o mesmo catalisador dos processos de síntese à alta pressão, porém com condições de operação intermediárias: pressão de $15 \mathrm{MPa}$ e temperatura de $300^{\circ} \mathrm{C}$. (FIEDLER, 1994 e BASF GROUP WEBSITE). A desvantagem observada neste processo era que, mesmo com a redução da temperatura e da pressão, as impurezas contidas no gás de síntese causavam a desativação prematura do catalisador.

A catálise à baixa pressão da síntese do metanol foi usada, primeiramente, de forma industrial, no processo desenvolvido pela ICI em 1966. O catalisador à base de óxido de cobreóxido de zinco foi inicialmente, estabilizado com alumina. Isto fez com que ocorresse uma conversão do syngas com altíssimo grau de pureza de metanol (cerca de 99,5\%). O próprio gás de síntese já apresentava uma menor presença de compostos sulforosos, sendo o teor de $\mathrm{H}_{2} \mathrm{~S}$ menor do que 1ppm. Em virtude do catalisador ser muito ativo e seletivo, a síntese ocorria na faixa de temperatura de $220-230^{\circ} \mathrm{C}$ e pressão de $5 \mathrm{MPa}$. O envelhecimento prematuro do cobre devido à sinterização pôde, então, ser evitado. (ECKHARD, 1994). A planta industrial, que empregava a tecnologia ICI, tinha um projeto inicial de produção de 300 t/dia. Porém, com o aumento da vida útil do catalisador, teve a sua capacidade produtiva aumentada para $600 \mathrm{t} /$ dia e apresentava um consumo energético de $36 \mathrm{GJ} / \mathrm{t}$. O processo da ICI empregado, até os dias de hoje, pelas empresas que utilizam gás natural como matéria prima, permite a obtenção de metanol com alto grau de pureza, a formação de subprodutos é mínima e o rendimento, incluindo os processos de loop, atinge um rendimento de até 99\%. 
Dados da J.E. Consultants (1999), mostram, que atualmente, as plantas que utilizam gás natural e reforma a vapor do metano na obtenção do syngas, apresentam um consumo energético médio de 29 GJ/t. (J.E. CONSULTANTS, 1999).

Em 1969, a Lurgi A. G. lançou seu próprio processo de síntese de metanol à baixa pressão, que foi, inicialmente, testado em planta piloto de $10 \mathrm{t} /$ dia de capacidade. Um ano depois, foi lançada uma planta de escala industrial com produção de 220.000 t/dia. A tecnologia, empregada na obtenção do syngas, é a oxidação parcial do metano. (J.E. CONSULTANTS, 1999 e LURGI AG, 2006).

Atualmente, a maioria dos catalisadores é composta de óxido de cobre - óxido de zinco e contem aditivos como alumina que dão maior estabilidade no processo de conversão. A principal diferença entre as diversas plantas está na forma de obtenção e purificação do gás de síntese. As maiores empresas detentoras de patentes para esta tecnologia são: Lurgi A.G., Haldor Topsoe, Mitsubishi Gas Chemical, UhdE GmB, UOP e ICI.

\subsection{Obtenção do Metanol}

\subsubsection{Produção do Gás de Síntese}

Materiais compostos de carbono, tais como o carvão, o coque, GN, petróleo e seus derivados entre outros, podem ser consideradas como matéria prima para a produção do gás de síntese. O fator econômico está intrinsecamente ligado à disponibilidade destes recursos. A análise do consumo de energia e dos impactos ambientais, mostra que estes variam de acordo com o processo escolhido. O gás de síntese é caracterizado através de um número estequiométrico, denominado $\mathbf{S}$, obtido a partir da equação 1:

$$
S=\left(\frac{\mathrm{H}_{2}-\mathrm{CO}}{\mathrm{CO}+\mathrm{CO}_{2}}\right)(\text { Equação 4.1) }
$$

As frações dos elementos são expressas em porcentagem do volume (\%vol). O valor ideal para o $\mathrm{S}$ é 2,0. Quando $\mathrm{S}>2,0$, há excesso de $\mathrm{H}_{2}$ na composição do gás de síntese. Quando $\mathrm{S}<$ 
2,0, há falta de $\mathrm{H}_{2}$ e a estequiometria, portanto, não é mais a ideal para a obtenção do metanol. Dados da Lurgi (2004), consideram a faixa de 2,0-2,1, como sendo a ideal.

\subsubsection{Síntese do Metanol}

A síntese do metanol ocorre de acordo com as reações 4.1 e 4.2, sendo a estequiometria ideal de 1CO: $2 \mathrm{H}_{2}$. Na modelagem da planta, será adotada a estequiometria das reações 4.1 e 4.2.

$$
\begin{aligned}
& \mathrm{CO}+2 \mathrm{H}_{2} \underset{\leftarrow}{\leftarrow} \mathrm{CH}_{3} \mathrm{OH} \quad \Delta \mathrm{H}=-90,77 \mathrm{~kJ} / \mathrm{mol} \text { (Reação 4.1) } \\
& \mathrm{CO}_{2}+3 \mathrm{H}_{2} \underset{\leftarrow}{\leftarrow} \mathrm{CH}_{3} \mathrm{OH}+\mathrm{H}_{2} \mathrm{O} \Delta \mathrm{H}=-49,16 \mathrm{~kJ} / \mathrm{mol} \text { (Reação 4.2) }
\end{aligned}
$$

Em uma primeira passagem do gás de síntese pelo reator, apenas 50\% do volume deste é convertido a metanol. É nesse momento que o equilíbrio termodinâmico é atingido. Na seqüência do processo, o metanol e a água resultantes são condensados e removidos, e, o gás de síntese remanescente é recirculado, através de um loop existente no sistema. A figura 4.3 apresenta as rotas mais usuais para a produção de metanol a partir do gás natural. 


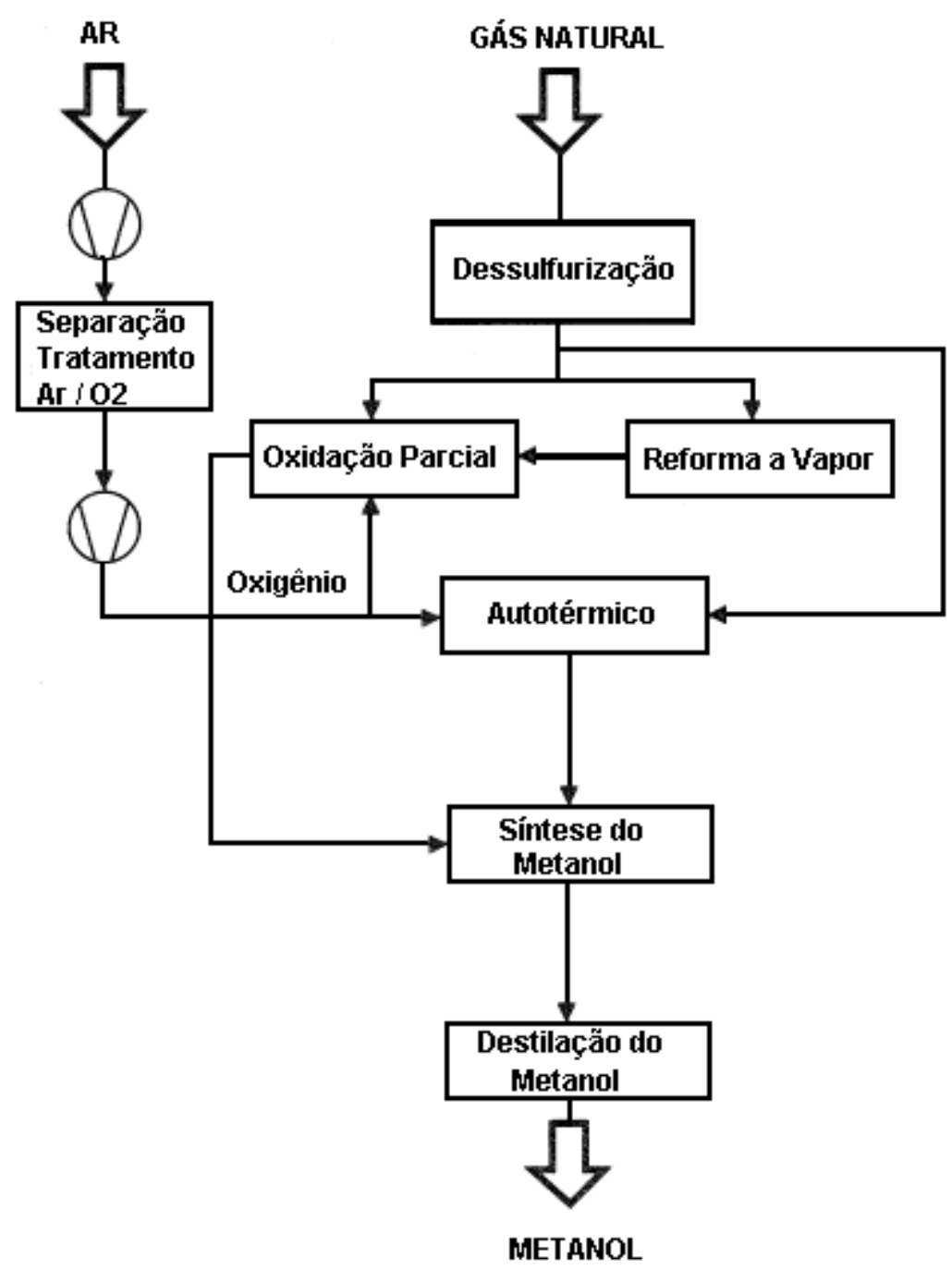

Figura 4.3. Principais rotas de produção de metanol a partir do gás natural Fonte: (elaboração própria) 
No diagrama, apresentado na figura 4.4, é possível acompanhar todo o processo de obtenção do metanol, incluindo o loop de síntese.

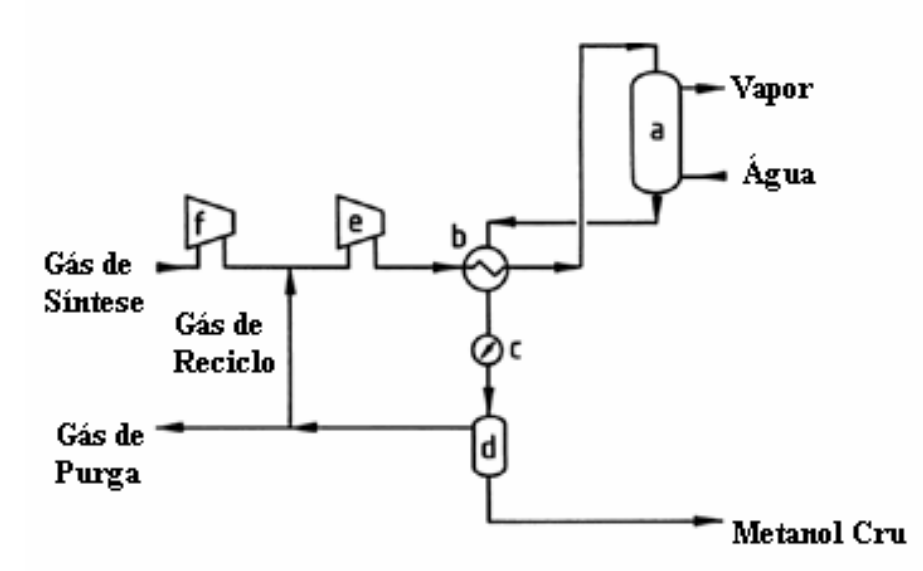

LEGENDA
a) Reator
b) Trocador de Calor
c) Cooler
d) Unidade de Separação
e) Compressor do Gás de Reciclo
f) Compressor do Gás
de Sintese (entrada)

\section{Figura 4.4. Diagrama do processo de produção do metanol, incluindo loop \\ Fonte: (FIEDLER, 2002; adaptação própria).}

O syngas da mistura gasosa (entrada do sistema) é, então, elevado a uma faixa de pressão de 5-10 MPa através de um compressor, normalmente multi-estágio (f). O gás remanescente é adicionado ao sistema, antes do estágio de recirculação. Um trocador de calor (b) é o responsável por transferir a energia do gás quente da saída do reator para o gás de entrada.

A formação exotérmica do metanol toma corpo no reator (a) a uma faixa de temperatura entre $200-300^{\circ} \mathrm{C}$, e, este calor poderá ser dissipado em um ou mais estágios, variando de acordo com o lay-out final do processo. A mistura é, então, resfriada por um cooler (c) após sua passagem por um trocador de calor (b). O calor proveniente da condensação (do metanol e da água), também pode ser utilizado em outras etapas.

Antes de ser destilado, o metanol cru é separado da fase gasosa através da unidade de separação (d) num separador. O gás proveniente da unidade de separação é enviado ao loop, entrando no compressor de gás de reciclo (e). A quantidade de gás de purga do loop é definida de acordo com a concentração e o montante absoluto de substâncias inertes presentes, bem como do 
número estequiométrico $\mathbf{S}$. $\mathrm{O} \mathrm{H}_{2}$ pode ser utilizado para ajustar a composição do gás obtido, a fim de que se atinja o valor ideal de $\mathbf{S}$. Outra forma de recuperação do gás de purga ocorre através de um processo denominado PSA. O gás pode, também, ser utilizado no reformador de calor.

\subsubsection{Destilação do Metanol}

O metanol, que deixa o reator, contem água e outras impurezas. A composição e os volumes de saída dependem de fatores, tais como as condições das reações, o gás de alimentação, o tipo e a vida útil do catalisador. O metanol cru apresenta-se, levemente alcalino, devido à adição de uma pequena quantidade de soda cáustica aquosa, utilizada para neutralizar os ácidos carboxílicos formados no processo. As impurezas, contidas no metanol cru, são separadas, geralmente, em dois estágios. Primeiramente, todos os componentes cujas temperaturas de ebulição sejam menores do que a do metanol, são removidos em uma coluna do tipo light ends. O metanol puro é destilado em uma ou mais colunas de destilação. Se as colunas operarem a pressões distintas, o calor, proveniente da condensação do vapor da coluna, que opera com maior pressão, poderá ser utilizado como energia térmica para a coluna, que trabalha a pressão mais baixa.

As figuras 4.5 e 4.6 apresentam, respectivamente, as etapas da produção de metanol através do processo da ICI (low-pressure methanol process) e do processo da Lurgi (low-pressure methanol process). 


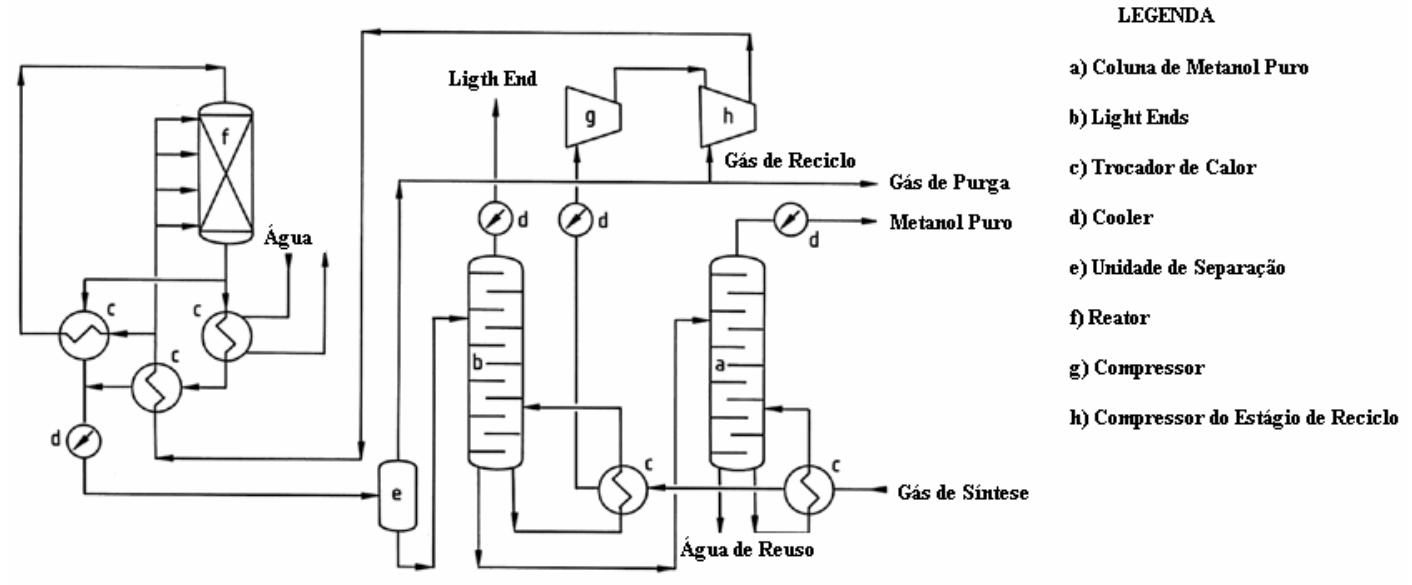

Figura 4.5. Diagrama de processo de obtenção de metanol da ICI

Fonte: (FIEDLER at al, 2002)

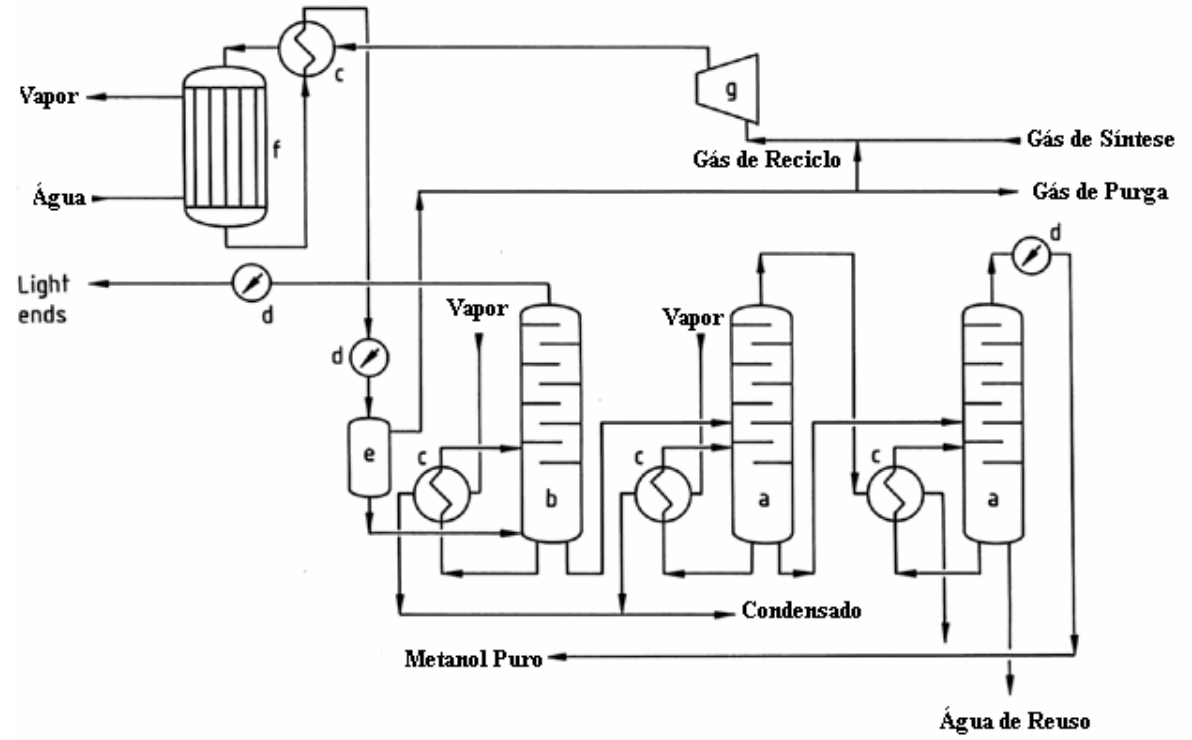

LEGENDA

a) Colura de Metanol Puro

b) Light End

c) Trocador de Calor

d) Cooler

e) Unidade de Separação

f) Reator

g) Compressor do Estágio de Reciclo

Figura 4.6. Diagrama de processo de obtenção de metanol da Lurgi

Fonte: (FIEDLEr at al, 2002, adaptação própria ) 


\subsection{Exemplo de uma planta industrial de produção de metanol}

Methanol Holding Trinidad (MHTL) Limited localizada em Trinidad e Tobago

A primeira planta de produção, em Trinidad e Tobago, iniciou suas atividades em 1983, com uma planta com capacidade instalada de 1,2 Mt/ano. Outras cinco plantas foram instaladas e a capacidade anual de produção daquele país é de $6 \mathrm{Mt} / \mathrm{ano.}$

O complexo industrial da MHTL Point Lisas utiliza a tecnologia da ICI Low-Pressure Methanol Synthesis Process. O gás natural, utilizado como matéria-prima, contem cerca de 96\% de metano. O metanol obtido apresenta um grau de pureza da ordem de 99,9\%.

\subsubsection{Etapas do processo}

O processo de síntese do metanol é divido em quatro etapas:

\subsubsection{Purificação da Matéria-Prima}

O GN e a água necessitam ser purificado antes do uso. O GN apresenta compostos sulfurosos, como impurezas, que devem ser removidas, a teores menores do que 1,0 ppm. As impurezas presentes na água devem ser removidas a teores menores do que 1,0 bpm. Essa água é utilizada para a produção de vapor. A não remoção de impurezas compromete a eficiência energética do processo, podendo causar um acúmulo indesejável de sujidades nos equipamentos.

\subsubsection{Reforma}

No processo de reforma, que ocorre na presença de catalisador base níquel, a conversão do $\mathrm{GN}$ e do vapor de água em gás de síntese (frações de $\mathrm{H}_{2}, \mathrm{CO}_{2}$ e $\mathrm{CO}$ ) representado pelas reações 4.3 e $4.4 \mathrm{O}$ CO é o produto intermediário para a obtenção do metanol.

$$
\begin{gathered}
\mathrm{CH} 4+\mathrm{H}_{2} \mathrm{O} \underset{\leftarrow}{\rightarrow} \mathrm{CO}+3 \mathrm{H}_{2}(\text { Reação 4.3) } \\
\mathrm{CO}+\mathrm{H}_{2} \mathrm{O} \underset{\leftarrow}{\rightarrow} \mathrm{CO}_{2}+\mathrm{H}_{2}(\text { Reação 4.4) }
\end{gathered}
$$


Esta composição obtida apresenta boa eficiência na conversão do gás de síntese para metanol. Este processo é levado adiante no reformador localizado dentro de uma fornalha, onde o combustível queimado é o GN.

\subsubsection{Síntese do Metanol}

Após a remoção do calor adicional do gás reformado, este é comprimido e enviado à unidade de síntese de metanol. Nesta etapa do processo, os reagentes são convertidos em metanol de acordo com as reações 4.5, 4.6 e 4.7

$$
\begin{aligned}
& \mathrm{CO}+2 \mathrm{H}_{2} \underset{\leftarrow}{\leftarrow} \mathrm{CH}_{3} \mathrm{OH} \quad \text { (Reação 4.5) } \\
& \mathrm{CO}+\mathrm{H}_{2} \mathrm{O} \underset{\leftarrow}{\stackrel{\mathrm{CO}_{2}}{+}+\mathrm{H}_{2} \quad \text { (Reação 4.6) }} \\
& \mathrm{CO}_{2}+3 \mathrm{H}_{2} \underset{\leftarrow}{\leftarrow} \mathrm{CH}_{3} \mathrm{OH}+\mathrm{H}_{2} \mathrm{O} \text { (Reação 4.7) }
\end{aligned}
$$

O produto formado apresenta volumes de $68 \%$ de metanol cru e $31 \%$ de água na sua composição. Os subprodutos formados, também são usados.

Segundo a MHTL (2005), obtem-se uma taxa de conversão em metanol de 5\% a cada passagem pelo reator. Por essa razão, utiliza-se um sistema de loop que absorve os compostos não transformados, aquecendo-os e enviando-os novamente ao processo de síntese. Os compostos não transformados são denominados gás não reagido. A reciclagem contínua do gás de síntese resulta na formação de gases inertes no sistema. O gás de reciclo é, continuamente, removido e enviado para ser queimado como combustível no reformador. O metanol cru obtido é condensado e enviado para a etapa de purificação. 


\subsubsection{Purificação do Metanol}

A solução de metanol obtida (mistura de $68 \%$ produto e $31 \%$ água) é purificada em duas etapas distintas através de colunas de destilação, denominadas coluna de topping e coluna de refino. O produto resultante apresenta $99 \%$ de pureza e é classificado como metanol refinado de classe AA.

\subsection{Usos e Aplicações do Metanol}

As duas aplicações mais importantes do metanol estão relacionadas ao setor químico e ao seu uso como fonte de energia, seja esta direta ou indireta. Seu uso como combustível automotivo e, também, em célula combustível é uma forma direta de energia. Já, a sua síntese para a obtenção do dimetileter (DME) e do metiltérciobutileter (MTBE) e sua conversão em gasolina, (através do processo Methanol to Gasoline - MTG) são consideradas aplicações indiretas de seu uso como energético.

Uma terceira aplicação do metanol é no setor petroquímico para a obtenção de olefinas leves, etileno e propileno, através do processo denominado Methanol to Olefins - MTO. Este processo ainda não é muito difundido, encontrando-se em fase de aprimoramento, principalmente, pela empresa UOP. Atualmente, as empresas petroquímicas de primeira geração acreditam que este processo pode ser uma forma de diversificar as fontes de matéria-prima a ser utilizada na obtenção de olefinas leves.

\subsection{Derivados do Metanol}

As rotas, mais comumente seguidas, relacionadas à produção dos derivados do metanol, estão apresentadas no fluxograma da figura 4.6. 


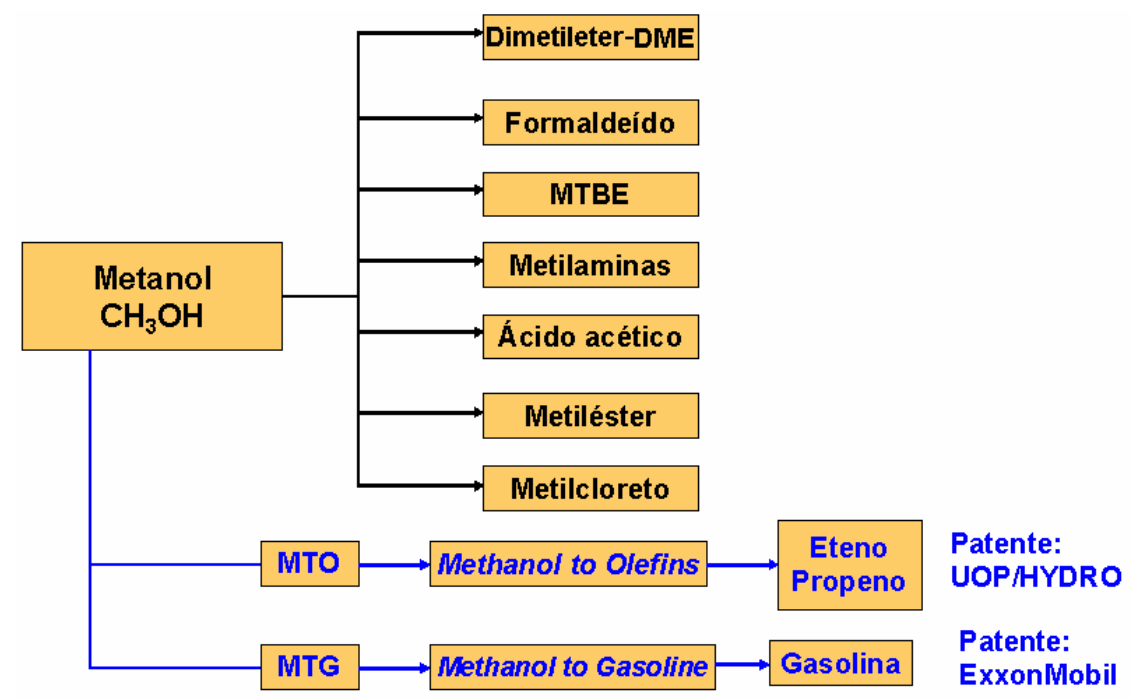

Figura 4.6. Diagrama dos derivados de metanol

Fonte: (GEROSA, 2006)

\subsubsection{Dimetiléter - DME}

$\mathrm{O}$ DME, de fórmula estrutural $\mathrm{CH}_{3} \mathrm{OCH}_{3}$, é considerado como o mais simples dos éteres. É utilizado, principalmente, como propelente em aerosóis, substituindo o Cloro-Fluor-Carbono (CFC), nas indústrias de tintas, cosméticos e agricultura. É considerado como inofensivo à saúde humana.

A rota mais comum para a produção do DME é a sua obtenção a partir da desidratação do metanol, sendo este último, geralmente, obtido a partir do GN. A transformação do syngas em metanol, operação denominada síntese de metanol, ocorre na presença de um catalisador a base de cobre e óxido de zinco $(\mathrm{Cu} / \mathrm{ZnO})$, normalmente, estabilizado com adição de alumina, visando evitar o seu envelhecimento prematuro, que pode ser causado pela presença de impurezas no gás de síntese, como por exemplo, o gás sulfídrico $\left(\mathrm{H}_{2} \mathrm{~S}\right)$. A síntese do metanol ocorre na faixa de temperatura de $220-230^{\circ} \mathrm{C}$ e sob pressão de $5 \mathrm{MPa}$.

A reação de desidratação do metanol, a fim de obter-se o DME, ocorre na presença de um catalisador base alumina ou aluminosilicatos (INT, 2005).

O processo de síntese direta, para a obtenção do DME a partir do syngas, ocorre na faixa de temperaturas entre $210-290^{\circ} \mathrm{C}$ e com pressões em torno de 3-10MPa (INT, 2005). Para tal, é necessária a escolha de catalisadores bifuncionais ou misturas de catalisadores. É importante que 
os catalisadores apresentem as funções hidrogenantes, para a síntese do metanol, e desidratantes, para a obtenção do DME.

$\mathrm{Na}$ etapa de purificação é necessário implantar sistemas de remoção de dióxido de carbono $\left(\mathrm{CO}_{2}\right)$, que pode ser utilizado na produção de gás de síntese, a partir do gás natural como forma de ajustar a relação estequiométrica de $\mathrm{H}_{2}$ :CO.

Em termos energéticos, a síntese direta do DME e a síntese do metanol são altamente exotérmicas, liberando grande quantidade de calor, que pode ser reaproveitado através de sistemas de trocadores de calor instalados ao longo do processo.

As principais empresas detentoras das patentes para a produção de DME, seja através da síntese direta, ou através da desidratação do metanol são: Haldor Topsoe, Linde AG, Toyo Engineering e Mitsubishi. A tabela 4.1 mostra as propriedades do DME em comparação ao propano, metano, metanol e óleo diesel.

Tabela 4.1 - Propriedades físico-químicas dos combustíveis

\begin{tabular}{lccccc}
\hline $\begin{array}{l}\text { Elemento } \\
\text { Propriedades }\end{array}$ & DME & Propano & Metano & Metanol & Óleo diesel \\
\hline Temperatura de Ebulição $\left({ }^{\circ} \mathrm{C}\right)$ & $-25,1$ & -42 & $-161,5$ & 64,6 & $180-370$ \\
Densidade (fase líquida g/cm3 20 $\left.{ }^{\circ} \mathrm{C}\right)$ & 0,67 & 0,49 & & 0,79 & 0,84 \\
Densidade (fase gasosa, relativa ao ar) & 1,59 & 1,52 & 0,55 & & \\
Pressão de Vapor Saturado (atm, 25C) & 6,1 & 9,3 & 246 & & \\
Temperatura de Ignição $\left({ }^{\circ} \mathrm{C}\right)$ & 235 & 470 & 650 & 450 & 250 \\
Limite de Explosividade (\%) & $3,4-17$ & $2,1-9,4$ & $5,0-15$ & $5,5-36$ & $0,6-6,5$ \\
índice de Cetana & $55-60$ & 5 & & 5 & $40-55$ \\
Capacidade Calorífica (kcal/Nm3) & 14.200 & 21.800 & 8.600 & & \\
Capacidade Calorífica (kcal/kg) & 6.900 & 11.100 & 12.000 & 4.800 & 10.000 \\
\hline
\end{tabular}

Fonte: (INT, 2005)

Aplicação: o DME apresenta grande versatilidade quanto ao seu uso. Destacamos três grandes aplicações, como na indústria química para a fabricação de formaldeído, seu uso como energético, principalmente, como substituto do GLP e óleo diesel de refinaria, e também, no setor petroquímico para a obtenção de olefinas leves como etileno, propileno e butadieno. 
Esta gama de aplicação do DME deve-se ao fato de suas características físico-químicas serem próximas as do GN e GLP.

\subsubsection{Formaldeído}

$\mathrm{O}$ formaldeído, $\mathrm{CH}_{2} \mathrm{O}$, é considerado como um dos mais versáteis produtos químicos, podendo seu uso, ser direcionado a várias finalidades. É o mais simples e o mais reativo dos aldeídos. Este é obtido através da oxidação catalítica do metanol, conforme reação 4.8.

$$
\mathrm{CH}_{3} \mathrm{OH}_{(\mathrm{g})}+1 / 2 \mathrm{O}_{2} \leftrightarrows \mathrm{CH}_{2} \mathrm{O}_{(\mathrm{g})}+\mathrm{H}_{2} \mathrm{O}_{(\mathrm{g})} \quad \Delta \mathrm{H}=-148,4 \mathrm{~kJ} / \mathrm{mol} \text { (Reação 4.8) }
$$

Os processos mais antigos, ainda em operação, utilizam catalisador com base lâminas de prata de micro espessura e sua temperatura de operação é relativamente alta, em torno de $500^{\circ} \mathrm{C}$. Os processos mais recentes utilizam catalisadores a base de óxido de ferro-óxido de molibdênio. Costuma-se utilizar óxidos de cromo ou cobalto para incrementar o catalisador. A reação de oxidação é exotérmica e estes processos mais novos operam na faixa de temperatura entre 400$425^{\circ} \mathrm{C}$ e a pressão atmosférica. Excesso de ar costuma ser utilizado para manter a razão metanol: ar abaixo do limite de explosividade. (MATAR e HATCH, 2002).

Em termos mundiais, conforme a sociedade francesa de química (2005), 40\% da produção de metanol é utilizada para a obtenção de formaldeído. Já no cenário nacional, conforme dados da ABIQUIM (2006), este valor está em torno de 44,3\%.

Aplicações: pode ser utilizado na fabricação de resinas (adesivas e aglomerantes), quando reagido com uréia, fenol e melaninas. Estas resinas são aplicadas na indústria moveleira, principalmente na produção de aglomerados, compensados e móveis mais rústicos. Também podem ser usadas nas indústrias têxteis, de borracha, entre outras (DISTELDORF, 2002). Como intermediário químico é aplicado na síntese de trimetilolpropano e neopentil glicol, os quais são aplicados na fabricação de poliuretano e poliester, resinas sintéticas e óleos lubrificantes

sintéticos. A aplicação direta do formaldéido ocorre como agente inibidor de corrosão nas indústrias metalúrgicas, na produção de filmes fotográficos, fabricação de circuitos impressos, entre outros. 


\subsection{3 Ácido Acético}

A carbonilação do metanol é, atualmente, a principal rota para a produção de ácido acético (MATAR e HATCH, 2002). Este é um processo exotérmico, onde o metanol é reagido com monóxido de carbono, conforme mostrado na reação 4.9 .

$$
\mathrm{CH}_{3} \mathrm{OH}+\mathrm{CO} \leftrightarrows \mathrm{CH}_{3} \mathrm{COOH} \Delta \mathrm{H}=-138,6 \mathrm{~kJ} / \mathrm{mol} \quad \text { (Reação 4.9) }
$$

Este processo foi, primeiramente, desenvolvido pela Basf, em 1913, operando a altas temperaturas $\left(250^{\circ} \mathrm{C}\right)$ e altas pressões (70 bar) e catalisador a base de cobalto iodado. Em 1960, a Monsanto desenvolveu um processo que operava a pressão atmosférica, temperatura em torno de $150^{\circ} \mathrm{C}$, cujo catalisador era a base de ródio iodado, o qual se apresentou mais seletivo, permitindo um rendimento da conversão na faixa de $99 \%$. O processo da BASF apresentava rendimento em torno de 90\% (CHEUNG, TANKE e TORRENCE, 2002).

Segundo outra fonte de pesquisa (MATAR e HATCH, 2002), o catalisador da Monsanto era base ródio e adicionava-se $\mathrm{CH}_{3} \mathrm{I}$, o qual agia como um acelerador.

A tecnologia da Monsanto é a mais comercialmente utilizada nos dias de hoje.

Aplicações: conforme Matar e Hatch (2002), a maior parte do ácido acético é utilizado para a produção de acetato de vinila, que é aplicado na produção de adesivos, filmes, papel e tecidos. O ácido cloroacético é utilizado na manufatura de produtos químicos, como glicerina, celulose, carboxi-metil. Outros importantes derivados são os ésteres de ácido acético, anidrido acético. Outros setores nos quais o ácido acético é aplicado são: farmacêuticos, fabricação de tintas e corantes e inseticidas.

\subsubsection{Metiltérciobutileter - MTBE}

O MTBE é produzido através da reação do metanol com um isobutano, conforme reação.<smiles>C[14CH2][14CH2][14CH2][14CH2]OC(C)(C)C</smiles> 
Este processo ocorre na denominada fase líqüida e a baixas temperaturas, normalmente, em torno de $50^{\circ} \mathrm{C}$, na presença de um catalisador sólido, de base ácida. (MATAR e HATCH, 2002 e UDO at al, 2002).

Durante o processo, ocorrem as reações de hidratação do isobuteno em terciário butil álcool, simultaneamente, com a desidratação do metanol em dimetiléter (DME). Em muitos casos, os produtos destas reações aparecem como subprodutos do processo.

Devido às limitações impostas pelo equilíbrio químico da reação, obtém-se apenas 92\% de rendimento no processo como um todo e, para que este valor seja atingido, é necessário uma equivalência molar entre os reagentes (metanol e isobuteno), além de uma temperatura de processo em torno de $59,85^{\circ} \mathrm{C}$ (Udo at al, 2002).

Aplicação: seu maior consumo é como aditivo da gasolina automotiva. Sua adição a este combustível ocorre, devido ao seu alto número de octanas, causando uma redução na quantidade de $\mathrm{CO}$ e hidrocarbonetos não reagidos, eliminados na combustão da gasolina.

\subsubsection{Hidrocarbonetos}

A reação de conversão catalítica do metanol a hidrocarbonetos é conhecida há mais de cem anos, porém, no início, só era considerada estável, se ocorresse em pequena escala e os catalisadores utilizados eram a base de zinco com sulfato de alumina.

No ano de 1975 (Matar e Hatch, 2002), um grupo de pesquisadores da empresa Mobil redescobriu este processo quando tentava obter compostos oxigenados a partir do metanol, utilizando como catalisador a zeólita ZSM-5. Mas, como resultado, obtiveram hidrocarbonetos.

Foi com o contínuo aumento do preço do petróleo que a Mobil voltou a atenção aos hidrocarbonetos obtidos, já que estes eram do grupo $\left(\mathrm{CH}_{2}\right)_{\mathrm{n}}$ (parafina + olefinas + aromáticos). Nesta faixa dos hidrocarbonetos encontra-se a gasolina. Pode-se considerar que a passagem do metanol pela ZSM-5 é uma reação de desidratação e oligomerização. Segundo Matar e Hatch (2002), a reação simplificada deste processo pode ser assim descrita (reação 4.11).

$$
\mathrm{nCH}_{3} \mathrm{OH} \leftrightarrows\left(\mathrm{CH}_{2}\right)_{\mathrm{n}}+\mathrm{nH}_{2} \mathrm{O} \quad \text { (Reação 4.11) }
$$


Temos, então, o surgimento de dois processos distintos: Methanol to Gasoline (Metanol para Gasolina) - MTG e o Methanol to Olefins (Metanol para Olefinas) - MTO .

\subsubsection{Methanol to Gasoline - MTG}

Este foi o processo que obteve a adesão mais rápida em escala industrial. Entre os anos de 1985 e 1986, foi inaugurada em Taranaki - Nova Zelândia, a Synthetic Fuel Corporation Gas to Gasoline Plant, uma planta industrial que obtém o metanol a partir do gás natural e, deste, a gasolina. Desde sua partida, produz cerca de 600.000 t/ano de gasolina (AMIGÓ, 2004; MATAR e HATCH, 2002).

Segundo dados de outra fonte de pesquisa consultada, o New Zealand Institute of Chemistry (2005), em 1979, o governo da Nova Zelândia optou por empregar a tecnologia MTG da Móbil como uma alternativa para reduzir a dependência do petróleo. A planta foi construída na região de Motonui e apresenta capacidade diária de produção de 14.000 bl/d e com grau de octanagem na faixa de 92-94.

A gasolina, ali produzida, pode ser transportada, através de navio até a refinaria Marsden Point para ser misturada com outras gasolinas, a fim de se obter este combustível nos padrões do país em questão (New Zealand Institute of Chemistry, 2005)

Neste processo, a primeira etapa consiste na conversão do metanol em dimetiléter na presença de um catalisador $\gamma-\mathrm{Al}_{2} \mathrm{O}_{3}$. Na seqüência, ocorre uma conversão de $100 \%$ do dimetiléter em hidrocarbonetos através de uma série de reatores de leito fixo, dispostos de forma paralela e, que trabalham adiabaticamente. A faixa de temperatura oscila de 340 a $407^{\circ} \mathrm{C}$. A reação é exotérmica, $\Delta \mathrm{H}=-55 \mathrm{~kJ} / \mathrm{mol}$ (ÁMIGO, 2004)

Os produtos obtidos neste processo apresentam a seguinte proporção:

$85 \%$ Gasolina;

13 a 14\% Condensados ( Propano, Butano e Iso-butano);

1 a 2\% Água; 


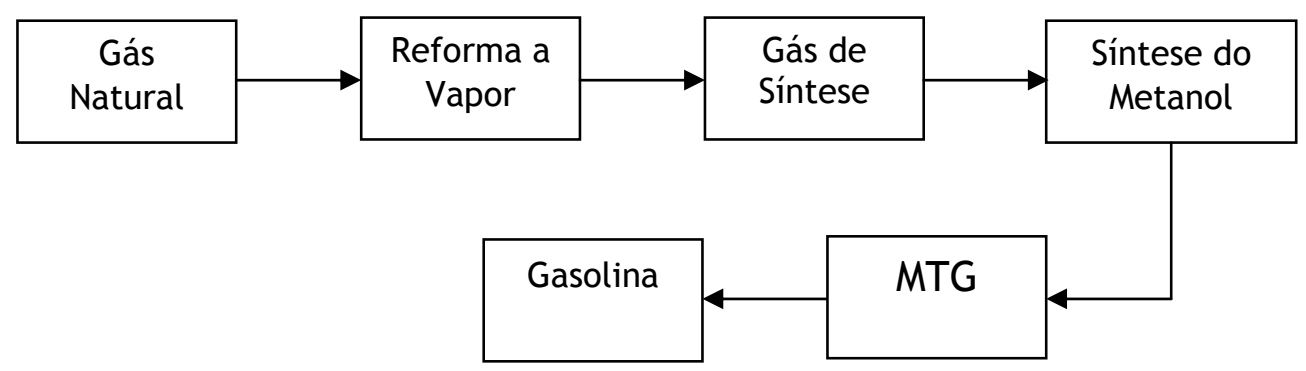

Figura 4.7. Diagrama do processo MTG

Fonte: (elaboração própria)

\subsubsection{Methanol to Olefins - MTO}

A tecnologia MTO, também teve início nos laboratórios da Mobil e sua base de aprimoramento foi o processo MTG.

O MTG utiliza como catalisador o ZM-5 e, na obtenção da gasolina, uma série de olefinas são formadas (cerca de 13, 14\% em volume). Este foi o ponto de partida para a obtenção de um processo catalítico que resultasse em maior proporção de olefinas.

Em 1990, um catalisador denominado SAPO-34 (Sílica, Alumina e Fosfato) foi desenvolvido para permitir a obtenção de uma elevada quantidade destas olefinas.

A empresa UOP aliou-se a HYDRO e desenvolveu o processo de conversão do metanol para olefinas, conhecido como UOP/HYDRO MTO e, diz a empresa, ser esta uma forma econômica e viável de converter gás natural em olefinas (Gas To Olefins - GTO). A planta é recomendada para regiões próximas aos campos produtores de gás, ou onde o acesso ao mesmo seja fácil, ou seja, com baixo custo de transporte.

O uso do metanol, para a produção de olefinas leves, agregará valor a este, reforçando o seu valor como commodity, ainda que aumentando a versatilidade de matéria-prima petroquímica.

Conforme a tabela 4.2, este processo apresenta flexibilidade de ajuste na razão entre a produção de etileno e propileno, a qual se ajusta através da demanda do mercado. 
Tabela 4.2 - Versatilidade da produção de olefinas leves no processo UOP/HYDRO

\begin{tabular}{lrr}
\hline $\begin{array}{l}\text { Produtos } \\
\text { (razão em peso) }\end{array}$ & $\begin{array}{c}\text { Etileno } \\
\text { Propileno } \\
\text { Alta produção }\end{array}$ & Alta produção \\
\hline Etileno & 0,57 & 0,43 \\
Propileno & 0,43 & 0,57 \\
Buteno e mais pesados & 0,19 & 0,28 \\
$\mathbf{C}_{\mathbf{3}}=/ \mathbf{C}_{\mathbf{2}}=$ & 0,77 & 1,33 \\
\hline
\end{tabular}

Fonte: (UOP, 2004)

Atualmente, há uma planta piloto localizada na Noruéga, onde o processo de conversão do metanol em olefinas consegue atingir um fator de $99,8 \%$ e, é considerado como um processo estável. A razão que relaciona a quantidade de entrada do metanol e a saída de olefinas não foi divulgada pelo consórcio UOP/HYDRO.

\subsection{Estado da Arte da Tecnologia de Produção de Metanol}

\subsubsection{Tecnologia Haldor Topsoe (Haldor Topsoe, 2006)}

De acordo com informações da empresa (catálogos técnicos e www.haldor.com), o GN é a matéria-prima predominante para a produção de metanol. Todas as plantas baseadas neste insumo são compostas de três etapas diferentes, e complementares entre si e de uma seção de utilidades: preparação do gás de síntese e reforma, síntese do metanol, destilação do metanol e utilidades. O lay-out típico de processo da Haldor Topsoe é apresentado na figura 4.9. 


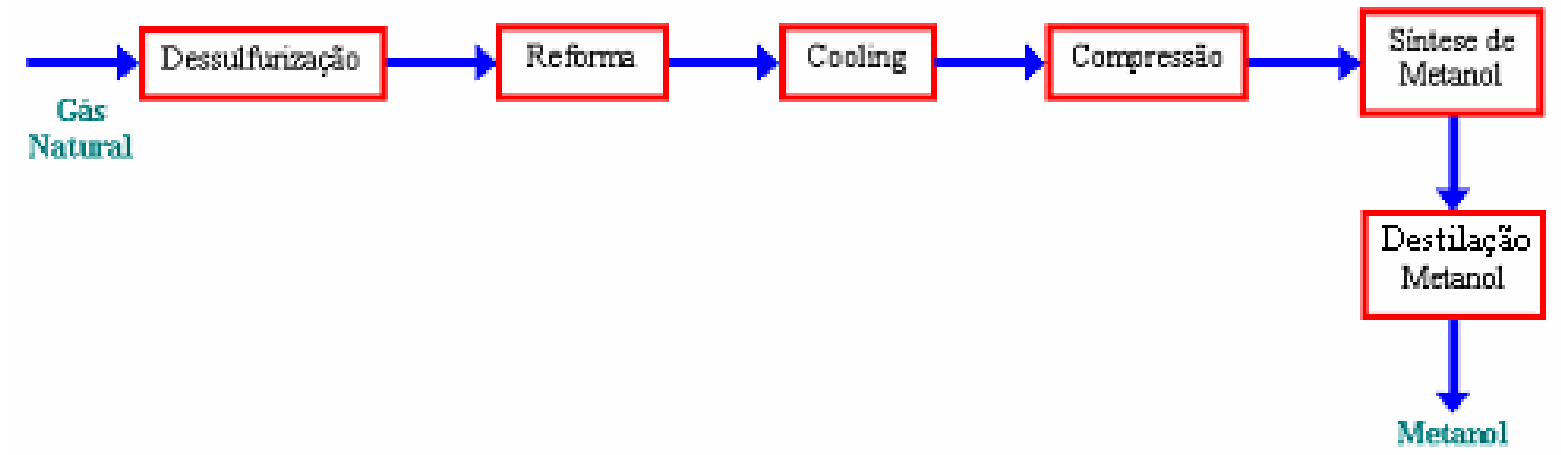

Figura 4.9. Diagrama de processo para produção de metanol Haldor Topsoe

Fonte: (HALDOR TOPSOE, 2006; adaptação própria)

O GN de entrada, se necessário pode passar por um estágio de compressão (isso requer uma unidade adicional). Em seguida, é dessulfurizado e enviado ao saturador, no qual é adicionado vapor de água. A unidade produtora de vapor é capaz de reaproveitar a água resultante da condensação do metanol destilado, fazendo com que o consumo total de água do processo seja menor do que nos convencionais. A mistura de GN e vapor de água é pré-aquecida e enviada ao reformador, onde ocorre a produção de gás de síntese. A Haldor destaca que há três tipos distintos de tecnologias de reforma, escolhidos de acordo com as necessidades de cada fabricante: convencional do tipo one-step - reformador tubular (SMR), two-step - reformador tubular (SMR), seguido de um reformador secundário a base de oxigênio e reforma autotérmica.

Após a reforma, o syngas é enviado para o synthesis loop, onde há: reatores adiabáticos em série (nas plantas de larga escala).

O metanol cru, obtido no loop de síntese, é enviado diretamente à estocagem (armazenamento) e o gás de reciclo é enviado a um compressor, após a etapa de purga dos gases inertes. Neste loop é compreendida também, a unidade de destilação do metanol, a qual pode ser projetada para que se obtenha produtos na faixa de graduação, conforme especificado pela U.S. Federal Grade AA Methanol. 


\subsubsection{Tecnologia Haldor Topsoe - Plantas de larga escala}

A Haldor considera como plantas de escala mundial, aquelas cuja produção diária esteja entre $1.500-5.000 \mathrm{Mt} / \mathrm{d}$.

A planta da Statoil, na Noruéga, utiliza a tecnologia two-step, e sua capacidade de produção é de $2.400 \mathrm{Mt} / \mathrm{d}$. Os reformadores utilizados proporcionam, diretamente, uma composição do syngas ideal para a síntese de metanol. Uma segunda planta, deste porte, localizada no Oriente Médio (nome da empresa não divulgado), está em fase de implementação. Como a capacidade de produção será de 3030 MTPD, a tecnologia a ser utilizada é a denominada straight tubular reforming. Com o uso desta tecnologia, aumenta-se a capacidade de produção de gás de síntese.

Para plantas com capacidade de produção maior ou igual a $10.000 \mathrm{Mt} / \mathrm{d}$, a Haldor dispõe de um reformador autotérmico, do tipo oxygen-blown, conforme demonstrado na figura 4.10.

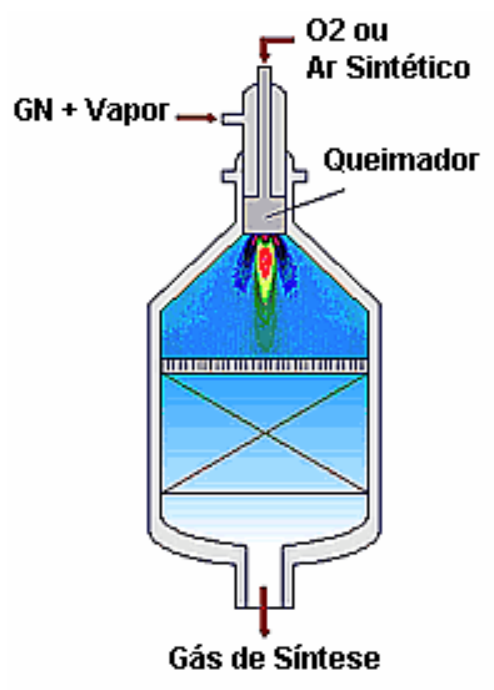

Figura 4.10. Reator ATR AirBlown - Haldor Topsoe Fonte: (HALDOR TOPSOE, 2005) 


\section{AMÔNIA}

\subsection{Histórico}

Em 1774, J.B. Priestley produziu, pela primeira vez, um composto denominado "amônia livre”. Dez anos depois, C.L. Berthollet reconheceu que a molécula de amônia era composta por $\mathrm{N}_{2}$ e $\mathrm{H}_{2}$. Foi somente em 1809, através do cientista W. Henry, que a razão volumétrica entre estes dois elementos foi descoberta, sendo esta 1: 3 e gerando a fórmula química $\mathrm{NH}_{3}$.

Em 1909, Fritz Haber e Carl Bosch desenvolveram o denominado processo Haber-Bosch para a síntese de amônia. Esse processo, utilizado até os dias de hoje, passou por aperfeiçoamentos. A primeira planta, localizada na Alemanha, pertencente a Basf Chemicals Group, entrou em operação no ano de 1913. O desenvolvimento da tecnologia de síntese da amônia apresenta uma certa semelhança com a síntese do metanol; tendo a Basf Chemical Group como a principal empresa no ponto de partida e desenvolvimento das respectivas tecnologias.

Conforme Basf (2006) e Bakemeier (1994), um estudo, realizado por Fritz Haber em 1908, apontava que o processo de síntese da amônia através da fixação do $\mathrm{N}_{2}$ no $\mathrm{H}_{2}$ era possível. Este requeria altas temperaturas e pressões, além de um catalisador especial. O projeto considerava uma etapa de reaproveitamento de toda a mistura que não fosse convertida na primeira passagem pelo reator de síntese da amônia, a qual se deu o nome de recycle synthesis loop.

A primeira planta mundial de síntese de amônia localizada em Oppau, Alemanha, entrou em operação no ano de 1913. A capacidade produtiva era de 7.200 toneladas anuais, que eram processadas, gerando 36.000 t/ano de sulfato de amônio. Uma segunda planta, com capacidade de 32.850 toneladas anuais (90 t/dia), foi instalada em 1917, em Leuna, Alemanha. Após o fim da I Guerra Mundial, sua capacidade foi aumentada para 127.750 toneladas anuais (350 t/dia).

\subsection{Processos de Produção de Amônia}

A produção ou síntese da amônia tem passado por constantes desenvolvimentos e adequações, que trouxeram melhorias significativas ao processo como um todo. 
O processo de obtenção de NH3 a partir do gás natural pode ser subdividido em:

-Obtenção do Gás de Síntese (syngas), compreendendo a produção do gás, a conversão do CO através da shift conversion e purificação do gás;

-Etapa de compressão;

-Síntese da amônia;

-Separação e recirculação (Synthesis Loop).

As etapas, que mais evoluíram ao longo do tempo, foram a obtenção do syngas, a recirculação e a compressão. Esta última, através do desenvolvimento de compressores especiais para os fluidos e para o processo como um todo (APPL, DANNSTADT-SCHAVERNHEIM, 2002). A figura 5.1 apresenta as rotas mais usuais para a produção de amônia.

\subsubsection{Obtenção do Gás de Síntese}

O objetivo desta etapa é produzir, da forma mais pura possível, a mistura gasosa de $\mathrm{N}_{2}$ e $\mathrm{H}_{2}$, na proporção 1:3. As matérias primas utilizadas são: água, ar e hidrocarbonetos. Entre eles está o gás natural, que é o mais utilizado.

Existem três processos mais importantes e mais utilizados para a produção de gás de síntese a partir de hidrocarbonetos:

-Reforma a Vapor do Metano (SMR - Steam Methane Reforming);

-Oxidação parcial do Metano (POX - Partial Oxidation of Methane);

-Reforma Autotérmica (ATR - Autothermal Reforming);

Estes processos foram descritos no terceiro capítulo (produção do gás de síntese).

\subsubsection{Remoção do CO Através da Shift Conversion}

$\mathrm{O}$ gás de saída dos reformadores apresenta em sua composição $\mathrm{H}_{2}, \mathrm{CO}, \mathrm{CO}_{2}, \mathrm{CH}_{4}$, (este, não reagido) e água. Esta última está ou no estado de vapor ou na forma condensada. A porcentagem em volume de cada componente e o estado físico da água dependem dos processos 
de reforma utilizados. Normalmente, a faixa de temperatura de saída desta mistura está entre 700$1400^{\circ} \mathrm{C}$ (Linde Group, 2006).

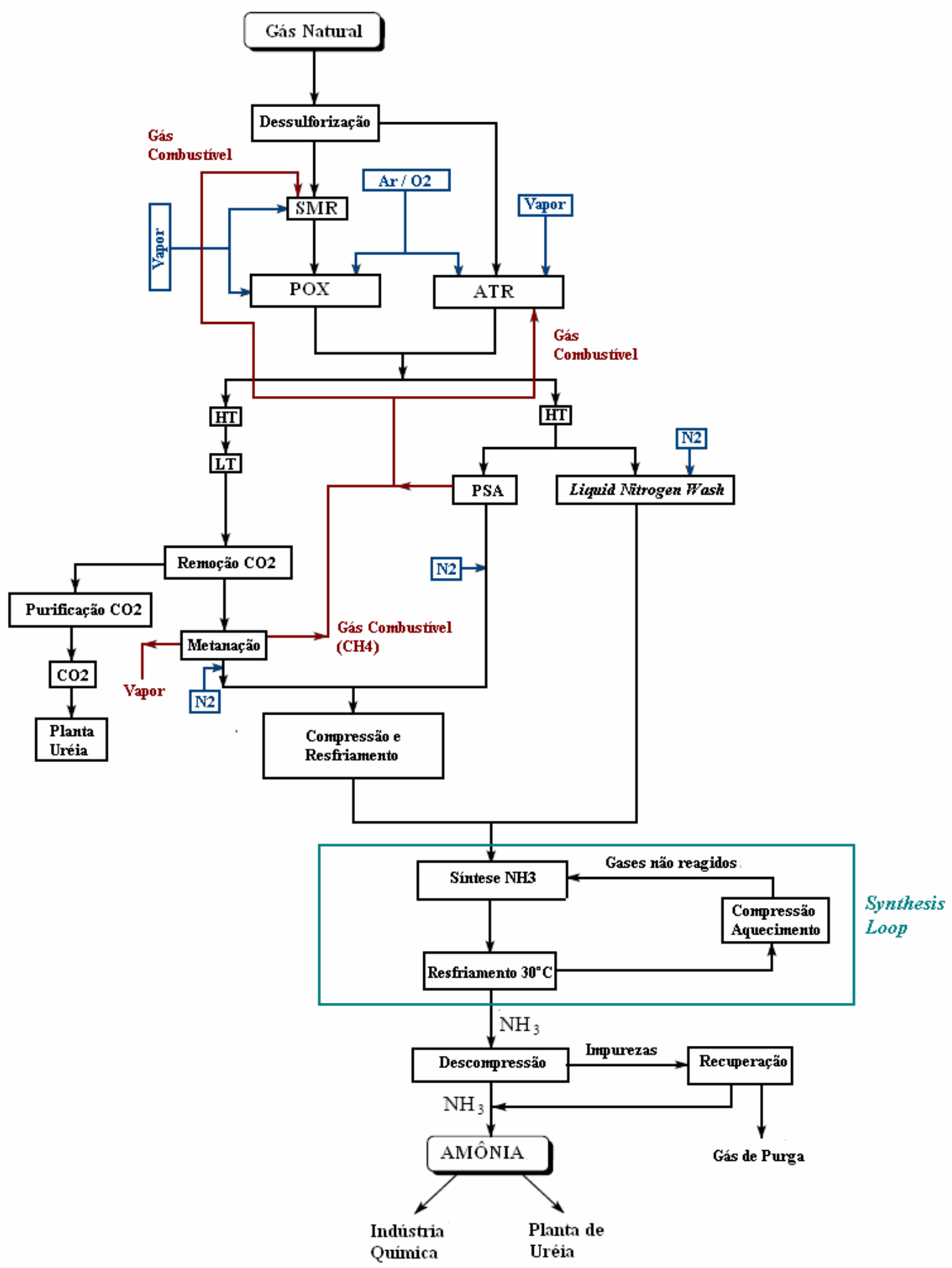

Figura 5.1. Rotas mais usuais para a produção de amônia

Fonte: (Elaboração própria) 
A reação conhecida como shift conversion (SC) é amplamente utilizada para a obtenção de $\mathrm{H}_{2}$ adicional; o $\mathrm{CO}$ é reagido com vapor e transformado em $\mathrm{CO}_{2}$ e $\mathrm{H}_{2}$, conforme mostrado na reação 5.1. O processo é exotérmico e limitado pelo equilíbrio químico, sendo este, dependente da temperatura da reação.

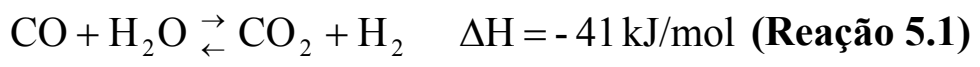

Há três distintos tipos de SC: shift conversion high temperature (HT), com faixa de temperatura de operação entre 300 e $450^{\circ} \mathrm{C}$ e $2,5 \% \mathrm{CO}$ em volume, na saída do gás (para o gás seco); shift conversion medium temperature (MT), também conhecida como isothermal shift conversion cuja faixa de temperatura varia de 220 a $250^{\circ} \mathrm{C}$, tendo a \% $\mathrm{CO}$ no gás de saída em torno de 0,5\% (para o gás seco); shift conversion low temperature (LT), com faixa de temperatura entre 180 e $250^{\circ} \mathrm{C}$ e cuja $\% \mathrm{CO}$ no gás de saída encontra-se em torno de $0,2 \%$. (Linde Group, 2006).

As condições citadas não são padrão para todas as patentes. Nas unidades desenvolvidas pela Johnson Matthey Catalysts (JM CATALYSTS), para a HT, a temperatura média de operação encontra-se em torno de $350^{\circ} \mathrm{C}$ e concentração de CO na saída varia de $10-15 \mathrm{~mol} \%$ até $1-2 \mathrm{~mol} \%$ (gás seco). Para uma maior produção de $\mathrm{H}_{2}$, a temperatura ideal do processo está em torno de $290^{\circ} \mathrm{C}$. Para a LT, a faixa de temperatura fica em torno de $190-210^{\circ} \mathrm{C}$ e concentração de CO na saída, entre $2 \mathrm{~mol} \%$ até 0,1-0,2 mol\% para o gás seco. (JOHNSON MATTHEY CATALYSTS, 2006).

Normalmente, o processo LT é aplicado na seqüência do HT com o intuito de remover ainda mais o CO presente na mistura gasosa. Conforme dados da Linde (2006), há necessidade de investimento adicional para plantas que produzem mais de $40.000 \mathrm{~m}^{3} / \mathrm{h}$ de $\mathrm{H}_{2}$. Ainda de acordo com Linde (2006), anteriormente, o processo LT era mais utilizado, tendo sido gradualmente substituído pelo PSA, representando uma maior eficiência na obtenção de $\mathrm{H}_{2}$, o que veio a possibilitar grau de pureza compreendido na faixa de 99,9 a 99,9999\%. Este depende da composição da mistura gasosa de entrada do processo. 
A curva, ilustrada na figura 5.2, representa a relação existente entre a temperatura, na qual as reações de shift conversion (LT, MT, HT) ocorrem e a porcentagem em volume de CO presente na saída do processo.

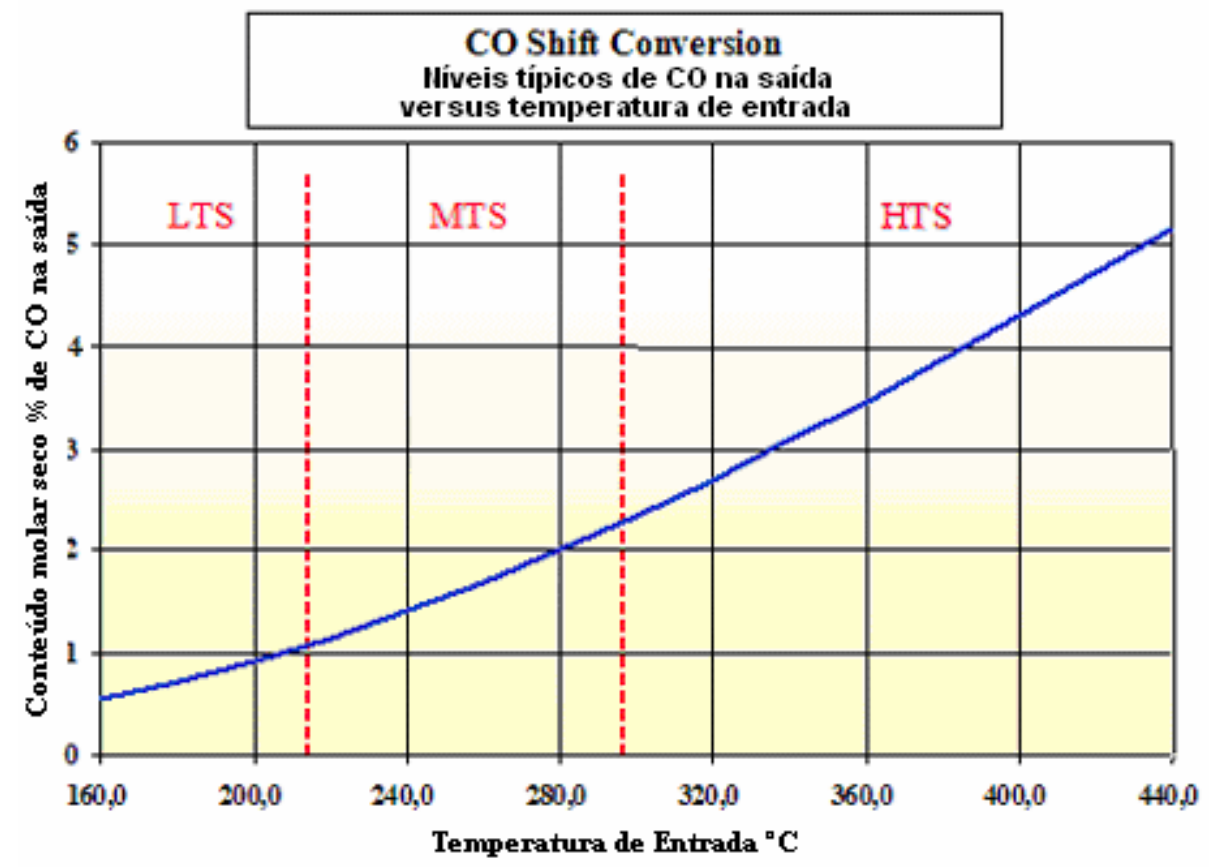

Figura 5.2. Relação entre a porcentagem em volume de CO presente na saída do processo versus a temperatura de operação

Fonte: (LINDE GROUP, 2006, adaptação própria)

Com respeito aos processos de shift conversion, existe a ressalva de que o catalisador utilizado na LT é extremamente sensível a compostos sulfurosos e clorídricos, não sendo recomendados quando o gás de síntese é obtido somente a partir da oxidação parcial não catalítica do metano. 


\subsubsection{Remoção de $\mathrm{CO}_{2}$}

$\mathrm{O} \mathrm{CO}_{2}$, produzido a partir da shift conversion, deve ser quase totalmente removido antes de o gás entrar para a síntese de amônia. A escolha pelos processos de remoção depende não somente da matéria-prima de entrada, quanto do processo de sua conversão em gás de síntese.

A concentração de $\mathrm{CO}$ bem como de outros gases é um dado importante na escolha dos processos de remoção do $\mathrm{CO}_{2}$, já que estes apresentam uma certa limitação.

Para as plantas de POX que utilizam $\mathrm{N}_{2}$ líqüido na lavagem do gás, a concentração máxima de $\mathrm{CO}_{2}$ permitida deve ser menor que 5ppm (Linde, 2006). Para plantas de SMR que utilizam o processo de metanação, uma faixa de concentração de 0,01 a $0,1 \%$ de $\mathrm{CO}_{2}$ do volume em questão, já pode ser considerada satisfatória.

Nas plantas que utilizam uma solução aquosa de cobre para a remoção do $\mathrm{CO}$, a quantidade de $\mathrm{CO}_{2}$ presente no gás de saída pode atingir valores na faixa de $0,2-0,5 \%$ de volume (BAKEMEIER at al, 1994)

Outros importantes fatores, que influenciam na escolha do método de remoção do $\mathrm{CO}_{2}$, são a pressão parcial do syngas cru e a presença ou não de compostos sulfurosos neste. Outros critérios a ser considerados são a flexibilidade do processo, demanda de energia, custo de investimento e manutenção.

Normalmente, a remoção do $\mathrm{CO}_{2}$ ocorre através da passagem da mistura gasosa por solventes físicos ou químicos. Solvente químico, também caracterizado como solvente de absorção, é aquele que ao entrar em contato com o $\mathrm{CO}_{2}$ produz uma reação do tipo reversível. Solvente físico é que dissolve o $\mathrm{CO}_{2}$ através de meios físicos.

Para a escolha do solvente ideal, deve-se levar em conta informações, tais como: o processo de reforma utilizado para a obtenção do syngas, a pressão parcial do $\mathrm{CO}_{2}$ e a presença ou não de compostos sulfurosos ( BAKEMEIER at al, 1994).

Os solventes químicos são mais recomendados quando o syngas é obtido a partir do SMR, pois está isento de compostos sulfurosos e o $\mathrm{CO}_{2}$ apresenta pressão parcial entre 0,4-0,7 MPa. Entre os solventes mais utilizados estão as soluções aquosas de carbonato de potássio e as alcanolaminas. Aminas primárias e secundárias, tais como monoetanolamina (MEA) e dietanolamina (DEA) respectivamente, são utilizáveis porque absorvem o $\mathrm{CO}_{2}$ rapidamente, porém o processo apresenta um alto consumo energético. 
Atualmente, as aminas terciárias, tais como trietanolamina (TEA) e metildietanolamina (MDEA) são as mais aplicadas comercialmente (BAKEMEIER at al, 1994). A absorção de $\mathrm{CO}_{2}$ é mais lenta, mas para que ocorra a dessorção do material absorvido, é necessária apenas uma redução de pressão no processo.

Os solventes físicos apresentam-se como melhor opção quando o syngas é obtido a partir do POX não catalítico, onde há a presença de ácidos em geral e compostos sulfurosos tanto no GN de entrada do processo, quanto no próprio syngas obtido. Este é passado pelo processo de SCHT, resistente a estas impurezas e os ácidos e compostos sulfurosos são convertidos basicamente a $\mathrm{H}_{2} \mathrm{~S}$. Os solventes físicos absorvem conjuntamente o $\mathrm{CO}_{2}$ e o $\mathrm{H}_{2} \mathrm{~S}$, presentes na mistura gasosa. A pressão parcial do $\mathrm{CO}_{2}$ está entre 1 e $3 \mathrm{MPa}$. Os solventes físicos mais utilizados, atualmente, são: polietileno dimetiléter e carbonato de propileno. O processo Rectisol, desenvolvido pelas empresas Lurgi e Linde, utiliza o metanol como solvente.

A corrosão dos equipamentos, tais como válvulas e tubulações, é o grande problema encontrado na etapa de remoção de $\mathrm{CO}_{2}$. Isto acaba por influenciar não somente o custo de capital do projeto, já que é exigida a utilização de ligas especiais de aço inox,como também nas constantes paradas para manutenção. Vários inibidores de corrosão têm sido adicionados aos solventes. Como exemplo deste avanço, podemos citar o desenvolvimento do composto Amine Guard criado pela empresa Union Carbide, que é uma mistura de MEA e inibidor de corrosão (Bakemeier at al, 1994).

\subsubsection{Purificação Final}

Esta é a última etapa, a qual a mistura gasosa é submetida antes de ser enviada à síntese de amônia, que visa à remoção de compostos oxigenados $\left(\mathrm{CO}, \mathrm{CO}_{2}, \mathrm{O}_{2} \mathrm{e} \mathrm{H}_{2} \mathrm{O}\right)$ para evitar danos ao catalisador.

Neste texto serão descritos apenas dois processos de purificação final. A escolha por um deles depende da porcentagem em volume de cada um dos componentes a ser removido.

-Methanation: este processo é mais utilizado quando o syngas é obtido através do SMR e na seqüência passa pelos processos SCHT e SCLT. A presença de CO no gás de entrada oscila entre $0,2-0,3 \%$ e $0,01-0,1 \%$ de $\mathrm{CO}_{2}$, dependendo do processo de limpeza aplicado. Trata-se de 
um processo simples que consiste em reagir o $\mathrm{CO}$ e o $\mathrm{CO}_{2}$ com $\mathrm{H}_{2}$ gerando $\mathrm{CH}_{4}$ e vapor, conforme as reações 5.2 e 5.3 que são altamente exotérmicas, calor este que pode ser aproveitado.

$$
\begin{gathered}
\mathrm{CO}+3 \mathrm{H}_{2} \leftrightarrows \mathrm{CH}_{4}+\mathrm{H}_{2} \mathrm{O} \Delta \mathrm{H}=-206 \mathrm{~kJ} / \mathrm{mol} \text { (Reação 5.2) } \\
\mathrm{CO}_{2}+4 \mathrm{H}_{2} \leftrightarrows \mathrm{CH}_{4}=2 \mathrm{H}_{2} \mathrm{O} \Delta \mathrm{H}=-165 \mathrm{~kJ} / \mathrm{mol} \text { (Reação 5.3) }
\end{gathered}
$$

As condições de operação são: temperatura na faixa de $250-350^{\circ} \mathrm{C}$ e pressão em torno de 3 $\mathrm{MPa}$ (A concentração de $\mathrm{CO}$ e $\mathrm{CO}_{2}$ na saída do processo é menor ou igual a $5 \mathrm{ppm}$ (APPL, DANNSTADT-SCHAVERNHEIM, 2002 e JMCATALYST, 2005).

O processo apresenta como vantagens: simplicidade, baixo consumo energético e baixo custo de implantação e manutenção. Porém, tem-se como desvantagem que uma parcela do excedente de $\mathrm{H}_{2}$ produzido nas etapas de shift conversion é consumido.

As duas principais empresas, que detêm as tecnologias do processo, são a Haldor Topsoe e a JMCatalyst. (HALDOR TOPSOE, 2005; JM CATALYST, 2005)

\subsubsection{1 -Liquid Nitrogen Wash}

Esse processo, normalmente, é utilizado para preparar e purificar o gás para a síntese de amônia. Em muitas plantas industriais, essa é a última etapa do processo de limpeza do gás. O liquid nitrogen wash remove impurezas como $\mathrm{CO}$, argônio, $\mathrm{CH}_{4}$ do fluxo de $\mathrm{H}_{2}$ da entrada do processo e estabelece a razão estequiométrica em 1:3 $\left(\mathrm{N}_{2}: \mathrm{H}_{2}\right)$, requerida para a síntese da amônia.

Este processo é constituído pela unidade de adsorção que remove os traços de água, $\mathrm{CO}_{2} \mathrm{e}$ solventes, como o metanol, este último, proveniente do processo Rectisol. A remoção destes compostos é necessária a fim de se evitar o congelamento da corrente gasosa devido às baixas temperaturas.

A unidade cold-box é a responsável pelo término da limpeza do gás, que ocorre pela utilização de processos criogênicos. A figura 5.3 mostra o diagrama simplificado desse processo. 


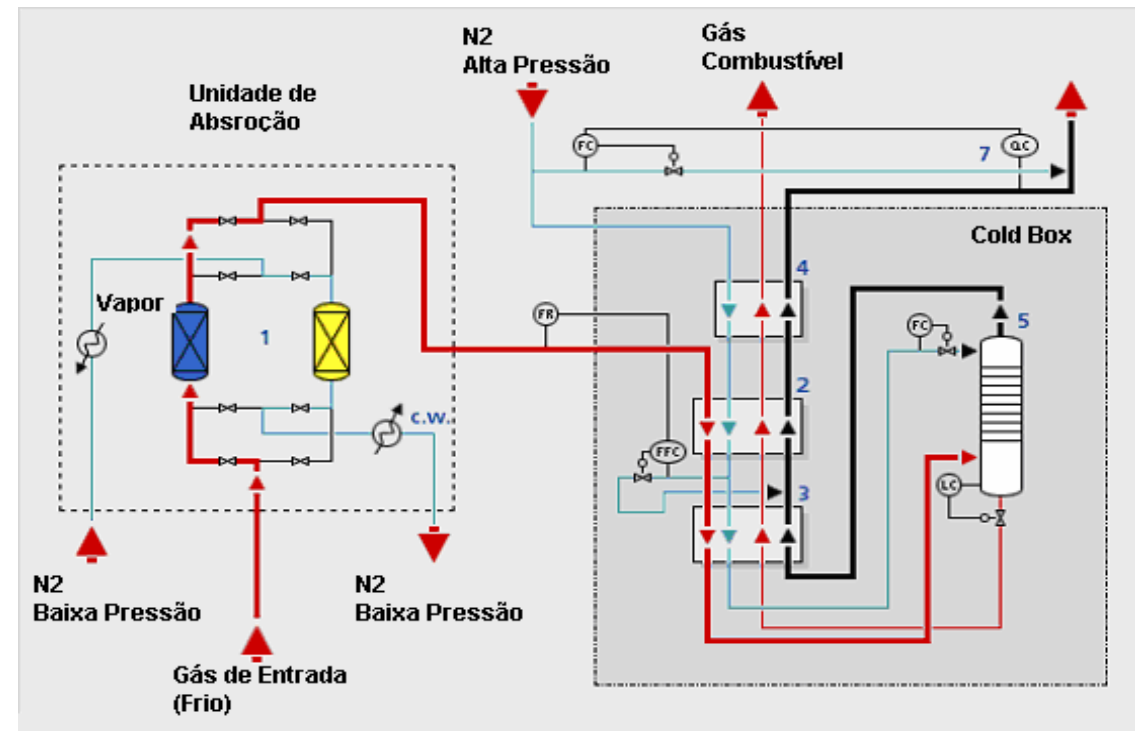

Figura 5.3 Diagrama simplificado do processo Liquid Nitrogen Wash da empresa Linde-AG

Fonte: (LINDE AG, 2006; adaptação própria)

\subsection{O Pocesso Haber-Bosch}

O processo de produção de amônia é considerado como um dos mais interessantes da indústria química, conforme Matar (2002), pois representa a primeira aplicação da termodinâmica em processo industrial.

Ainda de acordo com Matar (2002), o principal objetivo de muitas das pesquisas realizadas por Fritz Haber, era encontrar o catalisador que unisse uma razoável taxa de conversão de amônia a baixas temperaturas.

Atualmente, utiliza-se catalisador a base de óxido de ferro adicionado de outros óxidos, tais como óxido de potássio e óxido de alumínio, que auxiliam no aumento da eficiência de conversão à temperaturas relativamente baixas (em torno de $450^{\circ} \mathrm{C}$ ).

O processo Haber-Bosch combina o nitrogênio proveniente do ar com o hidrogênio que, comumente, provem do gás natural (metano) a fim de se obter a amônia. A reação, além de ser do tipo reversível, é também exotérmica (reação 5.4).

$$
\mathrm{N}_{2}+3 \mathrm{H}_{2} \leftrightarrows 2 \mathrm{NH}_{3} \Delta \mathrm{H}=-92 \mathrm{~kJ} / \mathrm{mol} \quad \text { (Reação 5.4) }
$$


A seqüência seguida pelo processo Haber-Bosch está representada na figura 5.4.

Quando a corrente de gás de síntese é submetida ao processo liquid nitrogen wash, ocorre a saída de uma mistura gasosa de $\mathrm{N}_{2}: \mathrm{H}_{2}$, cuja relação estequiométrica está ajustada corretamente em 1:3.

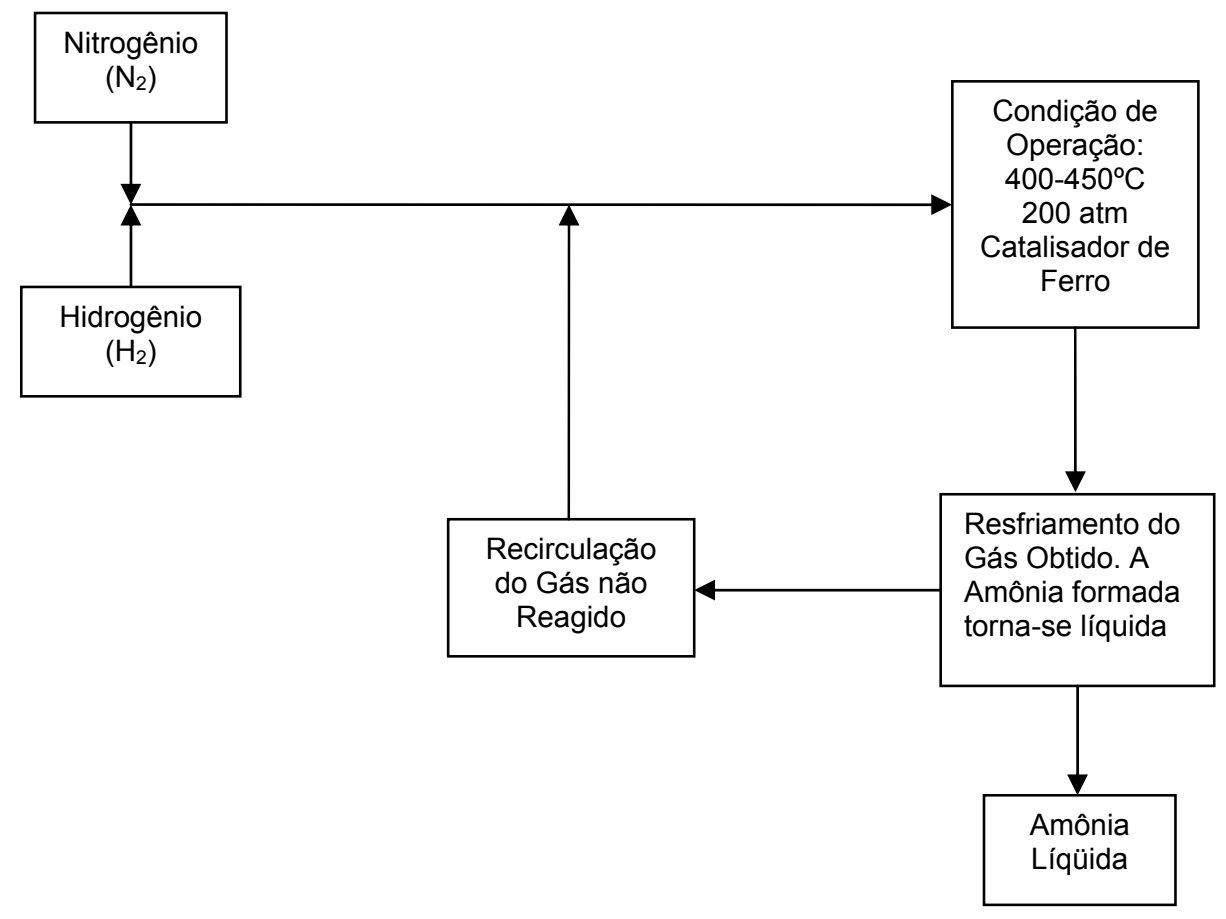

Figura 5.4. Representação esquemática do Processo Haber-Bosch

Fonte: (Elaboração própria)

\subsubsection{Detalhes do Processo Haber-Bosch}

Considerações sobre a catálise: quando o processo foi desenvolvido, o catalisador utilizado era apenas ferro, o que tornava sua operação bem simples. Atualmente, a fim de melhorar o rendimento do processo, foi adicionado ao catalisador, hidróxido de potássio, o que tornou seu manuseio um pouco mais complexo.

O catalisador não apresenta qualquer efeito na posição de equilíbrio da reação. A inserção de um catalisador no processo de síntese de amônia não aumenta a quantidade desta a ser produzida, apenas torna mais rápido o processo, fazendo com que o tempo de permanência da 
mistura no reator seja menor. Sem a presença deste, a reação seria muito lenta, tornando-se economicamente inviável.

Pressão: a pressão de operação do sistema varia de planta para planta. Pode-se tomar como base que a média exigida é de 200 atm. Dificilmente, será encontrada planta que trabalhe muito abaixo disso.

Recirculação: a cada passagem dos gases através do reator (onde ocorre o processo de catálise), em média apenas $15 \%$ do volume inicial é convertido em amônia. Porém, como existe o sistema de recirculação, o qual pega a corrente gasosa não reagida e a joga no sistema novamente, o rendimento final do sistema apresenta como média $98 \%$ de conversão.

Proporção da Mistura: a mistura de $\mathrm{N}_{2}$ e $\mathrm{H}_{2}$ que entra no reator, obedece a proporção de $1: 3$

A lei de Avogadro diz que igual volume de gases a mesma temperatura e a mesma pressão apresenta o mesmo número de moléculas; isto significa dizer que os gases, que vão para o reator, apresentam a mesma proporção em termos de molécula, que é a mesma proporção (razão) que demanda à reação.

Em alguns tipos de reações, pode-se optar por utilizar uma proporção maior de determinado reagente, visando um aumento de eficiência de conversão que não é o caso deste processo.

Temperatura: é necessário deslocar para a direita a posição de equilíbrio da reação, a fim de que se produza a maior quantidade possível de amônia nesta situação (equilíbrio). A temperatura aumenta o número de colisões entre as moléculas, aumentando a eficiência da reação. A reação é considerada exotérmica:

$$
\mathrm{N}_{2}(\mathrm{~g})+3 \mathrm{H}_{2} \leftrightarrows 2 \mathrm{NH}_{3} \Delta \mathrm{H}=-92 \mathrm{KJ} / \mathrm{mol} \text { (Reação 5.5) }
$$

Conforme o princípio de Le Chatelier, este processo será favorecido se trabalharmos a baixas temperaturas, pois o sistema deslocará a posição de equilíbrio para a direita e haverá maior produção de calor. Porém, a temperatura em que ocorre a síntese da amônia está entre 400 $450^{\circ} \mathrm{C}$, não podendo ser considerada como baixa, mas é a temperatura exigida pelo processo, na qual se utiliza o menor tempo de residência. Logo, a redução de temperatura sugerida pelo 
princípio de Le Chatelier, não se aplica a este processo, pois aumentaria o tempo de residência no reator.

Pressão: de acordo com o princípio de Le Chatelier, um aumento de pressão favorecerá a reação que produza um menor número de moléculas, resultando numa queda de pressão na saída do sistema. Visando a obtenção de tanta amônia quanto possível, na condição de equilíbrio, é necessária uma pressão tão alta quanto a estrutura do processo possa suportar.

O aumento de pressão faz com que as moléculas fiquem mais próximas umas das outras, aumentando o seu grau de agitação. No caso especifico da síntese de amônia, há probabilidade de que ocorram sérios danos à superfície do catalisador de ferro, caso haja um aumento na pressão de operação. A pressão média, empregada no processo Haber-Bosch, é de $200 \mathrm{~atm}$.

O emprego de pressões muito elevadas implica em altos custos de instalação, porque requer materiais de construção com alta resistência mecânica.

Separação da amônia: quando os gases saem do reator, encontram-se a uma alta temperatura e a uma alta pressão. Sabe-se que a liquefação da amônia ocorre a baixas pressões e baixas temperaturas. Logo, para que ocorra a separação da amônia formada da corrente gasosa não reagida, reduz-se a pressão e a temperatura do conjunto, ocorrendo a liquefação da amônia, seguida do processo de separação. A corrente gasosa não reagida é enviada ao sistema de recirculação, onde sofrerá um aumento de temperatura e pressão e depois, enviada ao processo novamente.

\subsection{Derivados da Amônia}

\subsubsection{Uréia}

Apresenta-se na forma de sólido cristalino, flocos ou grãos de coloração branca, cuja fórmula molecular é $\mathrm{CO}\left(\mathrm{NH}_{2}\right)_{2}$, sendo solúvel em água e álcool.

A uréia é sintetizada a partir da síntese da amônia com dióxido de carbono, reação 5.6, formando o composto carbamato de amônio $\left(\mathrm{NH}_{4} \mathrm{COONH}_{2}\right)$, o qual é, na seqüência, decomposto em uréia e água, reação 5.7 .

$$
\begin{gathered}
2 \mathrm{NH}_{3(\mathrm{~g})}+\mathrm{CO}_{2(\mathrm{~g})} \leftrightarrows \mathrm{H}_{2} \mathrm{~N}-\mathrm{COONH}_{4(\mathrm{~s})} \Delta \mathrm{H}=-126 \mathrm{~kJ} / \mathrm{mol} \text { (Reação 5.6) } \\
\mathrm{H}_{2} \mathrm{~N}-\mathrm{COONH}_{4(\mathrm{~s})} \leftrightarrows \mathrm{NH}_{2}-\mathrm{CO}-\mathrm{NH}_{2}(\mathrm{aq}) \\
+\mathrm{H}_{2} \mathrm{O}_{(\mathrm{l})} \Delta \mathrm{H}=+29 \mathrm{~kJ} / \mathrm{mol} \text { (Reação 5.7) }
\end{gathered}
$$


Conforme Matar (2002), a primeira etapa do processo de produção de uréia é exotérmica e o equilíbrio químico é favorecido a baixa temperatura (na faixa de $170-220^{\circ} \mathrm{C}$ ) e alta pressão $(200$ atm). A segunda parte do processo ocorre a uma temperatura em torno de $200^{\circ} \mathrm{C}$ e pressão por volta de 30atm.

$\mathrm{O}$ carbamato de amônio não reagido é decomposto em amônia e $\mathrm{CO}_{2}$, na etapa denominada decomposição, através de sucessivos rebaixamentos de pressão e elevações de temperatura. Na seqüência, estes gases são enviados à etapa de recuperação, onde são condensados e absorvidos, formando novamente o carbamato de amônio. Este, enviado através do loop de síntese ao reator para a produção de mais uréia.

A solução de uréia isenta de carbamato de amônio segue para a etapa de concentração, onde a água presente é retirada através da passagem desta solução pela unidade a vácuo. A água evaporada nesta seção é condensada e tratada para retornar ao processo.

A solução concentrada de uréia é enviada à etapa de granulação, que é composta por uma torre. Esta solução é enviada ao topo da torre, que goteja, lentamente, percorrendo a totalidade desta. Neste percurso, a solução entra em contato com o ar frio soprado no sentido contracorrente, cuja finalidade é resfriar e solidificar estas gotículas, formando o grão de uréia. A figura 5.5 apresenta o diagrama de produção da uréia.

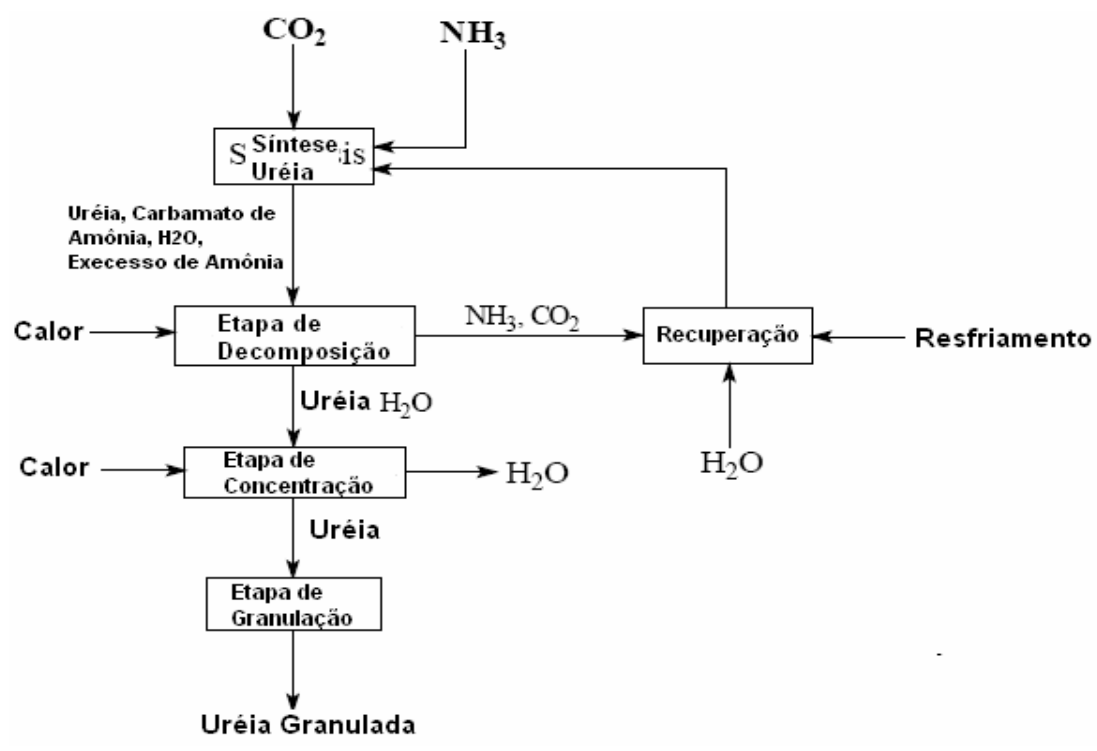

Figura 5.5 - Diagrama de produção de uréia

Fonte: (elaboração própria) 
Aplicação: utilizada para a fabricação de resinas plásticas, como uréia-formaldeído e elanina formaldeído, produtos farmacêuticos, alimentação animal, mas seu grande uso é na produção de fertilizantes nitrogenados. Conforme dados da ABIQUIM (2005), 68,8\% da produção nacional de uréia de 2004, foi utilizada com esta finalidade.

\subsubsection{Nitrato de Amônio}

Apresenta-se na forma sólida ou em flocos com coloração branca, cinza claro ou marrom, inodoro, solúvel em água e etanol.

$\mathrm{O}$ nitrato de amônio, $\mathrm{NH}_{4} \mathrm{NO}_{3}$, normalmente, é produzido a partir da neutralização do ácido nítrico com amônia e processado para a obtenção de fertilizantes de alta qualidade (ZAPP, 2002). Quando utilizado como fertilizante, seu consumo mundial é da ordem de $24 \%$ dos fertilizantes nitrogenados.

O nitrato de amônio também pode ser utilizado como um dos elementos para a fabricação de explosivos. A reação de formação deste é altamente exotérmica.

$$
\mathrm{NH}_{3(\mathrm{~g})}+\mathrm{HNO}_{3(\mathrm{l})} \rightarrow \mathrm{NH}_{4} \mathrm{NO}_{3(\mathrm{~s})} \quad \Delta \mathrm{H}=-146 \mathrm{~J} / \mathrm{mol} \text { (Reação 5.8) }
$$

No processo ocorre a pressão atmosférica ou pressões em torno de 0,4MPa, com temperaturas na faixa de $270-365^{\circ} \mathrm{F}$. (EPA, 1995)

Aplicação: é comumente utilizado como fertilizante na forma pura, diluída ou numa mistura de multinutrientes. Também pode ser utilizado em conjunto com a uréia em fertilizantes líqüidos. Na indústria de explosivos também encontra mercado.

\subsubsection{Sulfato de Amônio}

Normalmente, disponível em forma de pó branco, é um sólido cristalino de estrutura rômbica, inodoro e de sabor salgado. Solúvel em água e insolúvel em álcool e acetona. Absorve umidade do ar. Produz o gás amônia na reação com álcalis. 
$\mathrm{O}$ sulfato de amônio, $\left(\mathrm{NH}_{4}\right)_{2} \mathrm{SO}_{4}$, há pelo menos quatro modos distintos de produzí-lo, mas nesta tese será explicado apenas o processo a partir da amônia obtida através da transformação do gás natural.

Sua obtenção ocorre através da reação da amônia com ácido sulfídrico e o processo é altamente exotérmico, conforme demonstrado na reação 5.9:

$$
2 \mathrm{NH}_{3}(\mathrm{~g})+\mathrm{H}_{2} \mathrm{SO}_{4}(\mathrm{l}) \leftrightarrows\left(\mathrm{NH}_{4}\right)_{2} \mathrm{SO}_{4}(\mathrm{~s}) \Delta \mathrm{H}=-247 \mathrm{~kJ} / \mathrm{mol} \text { (Reação 5.9) }
$$

Aplicações: fertilizante nitrogenado, nutriente de microorganismos para produção de enzimas, beneficiamento de couros, produção de pós para extintores, aditivo em banhos de tinturas para tecidos e na produção de fermentos.

\subsubsection{Fosfato de Amônia}

Apresenta-se na forma sólida, de cor branca, com fraco odor de amônia e miscível em

água. Ácido fosfórico é reagido com amônia anidra, a fim de gerar o sulfato de amônia, $\mathrm{NH}_{4} \mathrm{H}_{2} \mathrm{PO}_{4}$.

Aplicação: a maior parte do fosfato de amônia é utilizada para a produção de monoamonia fosfato (MAP) e diamonio fosfato (DAP), sendo utilizado como componente para fertilizante.

\subsection{Estado da Arte da Tecnologia de Produção de Amônia}

\subsubsection{Lurgi A.G. MegaAmmonia}

Tecnologia recém desenvolvida pela referida empresa, cuja capacidade produtiva é maior ou igual a $1 \mathrm{Mt} / \mathrm{dia}$, sendo este o diferencial das tecnologias anteriores, as quais apresentavam capacidade máxima de produção na faixa de 0,73 a $0,84 \mathrm{Mt} / \mathrm{dia}$.

Este processo diferencia-se do convencional por não apresentar as limitações do SMR, pois utiliza o POX catalítico. Por trabalhar a alta pressão e, também utilizar a tecnologia 
Rectisol® Nitrogen Wash, obtendo um gás de síntese com elevado grau de pureza, evitando a presença do loop de síntese.

Outros itens que diferem do processo convencional são: a não presença de um reator de nitrogênio na planta, não necessidade de purga contínua dos gases inertes, ausência do processo de metanação e LTSC, não é necessário esforço (operação) para que se atinja a menor quantidade possível de metano não reagido devido ao reciclo deste gás e de outras impurezas, os quais são utilizados como gás combustível na etapa do POX.

As etapas deste processo são consideradas maduras e provadas. Atualmente, este processo está disponível para aplicação.

A figura 5.6 ilustra o diagrama da Mega Ammonia.

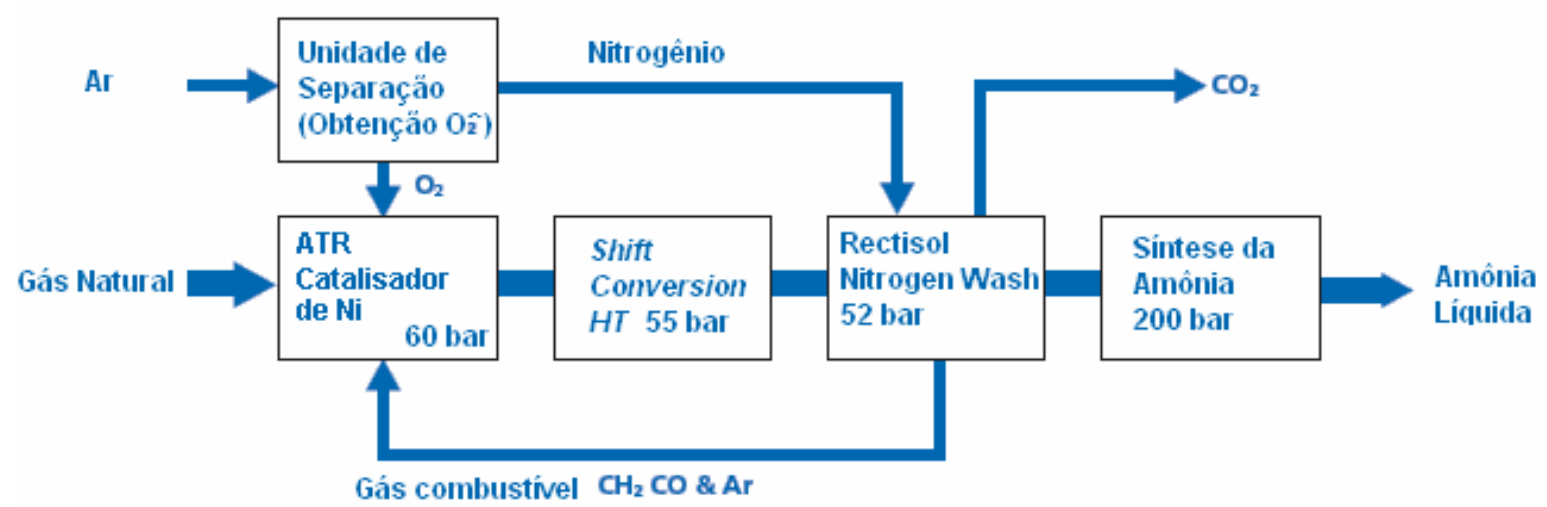

\section{Figura 5.6. Diagrama do processo Mega Ammonia da Lurgi AG}

Fonte: (LURGI AG,2006; adaptação própria)

Neste processo, após a dessulfurização, saturação e pré-reforma, o GN é enviado a um reformador ATR. O oxigênio proveniente da unidade de separação do ar é, também, enviado ao reformador ATR para a produção do syngas cru.

Este syngas obtido é enviado a um reator de HTSC para ser processado e na seqüência segue para a unidade de purificação denominada Rectisol ${ }^{\circledR}$ Nitrogen Wash. Neste processo as impurezas, $\mathrm{CH}_{4}, \mathrm{CO}$ e Ar, são removidas através da injeção de $\mathrm{N}_{2}$. Já o $\mathrm{CO} 2$ é absorvido pelo metanol (utilizado aqui como um solvente físico para a remoção de $\mathrm{CO}_{2}$ ) a baixas temperaturas (cold methanol). 
Após esta etapa, tem-se uma corrente de $\mathrm{CO} 2$ que pode ser reaproveitada industrialmente e as impurezas removidas agem como gás combustível. Já, o syngas purificado obtido é comprimido e misturado com a corrente do loop de reciclo e enviado a unidade de síntese de amônia.

O gás obtido no processo anterior é resfriado e a amônia líqüida obtida é separada da corrente de gás não reagido, o qual é enviado de volta ao processo.

\subsubsection{KAAP plus process - Kellogg Brown \& Root (KBR)}

O segundo processo apresentado pertence à empresa KBR e, apenas serão descritas as etapas que apresentam diversificação e/ou inovação tecnológica no processo de obtenção da amônia, pois a rota básica já foi detalhada anteriormente.

As três inovações que este processo apresenta são: KRES, purifier e KAAP Synthesis.

\subsubsection{KRES - KBR Reforming Exchanger System}

Este processo elimina o primeiro reformador, tradicional das tecnologias de produção de amônia, diminuindo os custos de capital. Os tubos radiais, padrão do reformador do tipo fired reformer foram substituídos por um único e robusto reformador, do tipo casco-tubo, denominado de reforming exchanger (gas heated reformer - reformador de gás aquecido). Esta nova patente de reformador é apresentada na figura 5.7. Os tubos reformadores são envoltos com o tradicional catalisador de níquel. 


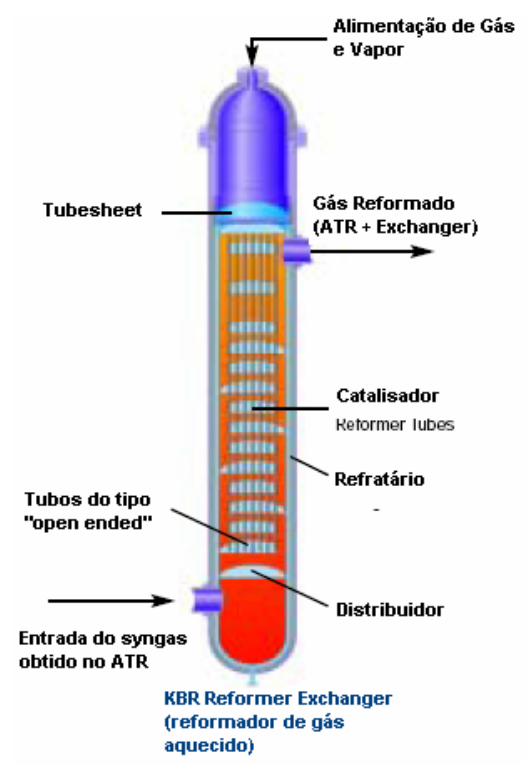

\section{Figura 5.7. Reformador de gás aquecido KBR}

Fonte (KBR, 2005; adaptação própria)

O calor, necessário para realizar a reação de reforma, é fornecido pelo gás proveniente do reformador ATR, o qual trabalha em paralelo com o reformador de gás aquecido, conforme demonstrado na seção 1 da figura 5.8.

Com o intuito de apresentar sempre a quantidade de calor suficiente para a realização da reação de reforma, o ATR é alimentado com excesso de ar de processo. Normalmente, conforme informações da própria KBR (2005), este excesso está na faixa de 50\% acima do requerido para o balanço de $\mathrm{N}_{2}$.

\subsubsection{Purifier - KBR Cryogenic Purifier}

A unidade de purificação, item 2, da figura 5.8, através de processo criogênico, que remove, simultaneamente, as impurezas pertencentes ao gás de síntese e ajusta a razão estequiométrica de $\mathrm{N}_{2}: \mathrm{H}_{2}$ para 1:3, o ideal para a síntese da amônia.

Esta unidade de purificação também serve como unidade de recuperação do gás de purga, como aquele rejeitado a partir do loop de síntese e passado pela unidade purifier.

A unidade remove todo o metano não reagido e a maior parte de argônio através da lavagem destes com excesso de $\mathrm{N}_{2}$. 


\subsubsection{KAAP Synthesis - KBR Advanced Ammonia Process}

O catalisador utilizado no processo KAAP, item 3, da figura 5.8, é a base de rutênio, o qual está sobre um suporte estável de grafita e apresenta uma atividade até 20 vezes maior que o catalisador tradicionalmente utilizado, a base de óxido de ferro. Como resultado, da utilização do catalisador a base de rutênio, ocorre uma redução na pressão de operação do loop de síntese, a qual é menor que 90bar. A pressão normal de operação dos loops tradicionais, inclusive os fornecidos pela própria KBR, operam com pressões no intervalo de 140-170bar.

A implantação do KAAP Synthesis tem como vantagem a utilização de apenas um compressor no loop de síntese, o que reduz o custo de capital e, também os custos de manutenção. O dimensionamento e a montagem deste mesmo loop, também apresenta redução dos mesmos custos, pois trabalha a pressões menores que os convencionais.

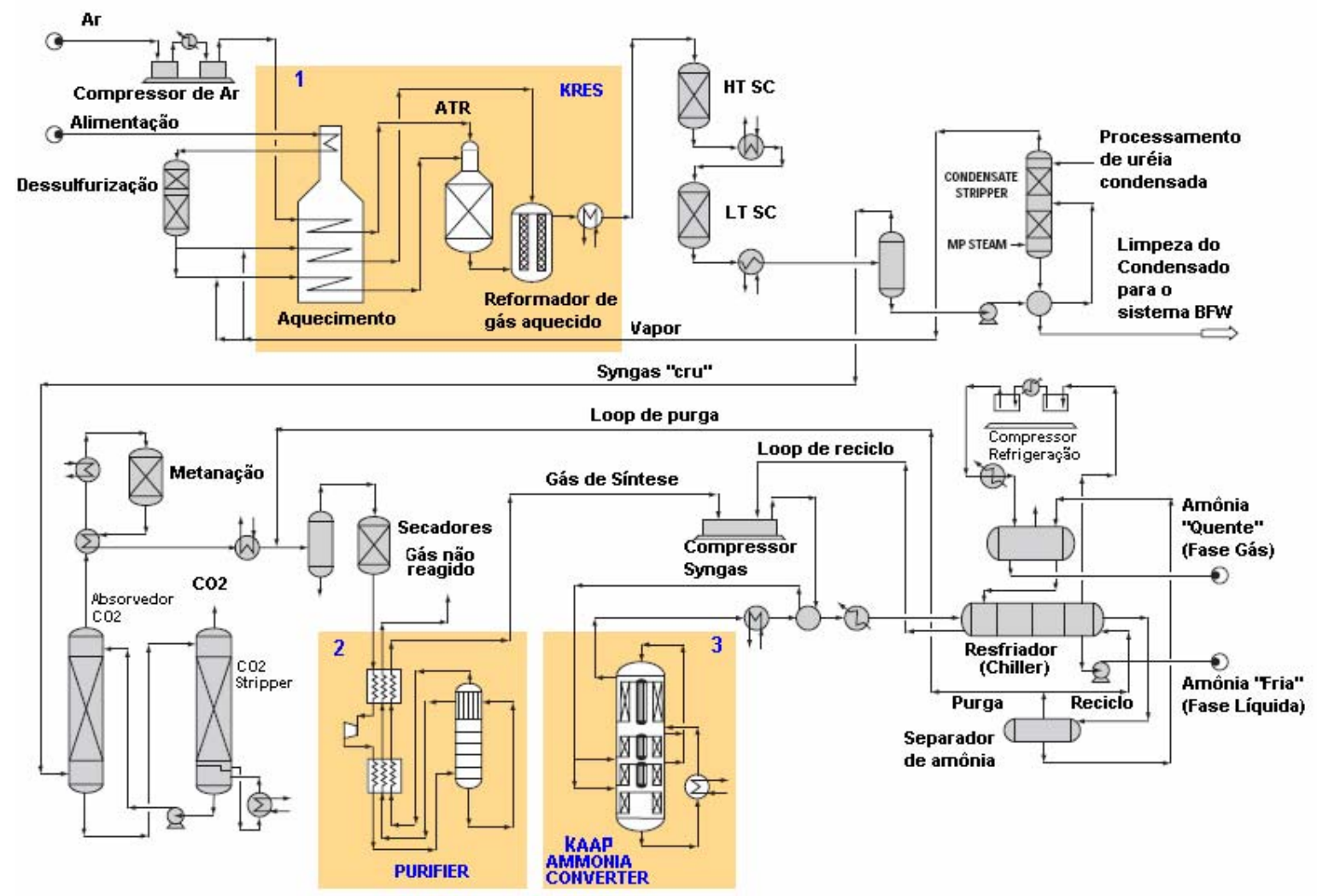

Figura 5.8 Diagrama de produção de amônia e uréia - Kaap plus process da empresa KBR

Fonte (KBR, 2005; adaptação própria) 
Sobre a implementação das três inovações tecnológicas citadas, a Kellogg destaca que o uso destas pode acarretar uma redução na faixa de $5-10 \%$ do custo de capital da planta e uma redução no consumo de energia do processo, na faixa de $0,1-0,2 \mathrm{Gcal} / \mathrm{bar}$. 


\section{HIDROGÊNIO}

É um gás incolor, inodoro e insípido, quando em estado natural, nas condições normais de temperatura e pressão (CNTP), sendo muito mais leve que o ar. É considerado como um composto quimicamente ativo, ou seja, é muito raro encontrá-lo de forma isolada na natureza. Encontra-se sempre ligado a outros elementos, formando moléculas, como por exemplo, hidrocarbonetos.

O hidrogênio $\left(\mathrm{H}_{2}\right)$ pode ser liquefeito, ocupando assim um volume 700 vezes menor que nas CNTP. Sua temperatura de liquefação é $-253^{\circ} \mathrm{C}$. Pode ser armazenado e transportado em cilindros e/ou tanques criogênicos. Acima desta temperatura, o $\mathrm{H}_{2}$ pode ser armazenado e transportado na forma de gás comprimido, em cilindros ou tanques adequados.

As misturas de hidrogênio e oxigênio $\left(\mathrm{O}_{2}\right)$ são inflamáveis e, dependendo da concentração de cada um destes compostos na mistura, esta pode ser explosiva.

Quando queimado, na presença de $\mathrm{O}_{2}$, libera, como produtos da combustão, apenas calor e água. Quando queimado com ar atmosférico, além de calor e água, libera, também óxidos de nitrogênio $\left(\mathrm{NO}_{\mathrm{X}}\right)$, provenientes da queima, em altas temperaturas, do nitrogênio do ar atmosférico com oxigênio comburente.

Atualmente, as maiores aplicações industriais do hidrogênio voltam-se para a fabricação de fertilizantes nitrogenados, produção de metanol e, dependendo do seu grau de pureza, para as indústrias alimentícias e farmacêuticas. Existem outras aplicações nas quais o $\mathrm{H}_{2}$ atua como reagente. Por exemplo: no processo de hidrogenação. Nas refinarias de petróleo, é utilizado, principalmente, na etapa de hidrotratamento e hidrocraqueamento. Há alguns anos, a sua utilização, como forma de energia, vem sendo estudada e, aplicações, tais como as células a combustível, já se encontram em estágio avançado, havendo, inclusive, unidades em funcionamento.

\subsection{Produção de Hidrogênio}

Conforme dados obtidos no portal célula combustível e apresentados na tabela 6.1, atualmente, são produzidos cerca de 480 bilhões de $\mathrm{m}^{3} / \mathrm{ano}$, de hidrogênio, a partir de diferentes fontes de matérias-primas. 


\section{Tabela 6.1 - Produção anual de hidrogênio}

\begin{tabular}{lc}
\hline \multicolumn{1}{c}{ Matéria-Prima } & Quantidade \\
\hline Carvão (processo de gaseificação) & 90 bilhões $\mathrm{m}^{3}$ \\
Gás Natural (Reforma a vapor) & 240 bilhões $\mathrm{m}^{3}$ \\
Petróleo (Reforma) & 150 bilhões $\mathrm{m}^{3}$ \\
\hline
\end{tabular}

Fonte: (PORTAL CÉLULA COMBUSTÍVEL, 2006)

Segundo informado pelas fontes de pesquisas consultadas, há uma grande dificuldade em se precisar o volume total de $\mathrm{H}_{2}$ produzido e o quanto deste volume é utilizado em cada aplicação, já que, muitas vezes, o $\mathrm{H}_{2}$ é um subproduto, ou seja, é gerado, compulsoriamente, em vários processos. Dependendo do local de sua produção, é destinado a uma determinada rota, que pode ser para uso como combustível (queima direta), reagente (hidrogenação) ou matéria-prima (fertilizantes).

Conforme dados publicados pelo DOE (2006), a demanda por $\mathrm{H}_{2}$ nos Estados Unidos é em torno de 9 Mt/ano; estima-se que, destas, cerca de 1,5 milhão são consumidas por refinarias e indústrias químicas.

Conforme NAE (2004) e BEES (2004), mais de $32 \mathrm{Mt} / \mathrm{ano}$ de $\mathrm{H}_{2}$ são produzidas a partir do gás natural, através do processo de reforma a vapor do metano (SMR). Ainda, segundo as mesmas fontes, há grandes plantas de SMR, do tipo single-train, cuja capacidade de produção é igual ou maior que $480 \mathrm{t}$ /dia de $\mathrm{H}_{2}$. A mesma fonte aponta que novos projetos de unidades de SMR do tipo multiple-train encontram-se em desenvolvimento, o que tornará ainda maior a capacidade de produção de $\mathrm{H}_{2}$.

A rota mais empregada na produção do $\mathrm{H}_{2}$ está apresentada na figura 6.1. 


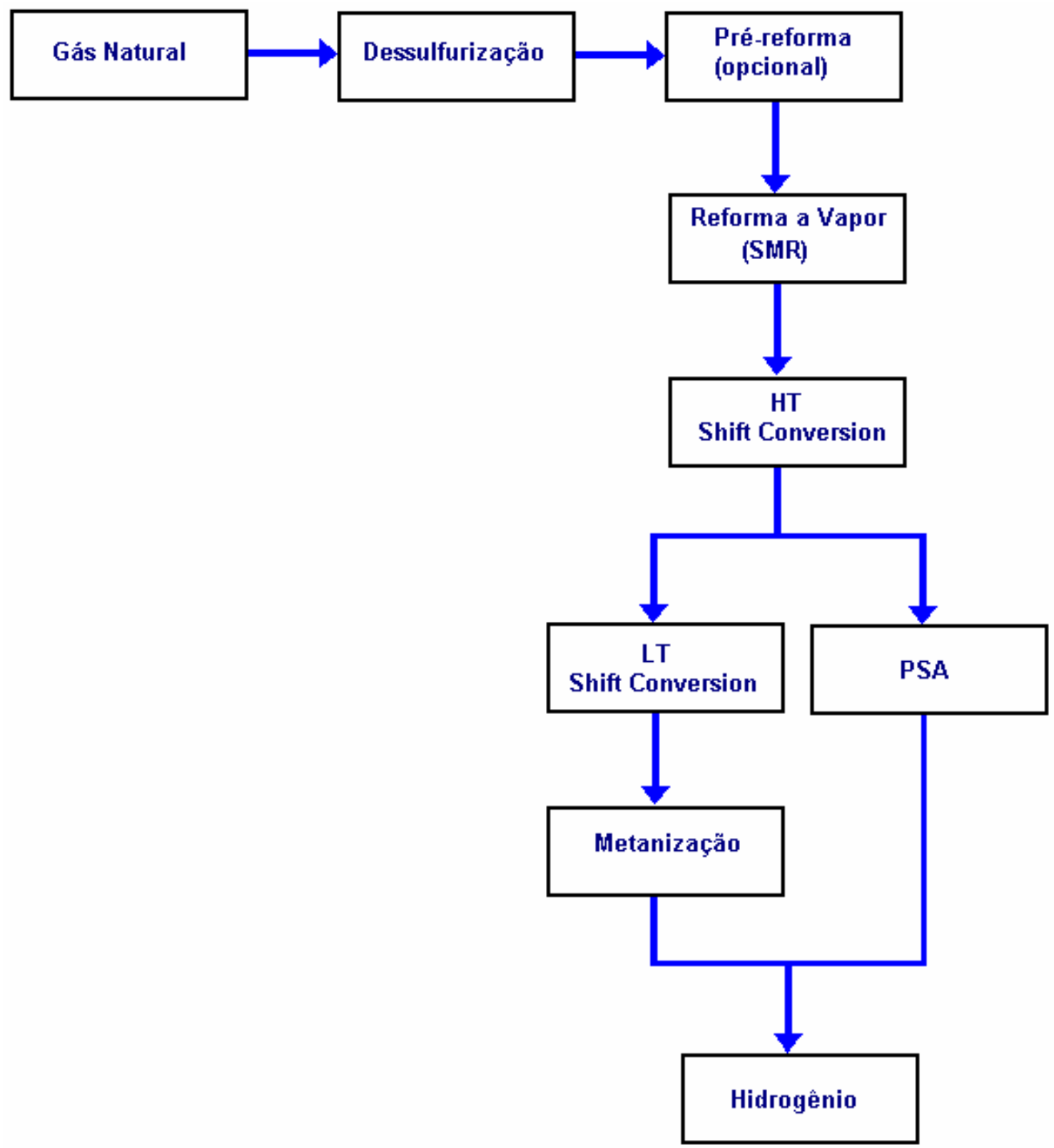

Figura 6.1. Rota mais empregada na produção de hidrogênio

Fonte: (elaboração própria)

De acordo com Lurgi AG (2005) e NAE (2004), o processo mais utilizado para a produção de hidrogênio a partir do gás natural, é a reforma a vapor, através da qual é produzido o gás de síntese, que, posteriormente, é enviado aos processos de shift conversion e subseqüentes etapas de purificação. 


\subsection{Purificação do $\mathrm{H}_{2}$ Através da Rota Pressure Swing Adsorption (PSA)}

A rota PSA é a tecnologia mais utilizada para a purificação de gases de uso industrial, tais como $\mathrm{O}_{2}, \mathrm{H}_{2}$ e $\mathrm{N}_{2}$. Este processo foi comercialmente introduzido por volta de 1960. É um processo utilizado para separar um gás específico de uma mistura gasosa.

Seu princípio de funcionamento baseia-se na capacidade de adsorção e dessorção, que determinados materiais apresentam, como carbono ativado e zeólitas. A escolha de cada um destes materiais deve ser feita de acordo com o gás que se deseja purificar.

A configuração típica de uma unidade de PSA envolve processos cíclicos, através de um determinado número de reatores conectados em série, os quais contém, internamente, um leito de material adsorvedor. Estes reatores são submetidos a constantes pressurizações e despressurizações com o objetivo de produzir um fluxo contínuo de gás purificado.

A figura 6.2 apresenta, de forma simplificada, o processo de PSA aplicado a uma mistura gasosa contendo $\mathrm{H}_{2}, \mathrm{CO}_{2}, \mathrm{CO}, \mathrm{N}_{2}, \mathrm{H}_{2} \mathrm{O}$ com o objetivo de obter $\mathrm{H}_{2}$ puro.

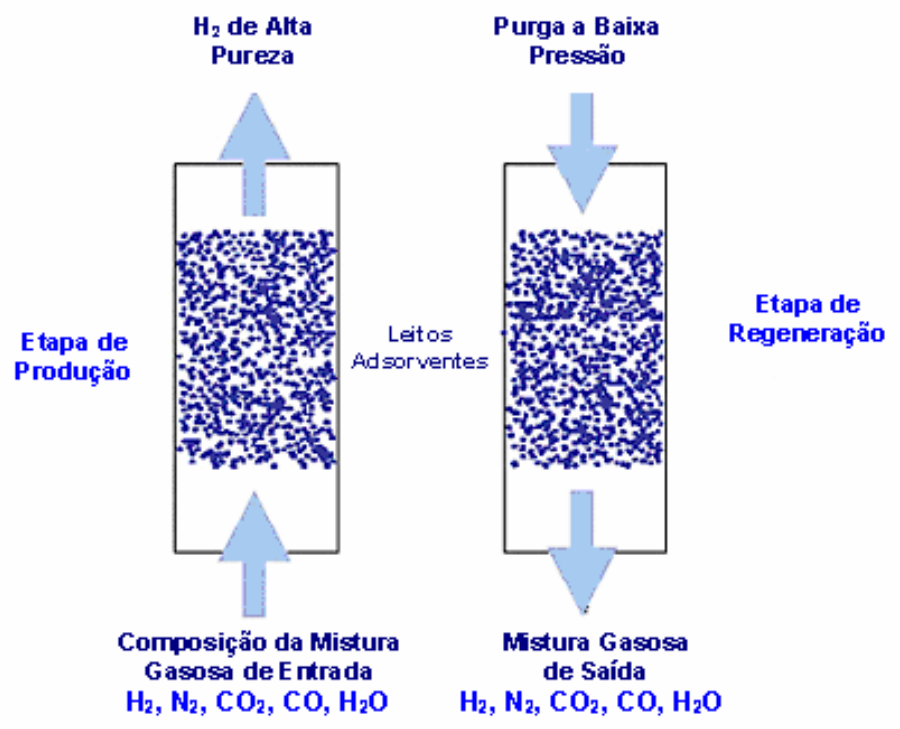

Figura 6.2. Esquema simplificado de funcionamento de um PSA

Fonte (QUESTAIR, 2006; adaptação própria) 


\subsubsection{Etapas do Processo PSA}

A corrente gasosa, contendo impurezas, é bombeada para dentro de um cilindro pressurizado, que contem o leito de material adsorvente. As impurezas do gás de entrada são adsorvidas para a superfície interna do leito adsorvedor, restando uma corrente de $\mathrm{H}_{2}$ dentro do reator, a qual é removida como um produto puro. A pressão do cilindro é reduzida para que haja a purga do material adsorvido. O processo se repete até atingir o grau de pureza desejado.

O PSA apresenta alta versatilidade quanto à origem da matéria-prima, dentre as quais, syngas produzido via SMR e gases de refinaria, entre outras.

Para processos que necessitem de alta quantidade de recuperação de hidrogênio, adsorverdores extras podem ser adicionados ao sistema. Múltiplos leitos são utilizados na etapa de adsorção para reduzir o tamanho dos vasos (reatores) e a quantidade de adsorvente a ser utilizada em cada um destes.

Conforme informado pela NatcoGroup (2005), em plantas com capacidade acima de $100.000 \mathrm{~m}^{3} / \mathrm{h}$, é possível utilizar apenas um single train de PSA.

O processo utilizado como exemplo foi desenvolvido pela empresa Axsia Howmar pertencente a Natco Group.

\begin{tabular}{|c|c|}
\hline Etapas do processo & Diagramas do Processo \\
\hline $\begin{array}{c}\text { Adsorção } \\
\text { O gás de entrada passa através do leito adsorvente } \\
\text { limpo, onde as impurezas serão seletivamente } \\
\text { adsorvidas. O produto } \mathrm{H}_{2} \text { puro deixa o leito à alta } \\
\text { pressão. }\end{array}$ & \\
\hline $\begin{array}{c}\text { Após a etapa de adsorção, o leito encontra-se } \\
\text { saturado de impurezas e necessita ser regenerado. } \\
\text { Para recuperar o } \mathrm{H}_{2} \text { aprisionado nos espaços } \\
\text { mortos, passa-se uma co-corrente de hidrogênio } \\
\text { despressurizado dentro do leito pressurizado. }\end{array}$ & \\
\hline
\end{tabular}


Despressurização Contra-Corrente

A despressurização final é do tipo contra-corrente, onde as impurezas são transferidas para a corrente gasosa de saída (offgas)

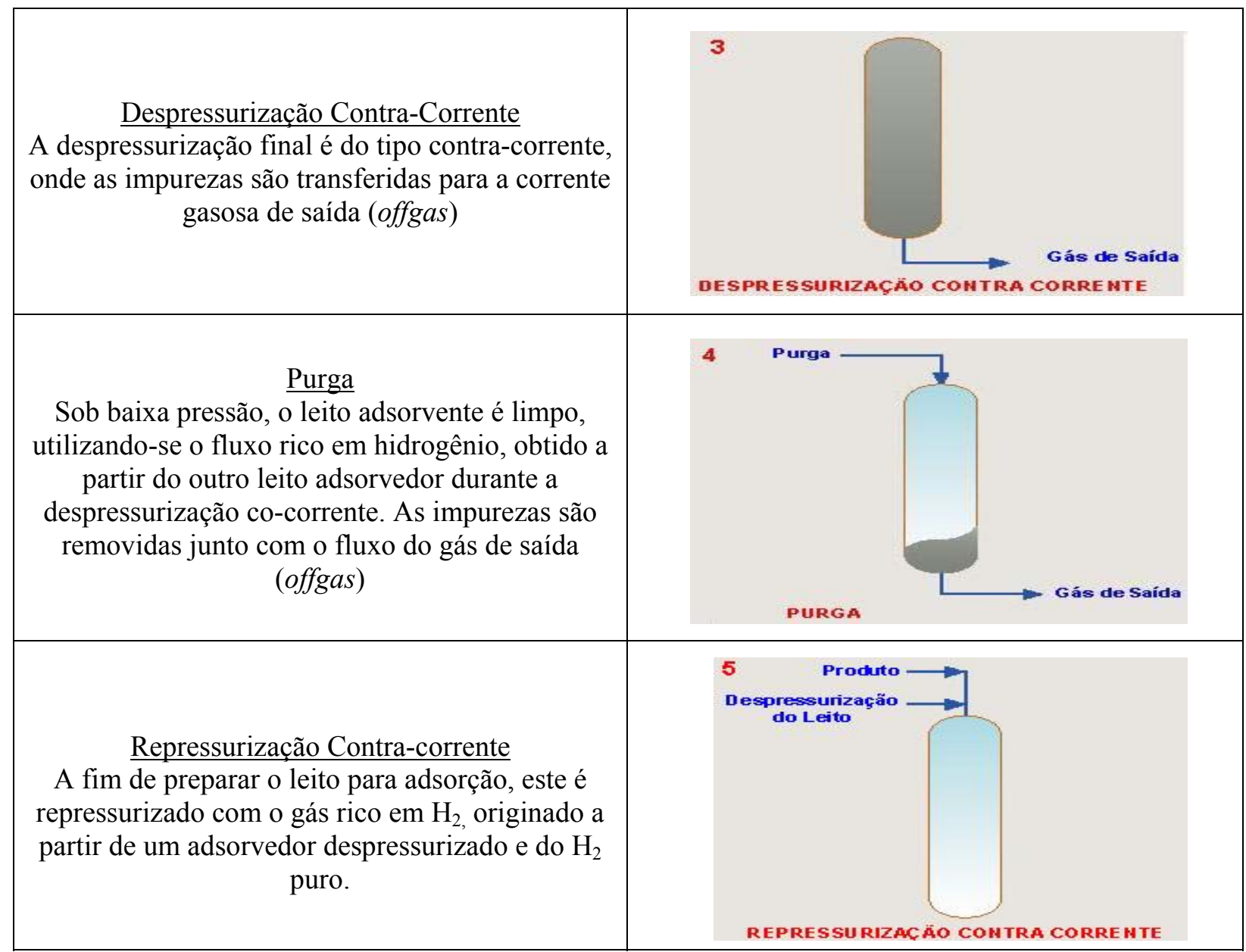

\subsection{Estado da Arte da Tecnologia de Produção do Hidrogênio}

\subsubsection{Produção de Hidrogênio - Processo Licenciado pela Foster Wheeler}

Aplicação: Produção de $\mathrm{H}_{2}$ a partir de hidrocarbonetos leves, via SMR.

Produtos: $\mathrm{H}_{2}$ de alta pureza e vapor.

Processo: A matéria-prima é previamente aquecida (1) e enviada a um sistema com dois leitos catalíticos fixos. Os compostos orgânicos sulfurosos presentes no gás de entrada, como, por exemplo, mercaptanas, são convertidos em $\mathrm{H}_{2} \mathrm{~S}$ e mono-olefinas. $\mathrm{Na}$ fase gás, os compostos sulfurosos são hidrogenados no primeiro leito catalítico de cobalto e óxido de molibdênio (2). O segundo leito é constituído de óxido de zinco para remover o $\mathrm{H}_{2} \mathrm{~S}$ por adsorção. Esta etapa é necessária, pois o $\mathrm{H}_{2} \mathrm{~S}$ é um veneno para o catalisador de níquel utilizado na etapa de SMR. 
A corrente gasosa obtida e purificada é misturada com vapor e aquecida antes de ser enviada ao reformador, onde será produzido o syngas. O gás de síntese obtido é composto de $\mathrm{H}_{2} \mathrm{e}$ $\mathrm{CO}$, apresentando pequenos traços de $\mathrm{CO}_{2}, \mathrm{CH}_{4}$ e vapor, sendo este resfriado e enviado a unidade de shift conversion (3), onde a maior parte do $\mathrm{CO}$ reagirá com vapor, formando $\mathrm{H}_{2}$ adicional e $\mathrm{CO}_{2}$.

O syngas da saída é resfriado, através de uma seqüência de trocadores de calor, antes de a água resultante ser recuperada e armazenada. A corrente gasosa resultante, que contém $\mathrm{H}_{2}$, é enviada a uma unidade de PSA (4), na qual a pureza do $\mathrm{H}_{2}$ de saída está em torno de 99,9\% e uma parcela do gás residual do PSA é utilizada como combustível para o reformador. Tanto a água, como o vapor saturado e o superaquecido são reaproveitados no processo.

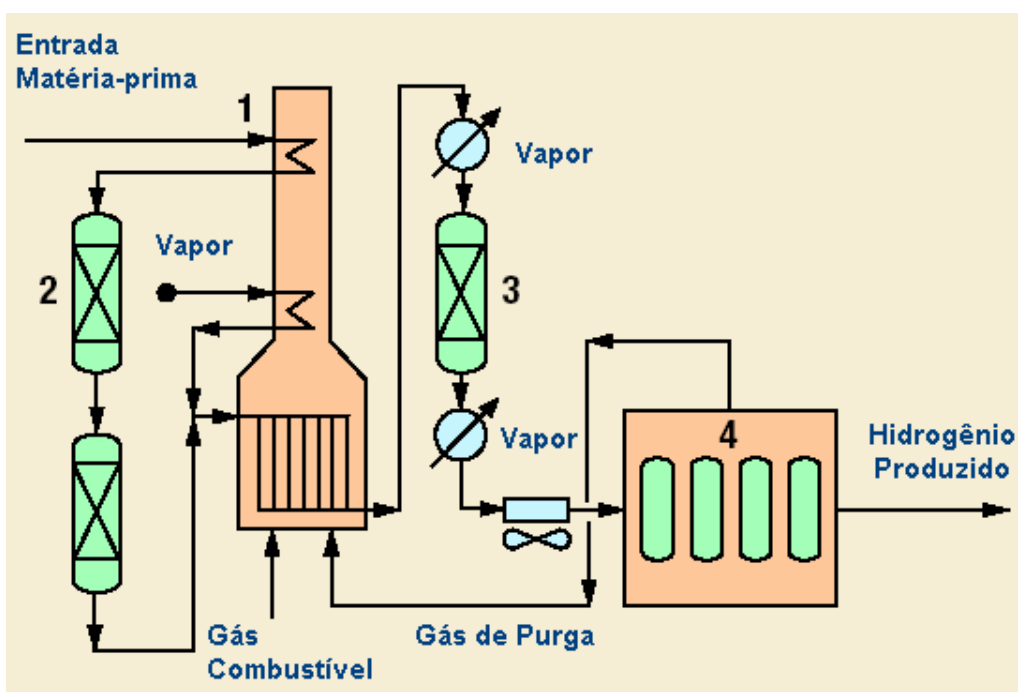

Figura 6.3 - Diagrama processo de produção de $\mathrm{H}_{2}$ da Foster Wheeler Fonte: (GAS PROCESS, 2004, adaptação própria)

\subsubsection{Produção de Hidrogênio a partir da Reforma a Vapor do Metano - Licenciado pela Haldor Topsoe}

Aplicação: produção de $\mathrm{H}_{2}$, com uma faixa de pureza entre 95-99,999\%

Matéria-prima: GN, GLP, nafta, gás de refinaria, entre outros hidrocarbonetos leves.

Processo: utilizando um reformador do tipo side fired SMR, patenteado pela própria Haldor Topsoe. A empresa indica que esta patente é considerada como uma planta de baixa 
exportação de vapor. Neste tipo de planta, o hidrocarboneto de entrada é dessulfurizado e na seqüência, adiciona-se vapor. Esta mistura gasosa é enviada a um pré-reformador. Uma reforma adicional é feita no reformador side fired SMR. Os gases resultantes do processo são encaminhados a um reator de shift conversion e, na seqüência, purificados através de uma unidade de PSA.

Os gases de saída do PSA (offgases) são utilizados como combustível na unidade de SMR. O excesso de calor, gerado na planta, é utilizado no processo de aquecimento e na geração de vapor.

Condições de Operação: este processo tem sua capacidade de produção na faixa de 5.000$200.000 \mathrm{~m}^{3} / \mathrm{h}$. A temperatura de saída do reator está em torno de $950^{\circ} \mathrm{C}$.

Detalhes do processo: a eficiência energética da planta pode chegar a 2,96Gcal/1000 Nm de gás natural (315Btu/scf). Este processo é flexível tanto em termos de pureza de $\mathrm{H}_{2}$, quanto em termos da capacidade produtiva.

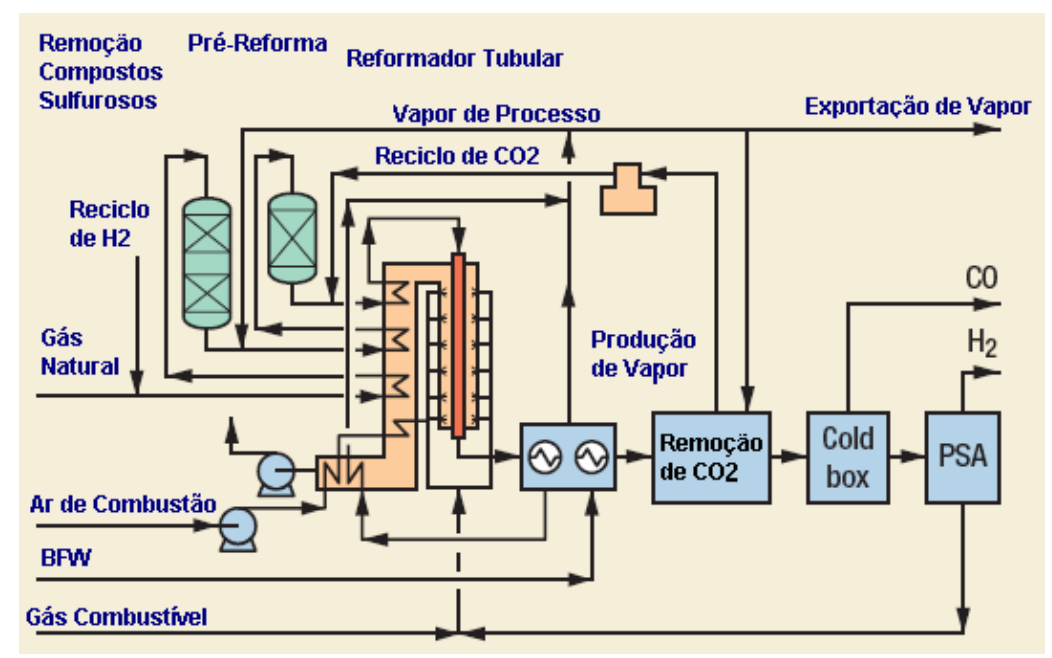

Figura 5.4. Diagrama do processo de produção de $\mathbf{H}_{2}$ da Haldor Topsoe

Fonte: (GAS PROCESS, 2004, adaptação própria) 


\subsubsection{Produção de Hidrogênio a partir da reforma a vapor. Licenciado pela Lurgi Oel- Gas-Chemie GmB}

Aplicação: Produção de $\mathrm{H}_{2}$ com alto grau de pureza ( $\geq$ 99,999\%). Este gás pode ser utilizado em processos químicos e no setor metalúrgico como agente redutor. Em termos de subproduto, pode-se ter a exportação de vapor, ou até mesmo a produção de eletricidade.

Matéria-prima: GN, gás associado e GLP.

Processo: a matéria-prima é misturada com uma parcela de $\mathrm{H}_{2}$ reciclado e esta é, depois, pré-aquecida a uma temperatura em torno de $350-380^{\circ} \mathrm{C}$. Os compostos sulfurosos são totalmente convertidos em $\mathrm{H}_{2} \mathrm{~S}$ através de um catalisador a base de cobalto-molibdênio e, então, adsorvidos pelo óxido de zinco e convertidos em $\mathrm{ZnS}$.

Adiciona-se vapor de processo à mistura dessulfurizada, a fim de otimizar a razão $\mathrm{CH}_{4}: \mathrm{H}_{2} \mathrm{O}$, em seguida, super-aquecida a uma faixa de temperatura em torno de $500-650^{\circ} \mathrm{C}$ e enviada ao reformador. Esta mistura passa pelos tubos do reformador, onde sob presença de um leito catalítico de níquel e uma temperatura em torno de $800-950^{\circ} \mathrm{C}$, é convertida em gás de síntese que ainda contém traços de $\mathrm{CO}, \mathrm{CH}_{4}$ e vapor. Este gás reformado é resfriado à temperatura de $33^{\circ} \mathrm{C}$ em uma caldeira.

$\mathrm{O} \mathrm{CO}$, presente nesta mistura gasosa, é convertido em $\mathrm{H}_{2}$ e $\mathrm{CO}_{2}$, através da reação de shift conversion, que ocorre sob presença de um catalisador de ferro-cromo. A presença de $\mathrm{CO}$ no gás de saída é em torno de $3 \%$ em volume. Este gás é resfriado à temperatura de $40^{\circ} \mathrm{C}$ e enviado à uma unidade de PSA, onde ocorre a separação do $\mathrm{H}_{2}$ dos demais gases presentes na mistura.

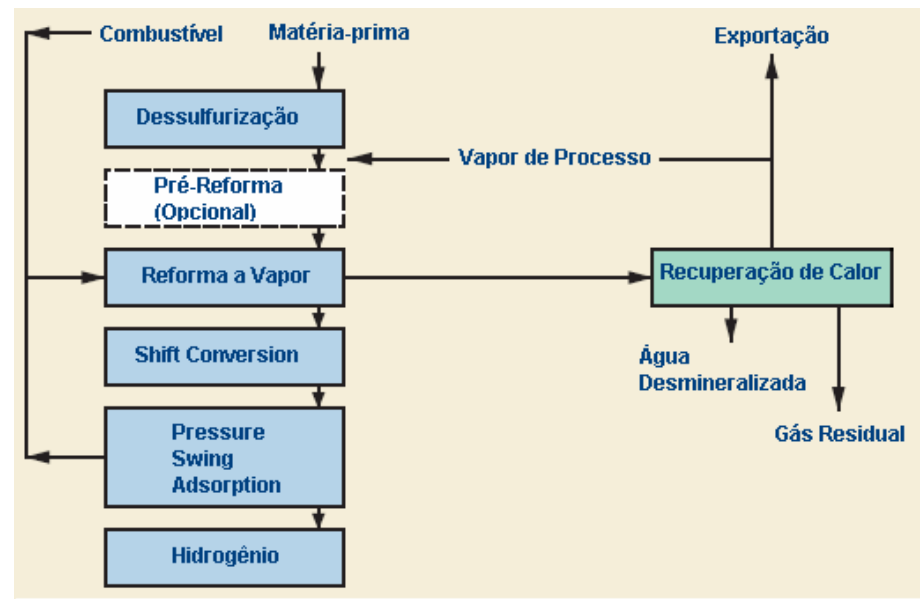

Figura 5.5. Diagrama do processo de produção de $\mathbf{H}_{2}$ da Lurgi Oel-Gas-Chemie GmbH Fonte: (GAS PROCESS, 2004, adaptação própria) 


\subsubsection{Produção de Hidrogênio. Licenciado pela UhdE GmbH}

Aplicação: produção de $\mathrm{H}_{2}$ para processos de refinaria, tais como hidrotratamento e hidrocraqueamento e outras aplicações petroquímicas e industriais.

Produtos: $\mathrm{H}_{2}$ com grau de pureza maior que $99,9 \%$. CO, $\mathrm{CO}_{2}$, e/ou eletricidade podem ser considerados como subprodutos do processo.

Matéria-prima: hidrocarbonetos leves.

Processo: A matéria-prima é dessulfurizada (1), misturada com vapor e convertida em syngas no reformador sob presença de um leito catalítico de níquel. O reformador (2) utilizado é do tipo top-fired. A temperatura, no reator, é em torno de $800-950^{\circ} \mathrm{C}$ e a pressão, entre $20-50$ bar. A alta pressão da geração de vapor (3) e o superaquecimento permitem o máximo aproveitamento de calor. A remoção do $\mathrm{CO}$ ocorre através da shift conversion high temperature (4) em um único estágio, utilizando um reator adiabático.

A mistura gasosa resultante é enviada a uma unidade de PSA (5) na qual o grau de pureza do $\mathrm{H}_{2}$ é de $99,9 \%$ ou maior.

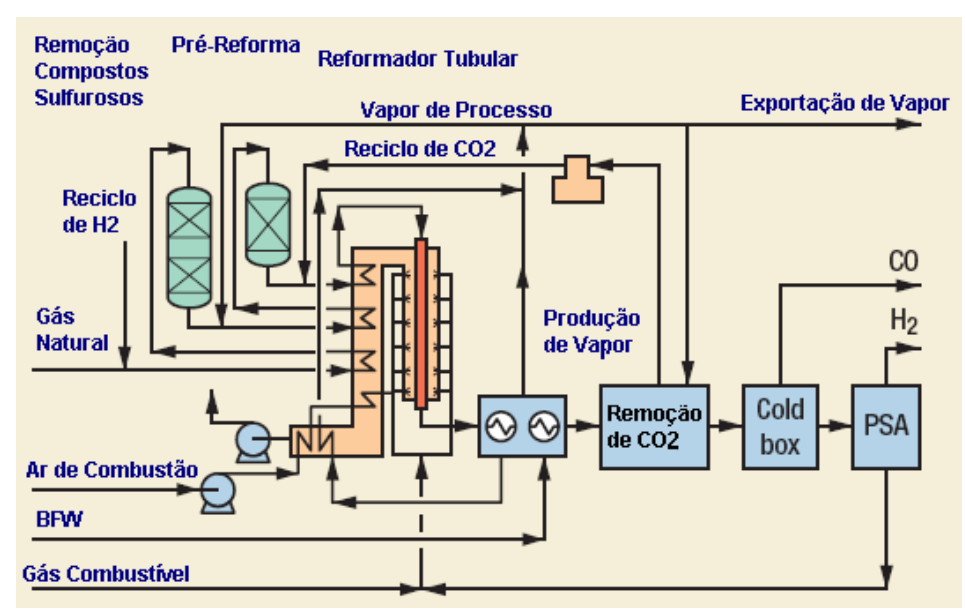

Figura 5.6. Diagrama do processo de produção de $\mathrm{H}_{2}$ da UhdE GmbH

Fonte (Gas Processes, 2004 adaptação própria). 


\section{ETENO}

$\mathrm{O}$ eteno ou etileno, $\mathrm{H}_{2} \mathrm{C}=\mathrm{CH}_{2}$, é o intermediário petroquímico de maior volume de produção mundial (GOMES, DVORSAK e HEIL, 2005) e também, o que apresenta a maior capacidade instalada em termos mundiais: 112,613 milhões de toneladas/ano (ABIQUIM, 2006).

Em 1940, as empresas de petróleo e química dos Estados Unidos conseguiram, através de processos de refino, separar a fração etano tanto do gás de refinaria quanto do gás natural, e este era transformado em eteno. A partir desta data, a produção deste intermediário petroquímico atingiu grandes volumes.

A grande importância do etileno neste setor deve-se a algumas de suas características, tais como sua estrutura simples com alta reatividade, facilidade de produção através dos processos de craqueamento, a olefina, que menos gera subprodutos quando reagida com outros compostos para a produção de derivados, facilidade no manuseio e transporte, entre outras.

\subsection{Matéria-Prima}

As principais matérias-primas utilizadas na produção do etileno são a nafta petroquímica, o etano, o GLP e o carvão mineral. No cenário brasileiro, apenas as duas primeiras são utilizadas.

A nafta é o insumo utilizado por $75 \%$ do parque petroquímico nacional, compreendendo as instalações localizadas em São Paulo - SP, Camaçari - BA e Triunfo - RS, as quais somadas, apresentam capacidade produtiva de 2,915 milhões de toneladas/ano (ABIQUIM, 2005). Em locais como Ásia, Europa e América Latina, a nafta é o principal insumo (Hiratuka, Garcia e Sabbatini, 2000).

Conforme Matai (2005), a nafta petroquímica é considerada a mais versátil das matériasprimas petroquímicas, pois, desta é possível obter não somente as olefinas leves, através de sua corrente gasosa, como os aromáticos, pela sua corrente líqüida. Estes últimos não podem ser obtidos quando se trabalha apenas com corrente gasosa.

A nafta é uma mistura de hidrocarbonetos, contendo de 6 a 10 carbonos. É obtida pelo processo de destilação atmosférica do petróleo, realizado pelas refinarias, conforme demonstrado na figura 7.1. Nesta etapa obtem-se o que se denomina nafta bruta. 


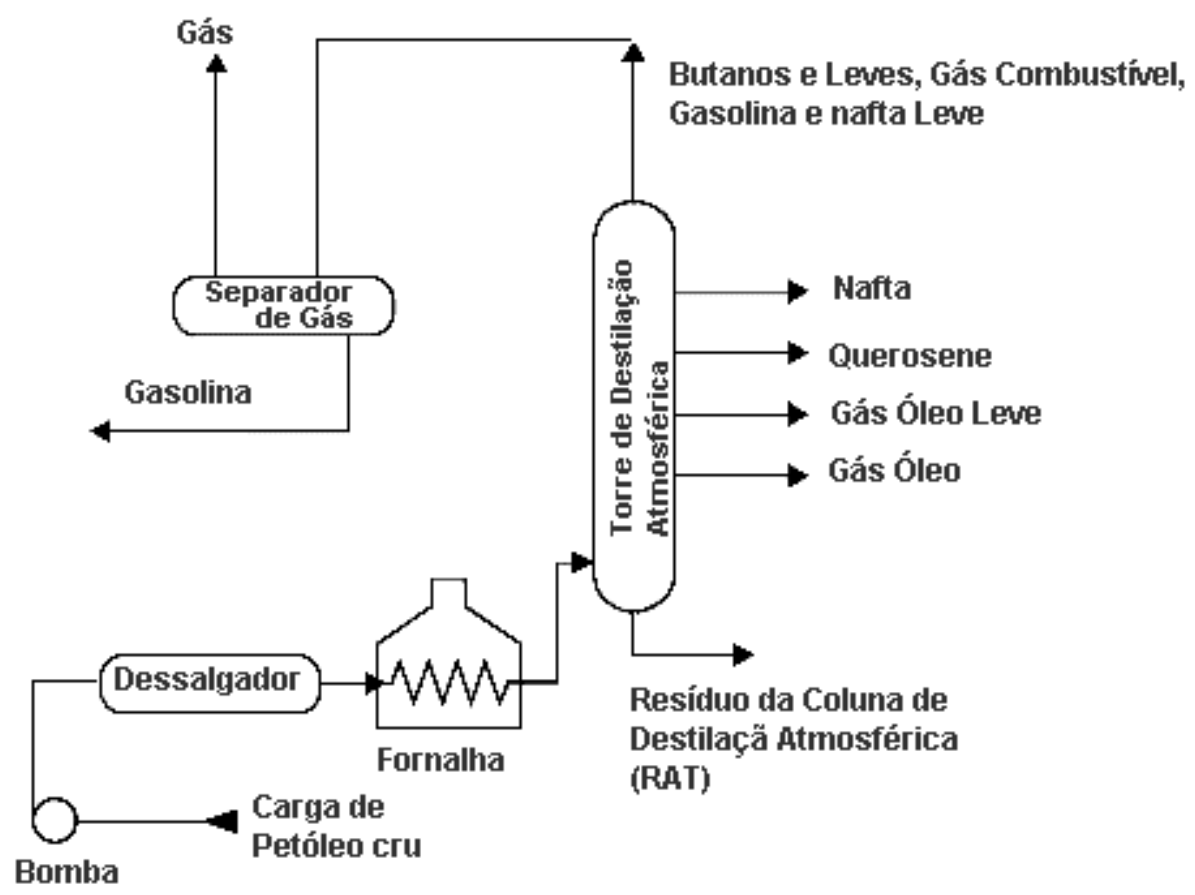

Figura 7.1. Diagrama da etapa de destilação atmosférica do petróleo

Fonte (Elaboração própria)

Dentro da indústria petroquímica de primeira geração, a nafta proveniente das refinarias, passa por etapas de fracionamento. De acordo com Matai (2005), esta, ao ser submetida ao processo de destilação, é separada em nafta leve (fração que contem de 1 a 5 átomos de carbono), nafta média (fração que contem de 6 a 8 átomos de carbono) e nafta pesada (fração que contem mais de 9 átomos de carbono).

Ainda de acordo com a mesma fonte, as frações bruta, leve e pesada são as cargas enviadas a unidade de pirólise, onde ocorre o fracionamento, a partir do qual são obtidas as olefinas leves, etileno, propeno e butadieno. A nafta média é a carga para a unidade de reforma catalítica, a qual, posteriormente, dará origem aos compostos aromáticos, ou seja, aos solventes como: benzeno, xileno e tolueno.

Cerca de $70 \%$ da nafta utilizada pelas centrais petroquímicas é oriunda do mercado nacional e fornecida pela Petrobras. Os 30\% restantes são importados pelas próprias centrais (GOMES, DVORSAK e HEIL; 2005). 
$\mathrm{O}$ etano, $\mathrm{C}_{2} \mathrm{H}_{6}$, é bastante utilizado como matéria-prima para a produção de etileno, principalmente, nos Estados Unidos e em países do Oriente Médio (Hiratuka, Garcia e Sabbatini, 2000).

No Brasil, a única central petroquímica a utilizar o etano como insumo, é a Rio Polímeros (Riopol), localizada em Duque de Caxias, estado do Rio de Janeiro. Além desta fração do GN, a Riopol utiliza também o propano.

O GN é extraído da Bacia de Campos, sendo este rico em etano, pois é associado ao petróleo e enviado às UPGN's Cabiúnas, onde ocorrerá o tratamento do GN e a separação das frações conhecidas como líqüidos do gás natural (LNG), que serão enviados à Refinaria Duque de Caxias (REDUC), da Petrobras, onde se obterá uma mistura gasosa contendo apenas as frações de etano e propano e por intermédio de dutos, abastecem a Riopol.

As frações de etano e propano são enviadas a unidade de pirólise, onde a corrente gasosa é aquecida num módulo térmico, etapa conhecida como craqueamento, ocorrendo a quebra controlada das moléculas de etano e propano para a formação do etileno e uma parcela de propileno.

Na seqüência, a corrente é enviada as etapas de compressão e secagem, seguindo para o resfriamento e por fim, às colunas de separação. A central gás-química apresenta capacidade de produção de 520 mil toneladas ano de etileno, que são consumidas internamente nas unidades de polimerização e 75 mil toneladas ano de propeno, as quais são vendidas ao mercado interno (RioPol, 2005).

Quando se compara uma central petroquímica base nafta com uma base gás (etano e propano) tem-se que a segunda é muito mais compacta, devido a não formação de solventes durante o processo de craqueamento catalítico do etano. Por esta razão, não há motivo de haver leitos de reforma catalítica e torre de destilação de líqüidos. Por conta da não necessidade destes equipamentos, o processo torna-se mais limpo, eficiente e menos danoso à saúde humana.

Porém, é necessário ressaltar que a corrente de aromáticos, produzida pela nafta, encontra grande mercado consumidor, sendo no cenário nacional e, também no internacional. A nafta, como insumo da petroquímica de primeira geração, apresenta alta versatilidade. É possível produzir maior quantidade de propeno além do butadieno.

Os aromáticos, originados a partir do craqueamento térmico da nafta para produção de etileno, apresentam grande absorção e importância no mercado interno. A capacidade produtiva 
destes, segundo dados da ABIQUIM (2005), é de 1,749 milhão t/ano, sendo 922.076 mil t/ano de benzeno, $296.250 \mathrm{mil}$ t/ano de tolueno e $531 \mathrm{mil} \mathrm{t} / \mathrm{ano}$ de xileno ${ }^{4}$. Para o butadieno, a capacidade de produção nacional, é de 360 mil t/ano (ABIQUIM, 2005).

Quando comparados, em termos de rendimento de processo, a conversão do etano é mais eficiente, apresentando, conforme Hiratuka (2000), rendimento médio de $80 \%$, enquanto a conversão da nafta tem $30 \%$.

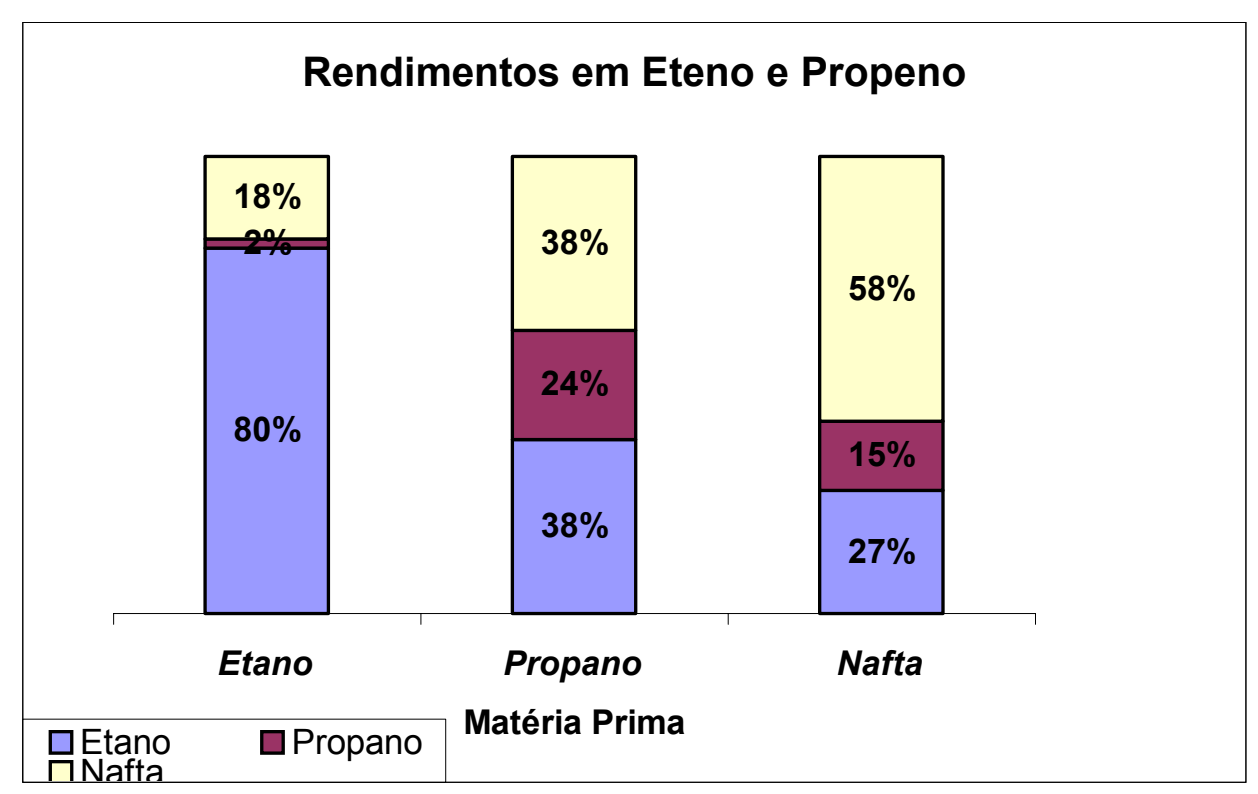

Figura 7.2. Rendimentos dos processos

Fonte: (MATAI, 2005 apud CMAI, 2005)

Porém, como será visto no item 7.3, sobre o estado da arte da obtenção de etileno, os rendimentos, tanto para a nafta quanto para o etano como insumo, variam de acordo com o detentor da patente em questão.

\footnotetext{
${ }^{4}$ o valor apresentado da produção do aromático xileno é a soma dos três tipos de xileno, sendo: xilenos mistos, 218 mil t/a, o-Xileno com 110mil t/ano e p-Xileno com 203 mil t/ano
} 


\subsection{Derivados do Eteno}

Termoplásticos: dentre os derivados do etileno, o grupo mais importante é o constituído pelos termoplásticos, entre os quais podemos citar os polietilenos, o polipropileno, o PVC, entre outros.

Termoplásticos são polímeros sintéticos que, quando expostos à ação do calor, podem ser facilmente moldados e, quando solidificados mantém as propriedades de sua nova estrutura.

\subsubsection{Polietileno de Alta Densidade}

Este produto teve sua produção comercial iniciada na década de 50 e, dentre os três tipos de polietileno disponíveis, é o que apresenta maior capacidade mundial instalada (Gomes, Dvorsak e Heil; 2005).

Conforme dados da ABIQUIM (2005), a capacidade nacional de produção de PEAD, em 2004, seria de 1,172 milhão de tonelada ${ }^{5}$ e a produção foi de 832.861 toneladas. As duas maiores aplicações do PEAD, no Brasil, estão voltadas para os processos de fabricação de filmes plásticos e sopro, sendo de $39,6 \%$ e $34,9 \%$, respectivamente.

Aplicação: fabricação de embalagens, principalmente, para as indústrias de cosmético, farmacêutica, alimentícia e limpeza.

\subsubsection{Polietileno de Baixa Densidade - PEBD}

Foi o primeiro polietileno a ser produzido, portanto é um produto maduro, de tecnologia de processo bastante difundida e apresenta baixa taxa de crescimento, devido ao seu custo de produção, que utiliza processo à alta pressão, já considerado ultrapassado (Gomes, Dvorsak e Heil, 2005). Normalmente, é processado juntamente com o polietileno de baixa densidade linear (PEBDL), visando à produção de filmes para embalagem.

A capacidade instalada de produção de PEBDL, no Brasil, é de 794.00 toneladas/ ano, e, em 2004, foram produzidas 672.645 toneladas. Sua grande aplicação é na fabricação de filmes:

\footnotetext{
${ }^{5}$ não incluí RioPol que iniciou sua produção em meados de 2005
} 
$81,7 \%$. Os setores que mais o consomem são: alimentício, com 51,1\%, e, higiene e limpeza, com $12,0 \%$.

Aplicação: fabricação de produtos como bobinas, rótulos, sacaria, tampas, frascos, lonas, tubos e mangueiras.

\subsubsection{Polietileno de Baixa Densidade Linear - PEBDL}

É um produto mais recente no mercado e, dentre os polietilenos, é o que apresenta maior taxa de crescimento de demanda (Gomes, Dvorsak e Heil, 2005). Como principais características apresenta impermeabilidade à água e alta soldabilidade, o que aumenta a sua aplicação na indústria alimentícia, na etapa de empacotamento dos produtos.

A capacidade instalada de produção de PEBD, no Brasil, é de 660.000 toneladas/ ano, e, em 2004, foram produzidas 407.021 toneladas. Sua grande aplicação é na fabricação de filmes, 96,1\%. Os setores que mais o consomem são: alimentício, com 59,7\%, industrial e construção civil, com 13,3\%, e higiene e limpeza, com 12,2\%.

Aplicação: fabricação de produtos como bobinas, rótulos, sacaria, tampas, frascos, lonas, tubos e mangueiras.

\subsubsection{Polipropileno}

Conforme Gomes (2005), o polipropileno é a resina termoplástica que apresenta o maior crescimento dentro do setor nos últimos anos, devido à eficiência das plantas produtoras e de sua versatilidade quanto à aplicação.

Como principais características apontam-se resistência à alta temperatura, resistência química, baixa densidade, resistência à fissura ambiental e baixo custo de produção, quando comparado as outras resinas.

Não apresenta riscos ao meio ambiente, podendo ser descartado, reciclado ou queimado.

A capacidade instalada de produção de propileno, em 2004, era de 1,425 milhão de tonelada, sendo 1,1130 milhão de tonelada, a quantidade produzida no referido ano. A principal 
aplicação é para processos de injeção, com 33\%, seguida pela fabricação de filmes plásticos, com 23,4\% (ABIQUIM, 2005).

Os setores que mais o utilizam são o alimentício, com 36,9\% e o de bens de consumo, com 35,2\% (ABIQUIM, 2005).

Aplicação: fabricação de produtos como bobinas, tampas, potes, big bags, garrafas, galões, caixas, utensílios domésticos, entre outros.

\subsubsection{Polietileno Tereftalato - PET}

O PET é um poliéster de grande importância mundial. Atualmente, sua maior aplicação é destinada à produção de garrafas para bebidas, onde, no cenário nacional, corresponde a 76,4\%, sendo o restante consumido pela indústria têxtil: 23,6\% (ABIQUIM, 2005).

Por apresentar, dentro de suas características, alta resistência mecânica e ser facilmente misturado as fibras de algodão, sua primeira aplicação foi voltada à indústria têxtil, na fabricação de fibras ${ }^{6}$ cujos nomes registrados são Dracon ${ }^{\circledR}$ e Fortrel ${ }^{\circledR}$. O tecido, fabricado com estas fibras, apresenta maior resistência ao enrugamento.

Aplicação: fabricação de vasilhames e fibras sintéticas.

\subsubsection{Poli cloreto de Vinila - PVC}

O PVC é um material plástico cuja composição em peso é $57 \%$ de cloro e $43 \%$ de etileno (Instituto do PVC, 2006). O cloro é obtido através da eletrólise do sal marinho, um processo eletrointensivo.

Para obter-se o PVC, mistura-se eteno e cloro, ambos na fase gasosa, que ao reagirem, produzirão o dicloro etano (DCE), o qual é transformado em monocloreto de vinila (MCV), que, ao passar pelo processo de polimerização, gera o PVC.

\footnotetext{
${ }^{6}$ Estas fibras são marcas patenteadas, sendo a Dracon pela DuPont, cuja produção teve início em 1929 e a patente adquirida em 1945. A fibra Fortrel foi produzida em 1959 pela Fiber Industries Inc, uma joint venture das empresas ICI e Celanese Corporation, atualmente a Wellman International Limited
} 
O seu grande mercado consumidor é o setor da construção civil, na fabricação de tubos e conexões com 45,6\%, seguido da fabricação de laminados, perfis e calçados, com 13,2\%, 12,2\% e $8,9 \%$, respectivamente.

Aplicação: fabricação de tubos e conexões, fios e cabos, laminados, perfis, calçados e embalagens.

\subsection{Estado da Arte da Tecnologia de Produção do Etileno.}

Nesta etapa serão descritos dois processos de produção de etileno, sendo, o primeiro destes, da Kellogg Brown \& Root e o segundo, da Lurgi AG e, ambos utilizam como insumo hidrocarbonetos leves e apresentam o maior rendimento de conversão para o etano.

Tecnologia de produção de etileno - Licenciada pela Kellog Brown \& Root ( KBR ) (Petrochemical processes, 2005 )

Aplicação: recuperação e craqueamento a vapor de alta performance para produzir etileno e propileno em grau polímero, $\mathrm{C} 4 \mathrm{~s}$, rico em butadieno, gasolina de pirólise, rica em aromáticos, hidrogênio e combustíveis.

Matéria-prima: etano, nafta e gás óleo (vácuo) são os insumos do processo.

Descrição: o forno de pirólise (SCORE - Selective Cracking Optimum Recovery) opera com baixo tempo de residência (aproximadamente 0,1 segundos) e baixa pressão. As condições de projeto e operação produzem alto rendimento na produção de olefinas.

A carga, proveniente do forno de pirólise (1), é processada através de calor e recupera o produto através de uma unidade de recuperação eficiente, confiável e de baixo custo. Os gases do craqueamento são resfriados e fracionados para a remoção da água e do ar combustível (2-5), são comprimidos (6), processados para remoção dos gases ácido (8) e seco (9). O $\mathrm{C}_{3}$ e os mais leves são separados como produtos de topo no depropanizador (10) e o acetileno produzido é hidrogenado no conversor de acetileno (11). A carga do conversor de acetileno é processada no sistema demetanizador (12-14), para separar o gás combustível e os produtos de hidrogênio. O fundo do demetanizador é enviado para o deetanizador (15), a partir do qual os produtos de topo fluem para o Separador de $C_{2}$ (16), que produz o etileno em grau polímero. A corrente de etano é, então, reciclada no forno de pirólise como insumo. 
$\mathrm{O}$ fundo do demetanizador flui para o separador de $\mathrm{C}_{3}$ (18), onde o pripileno grau polímero é recuperado como um produto de topo. $\mathrm{O}$ produto de fundo do separador de $\mathrm{C}_{3}$, propano, é reciclado no forno de pirólise como insumo. Os produtos de fundo do depropanizador, $\mathrm{C}_{4 \mathrm{~s}^{+}}$, fluem para o debutanizador (19) para recuperação dos produtos ricos em C4 e da gasolina de pirólise, rica em aromáticos.

Rendimentos de conversão: $84 \%$ etano, $38 \%$ nafta e $32 \%$ gás óleo, dependendo das características do insumo utilizado.

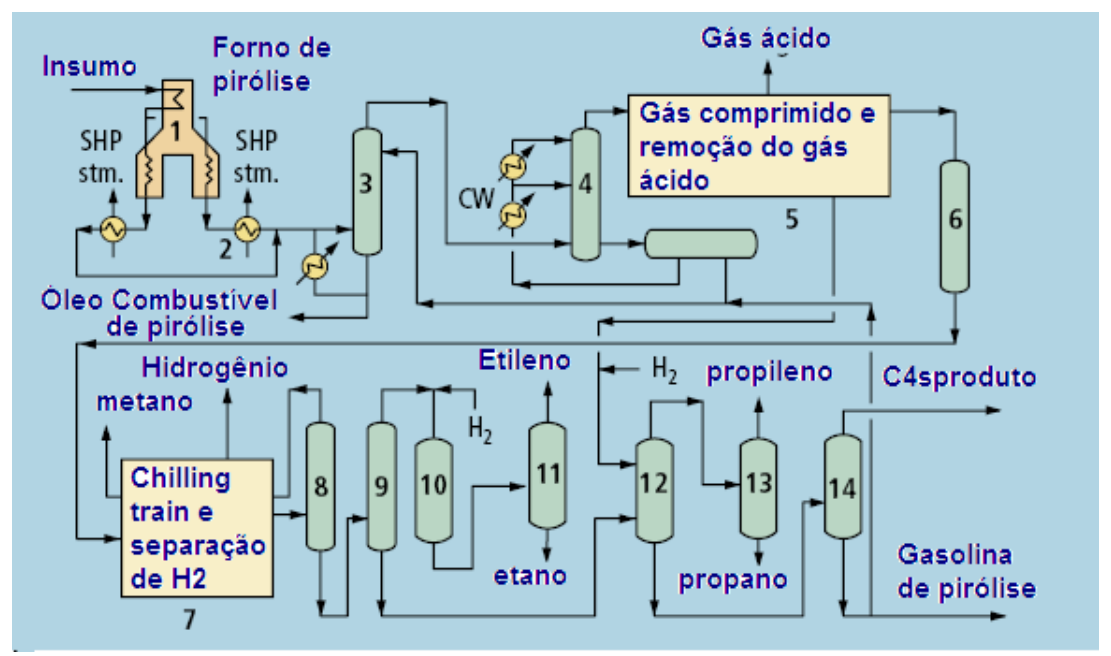

Figura 7.4. Tecnologia de produção de etileno da KBR

Fonte (Petrochemical Process 2005, adaptação própria )

\subsubsection{Tecnologia de produção de etileno - Licenciada pela Lurgi AG - (Petrochemical processes, 2005 )}

Aplicação: para produção de etileno e propileno grau polímero por termo-craqueamento. Os subprodutos são: $\mathrm{C}_{4}$, rico em butadieno e gasolina $\left(\mathrm{C}_{6}-\mathrm{C}_{8}\right)$, rica em aromáticos.

Matéria-prima: hidrocarbonetos leves, do etano à nafta petroquímicos e resíduos de hidrocraqueamento.

Descrição: o insumo de entrada e vapor de reciclo são pré-aquecidos e craqueados na presença de dilution steam nos fornos, altamente seletivos, PyroCrack (1). Estes fornos são otimizados pelo tempo de residência, temperatura e pressão, para a flexibilidade entre a alimentação real e a padrão, aumentando o rendimento na produção de olefinas. A carga de saída do forno é resfriada em linhas de transferência externas (2), gerando vapor de alta pressão e pelo quench com o óleo para os insumos líqüidos. 
A corrente de gás craqueada é resfriada e purificada em um fracionador primário (3) e passa pelo quench (5). O calor excedente é recuperado pela circulação de óleo, gerando vapor diluído (4) e pela circulação de água (5), para fornecer calor às caldeiras e aquecedores do processo. O gás craqueado, nas torres de quench, é comprimido (6) em um compressor multiestágio e seco em absorvedores de gás líqüido (8). $\mathrm{CO}_{2}$ e $\mathrm{H}_{2} \mathrm{~S}$ são removidos em um sistema de lavagem cáustica, localizados antes do último estágio de compressão.

O gás comprimido é aquecido e enviado à seção de recuperação: o deetanizador front-end (10), hidrogenação de $\mathrm{C}_{2}$ isotérmica front-end (11), cold train (12), demetanizador (13) e fracionador de etileno, à baixa pressão aquecido e bombeado (14), que é integrado com o ciclo de refrigeração do etileno.

$\mathrm{O} \mathrm{C}_{3}$, do fundo do deetanizador (10), é depropanizado (15), hidrogenado (16), para remoção do metilacetileno e propadieno (16) e fracionado para a recuperação do propileno grau polímero.

Componentes de $\mathrm{C}_{4}$ são separados dos componentes mais pesados em um debutanizador (18), para recuperação dos produtos $\mathrm{C}_{4}$ e da corrente de $\mathrm{C}_{5}$. O $\mathrm{C}_{5}$, juntamente com os condensados da seção aquecida, originam a gasolina rica em aromáticos.

Rendimento de conversão: $25 \%$ gás óleo, 35\% nafta, 45\% GLP, 83\% etano.

Energia: a energia específica consumida varia dentro da faixa de 6000, 5400, 4600 e 3800 $\mathrm{kcal} / \mathrm{kg}$ por etileno.

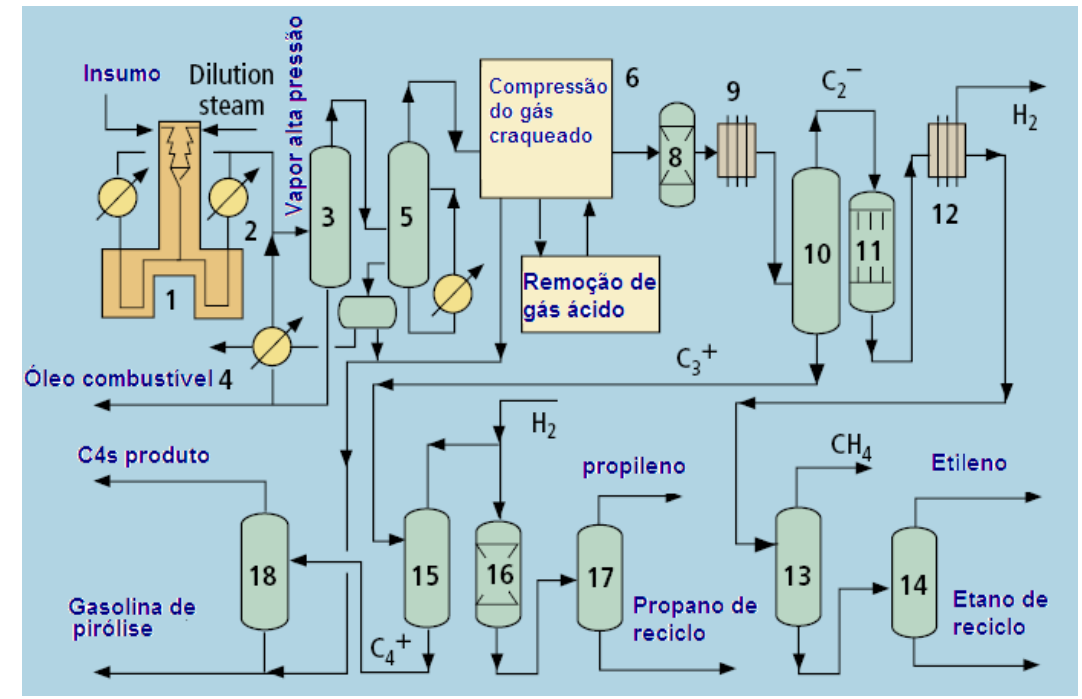

Figura 7.5 Tecnologia de produção de etileno da Lurgi AG

Fonte (Petrochemical Process 2005, adaptado pela autora ) 


\section{RESULTADOS}

Conforme levantamento bibliográfico realizado, onde foram identificadas as mais recentes tecnologias de produção de metanol, amônia e hidrogênio a partir do gás natural, mais precisamente, da fração metano, viabiliza-se a construção de uma planta gás-química, que integre a produção destes três compostos em um mesmo local.

Dados obtidos na etapa de modelagem apontam que para a produção de $1 \mathrm{~m}^{3}$ de metanol, são necessários $949,90 \mathrm{~m}^{3}$ de gás natural. Neste valor estão inclusos as perdas de processo e, também, o uso do gás natural como combustível, o que representa um acréscimo médio de $10 \%$ do volume de GN, utilizado somente como insumo.

A planta modelada tem capacidade nominal diária de produção de $961,84 \mathrm{~m}^{3}$ de metanol, consumindo $913.648 \mathrm{~m}^{3}$ de gás natural. O fator limitante desta produção está diretamente relacionado ao dimensionamento da unidade de SMR, que apresenta 200 tubos $^{7}$ reformadores.

Sabe-se que a densidade do metanol, a $25^{\circ} \mathrm{C}$ e a 1 atm de pressão, é de $780 \mathrm{~kg} / \mathrm{m} 3$, o que significa dizer que a planta produz diariamente, em toneladas, o correspondente a 750,24 t/dia. Sua capacidade, em um ano, seria de 273.836 t/ano.

Uma análise, de médio prazo da evolução da demanda (1998-2003), indica um crescimento da ordem de 25.772 t/ano, enquanto a análise de tendência de curto prazo (20012004), apresenta crescimento de 18.780 t/ano. Estes dados permitem inferir que há uma clara tendência de crescimento da demanda de metanol no Brasil, para os próximos anos. Considerando-se as duas informações, tomam-se os coeficientes angulares das duas retas de crescimento para se chegar a um valor médio, 22.276 t/ano. O gráfico 8.1 apresenta a situação para médio prazo, enquanto o gráfico 8.2 apresenta a situação para período de curto prazo.

\footnotetext{
${ }^{7} \mathrm{O}$ tubo do reformador apresenta diâmetro interno de 0,0945 metro e comprimento de 10,5 metros, considerando que o volume ocupado pelo catalisador seja de $52 \%$ do volume interno do tubo.
} 


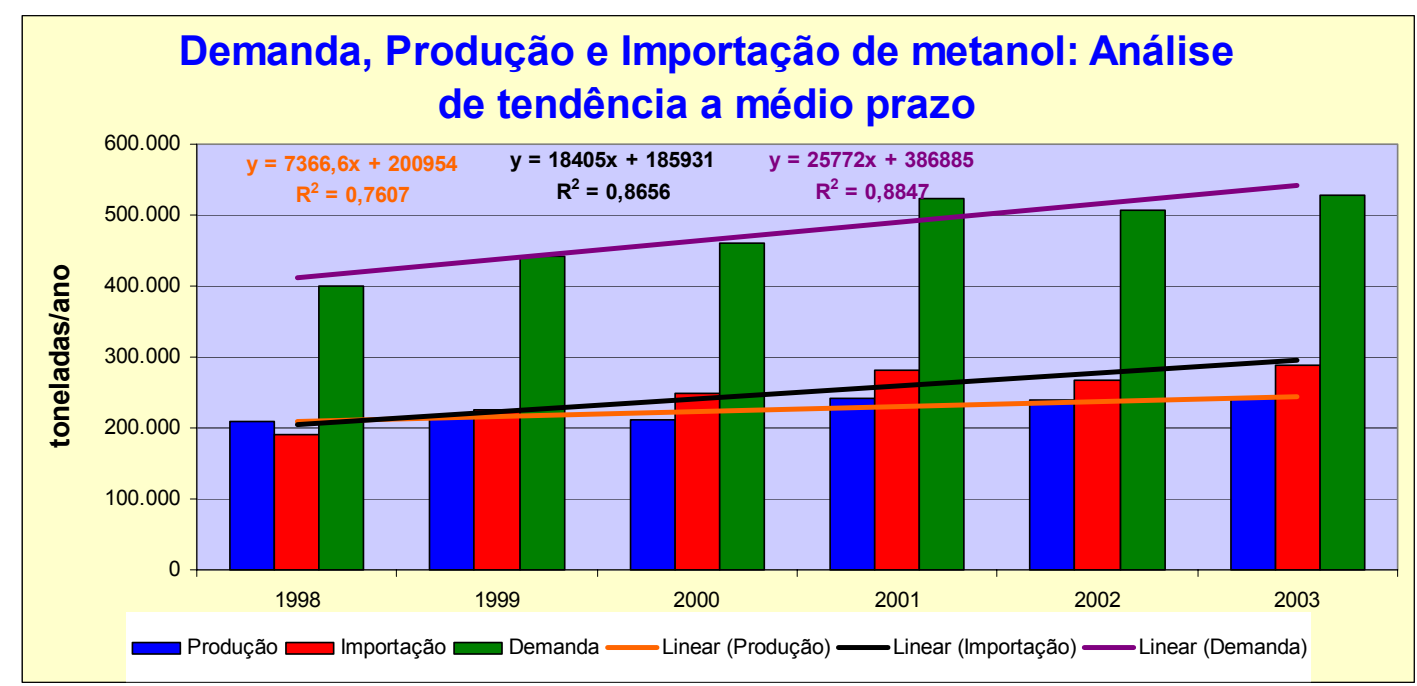

Figura 8.1 Análise de tendência, a médio prazo, da demanda, produção e importação de metanol

Fonte: (ABIQUIM, 2006; adaptação própria)

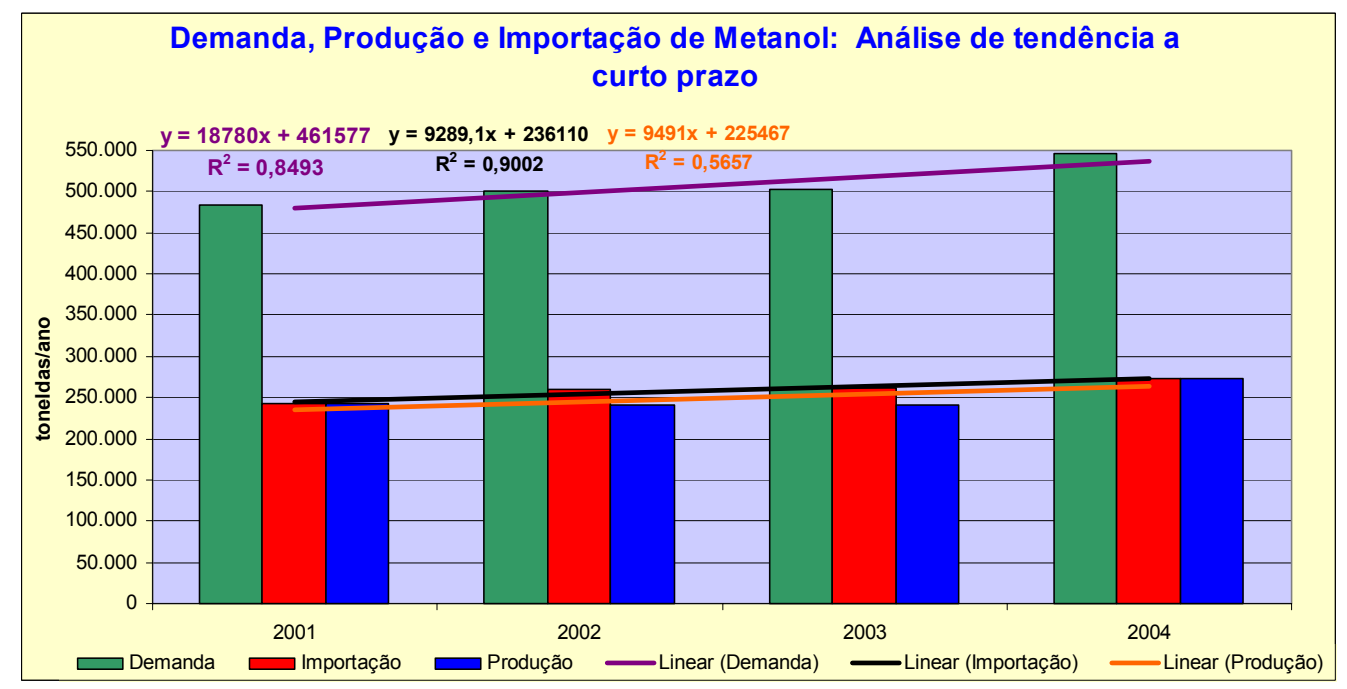

Figura 8.2 Análise de tendência, a curto prazo, da demanda, produção e importação de metanol

Fonte: (ABIQUIM, 2006; adaptação própria) 
Como as tendências de médio e curto prazos diferenciam de cerca de $40 \%$ entre si, a opção pela média restringe a volatilidade deste crescimento, conferindo maior robustez da análise.

O mesmo raciocínio foi utilizado para os dados relacionados à importação e à produção. Através da análise de tendência de médio e curto prazos, foram obtidos os coeficientes angulares e, na seqüência, suas respectivas médias. A tabela 8.1 concentra as informações acima mencionadas.

\section{Tabela 8.1 - Coeficientes angulares das análises de tendência de médio e curto prazos e suas respectivas médias}

\begin{tabular}{|c|c|c|c|}
\hline & $1998-2003$ & 2001-2004 & Média \\
\hline Demanda & 25.772 & 18.780 & 22.276 \\
\hline Importação & 18.405 & 9.289 & 13.847 \\
\hline Produção & 7.366 & 9.491 & 8.429 \\
\hline
\end{tabular}

Fonte: (elaboração própria)

O gráfico 8.3 apresenta as projeções de demanda, produção e importação de metanol, até o ano de 2030, não considerando a entrada em operação da expansão da Prosint, no cenário nacional, com 80.000 t/ano, em 2007.

Para a demanda de metanol, também não foi considerada a opção de se produzir biodiesel a partir da rota metílica, o que culminaria em um grande aumento do consumo, conseqüentemente, aumento da demanda, gerando uma maior importação.

$\mathrm{O}$ apêndice $\mathrm{A}$, deste trabalho, apresenta uma simulação do consumo do metanol para a produção do biodiesel a partir da rota metílica. Para tal simulação, foram consideradas as duas etapas de produção deste novo energético, ou seja, o diesel denominado B-2, o qual contem $2 \%$ de biodiesel e o diesel B-5, que conterá 5\% de biodiesel. 


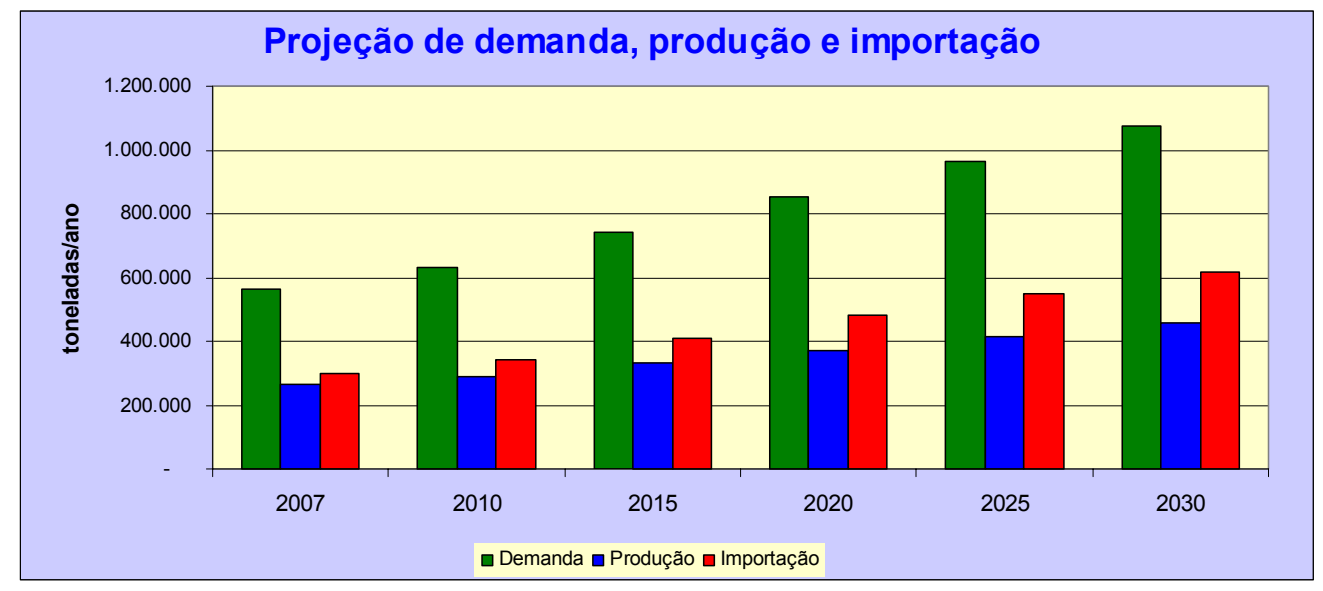

Figura 8.3 Projeção de demanda, produção e importação de metanol até 2030

Fonte: (elaboração própria)

Para a amônia, o cenário atual mostra-se menos crítico, o que justifica a decisão tomada, na etapa de modelagem da planta gás-química, de utilizar para a sua produção, $25 \%$ do gás de síntese produzido.

Os cálculos da modelagem apontam que, para ser produzido $1 \mathrm{~m}^{3}$ de amônia são necessários $0,71 \mathrm{~m}^{3}$ de gás natural, considerando que o rendimento total do processo, incluindo o loop de síntese, é de $90 \%$ e as perdas de processo somadas ao uso do GN, como combustível, representam $14 \%$. Com estes dados, conclui-se que a capacidade produtiva nominal diária corresponderia a $426.995 \mathrm{~m}^{3}$, consumindo o equivalente a $304.492 \mathrm{~m}^{3}$ de GN.

Sabendo-se que a densidade da amônia a $25^{\circ} \mathrm{C}$ e a $1 \mathrm{~atm}$ de pressão, equivale a $0,72 \mathrm{~kg} / \mathrm{m}^{3}$, a sua produção diária, em massa, equivaleria a 307,44 t e, ao longo de um ano, seriam produzidas $112.214 \mathrm{t}$.

A figura 8.4 apresenta a análise de tendência, realizada a curto prazo, para a amônia. A escolha de o estudo compreender apenas 4 anos, baseia-se no seu cenário nacional, que apresenta estabilidade. 


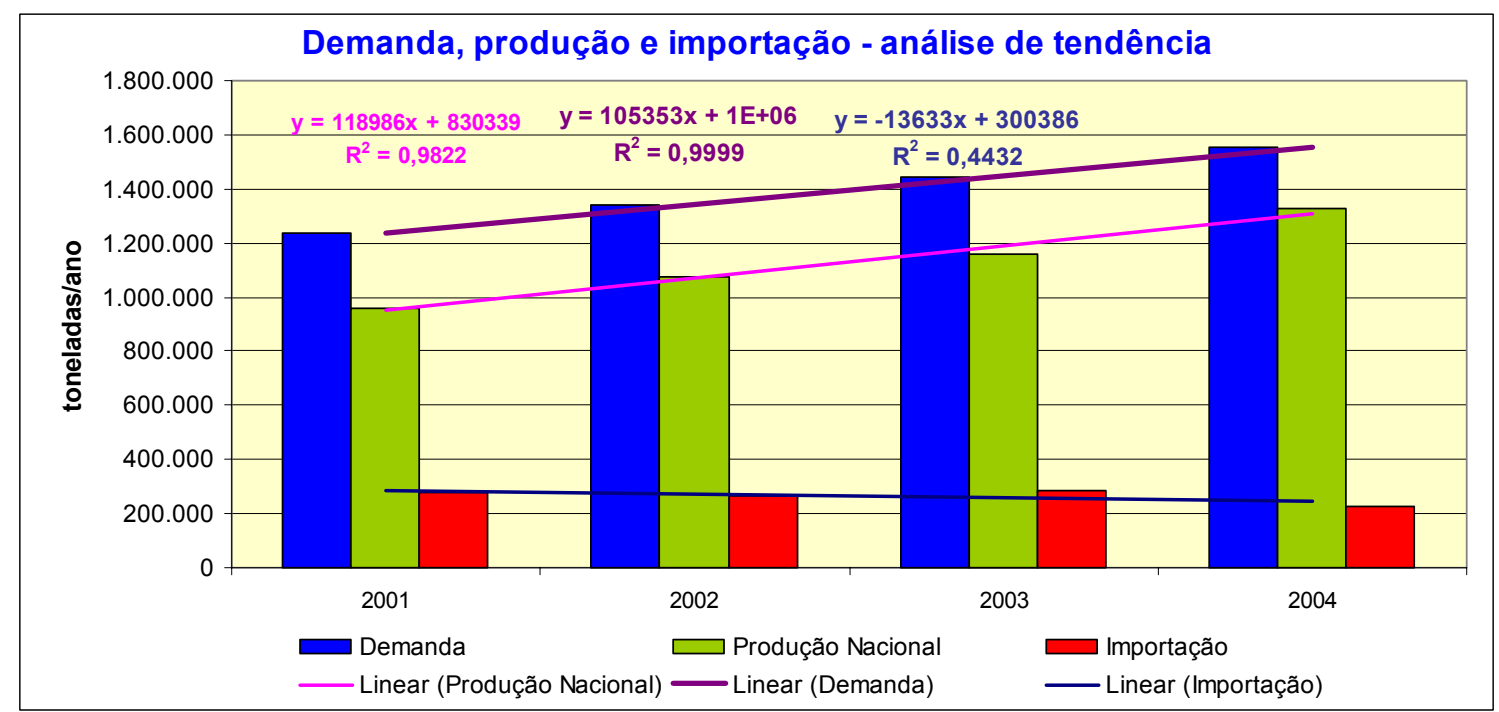

Figura 8.4 Análise de tendência, a curto prazo, da demanda, produção e importação de amônia

Fonte: (ABIQUIM, 2006; adaptação própria)

A figura 8.5 apresenta o estudo de projeção da demanda, produção e importação da amônia até o ano de 2030, sem levar em conta qualquer implantação de novas unidades industriais, ou até mesmo, expansões das existentes. A taxa de crescimento anual de cada um dos itens é o valor do coeficiente angular, obtido através da equação de correlação.

Torna-se importante ressaltar que, no presente trabalho não foram considerados os planos de expansão dos combustíveis alternativos, tais como biodiesel e etanol, o que culminaria em um grande aumento do consumo de fertilizantes nitrogenados.

Mantendo-se a tendência mundial, onde cerca de $74 \%$ da produção de amônia é voltada para a indústria de fertilizantes e, que devido as atuais restrições ambientais, o mundo volte seus olhares para a denominada plantação de energia limpa, o consumo de amônia e seus derivados tende a crescer. 


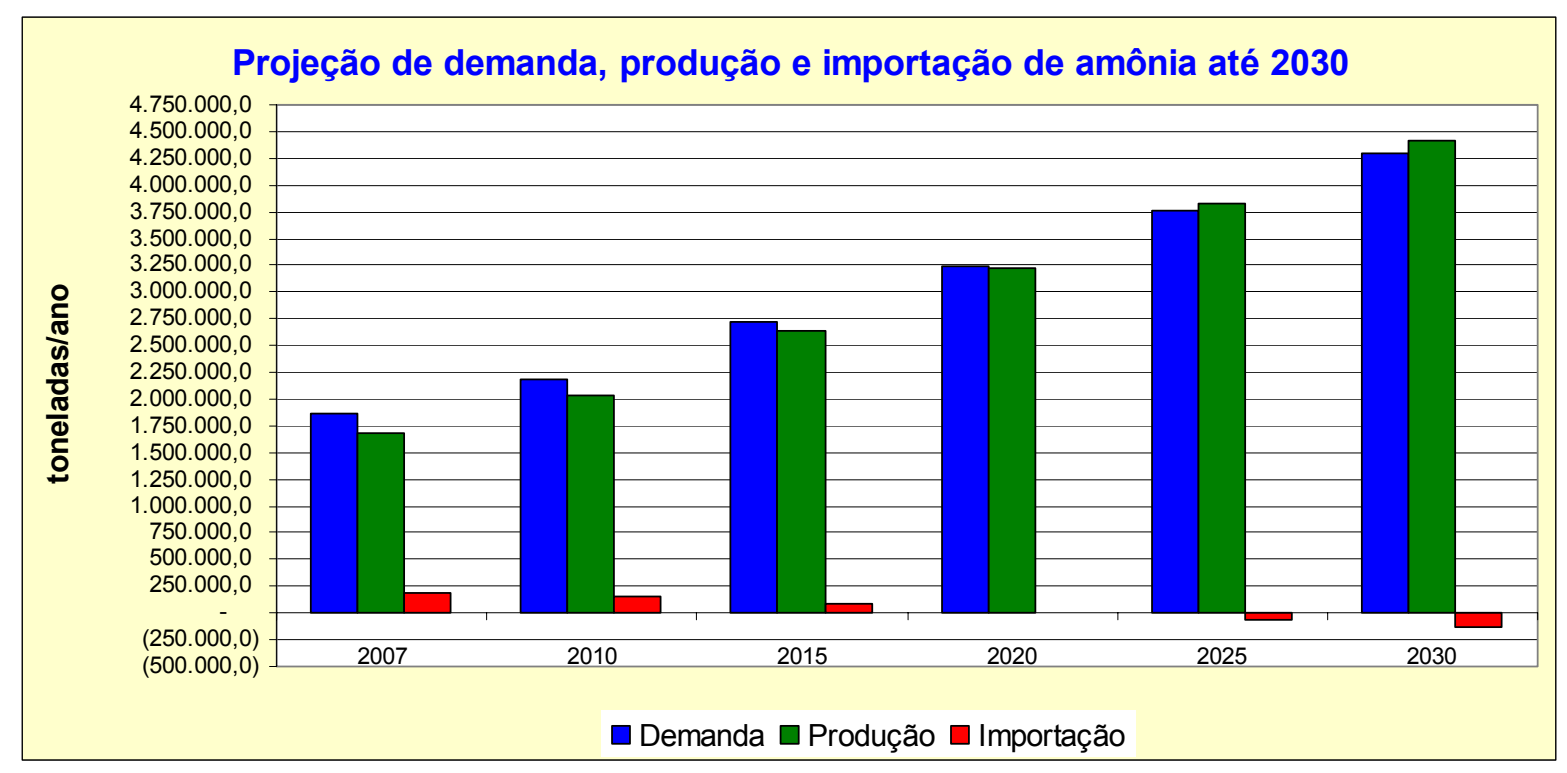

Figura 8.5 Projeção de demanda, produção e importação de amônia até 2030

Fonte: (elaboração própria)

Para se determinar a quantidade de hidrogênio útil, a ser obtido nesta planta, deve-se considerar o excedente deste, resultante da produção de amônia e metanol, ou seja, aquela quantidade que não é utilizada em nenhum dos dois processos.

Trabalhando-se com estes valores, necessita-se levar cada um destes à condição de $25^{\circ} \mathrm{C}$ e a $1 \mathrm{~atm}$ e, somando os mesmos teríamos uma produção diária de $371 \mathrm{Mm}^{3}$, que poderia ser utilizada como combustível interno, ou disponibilizado ao setor de utilidades do pólo, ou também, comercializado como gás industrial.

Sabendo-se que a densidade do hidrogênio, na condição acima mencionada, é de 0,072 $\mathrm{kg} / \mathrm{m}^{3}$, a capacidade produtiva nominal, em massa, deste gás seria de $267 \mathrm{t} /$ dia. O seu equivalente anual estaria na ordem de $97.455 \mathrm{t}$.

Finalizando a análise dos resultados encontrados, tem-se o estudo da produção do eteno a partir do gás natural, mais precisamente, de sua fração etano. Conforme já mencionado na etapa de modelagem, para que um novo empreendimento de uma central petroquímica de primeira geração seja viável, é necessário que a capacidade produtiva nominal desta, seja maior ou igual a 300.000 t/ano.

Para os cálculos do atual projeto, determinou-se uma central com capacidade produtiva nominal de 400.00 t/ano. Outros parâmetros importantes adotados para se determinar o volume 
de etano necessário, foram: percentual de etano presente no gás natural $(6,35 \%$ para o campo escolhido, Campo de Merluza, Bacia de Santos), rendimento médio da UPGN (94\%) e rendimento de conversão do processo (80\%). A combinação destes parâmetros determinou que a UPGN, responsável por enviar à central petroquímica a fração etano, processasse diariamente, um volume de gás natural da ordem de $20 \mathrm{Mm}^{3}$.

A tabela 8.2 apresenta o volume de cada fração a ser obtida diariamente, na UPGN, caso esta processasse apenas $20 \mathrm{Mm}^{3}$ de gás natural.

Tabela 8.2 - Volumes das frações obtidas na UPGN

\begin{tabular}{lrr}
\hline Elemento & \% Volume & Volume $\mathrm{m}^{3} /$ dia \\
\hline Metano & $87,12 \%$ & $17.351 .134,08$ \\
Etano & $6,35 \%$ & $1.264 .688,95$ \\
Propano & $2,91 \%$ & $579.566,12$ \\
I Butano & $0,52 \%$ & $103.565,08$ \\
N Butano & $0,87 \%$ & $173.272,34$ \\
I Pentano & $0,25 \%$ & $49.790,90$ \\
N Pentano & $0,23 \%$ & $45.807,63$ \\
Hexano & $0,18 \%$ & $35.849,45$ \\
Heptano e Sup & $0,20 \%$ & $39.832,72$ \\
Nitrogênio & $1,13 \%$ & $225.054,88$ \\
Dióxido Carbono & $0,24 \%$ & $47.799,27$ \\
Total & $100,00 \%$ & $19.916 .361,44$ \\
\hline
\end{tabular}

Fonte: (CONPET, 2005; adaptação própria)

Estudos da ABIQUIM (2006), apontam que novas centrais petroquímicas entrarão em operação até 2013, aumentando a capacidade produtiva nominal de eteno para 5.535.000 t/ano. A tabela 8.6 apresenta os valores e as respectivas centrais. 
Tabela 8.3 - Projeção do aumento da capacidade produtiva nominal de eteno no Brasil

\begin{tabular}{rrrl}
\hline & $\begin{array}{c}\text { Capacidade Produtiva } \\
\text { Nominal em t/ano }\end{array}$ & $\begin{array}{c}\text { Incremento da } \\
\text { Capacidade em } \\
\text { t/ano }\end{array}$ & Empresa \\
\hline $\mathbf{2 0 0 6}$ & 3.435 .000 & & \\
$\mathbf{2 0 0 7}$ & 3.635 .000 & 200.000 & PQU \\
$\mathbf{2 0 1 0}$ & 4.235 .000 & 600.000 & Braskem \\
$\mathbf{2 0 1 3}$ & 5.535 .000 & 1.300 .000 & Petrobras \\
\hline
\end{tabular}

Fonte: (ABIQUIM, 2006; adaptação própria)

O incremento de 200.000 toneladas refere-se à expansão da central petroquímica da PQU, localizada em Capuava, no estado de São Paulo. Quanto ao aumento de 600.00 toneladas da empresa Braskem, o mesmo está relacionado à construção de um pólo gás-químico na região centro-oeste brasileira, que visa aproveitar o gás natural boliviano. Por último, temos um acréscimo de 1.300.000 toneladas, que será proveniente do complexo petroquímico, a ser construído pela Petrobrás, localizado no estado do Rio de Janeiro, o qual processará o petróleo extraído do Campo de Marlim. Realizando uma projeção de demanda do eteno, até o ano 2030, e utilizando taxas anuais ${ }^{8}$ variadas de crescimento, teremos o seguinte cenário, apresentado na figura 8.6.

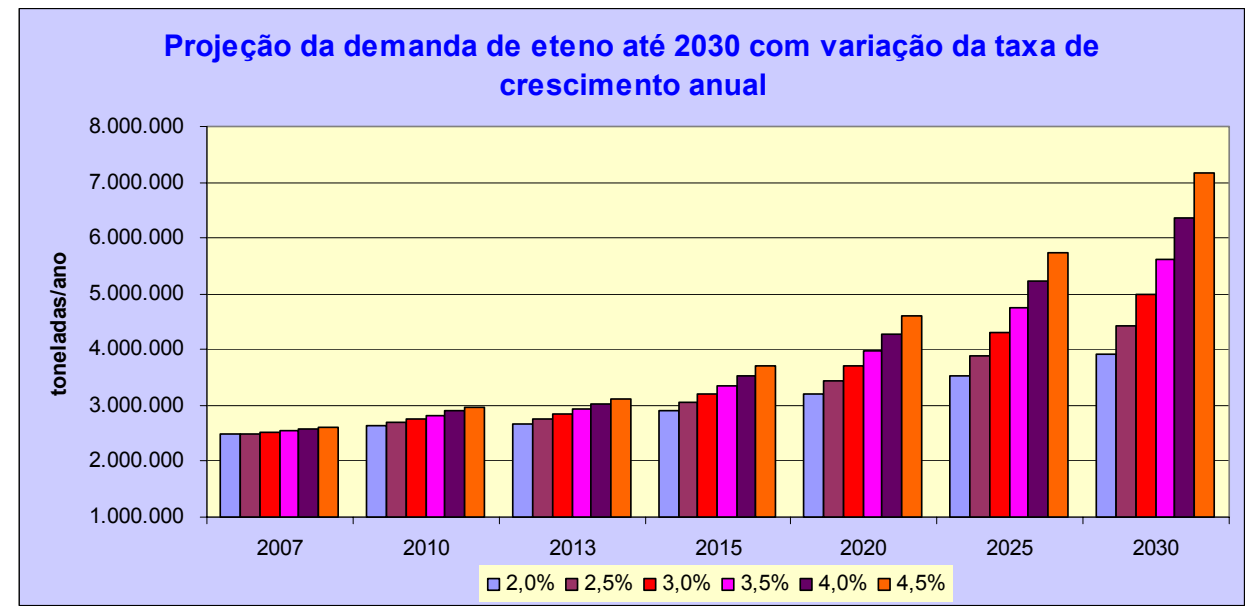

Figura 8.6 Projeção da demanda de eteno até 2030 com diferentes taxas de crescimento anual

Fonte: (elaboração própria)

\footnotetext{
${ }^{8}$ As taxas correspondem a uma análise do crescimento médio anual da demanda de eteno, nos últimos 10 anos.
} 


\section{CONCLUSÃO}

Relacionando a análise dos resultados obtidos com as projeções de demanda, chega-se à conclusão de que o dimensionamento de uma planta gás-química, com uma unidade de SMR de 200 tubos, não seria suficiente para eliminar, ao longo dos anos, a importação do metanol.

Utilizando como parâmetro base à necessidade de metanol a ser importada em 2030, ou seja, 620.000 t/ano, redimensionou-se a planta gás-química, obtendo como resultado uma unidade de SMR, de 340 tubos reformadores com diâmetro interno de 0,11 metro (ou seja, 0,0255 metro maior que o dimensionamento inicial) e, mantendo-se as demais características técnicas.

Com estas alterações, tem-se que a capacidade produtiva nominal diária de metanol é de $2.215 \mathrm{~m}^{3}$, equivalente a $1.728 \mathrm{t} / \mathrm{dia}(630.734 \mathrm{t} / \mathrm{ano})$, consumindo um volume de $2.104 .504 \mathrm{~m}^{3} / \mathrm{dia}$ de gás natural.

Supondo que o projeto de construção, desta planta gás-química, iniciasse sua produção em 2010, a unidade de metanol partiria operando com 54\% de sua capacidade produtiva nominal, caso não houvesse viabilidade econômica de exportação deste produto. Este porcentual, da capacidade produtiva, refere-se apenas à fabricação da quantidade de metanol, necessária para sanar a importação no ano de 2010.

A tabela 9.1 apresenta o porcentual da capacidade produtiva da unidade de metanol, a ser utilizado para que a importação do mesmo seja eliminada ao longo dos anos, para os quais se projetou a demanda nacional deste produto.

Tabela 9.1 - Porcentual da capacidade nominal da unidade de produção de metanol a ser utilizado para eliminar a importação.

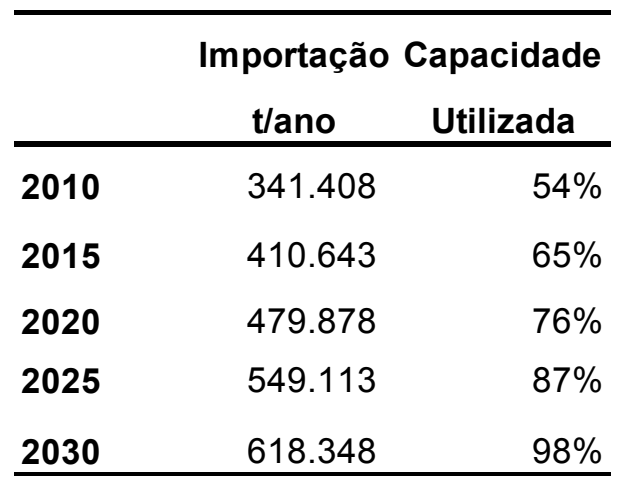

Fonte: (elaboração própria) 
Com as novas adaptações de projeto, a capacidade produtiva nominal de amônia será de $983.543 \mathrm{~m}^{3} /$ dia, equivalente a $708.151 \mathrm{~kg} / \mathrm{dia}(258.475 \mathrm{t} / \mathrm{ano})$, consumindo para tanto 701.501 $\mathrm{m}^{3} /$ dia de gás natural.

Com a entrada em operação desta unidade de amônia em 2010, utilizando $90 \%$ da sua capacidade produtiva nominal, já neste mesmo ano, haveria um excedente, que poderia ser destinado ao mercado externo, seja na forma de amônia ou agregando-se valor, como, por exemplo, exportando-se uréia. A tabela 9.2 apresenta os valores do excedente de produção de amônia projetado, até o ano de 2030.

Tabela 9.2 - Projeção do excedente de produção de amônia até 2030

\begin{tabular}{cc}
\hline Ano & $\begin{array}{c}\text { Excedente } \\
\text { Produção (t) }\end{array}$ \\
\hline 2010 & $86.506,1$ \\
2015 & $154.671,1$ \\
2020 & $222.836,1$ \\
2025 & $291.001,1$ \\
2030 & $359.166,1$ \\
\hline
\end{tabular}

Fonte: (elaboração própria)

No caso de a planta gás-química operar em sua totalidade a partir de 2010, o consumo diário de gás natural será de $2,81 \mathrm{Mm}^{3}$. Ao longo de um ano, será consumido 1,024 bilhão $\mathrm{m}^{3}$. Este valor corresponderia a $16,3 \%$ do volume de metano processado na UPGN, responsável pelo fornecimento do etano à central petroquímica. Para um período de 20 anos, será consumido o equivalente a 20 trilhões de $\mathrm{m}^{3}$ de gás natural, considerado-se, para tanto, que o pólo opere com sua capacidade nominal plena.

Neste momento, torna-se plausível analisar a construção de um complexo gás-químico, integrando as plantas de transformação do metano e do etano, em uma só localização geográfica.

Criará-se uma demanda firme pelo gás natural a ser processado na UPGN, durante um período mínimo de 20 anos, viabilizando a implantação da infra-estrutura necessária. 
Para que este fato se torne realidade, fatores como localização da UPGN, distância desta do complexo gás-químico, infra-estrutura de transporte das frações do gás natural, escoamento da totalidade da produção, entre outros, deverão ser analisados.

Como recomendações para trabalhos futuros, sugere-se a realização da avaliação econômica e ambiental dos processos, aqui presentes. Como segunda possibilidade de trabalho, poder-se-ia quantificar a influência do crescimento da produção dos biocombustíveis, biodiesel e etanol, na produção de metanol e amônia, tanto em termos nacionais, quanto internacionais.

Como último trabalho, sugere-se realizar a integração do presente estudo e demais recomendações, com as novas descobertas de gás natural no Brasil, a fim de checar se o volume deste energético, disponível no Brasil, será suficiente ou não, para um projeto de no mínimo 20 anos de vida útil. 


\section{REFERÊNCIAS}

ABRAM, A.; FORSTER, L.; A primer on ammonia, nitrogen, fertilizers and natural gas markets, 2005; Department of AED Economics - Ohio State University.

ABREU, P. L.; MARTINEZ, J. A. Gás natural: o combustível do novo milênio. Plural Comunicação, $2^{\mathrm{a}}$ edição, Porto Alegre - RS, 2003.

BRASIL. ANP - AGÊNCIA NACIONAL DE PETRÓLEO. Anuário estatístico brasileiro do petróleo e do gás natural 2003. Disponível em: http://www.anp.gov.br Acesso em 06 Janeiro de 2006.

BRASIL. ANP - AGÊNCIA NACIONAL DE PETRÓLEO. Anuário estatístico brasileiro do petróleo e do gás natural 2004. Disponível em: http://www.anp.gov.br Acesso em 06 Janeiro de 2006.

BRASIL. ANP - AGÊNCIA NACIONAL DE PETRÓLEO. Anuário estatístico brasileiro do petróleo e do gás natural 2005. Disponível em: http://www.anp.gov.br Acesso em 06 Janeiro de 2006.

BRASIL. ANP - AGÊNCIA NACIONAL DO PETRÓLEO Boletins Mensais do Gás Natural referente aos anos de 2004 e 2005. Disponível em http://www.anp.gov.br Acesso em 16 Julho de 2005.

BRASIL. ANP - AGÊNCIA NACIONAL DO PETRÓLEO Portaria $N^{\circ} 249$, de $1^{\circ}$ de Novembro de 2000. Disponível em: http://www.anp.gov.br Acesso em 06 Janeiro de 2006.

BRASIL. ANP - AGÊNCIA NACIONAL DO PETRÓLEO A Indústria de Gás Natural no Brasil, Rio de Janeiro, 16 de Janeiro de 2004, 167p. Disponível em: http://www.anp.gov.br Acesso em 09 Abril de 2005.

Ammonia Technology for Tomorrow, catálogo técnico, Kellog Brown Root, 2005.

BRASIL. ABIQUIM - ASSOCIAÇÃO BRASILEIRA DAS INDÚSTRIAS QUÍMICAS, Anuário Estatístico Associação Brasileira das Indústrias Químicas 2000, ano base 1999. 
BRASIL. ABIQUIM - ASSOCIAÇÃO BRASILEIRA DAS INDÚSTRIAS QUÍMICAS, Anuário Estatístico Associação Brasileira das Indústrias Químicas 2005, ano base 2004.

BRASIL. ABIQUIM - ASSOCIAÇÃO BRASILEIRA DAS INDÚSTRIAS QUÍMICAS, Anuário Estatístico Associação Brasileira das Indústrias Químicas 2006, ano base 2005.

APPL, M.; DANNSTADT-SCHAVERNHEIM; Ammonia - Occurrence and History and Production; parte integrante da Ullmann's Encyclopedia of Industrial Chemistry, 2002.

BAKEMEIER, H.; HUBERICH, T.; KRABETZ R.; LIEBE W.; SCHUNCK M.; Ammonia Physical Properties, Chemical Properties and Production; parte integrante da Ullmann's Encyclopedia of Industrial Chemistry, 2002.

BRASIL. MINISTÉRIO DE MINAS E ENERGIA E EMPRESA DE PESQUISA ENERGÉTICA - Balanço Energético Nacional (BEN), 2005 ano base 2004;

BRASIL. MINISTÉRIO DE MINAS E ENERGIA E EMPRESA DE PESQUISA ENERGÉTICA - Balanço Energético Nacional (BEN), 2006 ano base 2005;

Basf Chemical Group - Basf Historical Milestones; disponível em:

http://www.corporate.basf.com/en/ueberuns/profil/geschichte/?id=GJsIo9LR7bcp34s (acessado em Outubro de 2006).

BRASIL. INT - INSTITUTO NACIONAL DE TECNOLOGIA - Caderno de Tecnologia; DME: O Combustível do Futuro. Novembro de 2005, Rio de Janeiro.

CHEN, T.; Investigation of Catalytic Autothermal Reforming Process for Hydrogen Production; Institute of Nuclear Energy Research, Taiwan; University of British Columbia, Canada; 2005.

CHEUNG, H.; TANKE, R. S.; TORRENCE, G. P.; Acetic Acid - Production and Uses, parte integrante da Ullman's Encyclopedia of Industrial Chemistry, 2002.

CHRISTENSEN, P. V., Design and Operation of large capacity ammonia plants, trabalho apresentado na $4^{\text {th }}$ Conference for development and integration of petrochemical industries in the Arab States, 7-8 Maio de 2001, Bahrain. 
CO Shift Conversion, Linde Group, catálogo técnico on-line, disponível em: http://www.lindeengineering.com, acessado em Dezembro de 2005.

Coogee Chemicals Ltd. - www.coogee.com.au

DISTELDORF, W.; Formaldehyde - Uses, parte integrante da Ullman's Encyclopedia of Industrial Chemistry, 2002.

DYBKJÆR, Ib. Synthesis gas technology. Petroleum Economist, pp. 16-19, Janeiro de 2003. (Fundamentals of Gas to Liquids - Especial edition)

Dupont Trademark - http://heritage.dupont.com/touchpoints/tp_1950/overview.shtml acessado em Novembro de 2006.

DuPont Corporate - DuPont Heritage; disponível em: http://heritage.dupont.com (acessado em Outubro de 2006).

EIA / DOE. The U.S. Petroleum Industry: past as prologue1970-1992, September. Washington: DOE, 1993.

ERAMO, M; Ethylene, Propilene, demand will experience increased growth in 2005-10; Oil and Gas Journal 05/12/2005.

EXXON MOBIL (2003). Exxon Mobil's 2003 Economic and Energy Outlook. Disponível em http: //www.exxon.mobil.com. Acessado em Janeiro de 2006.

ERAMO, M.; Ethylene, Propilene, demand will experience increased growth in 2005-10; Oil and Gas Journal 05/12/2005.

FERREIRA, R.L.P.; BOMTEMPO, J.V.; ALMEIDA, E. L.F. Estudo das inovações tecnológicas em GTL com base em patentes: o caso Shell. In: CONGRESSO BRASILEIRO DE P \& D EM PETRÓLEO \& GÁS, 2., 2003. Rio de Janeiro. Anais eletrônicos... Rio de Janeiro: UFRJ, 2003.

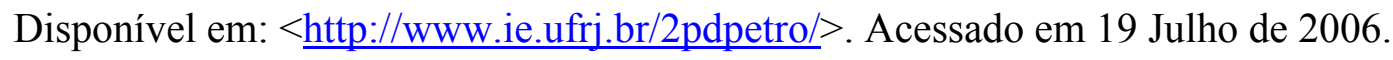

FIEDLER, E.; GROSSMANN, G.; KERSEBOHM, D. B.; WEISS, G.; WITTE, C.; Methanol Introduction; parte integrante da Ullman's Encyclopedia of Industrial Chemistry, 2002. 
FIEDLER, E.; GROSSMANN, G.; KERSEBOHM, D. B.; WEISS, G.; WITTE, C.; Methanol Production, Process Technology and Uses, parte integrante da Ullman's Encyclopedia of Industrial Chemistry, 2002.

FLEISCH, T.; British Petroleum - Gas-To-Products: More Options for Remote Gas Monetization, 2003. Palestra apresentada no SPE Meeting, Denver - USA, 6-9, October, 2003.

FLEISCH, T,; SILLS, R.; British Petroleum America; Feed stocks of the Future: The Case of Syngas, 2005. Palestra apresentada no Innovation Day, Philadelphia - USA, September, 7, 2005.

FLEISCH, T. H.; SILLS, R. A.; BRISCOE, M. D. GTL-FT in the emerging gas economy. Petroleum Economist, pp. 39-41, Janeiro de 2003. (Fundamentals of Gas to Liquids - Especial edition)

FLEISCH, T. H.; SILLS, R. A.; BRISCOE, M. D. 2002 - Emergence of the Gas-to-Liquids Industry: a review of global GTL developments. Journal of Natural Gas Chemistry, v. 11, pp. 1$14,2002$.

Gas Processes 2004, parte integrante da Hydrocarbon Processing. Gulf Publishing Company, 2004.

GEROSA, T.M; A versatilidade do gás natural nas aplicações industriais: um foco no seu uso como matéria-prima; Palestra apresentada no $2^{\circ}$ Seminário Internacional da Integração Energética Latino-Americana, em 31/08/2006.

GEROSA, T.M; MATAI, P.H.L.S; Análise das tecnologias atualmente disponíveis para a obtenção de gás de síntese a partir do gás natural, Rio Oil and Gas Conference, 2006.

GHAEMMAGHAMI, B.; GTL: Progress and Prospects - Study yields generic, coastal-based GTL plant. Oil\&Gas Journal, v. 99, n. 11, March 12, 2001.

GOMES, G.; DVORSAK, P., HEIL, T.; Indústria petroquímica brasileira: situação atual e perspectiva; Banco Nacional de Desenvolvimento - BNDES Setorial, Rio de Janeiro, $\mathrm{n}^{\mathrm{o}} 21$, $\mathrm{p}$. 75-104, Março de 2005. 
High Temperature Shift Conversion, Johnson Matthey Catalysts, catálogo técnico on-line, disponível em: http:/www.jmcatalysts.com/pct/marketshome.asp? marketid=27\&id=350, acessado em Janeiro de 2006.

Instituto do PVC - www.institutodopvc.org.br, acessado em Março de 2006.

J.E. Sinor Consultants Inc. - Methanol: Born in 1923 and still going strong; disponível em: http://www.edj.net/sinor/index.html (acessado em Agosto de 2005).

KRAMER, D. A.; Mineral Commodity Profile, U.S. Department of the Interior; U.S. Geological Survey, 2004.

Liquid Nitrogen Wash, Linde Group, catálogo técnico on-line, disponível em: http://www. lindengineering.com/process_plants/gas_processing/liquid_nitrogen_wash.php acessado em Dezembro de 2005.

Low Temperature Shift Conversion, Johnson Matthey Catalysts, catálogo técnico on-line, disponível em: http://www.jmcatalysts.com/pct/marketshome.asp?marketid=27\&id=351, acessado em Janeiro de 2006.

MARIANO J. B.; Impactos ambientais do refino de petróleo Rio de Janeiro: Interciência, 2005. $228 \mathrm{p}$.

MATAR, S.; HATCH, L.F; Chemistry of Petrochemical Processes, segunda edição, 2000, Gulf Publishing Company.

MARSCHNER, F.; RENNER, HJ.; Gas Production - Steam Reforming of Natural Gas and Others Hydrocarbons, parte integrante da Ullmann's Encyclopedia of Industrial Chemistry, 2002.

Mega Ammonia Process, Lurgi AG, catálogo técnico on-line, disponível em:

http://www.lurgi.com/website/fileadmin/user_upload/pdfs/09_Ammoniak-E.pdf,

Acessado em Dezembro de 2004. 
Methanation, Johnson Matthey Catalysts, catálogo técnico on-line, disponível em: http://www.jmcatalysts.com/pct/marketshome.asp? marketid=27\&id=352, acessado em Janeiro de 2006.

Methanex - www.methanex.com, acessado em Junho de 2005.

Methanol Holdings Trinidad \& Tobago - www.ttmethanol.com, acessado em Abril de 2005.

Ministry of Energy and Energy Industries of Trinidad \& Tobago - www.energy.gov.tt, acessado em Junho de 2005.

MONTENEGRO, R., S.P; PAN, S., S.K; Gás Natural como matéria-prima para a produção de eteno no Estado do Rio de Janeiro; Banco Nacional de Desenvolvimento - BNDES Setorial, Rio de Janeiro, $n^{\circ} 12$, p. 135-160, Setembro de 2000.

OLIVEIRA, T; BONTEMPO, J. V; ALMEIDA, E. F; Um Estudo de Prospecção e de Estratégias de Inovação: O Caso Dimetil Éter (DME) - Um Novo Combustível Derivado do Gás Natural; 2003, Rio de Janeiro.

PETERS, U.; NIERKICH, F.; SAKUTH, M.; LAUGIER, M.; Methyl Tert Butyl Ether Production and Uses, parte integrante da Ullman's Encyclopedia of Industrial Chemistry, 2002.

PETROBRAS - Plano Estratétégico 2007-2011, Rio de Janeiro 2007;

Petrochemical Processes 2005 - Hydrocarbon Processing, Maio de 2005.

Rectisol®, Linde Group, catálogo técnico on-line, disponível em:

http://www.linde-process-ngineering.com/process_plants/gas_processing/rectisol_wash.php

Acessado em Janeiro de 2006.

REDDY, K.T; BASU, S; Gas-to-liquid Technologies: India's perspective, 15/12/2006 (Aceito para publicação na Fuel Processing Technoloy, edição a definir).

Rio Polímeros S.A. www.riopol.com.br, acessado em Maio de 2005. 
SANTOS, E. M., E. et al. Gás natural: estratégias para uma energia nova no Brasil. São Paulo, Ed. ANNABLUME, Agosto de 2002, 352 p., 2002.

SCHLICHTING, H.; Update on Lurgi Syngas Technologies; Lurgi Oel Gas Chemie GmbH, Germany, 2003. Trabalho apresentado no congresso: Gasification Technologies - 12-15 October 2003 - San Francisco - USA.

SZKLO, A. S.; Fundamentos do refino de petróleo; Rio de Janeiro: Inter-ciência, 2005. 207 p.

Sociedade Francesa de Química;

http://www.sfc.fr/Donnees/orga/methanol/texmeol.htm\#Productions; acessado em 18/03/2006.

SONG X., GUO Z.; Technologies for direct production of flexible H2/CO synthesis gas; Energy Conversion Management, Ed. 47- 2007.

SPATH, P.L; DAYTON, D.C; Preliminary Screening - Technical and Economical Assessment of Synthesis Gas to Fuels and Chemicals with Emphasis on the Potential for Biomass - Derived Syngas; NREL - National Renewable Energy Laboratory, 2003.

SUPP, E.; BREJC, M.; LIEBNER, W.; Gas Production - Non-catalytic Partial Oxidation and Special Gasification Processes for Higher-Boiling Hydrocarbons, parte integrante da Ullmann's Encyclopedia of Industrial Chemistry, 2002.

The Hydrogen Economy: Opportunities, Costs, Barriers, and R\&D; National Academy Engineering (NAE), Board on Energy and Environmental Systems (BEES); 2004. Disponível em: http://newton.nap.edu/books/0309091632/html/R1.html , acessado em 26/9/2006.

The Free Encyclopedia; www.wikipedia.org - acessado em 22/03/2005.

The New Zealand Institute of Chemistry - www.nzic.org.nz, acessado em Junho de 2006.

UOP/HYDRO MTO Process - Methanol to Olefins Conversion, UOP LLC, catálogo técnico 2004, disponível em www.uop.com, acessado em Janeiro de 2006.

WADDACOR, M.; GTL Era is dawning, after 80 years of R\&D. Petroleum Economist, pp. 4-7, January, 2003. (Fundamentals of Gas to Liquids - Especial edition). 


\section{APÊNDICE A - SIMULAÇÃO DA PRODUÇÃO DE BIODIESEL PELA ROTA METÍLICA}

A produção de biodiesel pode ser feita através de duas rotas: a metílica e a etílica, e, utiliza-se como agente de transesterificação, o metanol e o etanol, respectivamente. Para a presente simulação será apenas analisada a produção de biodiesel a partir do metanol.

Conforme estabelecido pelo governo federal, a partir de 2007, será obrigatório que o diesel produzido contenha $2 \%$ de biodiesel e a partir de 2009 , este volume aumente para $5 \%$. Conclui-se que, em 2007, a produção de biodiesel comece a crescer para atingir a meta estabelecida. De acordo com estudo realizado por Parente (2003), a utilização do metanol, para a obtenção de biodiesel, é mais vantajosa técnica e economicamente, quando comparada ao etanol. Este último apresenta como vantagens a disponibilidade local do produto, facilidade de manuseio e não toxidade, entre outras. A tabela A.1 aponta as principais características econômicas e técnicas do processo de produção de biodiesel, comparando a utilização destes dois reagentes.

Tabela A.1 - Comparação entre as rotas metílica e etílica para a produção de biodiesel

\begin{tabular}{lcc}
\hline \multicolumn{2}{c}{ Comparação das Rotas } & Metílica e Etílica \\
\hline $\begin{array}{l}\text { Quantidades e condições usuais } \\
\text { médias aproximadas }\end{array}$ & Metílica & Etílica \\
Vol. de álcool (1000 litros biodiesel) & $90 \mathrm{~kg}$ & $130 \mathrm{~kg}$ \\
Preço médio álcool (US\$(kg) & 190 & 360 \\
$\begin{array}{l}\text { Excesso recomendado de álcool } \\
\text { recuperável, por destilação }\end{array}$ & $100 \%$ & $650 \%$ \\
Temperatura recomendada & $60 \mathrm{C}$ & $85 \mathrm{C}$ \\
Tempo da reação (minutos) & 45 & 90 \\
\hline
\end{tabular}

Fonte (Parente, 2003)

A tabela mostra que, não somente é necessária maior quantidade de etanol por unidade de biodiesel produzido, como o tempo de reação deste agente é maior, diminuindo, assim, o rendimento do processo. Outro fator que deve ser apontado é a concorrência interna de mercados de biocombustíveis, pois a utilização do etanol como combustível automotivo voltou fortemente após o lançamento da tecnologia flex fuel. Porém, diferente do que ocorre com os veículos de passeio, os quais apresentam flexibilidade quanto à escolha de seu combustível (álcool, gasolina e, em alguns modelos, gás natural). O diesel, produzido a partir de 2007, não terá esta flexibilidade, ou seja, haverá a obrigatoriedade de adição de $2 \%$ de biodiesel àquele fabricado em 
território nacional. Nestas condições, a produção de diesel torna-se correlacionada a questões de safra, o que aumenta as condições para se ter, também, a fabricação do biodiesel por rota metílica.

A utilização do metanol como agente de transesterificação passa a ser uma alternativa interessante, pois sua produção ocorre de forma contínua e sua única volatilidade relaciona-se ao preço do gás natural, principal matéria-prima. Algumas desvantagens de seu uso devem ser mencionadas, tais como a alta toxidade, a dificuldade na manipulação, o que tornaria difícil sua aplicação para os projetos de cunho social. Outro ponto crítico é a sua baixa produção nacional e a imprevisibilidade de novos investimentos significativos para suprir a demanda.

A fim de obter-se a quantidade média de metanol a ser consumida na produção de biodiesel, realizou-se uma simulação, cujos parâmetros utilizados, são apresentados na tabela A.2.

Tabela A.2 - Relação dos parâmetros utilizados na simulação do consumo de metanol para produção de biodiesel

\begin{tabular}{lcc}
\hline \multicolumn{3}{c}{ Relação dos Parâmetros - Simulação } \\
\hline \multicolumn{3}{c}{ Metanol } \\
Densidade (25C) & $\mathrm{kg} / \mathrm{m} 3$ & 786,6 \\
Volume (p/ 1m3 de biodiesel) & $\mathrm{m3}$ & 0,114 \\
Preço cif & $\mathrm{US} \$ / \mathrm{m} 3$ & 253,75 \\
Cap. Nominal 2005 & toneladas & 277.180 \\
Cap. Nominal 2008 & toneladas & 350.180 \\
\multicolumn{3}{c}{ Óleo Diesel } \\
Consumo médio & $1000 \mathrm{m3}$ & $34.893,50$ \\
& Biodiesel \\
Produção biodiesel (2\%) & $1000 \mathrm{m3}$ & 697,870 \\
Produção biodiesel (5\%) & $1000 \mathrm{m3}$ & 1.744 \\
\hline
\end{tabular}

Fonte (elaboração própria)

O volume de óleo diesel utilizado na simulação, 34,89 milhões de $\mathrm{m}^{3}$, é a média do volume consumido no período compreendido entre os anos de 2001-2005, com base nos dados publicados no Balanço Energético Nacional 2006, ano base 2005. O dado relativo à capacidade nominal de produção de metanol para 2008, leva em consideração a futura ampliação da Prosint.

O resultado da simulação é apresentado na figura A.1, onde foram atribuídos percentuais ao volume de biodiesel a ser produzido através da rota metílica. 


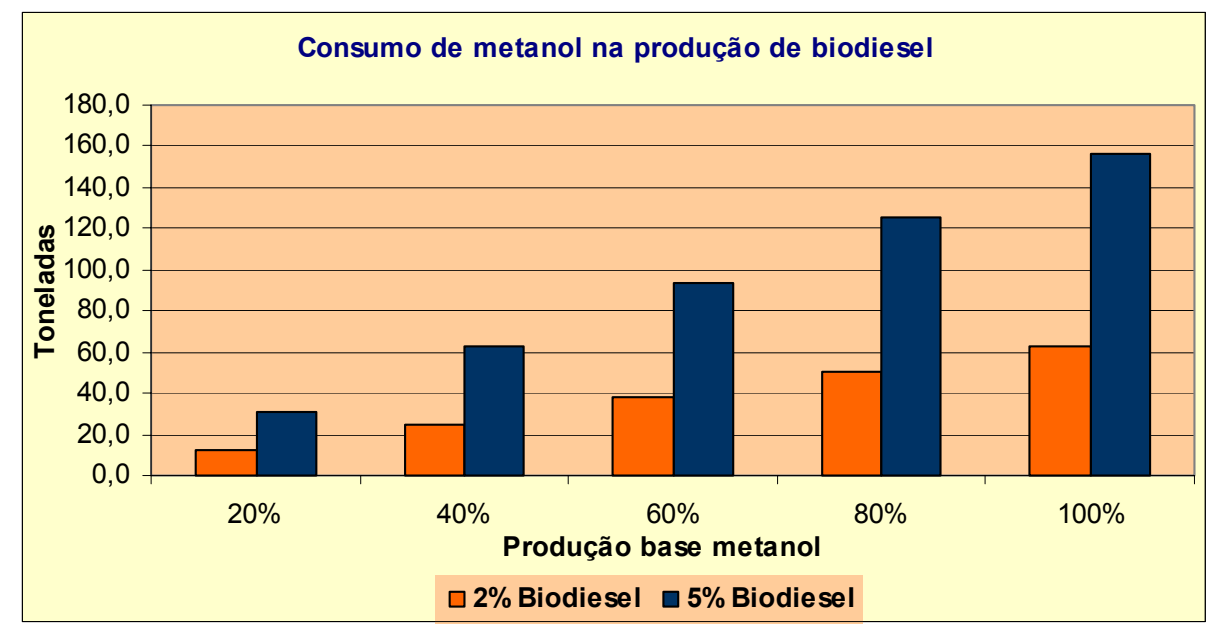

Figura A.1 Simulação do consumo de metanol para a produção de biodiesel

Fonte(elaboração própria)

Os custos com importação de metanol, bem como o percentual correspondente a capacidade produtiva nominal do Brasil a ser consumido com a produção de biodiesel, são consolidados na tabela A.4.

Tabela A.3 - Custos com importação e percentual a ser utilizado da capacidade nominal instalada de metanol

\begin{tabular}{|c|c|c|c|c|c|}
\hline \multicolumn{6}{|c|}{ Importação e percentual a ser utilizado da capacidade nominal } \\
\hline \multicolumn{2}{|c|}{ Importação } & \multicolumn{2}{|c|}{$\%$ Capacidade } & \multicolumn{2}{|c|}{$\%$ Capacidade } \\
\hline \multicolumn{2}{|c|}{ (1000 US\$ cif) } & \multicolumn{2}{|c|}{ Nominal 2005} & \multicolumn{2}{|c|}{ Nominal 2008} \\
\hline $2 \%$ & $5 \%$ & $2 \%$ & $5 \%$ & $2 \%$ & $5 \%$ \\
\hline $4.037,5$ & $10.093,8$ & $4,52 \%$ & $11,29 \%$ & $3,57 \%$ & $8,94 \%$ \\
\hline $8.075,1$ & $20.187,6$ & $9,03 \%$ & $22,58 \%$ & $7,15 \%$ & $17,87 \%$ \\
\hline $12.112,6$ & $30.281,5$ & $13,55 \%$ & $33,86 \%$ & $10,72 \%$ & $26,81 \%$ \\
\hline $16.150,1$ & $40.375,3$ & $18,06 \%$ & $45,15 \%$ & $14,30 \%$ & $35,74 \%$ \\
\hline $20.187,6$ & $50.469,1$ & $22,58 \%$ & $56,44 \%$ & $17,87 \%$ & $44,68 \%$ \\
\hline $10.093,8$ & $25.234,5$ & $11,29 \%$ & $28,22 \%$ & $8,94 \%$ & $22,34 \%$ \\
\hline
\end{tabular}

Fonte: (Elaboração própria) 